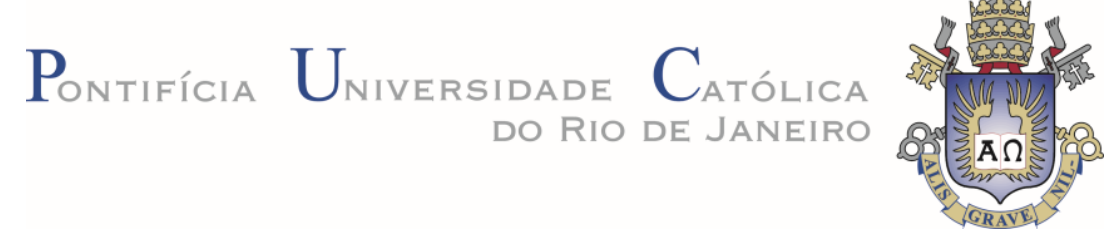

Daniel Moura Nogueira

INFOGRAFIA NO BRASIL:

panorama de uma linguagem multimodal

Tese de Doutorado

Tese apresentada como requisito parcial para a obtenção do grau de Doutor em Design pelo Programa de de Pós-Graduação em Design da PUC-Rio.

Orientadora: Profa. Vera Lúcia Moreira dos Santos Nojima Co-orientador: Prof. Frederico Braida Rodrigues de Paula 


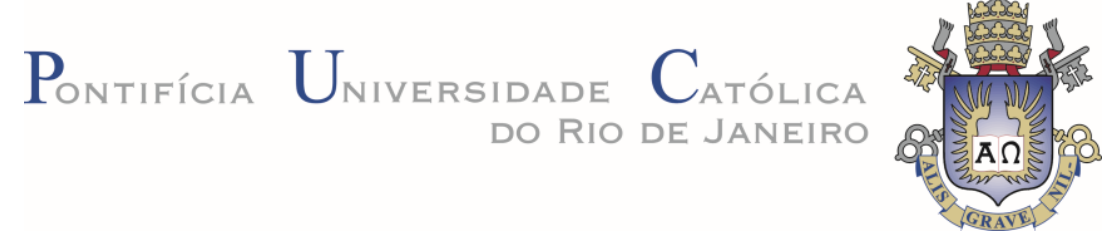

Daniel Moura Nogueira

\begin{abstract}
INFOGRAFIA NO BRASIL: panorama de uma linguagem multimodal
\end{abstract}

Tese apresentada como requisito parcial para obtenção do grau de Doutor ao Programa de PósGraduação em Design da PUC-Rio. Aprovada pela Comissão Examinadora abaixo.

Profa. Vera Lúcia Moreira dos Santos Nojima

Orientadora

Departamento de Artes e Design - PUC-Rio

Prof. Frederico Braida Rodrigues de Paula

Coorientador

Departamento de Arquitetura e Urbanismo - UFJF

Profa. Rita Maria de Souza Couto

Departamento de Artes e Design - PUC-Rio

Prof. Ary Pimenta de Moraes Filho Departamento de Análise e Representação da Forma Escola de Belas Artes - UFRJ

Prof. Marcus Vinícius Dohmann Brandão

Departamento de Comunicação Visual

Escola de Belas Artes - UFRJ

Profa. Nathalia Chehab de Sá Cavalcante Departamento de Artes e Design - PUC-Rio 
Todos os direitos reservados. É proibida a reprodução total ou parcial do trabalho sem autorização da universidade, do autor e do orientador

\section{Daniel Moura Nogueira}

Graduado em Desenho Industrial - Programação Visual pela Escola de Belas Artes - UFRJ, em 2004. Mestre em Design pelo Programa de Pós-Graduação da PUC-Rio, em 2014. Sóciodiretor do escritório de design Chalk Studio, desde 2004, tendo atuado em projetos de comunicação visual e design da informação junto a empresas como Petrobras, Banco do Brasil, Vale, Sindicom, dentre outras. Foi diretor da Associação dos Designers Gráficos do Brasil (ADG - Brasil), gestão 2013-2015. Fundador do projeto Design é a sua vida!, iniciado em 2008, tendo ministrado palestras sobre a prática do design em diversas Instituições de Ensino Superior no país. Foi professor substituto do Departamento de Comunicação Visual da Escola de Belas Artes da UFRJ nos períodos de 2009-2011 e 2014-2016. Fundador do projeto Infoview, que atua no ensino, difusão e pesquisa da infografia, desde 2015.

Ficha Catalográfica

Nogueira, Daniel Moura

Infografia no Brasil: panorama de uma linguagem multimodal / Daniel Moura Nogueira ; orientadora: Vera Lúcia Moreira dos Santos Nojima ; co-orientador: Frederico Braida Rodrigues de Paula. -2019.

242 f.: il. (color.) ; $30 \mathrm{~cm}$

Tese (doutorado) - Pontifícia Universidade Católica do Rio de Janeiro, Departamento de Artes e Design, 2019.

Inclui bibliografia

1. Artes e design - Teses. 2. Infográfico. 3. Visualização de dados. 4. Design da informação. 5. História da infografia. 6. Ensino da infografia. I. Nojima, Vera Lúcia Moreira dos Santos. II. Paula, Frederico Braida Rodrigues de. III. Pontifícia Universidade Católica do Rio de Janeiro. Departamento de Artes e Design. IV. Título. 
Para meus pais, Cel. Osmar Carvalho Nogueira e Ierecilda Moura Nogueira. 


\section{Agradecimentos}

À CAPES e à PUC-Rio, pelos auxílios concedidos, sem os quais este trabalho não poderia ter sido realizado.

À minha orientadora, Vera Nojima, por ter me aceitado no programa, permitindo a realização desta tese.

Ao meu coorientador, Frederico Braida, pelos conselhos e incentivos, pela atenção e disponibilidade no acompanhamento do trabalho.

Aos profissionais, pesquisadores e professores que contribuíram com entrevistas, coletas de dados e auxílio em diversas situações, tais como Ary Moraes, Gabriel Silveira, Guilhermes Damian, Mario Leite, Alexandre Lage, Ricardo Cunha Lima, Rita Couto, Tattiana Teixeira, Marcus Dohmann, para citar alguns.

A Mário Alexander P. Hortêncio Cabral e demais irmãos do Colégio Militar, pelo apoio e incentivo inestimáveis por tantos anos.

A Natascha Scagliusi, Fernanda Pina, Luiza Arigoni e Mônica Lopes, fontes de apoio e amizade descobertas durante o percurso na PUC-Rio.

A Tarso Moura, Iara Cunha, André Santoro e tantos outros amigos, pelo apoio ao longo da minha trajetória.

Aos meus pais, Cel. Osmar Carvalho Nogueira e Ierecilda Moura Nogueira, que não mediram esforços para me proporcionar uma boa educação.

Aos meus irmãos, pelo apoio, cada qual do seu jeito.

À Flávia Porto, pela companhia, compreensão e por ter se tornado uma das motivações para a conclusão deste trabalho da melhor forma possível.

A todos os que aqui não citei, mas contribuíram de alguma forma para a realização desta tese.

O presente trabalho foi realizado com apoio da Coordenação de Aperfeiçoamento de Pessoal de Nível Superior - Brasil (CAPES) - Código de Financiamento 001. 


\section{Resumo}

Nogueira, Daniel Moura; Nojima, Vera Lúcia Moreira dos Santos; Paula, Frederico Braida Rodrigues de. Infografia no Brasil: panorama de uma linguagem multimodal. Rio de Janeiro, 2019. 242p. Tese de Doutorado Departamento de Artes e Design, Pontifícia Universidade Católica do Rio de Janeiro.

Esta tese aborda o tema da linguagem infográfica, um dos produtos do Design da Informação, no Brasil. Os infográficos são amplamente usados como ferramenta de comunicação pela mídia, com o intuito de transmitir informações de modo sintético, claro e atraente por meio de representações visuais diagramáticas multimodais, onde coexistem diversas modalidades comunicativas, que combinam linguagem verbal e não verbal. A pesquisa analisa o persistente problema da nomenclatura na infografia, bem como tipologias relevantes. Propõe uma linha do tempo da evolução dos infográficos, traça um breve histórico da infografia no Brasil e examina sua participação na maior premiação de infografia mundial (Malofiej) ao longo dos últimos 26 anos. Investiga e analisa dados acerca do ensino da infografia no país, observando a presença de disciplinas ligadas ao tema nos cursos superiores de jornalismo e design. Os aportes teóricos se encontram nas obras de Cairo, De Pablos, Sancho, Tufte, Moraes e Kanno, que desenvolveram investigações acerca da linguagem infográfica e visualização da informação. Foram realizadas pesquisas bibliográficas, documentais e entrevistas junto a profissionais premiados internacionalmente e professores, como forma de mapear conceitos, pressupostos teóricos e questões relacionadas ao atual cenário da infografia. O trabalho visou reunir dados que permitam a construção de um diagnóstico da infografia no Brasil na esfera acadêmica e sua práxis, algo não revelado de forma integrada por pesquisas anteriores, bem como oferecer uma reflexão acerca do papel da infografia e sua perspectiva como ferramenta informativa no cenário contemporâneo nacional. Como resultado, elaborou-se uma série de infográficos que traçam um panorama da infografia brasileira, de modo a disponibilizar dados para a comunidade de infografistas, jornalistas, designers e professores do campo do Design da Informação.

\section{Palavras-chave}

Infográfico; visualização de dados; design da informação; história da infografia; ensino da infografia. 


\section{Abstract}

Nogueira, Daniel Moura; Nojima, Vera Lúcia Moreira dos Santos (Advisor); Paula, Frederico Braida Rodrigues de (Co-advisor). Infographics in Brazil: a panorama of a multimodal language. Rio de Janeiro, 2019. 242p. Doctoral Thesis - Departamento de Artes e Design, Pontifícia Universidade Católica do Rio de Janeiro.

This thesis addresses the theme of infographic language, one of the products of Information Design, in Brazil. Infographics are widely used as a communication tool by the media, with the purpose of transmitting information in a synthetic, clear and attractive way through multimodal diagrammatic visual representations, combining verbal and nonverbal language. The research analyzes the persistent problem of nomenclature of the infographics, as well as relevant typologies. It proposes a timeline of the evolution of infographics, traces a brief history of infographics in Brazil, and examines its participation in the biggest infographics award worldwide (Malofiej) over the last 26 years. It analyzes data on the teaching of infographics in the country, observing the presence of disciplines related to the subject in journalism and design graduations. The theoretical contributions are found in the works of Cairo, De Pablos, Sancho, Tufte, Moraes and Kanno, who have developed research on infographics and information visualization. Bibliographical and documentary research as well as interviews with awarded professionals and professors were carried out as a way of mapping concepts, theoretical assumptions and issues related to the current infographic scenario. The aim of this study was to gather data that allow the construction of a diagnosis of infographics in Brazil in the academic sphere and its praxis, something not revealed in an integrated way by previous researches, as well as offer a reflection about the role of infographics and its perspective as an information tool. As a result, a series of infographics were created, providing data to the community of journalists, designers and professors in the field of Information Design.

\section{Palavras-chave}

Infographics; data visualization; information design; history of information graphics; teaching of information graphics. 


\section{Sumário}

1 Introdução 15

1.1. Estrutura da tese $\quad 24$

2 Definições: o persistente conflito sobre a nomenclatura 27

2.1. Gráficos 32

2.2. Visualização de dados $\quad 37$

2.3. Infográfico 41

2.4. Infográfico digital $\quad 50$

2.5. Considerações sobre os termos essenciais 56

3 Das origens à infografia contemporânea: a construção de uma linha do tempo 58

3.1. Percurso(s) histórico(s): cruzando óticas variadas 59

3.1.1. Tufte: a referência na esfera da visualização de informações $\quad 60$

3.1.2. Few: o caminho da visualização das informações 65

3.1.3. Cairo: as fontes de origem da infografia 67

3.1.4. Linhas adicionais: Holmes e Kanno 70

3.1.5. Resultados obtidos pelo processamento dos dados 72

3.2. Breve história da infografia: das cavernas aos smartphones $\quad 74$

3.2.1. Cartografia e estatística 75

3.2.2. Ilustração científica $\quad 85$

3.2.3. Jornalismo impresso $\quad 88$

3.2.4. Infografia digital ou online 99

3.2.5. Um momento de reflexão necessário 100

3.2.6. O mobile first torna-se realidade 102

3.3. Linha do tempo em formato gráfico-visual 103

4 Dos dados ao conhecimento, suas abordagens e categorias 108

4.1. O processo de esclarecer: dos dados não estruturados ao conhecimento108

4.2. Entre a estética e a objetividade 113 
$\begin{array}{ll}\text { 4.3. Categorias } & 120\end{array}$

$\begin{array}{ll}\text { 4.3.1. Categorias por forma } & 121\end{array}$

4.3.2. Categorias orientadas pelo lead jornalístico 123

4.3.3. Catalogação de ferramentas $\quad 125$

4.4. Conclusões sobre o capítulo 129

5 Infografia no Brasil: a participação no Malofiej 130

$\begin{array}{ll}\text { 5.1. Origens } & 131\end{array}$

5.2. Reformas editoriais e intercâmbio de conhecimento 134

5.3. O Malofiej em dados 139

5.4. Uma análise da participação do Brasil no Malofiej 144

5.5. Infográfico: O Brasil no Malofiej 153

5.6. Conclusões sobre o capítulo 155

6 Dados sobre a infografia no Ensino Superior no Brasil 156

6.1. Os Currículos Mínimos Profissionais 157

$\begin{array}{ll}\text { 6.1.1. No Jornalismo } & 158\end{array}$

6.1.2. No Design 160

6.1.3. A nova Lei de Diretrizes e Bases da Educação Nacional 162

6.2. Dados sobre a presença da infografia no Jornalismo e Design 166

6.3. Considerações sobre o capítulo 179

7 Reflexões: perspectivas para a infografia em um jornalismo em mutação 181

$\begin{array}{lc}\text { 7.1. Uma linguagem multimodal } & 184\end{array}$

7.2. A instabilidade pela falta de um modelo 190

7.3. Novas tecnologias: a linguagem infográfica perdura 199

7.4. O papel da academia no país 203

7.5. A infografia não é a "salvadora da pátria" 211

$\begin{array}{ll}\text { 7.6. Conclusões sobre o capítulo } & 215\end{array}$

8 Conclusão e desdobramentos futuros $\quad 217$

$\begin{array}{ll}\text { Referências bibliográficas } & 224\end{array}$ 
Apêndice I

Apêndice II

239

Apêndice III

241

Apêndice IV

242 


\section{Lista de figuras}

Figura 1 - Gráfico com a expectativa de evolução da quantidade $\quad 17$

Figura 2 - Fundamentos teóricos e práticas relacionadas ao design $\quad 31$

Figura 3 - Exemplos de representações gráficas de Nicole D'Oresme 34

Figura 4 - Informações em texto verbal e a respectiva visualização $\quad 34$

Figura 5 - Exemplo de características de eixo cartesiano 36

Figura 6 - Visualização de dados presente na matéria It's Not Your... 38

Figura 7 - Exemplo de infográfico do tipo "passo a passo" 43

Figura 8 - Wordless diagrams - How to slice an avocado 48

Figura 9 - Parte de um digital poster ou infaxgraphics 49

Figura 10 - Versões impressa (à esquerda) e online (à direita) 51

Figura 11 - Imagem ilustrativa de pequena parte do processo 73

Figura 12 - Itens selecionados, organizados em ordem cronológica. $\quad 74$

Figura 13 - Parte da câmara Shaft of the Dead Man e detalhe $\quad 76$

Figura 14 - (1) Mapa babilônico em tabuleta de argila (esq.) $\quad 76$

Figura 15 - Reprodução do mapa de Ptolomeu da Leinhart Holle $\quad 78$

Figura 16 - Exemplares de mapas dos nativos das Ilhas Marshall $\quad 79$

Figura 17 - Mapeamento do surto de cólera em Londres 80

Figura 18 - Representações visuais esquemáticas no lugar de tabelas 82

Figura 19 - Gráfico multivariado Principal Nations of Europe 82

Figura 20 - Diagrama das causas de mortalidade do exército britânico 83

Figura 21 - Infográfico sobre a marcha de Napoleão na Rússia $\quad 84$

Figura 22 - Clássico mapa do metrô de Londres 85

Figura 23 - Studies of the Shoulder and Neck, Leonardo da Vinci $\quad 86$

Figura 24 - Reproduções do Vitruvian Man, de Leonardo da Vinci $\quad 87$

Figura 25 - Capa e exemplo do tratado anatômico De humani corporis...88

Figura 26 - Capa do The Times com um dos primeiros infográficos $\quad 89$

Figura 27 - Capas do jornal Londrino The Guardian 90

Figura 28 - Capa e mapa colorido do clima nos EUA 91

Figura 29 - A interface gráfica e o Macintosh 93

Figura 30 - Capas dos jornais The New York Times e The San Diego... 94

Figura 31 - Uso de recursos gráficos combinados 96 
Figura 32 - A infografia espanhola influenciou diversos veículos

Figura 33 - Infográfico La ballena Franca, de Jaime Serra 98

Figura 34 - Imagem de exemplo do Sector Snapshot, do NYT 100

Figura 35 - Infográfico publicado pelo jornal El País 102

Figura 36 - Proposta gráfica reduzida da linha do tempo 104

Figura 37 - Imagem da primeira parte da linha do tempo 105

Figura 38 - Imagem da segunda parte da linha do tempo 106

Figura 39 - Gráfico DIKW identificando as etapas de transição 110

Figura 40 - Exemplos de infográficos analíticos e estetizantes 115

Figura 41 - Gráfico de análise de preferências na abordagem projetual 116

Figura 42 - Infográfico desenvolvido por Holmes 118

Figura 43 - Infographia, poster com mapeamento das categorias 123

Figura 44 - Gráfico com proposta de taxonomia de infográficos $\quad 124$

Figura 45 - Imagem da Tabela periódica dos métodos de visualização 127

Figura 46 - Imagem do Datavizproject exibindo parte dos exemplos 128

Figura 47 - Gráfico A Navegação Brasileira, publicado no jornal 132

Figura 48 - Primeiro infográfico publicado no jornal O Globo 133

Figura 49 - Infográfico Mike Tyson, responsável pelo primeiro prêmio 137

Figura 50 - Quantidade de trabalhos inscritos no Malofiej de $1993 \quad 141$

Figura 51 - Quantidade de veículos de comunicação inscritos 141

Figura 52 - Quantidade de países participantes no Malofiej de $1993 \quad 141$

Figura 53 - Número total de medalhas concedidas por ano 143

Figura 54 - Número total de medalhas por tipo (ouro, prata e bronze) 144

Figura 55 - Infográfico "A dor dos ossos do ofício", da revista Veja 146

Figura 56 - Infográfico "Golpes de Mestre" 147

Figura 57 - Ranking por número de medalhas recebidas por veículos 148

Figura 58 - Ranking por número de medalhas confirmadas 149

Figura 59 - Número total de medalhas brasileiras confirmadas $\quad 150$

Figura 60 - Número total de medalhas brasileiras confirmadas por ano 151

Figura 61 - Número total de medalhas brasileiras por ano 152

Figura 62 - Versão reduzida da proposta de infográfico 153

Figura 63 - Proposta de infográfico sobre a participação da infografia 154

Figura 64 - Mapa com cidades que oferecem pelo menos um curso $\quad 170$

Figura 65 - Mapa com cidades que oferecem pelo menos um curso 171 
Figura 66 - Cidades com pelo menos um curso presencial de design 174 Figura 67 - Cidades com pelo menos um curso presencial 175

Figura 68 - Instituições com pelo menos um curso presencial 176

Figura 69 - Versão reduzida do infográfico sobre a disponibilidade $\quad 177$

Figura 70 - Versão adaptada do infográfico sobre a infografia $\quad 178$

Figura 71 - Exemplo de reportagem da seção Fact Checker 196

Figura 72 - O fact-check também está se consolidando no Brasil 197

Figura 73 - Exemplo de reportagem com de checagem de fatos 198

Figura 74 - Imagem da apresentação videográfica The Dangers of... 201

Figura 75 - Ambiente com sobreposição de tecnologias e realidade 202

Figura 76 - Proposta de cartaz Infografia no Brasil 222 


\section{Lista de quadros}

Quadro 1 - Exemplos de mapas de dados mencionados por Tufte 61

Quadro 2 - Exemplos de gráficos de séries temporais 63

Quadro 3 - Exemplos de gráficos narrativos de espaço e tempo 63

Quadro 4 - Exemplos de gráficos relacionais mencionados por Tufte $\quad 64$

Quadro 5 - Marcos históricos apontados por Few 66

Quadro 6 - Marcos históricos da Cartografia e Estatística 68

Quadro 7 - Marcos históricos da ilustração científica 69

Quadro 8 - Marcos da infografia jornalística apontados por Cairo 70

Quadro 9 - Raízes da infografia extraídos do Infographia, de 201171

Quadro 10 - Origens da infografia extraídos do livro Infografe 72

Quadro 11 - Cursos de design identificados 168

Quadro 12 - Cursos de jornalismo identificados 168

Quadro 13 - Total de cursos identificados de design por modalidade 169

Quadro 14 - Total de cursos identificados de jornalismo 169

Quadro 15 - Total de cidades que oferecem pelo menos um 170

Quadro 16 - Total de cidades que oferecem pelo menos um curso 171 


\section{1}

\section{Introdução}

O uso combinado de texto e imagem para representar determinados tipos de informação está presente em diversos suportes, tais como revistas, jornais, livros, manuais técnicos, documentos acadêmicos, propagandas, portais de comunicação, aplicativos para tablets e smartphones, vídeos informativos, mídias sociais, dentre outros. Gráficos e infográficos nos auxiliam a compreender diversos tipos de informações, tais como o funcionamento e uso de uma máquina, como ocorreu um determinado fenômeno natural, a situação econômica do país, que roupa usar ao ver a previsão climática, a cadeia de acontecimentos que determinaram um acidente nas páginas de um jornal, qual trajetória seguir a partir de um mapa com o aplicativo de trânsito no celular, quais alimentos comprar segundo a quantidade de carboidratos ideal para a saúde, entre outros. De acordo com Tufte (2011, p.87, tradução nossa) "grande parte do mundo atualmente é observada e avaliada quantitativamente - e gráficos bem projetados são muito mais eficazes do que palavras em mostrar tais observações ${ }^{1 "}$. Ou seja, informações e escolhas que influenciam o cotidiano, comportamento, sentimentos e relações sociais derivam de análises de uma miríade de gráficos e infográficos (em um sentido amplo) exibidos pelos meios de comunicação. A linguagem do design gráfico é um sistema intuitivo que se integra com a experiência pessoal do leitor. Nessa linguagem incluem-se os produtos do design da informação, tais como os infográficos.

Apesar da penetrabilidade das tecnologias de informação no cotidiano dos indivíduos, uma característica indicadora de desenvolvimento social, não somos capazes de lidar facilmente com o volume excessivo de dados gerados diariamente. A quantidade de dados constituídos globalmente no ano de 2017, de quase 20 zettabytes $^{2}$ (Figura 1), supera os dados gerados pela humanidade nos cinco mil anos

\footnotetext{
${ }^{1}$ No original "much of the world these days is observed and assessed quantitatively - and well-designed graphics are far more effective than words in showing such observations."

${ }^{2}$ Um Zettabyte (ZB) é uma unidade de informação ou memória. Ele corresponde a 1.000.000.000.000.000.000.000 $\left(10^{21}\right)$ ou $1180591620717411303424\left(2^{70}\right)$ Bytes. Fonte: Tech Terms Dictionary
} 
anteriores. No entanto, estima-se que apenas $0,5 \%$ desse volume seja efetivamente analisado para auxíliar a tomada de decisões operacionais (IDC, 2012, p.11). Para fins de comparação, dadas as devidas diferenças de arquitetura tecnológica, a capacidade somada de armazenamento de memória do principal computador da espaçonave do Programa Apollo, o Apollo Guidance Computer (AGC), que levou o homem à Lua, em 1969, era de aproximadamente 71 kilobytes $^{3}$. Um smartphone com 8 gigabytes de RAM e 512 gigabytes de armazenagem interna, 50 anos depois, possui um espaço mais de 7 milhões de vezes superior. Para Wurman (2001, p.17, tradução nossa), o excesso na quantidade de informações "começou a obscurecer as diferenças radicais entre dados e informação, entre fatos e conhecimento. Nossos canais de percepção estão em curto-circuito ${ }^{4}$. Para tal, gráficos auxiliam a analisar, interpretar e compreender esses dados de uma forma sintética e direcionada à capacidade cognitiva do ser humano. Conforme Few (2009, p.7), uma boa análise de dados ajuda a compreender o que está acontecendo em um determinado momento e a melhor prever o que pode acontecer sob certas circunstâncias no futuro, de maneira que seja possível criar oportunidades e prevenir problemas. Cairo (2008, p.37) sustenta que a análise, tratamento e transmissão de informações pode atenuar o efeito de sobrecarga ocasionado pelo excesso de informações em nossa atual sociedade. Um tipo de profissional que domine as formas de codificação apropriadas para cada caso será capaz de gerar visualizações de informação que sirvam de apoio à cognição. Ou seja, em determinadas situações, os infográficos possuem o potencial de auxiliar a busca de informações de forma efetiva.

${ }^{3}$ O AGC utilizava um sistema com palavras de 15 bits, com 2.048 palavras de memória apagável em memória de núcleo magnético e 36.864 palavras de memória fixa, em um núcleo de memória de corda (NASA, 1971, p. 76, tradução nossa), com fios costurados através de núcleos magnéticos, onde os softwares necessários para a missão ficavam armazenados. Os valores equivalem a aproximadamente 3840 bytes de RAM (Random Access Memory) e 69,120 bytes de ROM (Read Only Memory).

${ }^{4}$ No original "The glut has begun to obscure the radical distinctions between data and information, between facts and knowledge. Our perception channels are short-circuiting." 


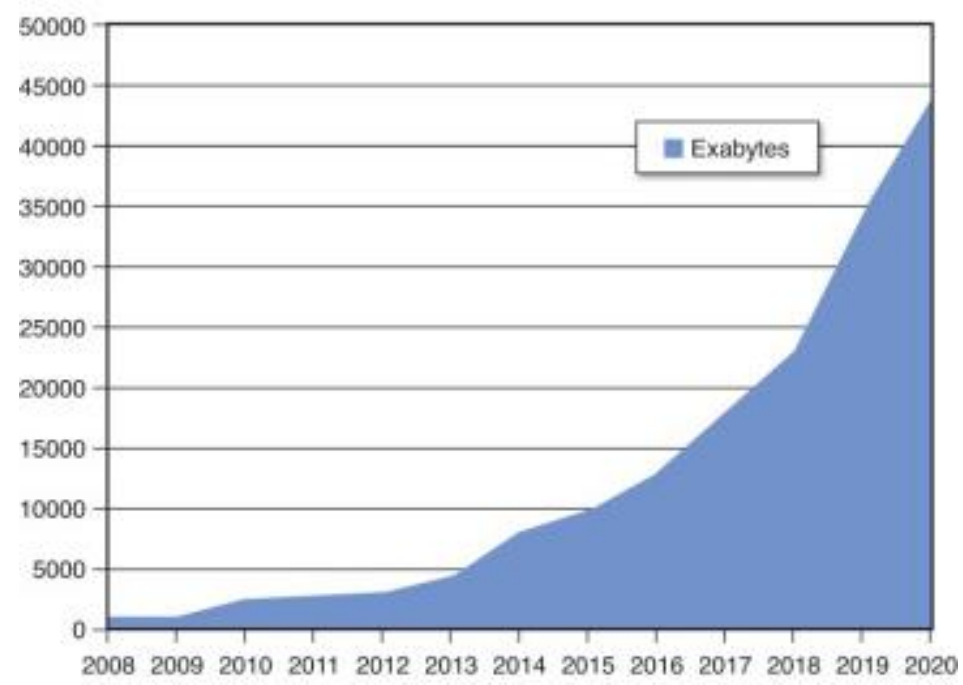

Figura 1 - Gráfico com a expectativa de evolução da quantidade de dados gerados globalmente, por ano, em exabytes, até 2020 (IDC, 2012, p.3).

Cabe ressaltar que infográficos são adequados a tipos específicos de informação em que o papel exclusivo do texto, dos dados tabulares, das fotografias ou das ilustrações isoladas não seriam suficientes para tornar o leitor apto a assimilar o conteúdo de forma plena. De acordo com Kanno, o infográfico "não tem o poder milagroso de 'fazer coisas complexas ficarem simples', ele é apenas a melhor maneira de representar certo tipo de informação" (KANNO, 2013, p.11). Ou seja, são usados "sempre que se pretende explicar algo, de uma forma clara e, sobretudo, quando só o texto não é suficiente para fazê-lo de maneira objetiva" (TEIXEIRA, 2007, p. 112).

Gráficos e infográficos nos ajudam a pensar e, no fim, auxiliam a tomar boas decisões. No entanto, essas decisões partem de informações que são transmitidas por meio do discurso presente em um suporte, seja ele uma revista, uma embalagem, uma apresentação corporativa, um portal informativo online, um aplicativo em um smartphone, entre outros. Essas informações, ao comunicarem algo a alguém, possuem uma retórica verbal e outra visual, que interagem entre si. Conforme Bonsiepe (1996, p.90), sem retórica a comunicação humana se torna asséptica, uma não comunicação. Não há informação sem retórica, ou seja, recursos linguísticos presentes nas visualizações, gráficos e demais produtos do design da informação levam o leitor a concordar com uma determinada opinião que lhe foi apresentada. De acordo com o teórico: 
O propósito da retórica é o uso eficiente da linguagem para moldar atitudes nos outros e influenciar seu comportamento. Onde há coerção, não há necessidade de retórica, além disso, onde a coerção prevalece, a retórica nem é possível. Porque a persuasão pressupõe a possibilidade de escolha" " (BONSIEPE, 1996, p.71, tradução nossa).

Portanto, não há uma neutralidade, seja qual meio for, onde se pressupõe o convencimento por meio de uma argumentação (e não por imposição) a um leitor. A escolha dos argumentos, das ferramentas e da filtragem dos dados é, acima de tudo, uma interpretação - e o designer responsável pela elaboração do gráfico é um ator fundamental, por ser responsável pela "tradução" ou mediação do discurso desejado em uma narrativa gráfica.

Designers e jornalistas visuais aprenderam a aprimorar os infográficos por meio da prática diária, de forma empírica, e da troca de experiências entre os profissionais ao longo das décadas. Os jornais e revistas poderiam ser comparados a um laboratório de testes, onde os resultados eram observados após a publicação e ajustes seriam aplicados a projetos similares subsequentes. A primeira apresentação de uma fundamentação teórica surgiu com Jacques Bertin (1918-2010), com o livro Sémiologie Graphique, em 1967. O uso racionalizado de atributos visuais como contraste, cores, texturas, direções, volumes etc. poderiam tornar mais evidentes as afirmações presentes em gráficos e visualizações de dados, aumentando a eficácia da mensagem. Compreender melhor a cognição humana fez com que a possibilidade de interpretação dos gráficos esquemáticos fosse incrementada, reduzindo ruídos, favorecendo a construção de um discurso visual mais eloquente. A partir de Bertin, não apenas a experiência do cotidiano e a intuição tornam-se determinantes, mas o uso de premissas baseadas em pesquisas e testes que podem ser consultados por quaisquer indivíduos interessados no assunto. A informalidade perde espaço e os profissionais passam a ter uma fonte de consulta não restrita a um "círculo de iniciados". Após Bertin, outros pesquisadores estabeleceram obras que oferecem subsídio ao campo da infografia, tais como Tufte, Holmes, Few, Ware, De Pablos, dentre outros.

${ }^{5}$ No original "Der Zweck der Rethorik besteht in der effizienten Verwendung sprachlicher Mittel, um bei anderen Menschen Einstellungen zu bilden und ihre Handlungen zu beeinflussen. Wo Zwang herrscht, bedarf es keiner Rhetorik, mehr noch, wo Zwang herrscht, ist Rhetorik nicht möglich. Denn Persuasion setzt Wahlmöglichkeit voraus." 
Apesar da contribuição de pesquisadores em relação a percepção visual, comunicação, elaboração de gráficos, semiologia e outros tópicos, o desenvolvimento da infografia e sua prática ao longo do tempo deve considerar, de forma preponderante, questões advindas do impacto das mudanças nos paradigmas do campo do jornalismo. É preciso notar a influência das evoluções de ordem tecnológica (tanto na produção do jornal impresso, no parque industrial, quanto na elaboração das páginas, nas editorias), a(s) crise(s) financeira(s) no mercado editorial, a crescente velocidade de acesso às informações (e constante necessidade de publicação para consumo "imediato"), o aumento do volume de dados disponíveis, a transição da infografia impressa para a digital e a posterior reorientação de prioridade do digital do desktop para o mobile ${ }^{6}$, e, mais recentemente, a intensa competição de audiência com as mídias sociais. Os atributos visuais e elementos retóricos explorados na infografia impressa ganham um novo leque de oportunidades quando aplicados em suportes digitais. Um novo repertório de ferramentas e tecnologias foi desenvolvido. Se, em um primeiro momento, as telas onde os infográficos online eram exibidos tornavam-se cada vez maiores nos computadores pessoais, hoje devem caber na palma da mão, nas telas dos celulares.

Desde o surgimento da infografia digital ou online, inúmeros elementos foram adicionados à equação, tais como animações, diversas possibilidades de interação, volumes praticamente ilimitados de dados, aquisição de dados em tempo real, opção de se lidar com a dimensão do tempo, novas tecnologias e linguagens de programação disponíveis aos desenvolvedores, dentre outros. Ao longo do tempo, intensifica-se a questão de distanciamento entre as versões impressa e online das publicações. Então, como equalizar o projeto em meio a diferenças tão distintas entre os suportes? Como exemplo da contemporaneidade do tema, a Folha de S. Paulo, jornal de maior circulação no Brasil ${ }^{7}$, fundado em 1921, unificou o projeto gráfico de suas versões impressa e digital, no dia 20 de abril de 2018. A recente reforma gráfica (e tecnológica) destaca que "texto, imagem e infografia passaram a

${ }^{6}$ Segundo dados do Pew Research Center, consolida-se a superação, em 2016, da quantidade de acessos a veículos de informação por meio de dispositivos móveis, em comparação aos computadores e notebooks, nos EUA. (PEW, 2018)

${ }^{7}$ De acordo com o Instituto Verificador de Circulação a Folha de S. Paulo é o maior jornal do Brasil, levando-se em consideração a soma do número de exemplares de circulação impressa e número de assinaturas digitais (IVC, 2017). 
ser editados com o peso devido" e reforça, ainda, que a versão digital dará mais ênfase ao conteúdo visual com "fotos maiores nas reportagens e capas, com mais destaques para vídeos e infográficos" (FOLHA, 2018). O jornal O Globo, fundado em 1925, também fez, no dia 29 de julho de 2018, o lançamento de um projeto gráfico para suas versões impressa e digital, o qual "funciona como ponte entre o o impresso e o site" (O GLOBO, 2018a) e no qual o papel dos infográficos também é destacado. De acordo com Chico Amaral, editor executivo que assina o projeto "os infográficos estão de roupa nova, num esforço para torná-los ainda mais práticos e analíticos. Legibilidade é o ponto-chave, sem abrir mão da profundidade" (O GLOBO, 2018a). Ou seja, a linguagem infográfica é usada como elemento comunicacional fundamental nos grandes veículos noticiosos, ganhando atenção e investimento em meio a aprimoramentos gráfico-visuais e tecnológicos dos suportes impresso e online.

Portanto, o uso da linguagem infográfica passa por modificações estruturais constantes que acompanham avanços tecnológicos e a forma como a sociedade faz uso das tecnologias de comunicação e informação. Se as mudanças se dão em intervalos de tempo curto, dificultam o estabelecimento de termos universalmente reconhecíveis de forma coerente, metodologias de projeto que perdurem e fundamentação teórica consolidada útil à comunidade acadêmica. Além disso, os atores envolvidos no processo de elaboração de infográficos passam, cada vez mais, a ter a necessidade de dominar expertises variadas para que se desenvolvam no campo. Como pode se observar na declaração de Hannah Fairfield, ex-diretora de gráficos do The Washington Post e professora do curso de jornalismo de Columbia, em entrevista a Cairo, acerca de uma das características que procura no tipo de profissional que o veículo buscava contratar:

Eu procuro pessoas que estejam dispostas a pensar em projetos em todas as formas que publicamos - na versão impressa, na $W e b$ e em dispositivos móveis. Isso afeta a maneira como você planeja e executa qualquer projeto de infográfico desde o início: como fica uma história no papel, na tela do computador, em um iPad ou em um telefone celular? Você tem que estar preparado para todos eles ${ }^{8}$ (CAIRO, 2013, p.278, tradução nossa).

${ }^{8}$ No original "I look for people who are willing to think of projects in all forms that we publish in print, on the Web, and on mobile devices. This affects the way you plan and execute any infographics project from the very beginning: what does a story look like on paper, on a computer screen, on an iPad, or on a cell phone? You have to be prepared to design for them all." 
Os profissionais envolvidos no tema da infografia encontram-se, então, em um momento complexo. Por um lado, os veículos de informação passam por crises persistentes ao longo dos anos, com o enxugamento de equipes, acúmulo de funções, fechamento de publicações, redução da receita proveniente de anunciantes, concorrência com meios "não tradicionais" como Facebook, por exemplo. Por outro, a busca por ferramentas eficazes, inovadoras e atrativas de contar uma determinada história demandam profissionais cada vez mais versáteis, capazes de se adaptar rapidamente às questões tecnológicas e sociais que influenciam sua atuação. É nesse cenário atual que que essa pesquisa buscou oferecer um panorama auxiliador para a compreensão do campo, como forma de gerar subsídio para os profissionais, docentes e pesquisas futuras.

Motivado pela atuação na área do design da informação, desenvolvendo gráficos, visualizações de dados e infográficos, nos últimos 15 anos, para empresas do segmento de óleo e gás; pela experiência acadêmica, tendo criado e lecionado por quatro semestres a disciplina de Projeto de Infografia no Curso de Comunicação Visual - Design, na Escola de Belas Artes da UFRJ e pela fundação do projeto Infoview, relacionado ao ensino e difusão da linguagem infográfica por meio de palestras, workshops e exposições, o presente autor buscou trazer à luz do pensamento científico o cruzamento de questões vivenciadas entre o mercado e a academia. Esta tese visou traçar um panorama da infografia brasileira, investigando questões como suas origens, inconsistências terminológicas, problemas atuais enfrentados pelos profissionais do design da informação relacionados à prática da infografia (impressa e online), bem como o quadro do ensino da infografia no Brasil. Sob a hipótese de que há um diagnóstico ainda não revelado da infografia nacional contemporânea, visto que pesquisas anteriores não integram dados sobre a academia e o mercado de forma completa, o presente trabalho oferece uma reflexão atual sobre a presença da infografia como disciplina nas instituições de ensino superior (IES) e discute o papel e as perspectivas da linguagem infográfica como ferramenta informativa nos principais meios de comunicação nacionais.

Como fundamentação teórica acerca da infografia, partiu-se das obras de Cairo (2008, 2013), Tufte (1983, 2001, 2006), De Pablos (1999), Sancho (2000, 2001), Few (2004, 2006, 2007, 2009), Kanno (1998, 2008, 2013), Moraes (1998, 2009, 2013, 2015) e Teixeira $(2006,2007,2010)$. Foi realizada uma pesquisa bibliográfica e documental durante a investigação, na qual foram compilados dados 
acerca da história da infografia, da sua terminologia, do desenvolvimento da infografia no Brasil, das tipologias propostas por pesquisadores, do mapeamento de conceitos e da participação dos veículos de comunicação brasileiros no Malofiej (principal evento global de infografia, que acontece anualmente em Pamplona, na Espanha). Foram coletados, estruturados e analisados dados relativos ao ensino da infografia no país, com a investigação de grades curriculares e ementas de disciplinas de mais de 245 cursos nacionais de graduação em design e, também, 334 cursos de graduação em comunicação social com habilitação em jornalismo. Os dados obtidos permitiram a geração de gráficos que possibilitam reflexões sobre o ensino da infografia no Brasil. Entrevistas semiestruturadas ${ }^{9}$ foram gravadas em áudio e vídeo junto a seis profissionais brasileiros premiados internacionalmente (com prêmios SND e/ou Malofiej) e professores, com a coleta de dados qualitativos fundamentais para a elucidação de questões de ordem histórica, tecnológica e de tópicos contemporâneos. Investigaram-se, ainda, pesquisas no campo da percepção visual, compiladas por Ware $(2004,2008,2013)$, de forma a relacionar a manipulação dos atributos visuais e figuras retóricas nos gráficos e infográficos ${ }^{10}$ em mídia impressa e online.

O tema da pesquisa foi o desenvolvimento da linguagem infográfica no Brasil, desde suas origens, passando pelo reconhecimento do país como potência mundial e expondo a situação atual ${ }^{11}$ do campo. O objetivo geral da pesquisa foi elaborar gráficos e infográficos que auxiliem a traçar uma linha do tempo e um panorama da prática e do ensino da infografia no Brasil. Em paralelo, visamos disponibilizar online os dados sobre a infografia nacional, bem como informações e trechos relevantes das entrevistas realizadas. Dentre os assuntos abordados nas entrevistas, estão: a construção do discurso visual e da narrativa, a relação entre o discurso verbal e o visual, a identificação de problemas na confecção de infográficos atualmente, as metodologias, as questões de ordem tecnológica, o modo do ensino da infografia no país, os aspectos culturais acerca do tema e da

9 Exemplos do roteiro da entrevista utilizada, do Termo de Consentimento Livre e Esclarecido (TCLE) e do Termo de Autorização de uso de Imagem e Depoimentos (TAID) estão incluídos nos Apêndices I, II e III, ao final deste documento.

${ }^{10}$ Esses temas foram abordados em trabalho anterior e serão retomados apenas como suporte ao desenvolvimento das análises e comentários. O conteúdo completo pode ser acessado em Nogueira (2014).

${ }^{11} \mathrm{O}$ termo "atual" se refere ao período compreendido entre a coleta dos dados desta pesquisa e a sua publicação, ou seja, entre os anos de 2016 e 2019. 
indústria jornalística. Todos os entrevistados prestaram seus depoimentos presencialmente, em suas cidades, mediante assinatura de Termo de Consentimento Livre e Esclarecido (TCLE), bem como de Termo de Autorização de uso de Imagem e Depoimentos (TAID). Partes dos relatos foram distribuídas ao longo dos capítulos, de acordo com o tema, tendo em vista que os entrevistados trataram de assuntos diversos, contribuindo com uma visão do mercado, da prática, a esta investigação.

Partindo-se do objetivo central, os objetivos específicos para delinear o percurso lógico da investigação foram:

- mapear conceitos, tipologias e caracterizar os termos "visualização de dados", "visualização da informação". "gráfico" e "infográfico";

- identificar as origens da linguagem infográfica, suas funções e desenvolvimento ao longo do tempo no campo do jornalismo;

- elaborar uma linha do tempo com as origens e marcos na infografia e visualização de dados;

- investigar a evolução da infografia no Brasil;

- identificar os veículos de comunicação de destaque no campo por meio de análise documental dos relatórios anuais da principal premiação internacional de infografia (Malofiej);

- identificar os cursos e disciplinas que oferecem subsídios aos jornalistas visuais e designers de informação em território nacional;

- caracterizar a infografia como uma linguagem multimodal;

- realizar análises dos dados obtidos e confeccionar gráficos e infográficos que sirvam de base para pesquisas posteriores;

- refletir sobre os dados, observando as perspectivas e possibilidades para o campo;

O objeto de estudo foram as questões relacionadas à evolução da infografia no Brasil, sob o prisma da prática e sua relação com a academia. Para que um recorte com um maior controle fosse estabelecido, o corpus da pesquisa limitou-se aos infográficos publicados em veículos de comunicação brasileiros premiados com o Malofiej, o maior prêmio mundial de Infografia. 
A tese visa colaborar com o campo do Design da Informação, com a disponibilização de material que contribua para a elaboração de bases teóricas a respeito da infografia, observando a presença do tema nas instituições de ensino superiores brasileiras e ressaltando a importância do papel do designer no processo de construção de conhecimento.

\section{1.}

\section{Estrutura da tese}

Esta tese se constitui de oito capítulos, descritos a seguir:

Capítulo 1 - Introdução: neste capítulo são apresentados os termos gerais da pesquisa: delineamento, tema, motivações, objetivos, objeto de estudo, justificativa de relevância, métodos de pesquisa e descrição dos capítulos.

Capítulo 2 - Definições: o persistente conflito sobre a nomenclatura: são abordadas questões sobre a terminologia, a dificuldade em se estabelecer uma nomenclatura na área e os problemas derivados desse fato. Foi realizada uma extensa investigação acerca das propostas terminológicas, observando diferenças e semelhanças entre as definições de autores como Tufte (2001), Sancho (2001), De Pablos (1999), Peltzer (1991), FEW (2009), Moraes (1998, 2013, 2015), entre outros. São discutidos e definidos os vocábulos essenciais "gráfico", "infográfico", “infográfico digital”, "visualização de dados" e "visualização de informação", com o objetivo de consolidar os termos adequados.

Capítulo 3 - Das origens à infografia contemporânea: a construção de uma linha do tempo: partindo-se de investigações realizadas por autores de referência como Tufte (2001), Cairo (2008), Few (2009), Friendly e Denis (2001), Holmes (2011) e Kanno (2013), são analisadas diferentes narrativas sobre a evolução da infografia e visualzação de dados. A partir do resultado obtido, um breve histórico da infografia é elaborado, com descrições dos elementos relevantes para a construção de uma nova proposta de linha do tempo, de modo a expor suas origens em disciplinas como a cartografia, estatística, ilustração científica e infografia jornalística e traçar um percurso até o momento atual.

Capítulo 4 - Dos dados ao conhecimento, suas abordagens e categorias: descreve-se o processo de transição dos dados não estruturados ao conhecimento e a possibilidade de se tornarem sabedoria, observando-se o papel da infografia nesse 
sistema. Levanta-se a discussão entre abordagens estéticas versus a objetividade no espectro da infografia e visualizações de dados em veículos jornalísticos. São examinadas diferentes classificações e tipologias, de acordo com as categorias propostas por Kanno (2013), De Pablos (1999), Peltzer (1991), Holmes (2011), Moraes (2013), Roam (2009), dentre outros. Discute-se a útilidade referencial de catalogações de ferramentas gráficas, observando-se exemplos difundidos no meio.

Capítulo 5 - Infografia no Brasil: a participação no Malofiej: são identificadas as origens da infografia no Brasil, partindo-se de investigações de Kanno (2013), Moraes (1998, 2013, 2015) e Teixeira (2010). De forma breve, descreve-se o processo de intercâmbio cultural que auxiliou o desenvolvimento da linguagem infográfica nos principais veículos de comunicação jornalística do país. A partir de pesquisa documental e bibliográfica, foi possível realizar uma inédita reunião de dados provenientes de 26 anos de existência do Malofiej, examinando a participação do Brasil na premiação, observando sua evolução e reconhecimento como potência mundial no domínio da infografia. Apresenta-se uma série de análises de dados e gráficos que relacionam o papel do país no campo da infografia jornalística.

Capítulo 6 - Dados sobre a infografia no Ensino Superior no Brasil: neste capítulo faz-se uma investigação do sistema de ensino e mapeamento de disciplinas relacionadas à prática da infografia em cursos de design e jornalismo no país. Justifica-se o recorte nos cursos de comunicação social com habilitação em jornalismo e design, com habilitações relacionadas ao design gráfico, digital, da informação, multimídia e afins. Traça-se um breve histórico dos Currículos Mínimos nesses cursos, bem como as possibilidades trazidas desde a promulgação da nova Lei de Diretrizes e Bases da Educação Nacional (LDBN). São analisados e transformados em visualizações os dados coletados de 245 cursos de graduação em design e 334 cursos de graduação em jornalismo de instituições de ensino superior brasileiras, com mapeamentos que demonstram a distribuição geográfica dos cursos, verificando a presença de disciplinas cujo tema objetivo seja infografia de forma direta ou que o tema seja parte da ementa, com destaques para aspectos regionais e socioeconômicos.

Capítulo 7 - Reflexões: perspectivas para a infografia em um jornalismo em mutação: o capítulo apresenta uma discussão sobre os resultados, a fim de oferecer uma visão panorâmica sobre o papel e as perspectivas para a infografia no 
Brasil. Justifica-se o uso do termo linguagem multimodal. Discute-se a intrínseca relação entre a "crise" do jornalismo e a sociedade, sua constante mudança e, consequentemente, a influência na infografia. Identificam-se exemplos que demonstram a flexibilidade da linguagem infográfica e sua capacidade de inserção em novos produtos nos meios de comunicação. Observa-se a potencial relevância da academia no Brasil, bem como se pontua que o papel da infografia não é salvar a indústria de notícias.

Capítulo 8 - Conclusão e desdobramentos futuros: por fim, são apresentadas as conclusões obtidas. São revisados os papéis dos estudos das informações coletadas por meio do referencial teórico, das entrevistas e das análises realizadas com base nos dados e gráficos. Avalia-se o percurso empreendido ao longo do tempo, com o objetivo de dar fechamento à pesquisa. Apresenta-se, ainda, possíveis desdobramentos futuros identificados. 


\section{Definições: o persistente conflito sobre a nomenclatura}

Apesar do desenvolvimento da infografia como linguagem e do amplo uso de infográficos como ferramenta comunicacional em diversos meios, persiste o debate sobre o que é e o que não é infografia. É notório que o estabelecimento de uma nomenclatura, fixando um vocabulário próprio ao design da informação, auxilia o trânsito de mensagens com vocábulos prontamente identificáveis. Esse benefício se estende tanto aos atores envolvidos no desenvolvimento de infográficos, quanto aos que se dedicam à pesquisa, aos e docentes e aos leitores e usuários, que, com o tempo, seriam capazes de incorporar os termos ao seu repertório. Quando não há um uso coerente de termos, podem surgir problemas diversos, os quais resultam em ruídos na comunicação entre profissionais. Exemplos disso: (1) um indivíduo pode solicitar uma determinada peça e receber outra, atrasando o cronograma em um ambiente onde o tempo é um elemento fundamental e (2), no meio acadêmico, um docente emprega um determinado termo em sua disciplina, enquanto outro pode usar um termo diferente para se referir a uma mesma ferramenta, o que perpetua o problema entre os alunos. Ainda no âmbito acadêmico, a busca por determinados vocábulos para a realização de pesquisas fica prejudicada, o que exige maior dedicação de tempo e esforço durante a fase de consultas. Por exemplo, de acordo com Horn (1999, p.21), muitos campos do saber fazem uso do design da informação, porém a pesquisa fica dificultada pelo fato de não haver uma indexação adequada e o tema deve ser encontrado de forma indireta:

Todas as pesquisas sobre comunicação, educação, aprendizagem, fatores humanos em tecnologia, design de interface de computador e percepção se apoiam no uso de design de informação. No entanto, a maioria das pesquisas não usa o termo, mesmo como uma categoria de indexação. Para localizar citações relevantes para o design de informações em bancos de dados de pesquisa, portanto, temos que verificar muitas outras palavras-chave ${ }^{12}$ (HORN, 1999, p.21).

12 No original "Research on communication, education, learning, human factors in technology, computer interface design, and perception all bear on the use of information design. However, most of research does not use the term, even as an indexing category. To locate citations relevant to information design on research databases, therefore, we have to check many other keywords." 
O design da informação busca apresentar meios que possibilitem a localização e a compreensão de informações por parte dos usuários/leitores. Dessa forma, a informação poderá ser assimilada e será capaz de auxiliar a tomada de uma decisão e/ou se tornar conhecimento. Cabe ressaltar que fixamos, neste trabalho, o recorte na área do design da informação ${ }^{13}$ relativo a representações gráficas da informação que visem elucidar processos ou fenômenos, onde se insere infografia. Nesse recorte do design da informação, a ausência de uma terminologia bem estabelecida dificulta o briefing e a identificação eficaz de qual tipo de ferramenta (fotografia, ilustração, mapa, tabela, diagrama, infografia, entre outras) poderá cumprir de maneira efetiva o objetivo comunicacional de uma determinada pauta ou peça gráfica ${ }^{14}$ - quando esse objetivo não pode ser bem realizado apenas pelo texto. Ainda hoje, ao não saber definir o nome exato do que se deseja em uma página, os infográficos continuam sendo chamados simplesmente de "arte" por profissionais das demais áreas que atuam em algumas equipes editoriais e agências no Brasil ${ }^{15}$. Outra incongruência usual é denominar de infográfico o mero uso de uma ilustração ou um gráfico cartesiano em um texto sem que ambos possuam relação complementar substancial. Assim, é possível receber a solicitação de um “info" que, na prática, não é um infográfico, e pode ser apenas um dado ilustrado com fim estético que não complementa informação verbal, não auxilia a compreensão da mensagem. Neste caso, a palavra "info" funciona como um neologismo que preenche a lacuna de uma definição funcional da peça em questão. Os termos info e arte ainda são usados por ausência de definições consolidadas no campo da infografia, seja por imprecisão ou por desconhecimento do profissional.

Devemos, portanto, aprofundar a questão, observar a variedade de termos circulantes, suas razões e, posteriormente, estabelecer os conceitos adotados nesta pesquisa. Desta maneira, este capítulo busca trazer subsídios a elucidação de uma inconveniente e perene adversidade relacionada aos termos básicos na esfera do design da informação, especialmente no que tange à infografia.

${ }^{13} \mathrm{O}$ design da informação é uma área do design gráfico que também lida com sistemas de sinalização, interfaces, projetos multimidiáticos, dentre outros que não são o foco desta pesquisa.

${ }^{14}$ Cabe ressaltar que o termo gráfica, neste caso, se refere às características gráfico-visuais de uma peça que pode ser impressa, digital ou mesmo tridimensional.

15 Segundo Kanno (2013, p.33), "na imprensa brasileira, é comum que a infografia e a diagramação sejam chamados de Editoria de Arte, ou Departamento de Arte, mas eles não devem se deixar seduzir pela denominação. Não é 'arte' o que fazem." 
É possível encontrar uma miríade de propostas terminológicas para os produtos do design da informação. Dentre os vocábulos encontrados na bibliografia consultada durante a pesquisa, mantendo-se no âmbito do uso integrado de texto e imagem com fins informativos, estão: statistic graphs, visual graphs, information graphics, information visualization, infovis, informational graphics, explanation graphics, infographics, data visualization, dataviz, graphical data, diagram graphics, diagrammatics, narrative diagrams, representación diagramática de datos, datos estadísticos visuales, informaciones visuales, diseño visual de información, infogramas, diagramas, gráficos diagramáticos, infográficos, gráficos, visualizações de informação, visualização de dados, gráficos informativos, infos, entre outros. Esses termos são usados por pesquisadores e profissionais de diversas áreas, dada a multidisciplinaridade inerente ao desenvolvimento de visualizações de dados e infográficos.

A Sociedade Brasileira de Design da Informação (SBDI), que expressa o papel e designações da área, propõe a seguinte definição:

Design da Informação é uma área do design gráfico que objetiva equacionar os aspectos sintáticos, semânticos e pragmáticos que envolvem os sistemas de informação através da contextualização, planejamento, produção e interface gráfica da informação junto ao seu público-alvo. Seu princípio básico é otimizar o processo de aquisição da informação efetivado nos sistemas de comunicação analógicos e digitais (SOCIEDADE BRASILEIRA DE DESIGN DA INFORMAÇÃO, 2006).

Para Wildbur e Burke (1998, p.6), o design da informação fundamenta-se em selecionar, organizar e apresentar a informação a uma determinada audiência, com o objetivo principal de apresentá-la de forma eficiente. A importância da precisão e eficiência também é destacada por Horn (1999, p.15), segundo o qual o design da informação tem por objetivo desenvolver documentos que sejam compreensíveis, precisos e fáceis de se transformar em ações efetivas. $\mathrm{O}$ autor reforça, ainda, que o design da informação visa projetar interações por meio de interfaces humanocomputador eficientes. De acordo com a Society for Technical Communication's (STC), o design da informação é a tradução de dados complexos, desorganizados ou não estruturados em informação valorosa e significativa. Ou seja, de uma forma abrangente, o design da informação deve consistir em práticas que tornem peças gráfico-visuais potencialmente eficazes no ato de informar, orientar ou ensinar a um determinado público. Neste segmento, os infográficos se inserem, embora ainda não tenham delimitações terminológicas definitivas. 
Há inúmeros debates e propostas na tentativa de estabelecer fronteiras entre o que é uma visualização de dados, um infográfico ou um gráfico ilustrado, por exemplo. Conflitos relativos às questões semânticas, conceituais ou problemas advindos da tradução dos vocábulos tornam a situação ainda mais complicada. No Brasil, onde há poucas obras nacionais relevantes sobre o campo e a quantidade de traduções é reduzida e, por vezes, imprecisa, amplia-se a dificuldade em se firmar uma terminologia consensual.

Cabe lembrar que a questão da imprecisão terminológica, advinda tanto de amplitude conceitual e diversidade cultural, quanto de traduções, não se limita a língua portuguesa, sendo motivo de debate também na língua espanhola, como pode se observar no comentário de Sancho (2000, p.123, tradução nossa, grifo nosso) acerca do uso do termo gráfico(a) para determinar uma infografia jornalística:

Profissionalmente eles [os infográficos jornalísticos] são chamados de gráficos muitas vezes: algumas vezes para abreviar; outras para simplificar o termo em inglês; outros por desconhecimento das diferentes peculiaridades que eles têm; e também por causa da ambigüidade e amplitude que o termo gráfico costuma ter ${ }^{16}$.

O campo acadêmico não solucionou, até o presente momento, a questão da inconsistência terminológica. É possível que palavras diferentes refiram-se a um mesmo tipo de representação visual ou que o mesmo termo refira-se a diferentes produtos. Sobre a ocorrência do uso de termos diferentes para produtos semelhantes, Horn (1999, p.17) menciona distinções terminológicas entre diferentes atividades que fazem uso do design da informação e afirma que o design da informação ainda não é uma profissão totalmente integrada. O autor exemplifica que "em jornais e revistas são chamados information graphics; nos negócios, chamam-se presentation graphics ou business graphics; e na ciência, são conhecidos como scientific visualizations". Ou seja, existe uma inconsistência influenciada pelo vocabulário específico do campo de atuação onde o "gráfico informativo" está inserido.

No Brasil, termos comuns são gráficos, referindo-se a visualizações como gráficos de barra, pizza, volume; mapas para representações geográficas e infográficos, quando a estrutura diagramática é mais complexa e detém uma

${ }^{16}$ No original "Profesionalmente se les llama demasiadas veces gráfico/a: unas veces para abreviar; otras para simplificar su término inglés; otras por desconocimiento de las distintas peculiaridades que tienen; y también por la ambigüedad y amplitud que, a menudo, tiene el término gráfico." 
narrativa interna. Não é incomum confundir um texto acompanhado de um gráfico cartesiano ou uma ilustração com um infográfico.

O diagrama proposto por Cairo $(2008$, p.24) auxilia a compreender a dificuldade em se estabelecer um consenso terminológico, dada a extensa variedade de disciplinas relacionadas à estrutura de concepção de uma visualização de informação jornalística. Campos distintos como a psicologia cognitiva, a ergonomia e a psicologia ambiental subsidiam teoricamente a comunicação visual, o design gráfico, o design de interação e a redação (Figura 2). Ou seja, são diversos profissionais, de origens heterogêneas, complementando-se.

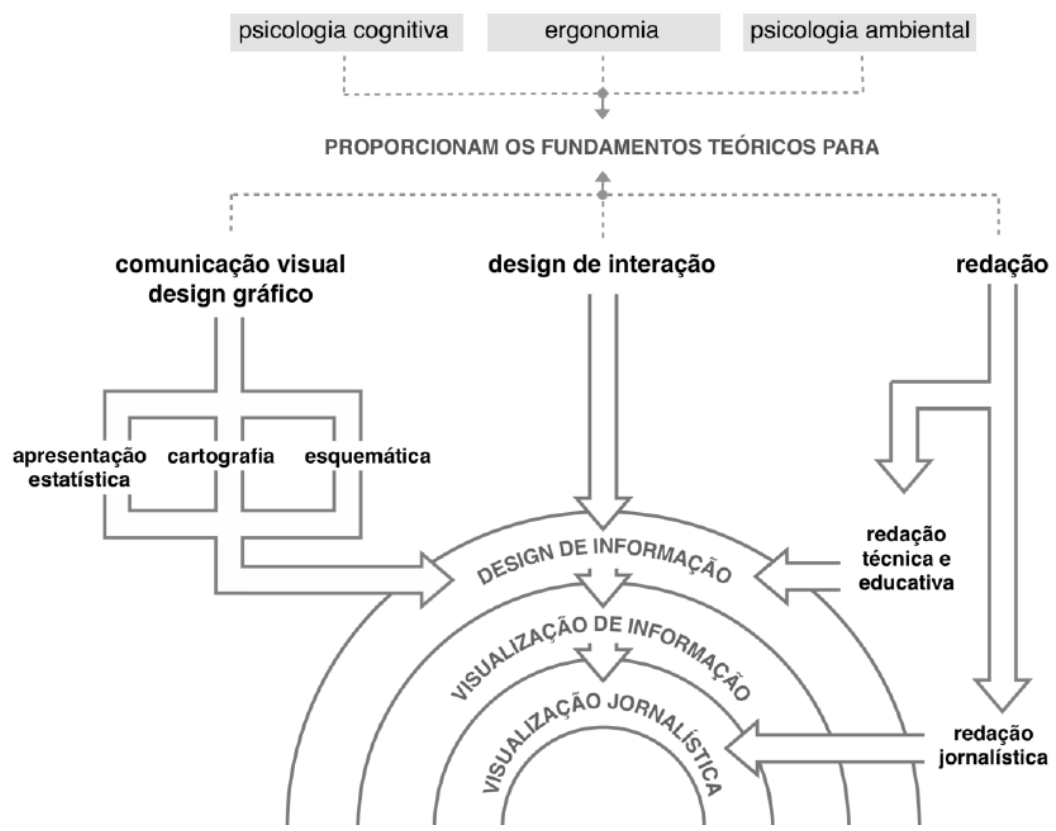

Figura 2 - Fundamentos teóricos e práticas relacionadas ao design da informação jornalística. Fonte: CAIRO (2008, p.24).

Para Kanno (2013, p.10), o jornalismo visual combina estrategicamente texto (informação verbal) e imagens (informação gráfica) para melhorar a eficiência da comunicação jornalística. A informação verbal pode ser escrita ou falada e a informação gráfica pode ser transmitida usando fotografias, infográficos, ilustrações, tipografias, animações, vídeos etc. O infográfico, então, distingue-se dos demais recursos oferecendo uma forma alternativa de leitura:

O que vai diferenciá-lo [o infográfico] é a ausência do texto/narrativa convencional (colunas de texto) que é substituído por cotas, legendas e blocos de texto em tópicos e o uso intensivo de diagramas - representação gráfica de fatos, fenômenos ou 
relações por meio de figuras geométricas (pontos, linhas, áreas etc.) (KANNO, 2013, p.10).

Ainda para este autor, é possível segmentar infográficos em categorias gerais como artes-texto, gráficos, mapas e diagramas ilustrados para resumir e caracterizar as funções de cada tipo de visualização (KANNO, 2013, p.60). Autores, como De Pablos (1999), Peltzer (1991), dentre outros, propõem caracterizações em diferentes graus de complexidade. No entanto, as categorias são um assunto que abordaremos mais adiante, após um maior esclarecimento e diferenciação de termos essenciais, fonte de confusões estruturais na comunicação em relação as principais ferramentas do campo.

A variedade de expressões encontradas tornou necessária uma delimitação de forma mais precisa sobre qual a terminologia seria apropriada para a pesquisa aqui relatada. Os termos usados por autores de referência para a área do design da informação, tais como Bertin (1967), Tufte (1983), Peltzer (1991), De Pablos (1999), Card, Mackinley e Shneiderman (1999), Sancho (2000), Cairo (2008), Few (2009), Moraes (2013), dentre outros, mostram-se divergentes em alguns momentos. No entanto, mesmo sem uma fronteira rígida, é preciso estabelecermos o que é um infográfico, diferenciando-o de um gráfico, por exemplo (uma incongruência frequente). É interessante, também, aprofundarmos termos como a visualização de dados e visualização de informação, por serem proeminentes.

\section{1.}

\section{Gráficos}

O termo "gráfico", de uma forma geral, não provoca estranhamento, mesmo em indivíduos não ligados ao design da informação. A presença constante de gráficos cartesianos desde o período escolar, além do intenso uso de gráficos (pizza, barra etc.) em diversos meios de comunicação, manuais, embalagens, propagandas, websites, mídias sociais, dentre outros, torna-o parte do repertório das pessoas com certa naturalidade. De fato, os gráficos fazem parte da comunicação humana há milênios. Há registros preservados de manifestações do uso de gráficos presentes em manuscritos, incunábulos e livros com séculos de idade. É possível notar a importância dos gráficos no desenvolvimento da matemática e da geometria, tal como em Os Elementos, de Euclides (300 a.C.) e em diversos campos do saber, 
como astronomia, física, economia, para citar alguns. No entanto, foi o estudo analítico de dados variáveis realizado pelo clérigo francês Nicole d'Oresme (13201382), o bispo de Lisieux, em Tractatus de configurationibus qualitatum et motuum $^{17}$, em 1353, que representou um marco para os gráficos de dados. Os gregos usavam as representações gráficas como forma de compreender as relações complexas entre círculos e triângulos estruturando o espaço bidimensional. No entanto, Oresme buscou rastrear uma quantidade mensurável como posição, velocidade ou temperatura durante um intervalo de tempo e torná-la uma representação geométrica, o que era uma ideia inovadora (MUMFORD, 2006, p.3). Os gráficos de Oresme usam coordenadas retangulares ${ }^{18}$, latitude e longitude, que mostram distribuição uniforme ou não-uniforme de quantidades por meio de formas geométricas (Figura 3). A relação quantitativa de uma determinada qualidade (brilho, velocidade) em relação ao tempo ou espaço por meio de barras e as formas geradas por essas barras proporcionam uma visualização dos dados de uma maneira mais apropriada ao cérebro humano - se comparadas a dados tabulares ou texto puro. Destes princípios derivam a concepção de visualizações por meio de gráficos de barra e as fundações para a geometria analítica, por exemplo.

${ }^{17}$ Tratado sobre as configurações de qualidades e movimentos (tradução nossa).

${ }^{18} \mathrm{O}$ sistema de coordenadas de Nicole d'Oresme ajudou a estabelecer as bases que levaram à descoberta da geometria analítica de René Descartes (1596-1650), séculos mais tarde (KIRSCHNER, 1998). 


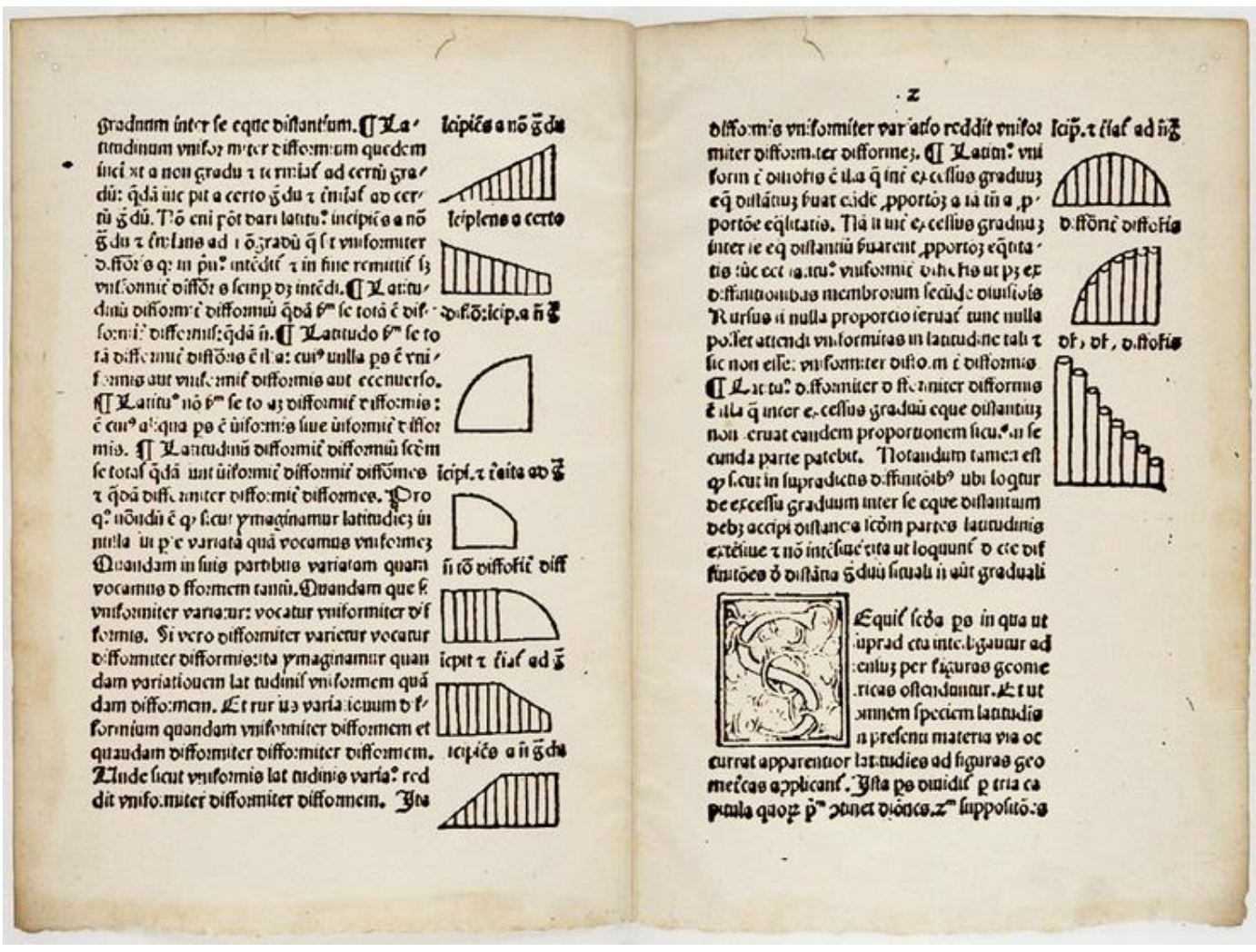

Figura 3 - Exemplos de representações gráficas de Nicole D’Oresme, nas páginas do livro Tractatus de latitudinibus formarum, publicado por Johannes de Sancto Martino, em 1482, 1486, 1505 e 1515. O conteúdo foi extraído de parte do manuscrito de Oresme Tractatus de configurationibus qualitatum et motuum, do século XIV (TASCHOW, 2003). (Disponível em < https://i.pinimg.com/564x/5f/87/d4/5f87d465c3731af312de3ec333e48bf5.jpg> Acesso em: 12 mar. 2018).

De acordo com Tufte (2011, p.9), gráficos ou visualizações de dados são representações visuais de quantidades medidas por meio do uso combinado de pontos, linhas, sistemas de coordenadas, números, símbolos, palavras, sombreamentos e cores. As visualizações podem substituir grandes blocos de dados e textos de forma sintética (Figura 4), além de ofertarem uma forma mais palatável de observar quantidades mensuráveis e compará-las.

O jornal A vendeu 100 milhões de cópias no ano de 2011, enquanto o jornal B vendeu apenas 75 milhões, ficando em segundo lugar geral. $O$ jornal $C$ vendeu um total de 50 milhões de cópias.
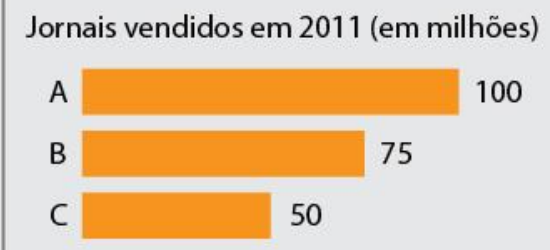

Figura 4 - Informações em texto verbal e a respectiva visualização de dados, baseada no exemplo de Dana Wong. Fonte: do autor. 
A palavra gráfico, no sentido aplicável a este trabalho, é um substantivo masculino que, em língua portuguesa, pode definir ${ }^{19}$ : representação gráfica de um fenômeno estatístico que dá uma visão geral de como o conjunto de dados ou de quantidades relativas àquele fenômeno se relaciona; diagrama, esquema; traçado obtido em aparelhos para estudo de fenômenos físicos ou biológicos; (Álgebra) conjunto de pontos ou segmentos de linhas que unem pontos distintos; (Estatística, Matemática) em um sistema de coordenadas, curva ou superfície que representam uma função. Ao considerarmos as traduções possíveis para "gráfico" como substantivo, é possível encontrar os temos graph, chart, diagram e spread sheet, em inglês. De acordo com Ribas (2000, p.4), é justamente na tradução que recai parte do problema:

Em inglês, as traduções corretas para a palavra 'gráfico' são chart (n. map for navigators; table, diagram, or outlined map showing special information) e graph (n. diagram of line(s) showing the relationship between quantities. - v.t. draw a graph of.). O vocábulo graphic é adjetivo (a. of drawing, painting or engraving; giving a vivid description), enquanto graphics é substantivo (n.pl. diagrams etc. used in calculation and design). E finalmente, diagram é substantivo (n. drawing that shows the parts of a thing or how it works, or represents the operation of a process etc. diagrammatic a., diagrammatically adv.).

Ou seja, para a autora, as palavras adequadas ao significado de gráfico seriam chart e graph, além de haver diferenças entre graphic (adjetivo) e graphics (substantivo) as quais nem sempre são consideradas nas traduções. Ademais, afirma que:

No inglês, graphics é diagram, mas diagram, não é o mesmo que chart ou graph, as traduções corretas para 'gráfico', em português. Por outro lado, chart e graph podem ser diagrams, porém, o contrário não ocorre, ou seja, diagram não é o mesmo que chart ou graph. Se fizermos, portanto, a tradução correta do inglês para o português identificaremos que 'diagrama' não é sinônimo de 'gráfico', embora em nossa língua o seja (RIBAS, 2000, p.4).

Portanto, para Ribas (2000, p.5) um diagrama diferencia-se de um gráfico em inglês, apesar de serem termos sinônimos em português. Desta forma, pontua-se um entrave na homogenização dos termos, dada as variações originárias de traduções imprecisas.

\footnotetext{
${ }^{19}$ De acordo com o Dicionário Brasileiro da Língua Portuguesa Michaelis (Disponível em: $<$ http://michaelis.uol.com.br/moderno-portugues/busca/portugues-brasileiro/gr\%C3\%A1fico/> Acesso em: 14 Mar. 2018)
} 
Para Sancho (2001, p.104), há dois sentidos para o uso da palavra gráfico. Um para definir todo o conteúdo gráfico de uma página, de uma forma ampla e, outro, para referir-se a uma unidade elementar de informação gráfica, a qual denomina de infograma.

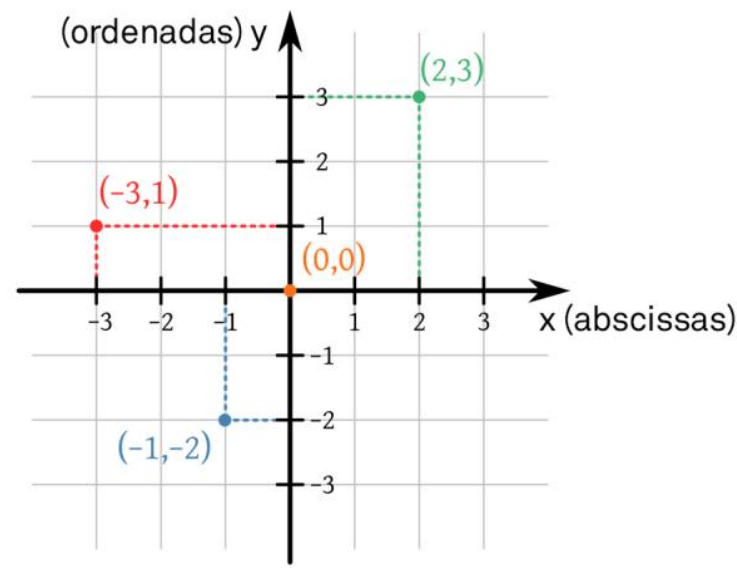

Figura 5 - Exemplo de características de eixo cartesiano, com os eixos vertical y (ordenadas) e horizontal $\mathrm{x}$ (abscissas). O par formado pelas duas cordenadas localiza a posição do ponto no plano cartesiano. Fonte: do autor.

Segundo a descrição de Peltzer, um gráfico é uma "representação visual de uma informação, consistindo de uma ou várias correlações entre uma série finita de conceitos variáveis e uma invariável ${ }^{20 "}$ (PELTZER, 1991, p.129, tradução nossa). De acordo com Ribas (2000, p.10), é o eixo cartesiano (Figura 5) que distingue o gráfico (chart, graph) da infografia (diagram) e a relação entre variáveis é identificada nas caracterizações de gráficos por outros autores além de Peltzer, tais como De Pablos (1999), Sancho (2001) e Moraes (2013). Reconhecer um gráfico e, portanto, diferenciá-lo de um infográfico passa a ser uma tarefa de identificação das variáves no uso de eixos cartesianos como forma de representar visualmente suas relações (velocidade x tempo, causa x efeito). No entanto, há uma extensa classe de peças de design de informação que são caracteristicamente similares a gráficos e de caráter abstrato intenso para a representação de valores: as visualizações de dados. Cabe, então, identificarmos as diferenças entre gráficos $\mathrm{e}$ visualizações de dados para, posteriormente, delimitarmos o termo infográfico.

${ }^{20}$ No original "Representación visual de una información, consistente en una o varias correnponcencias entre uma serie finita de conceptos variables y una invariable." 


\section{2. \\ Visualização de dados}

Segundo Tufte (2001, p.10) o uso de imagens abstratas para representar números é recente e talvez isso se deva ao fato da diversidade de habilidades necessárias para o seu desenvolvimento. Apenas com a consolidação de expertises artístico-visuais, empirico-estatísticas e matemáticas, os gráficos estatísticos puderam se desenvolver. Estes só surgiram em 1750-1800, muito depois dos gráficos cartesianos, de cálculo e das bases da teoria de probabilidade (TUFTE, 2001, p.10). De fato, as representações visuais em diagramas estatísticos, o uso de comprimento e área para mostrar quantidades, gráficos de séries temporais, gráficos de dispersão (scatterplots), dentre outros, só se desenvolveram a partir do sistema da "aritmética linear" de William Playfair (1759-1823).

As visualizações, para Tufte (2001, p.13) devem obedecer a determinadas orientações para que comuniquem ideias complexas com clareza, precisão e eficiência. De acordo com o autor, elas devem: (1) mostrar os dados; (2) induzir o leitor a pensar sobre o conteúdo em vez pensar sobre a metodologia, design gráfico, a tecnologia usada para sua elaboração etc.; (3) evitar distorcer o que os dados têm a dizer; (4) apresentar vários números em um pequeno espaço; (5) dar coerência a grandes conjuntos de dados; (6) encorajar o olho a comparar diferentes pedaços dos dados; (7) revelar dados em vários níveis de detalhe, de uma visão geral até as estruturas mais refinadas; (8) servir a um propósito razoavelmente claro: descrição, exploração, tabulação ou decoração e (9) estar integradas com as descrições estatísticas e verbais do conjunto de dados. Em suma, os gráficos devem revelar os dados, ou seja, auxiliar o leitor a ser capaz de obter informação a partir da exibição processada de conjuntos de dados que seriam demasiadamente trabalhosos de serem articulados pela cognição e memória de curto prazo humanas. Destacamos o fato de não haver menção a requisição ou restrição no sentido de os dados serem exibidos ou processados por aparatos tecnológicos complexos como computadores ou smartphones. Como exemplo, podemos citar a visualização de dados do New York Times que compila os dados de temperaturas médias anuais dos verões, desde 1951 até 2015, indicando um aumento da temperatura nos últimos anos. Em sua versão online, há uma animação mostrando a evolução dos dados, mas a exibição 
dos dados estáticos em formato impresso (Figura 6) permite a mesma exploração dos dados, comparando-os com o período de base em cinza.

\section{It's Not Your Imagination. Summers Are Getting Hotter.}

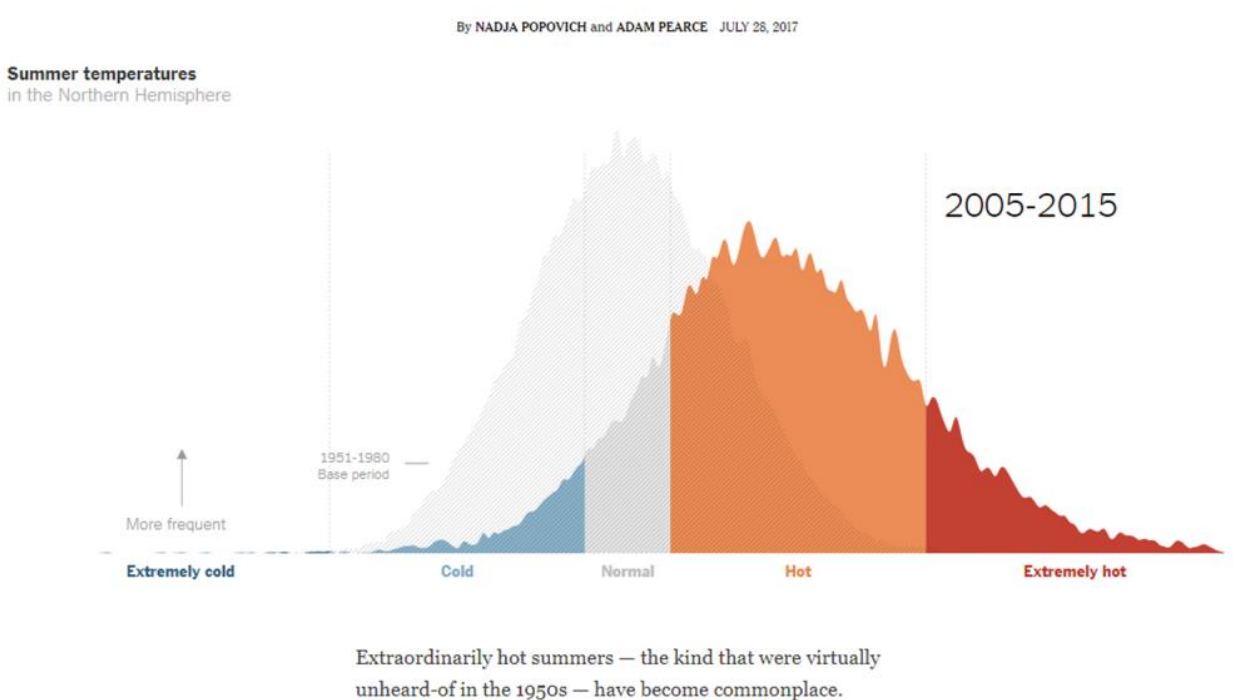

Figura 6 - Visualização da dados presente na matéria It's Not Your Imagination. Summers Are Getting Hotter, do NYT, por Nadja Popovich e Adam Pearce, publicada em 28 de julho de 2017 (Disponível em: $\quad$ <https://www.nytimes.com/interactive/2017/07/28/climate/more-frequent-extreme-summerheat.html> Acesso em: 24 mar. 2018)

Segundo Kosara (2007, p.2), para que um diagrama esquemático seja uma visualização de dados, ele deve cumprir algumas exigências:

- Uma visualização baseia-se em dados não visuais. Parte-se de dados abstratos ou não exatamente visíveis e apresenta-se o resultado de forma gráfica;

- O resultado necessariamente produz uma imagem. Se a imagem é uma pequena parte do resultado, não se trata de uma visualização;

- O resultado deve ser compreensível. A visualização deve fornecer meios para que se entenda e aprenda algo com os dados apresentados.

O termo visualização, proveniente da definição em inglês (visualization), quando se refere à representação visual de informação, em suas formas mais comuns, pode acompanhar três palavras: dados (data visualization), informação 
(information visualization) ou científica (scientific visualization). De acordo com Few (2009, p.12), o termo visualização de dados englobaria todos os tipos de representações visuais que tenham por objetivo auxiliar a exploração, análise e comunicação de dados. Os termos visualização da informação e visualização científica seriam subgrupos da visualização de dados, pois referir-se-iam a tipos particulares de representação visual.

Card, Mackinlay e Shneiderman (1999 apud FEW, 2009, p.13, tradução nossa) definem a visualização da informação como "o uso de representações visuais de dados abstratos, baseadas em computadores, interativas, para ampliar a cognição ${ }^{21 "}$ ", ou seja, circunscrita ao uso de computadores e interações. Já a visualização científica teria como tendência o uso de representações visuais mais condizentes com a referência física, em detrimento ao uso de abstrações gráficas. Para Few, um exemplo de visualização científica seria um exame de ressonância magnética, onde o resultado é o mais próximo possível de uma representação visual da região investigada do corpo do paciente (FEW, 2009, p.12).

Segundo as características da definição de Card, Mackinlay e Shneiderman, o uso do termo visualização de informação estaria restrito a um segmento do design da informação, reservado ao uso de visualizações interativas e/ou normalmente exibidas em telas de computadores. Observando detalhadamente, para os autores, as visualizações de informação seriam:

- Baseadas em computadores: as visualizações são exibidas por meio de computadores, normalmente em uma tela;

- Interativas: podem ser manipuladas livremente de forma simples e direta, inclusive por meio de filtros e com possibilidade de focar em determinados dados;

- Representações visuais: as informações são exibidas por meio de atributos, tais como cor, forma, tamanho, posição etc. que constituirão uma imagem onde será possível observarmos padrões, tendências e exceções que, de outro modo, poderiam não ser identificadas;

- Dados abstratos: informações como dados quantitativos, relações entre elementos e processos são conceitos abstratos que não possuem

${ }^{21}$ No original "[information visualization is] the use of computer-supported, interactive, visual representations of abstract data to amplify cognition." 
representações físicas como o corpo humano ou um mapa de uma região. As visualizações devem mapear essas relações e elementos e usar atributos que os representem visualmente de forma que façam sentido;

- Ampliadores de cognição: as visualizações ampliam a capacidade de raciocínio, de modo a auxiliar a memória com elementos que podem ser prontamente acessados e ajudar na construção de significados representando dados de uma forma que o cérebro possa assimilar mais facilmente.

Para Manuel Lima, autor do Visual Complexity, a elaboração de visualizações de informação é uma disciplina derivada da infografia, que cresceu consideravelmente nas últimas décadas. O estabelecimento de uma "era de ouro" da prática das visualizações de dados permitiu o desenvolvimento de diversas competências, técnicas e novas metodologias. Para tal evolução, Lima (2008, p.45) cita a convergência de alguns fatores imprescindíveis, tais como: (1) a ampla capacidade de geração e armazenamento de dados proporcionados pela informática contemporânea, na qual as visualizações são importantes ferramentas para gestão e classificação de uma grande quantidade de informações; (2) o aumento da disponibilidade de dados online por parte de governos, empresas e instituições, abertos a consulta pública - o que fomentou, inclusive, a disseminação de extensões de arquivos que facilitam a transmissão e compatibilidade de dados (ex: XML, RDF, APML e XMPP) -; (3) o crescimento de grupos sociais complexos, propiciados pelas redes sociais e seu extenso compartilhamento de conteúdo; (4) a democratização das ferramentas usadas para criação de visualizações (ex: Processing, VVVV, Flash), bem como iniciativas de código aberto (ex: Prefuse e Modest Maps) e (5) e a incorporação de novos métodos de visualização de informação pelos meios de comunicação de massa, como jornais (NYT), redes de TV (CNN) e revistas (Wired).

Portanto, de acordo com as características descritas anteriormente, dados transformados em representações visuais em um diagrama, um gráfico tipo pizza, um gráfico em barras ou um mapa em mídia impressa (papel/jornal), meio audiovisual (TV), meio hipertextual (internet) ou quaisquer outros suportes que 
permitam a exibição por meio de imagens, seriam representações visuais que poderiam estar englobadas pelo termo visualização de dados.

Para este trabalho, foi usada uma definição ampla que entra em acordo com Few, para quem a visualização de dados é um conceito "guarda-chuva", que engloba diversos termos (FEW, 2009, p.12). Então, o termo visualização de dados foi usado para se referir a uma representação visual diagramática de dados quantitativos ou qualitativos que tenha por objetivo auxiliar a exploração, a análise, a compreensão e a comunicação dos dados, independentemente do suporte (digital ou não).

\section{3. Infográfico}

O termo infográfico, apesar de recente, é muito difundido no Brasil. Conhecido desde a década de 1980, pode-se afirmar que ele melhor se disseminou no meio jornalístico nacional a partir da década de 1990. Em 1992, a vinda de dois jornalistas ligados à Universidad de Navarra, Juan Corrales (professor) e Mário

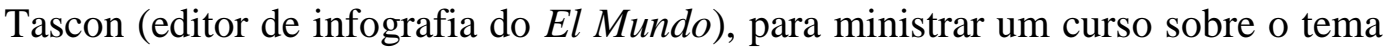
na redação do jornal $O$ Dia (MORAES, 2013, p.50), foi um dos marcos desse período de difusão. Desde então, ao longo dos anos, o termo passou a ser implementado em diversas redações e tornou-se "comum" até mesmo para o público. Atualmente, entretanto, mesmo sendo um vocábulo usado corriqueiramente, ainda há uma dúvida persistente acerca do que seria, efetivamente, um infográfico. Em alguns casos, dizer "infográfico" é um meio de destacar a importância do que se quer apresentar, mesmo que seja apenas um gráfico. É comum notar certa hesitação por parte dos próprios jornalistas ao tentarem escolher o termo correto, tal como proferido por Leila Sterenberg, durante o programa Estúdio I, em entrevista com o editor do Infoglobo: "Roberto [Maltchik], seguinte, você trouxe aqui para a gente alguns gráficos... infográficos, para, enfim, chamar com a palavra bonita, que mostram como ficou a situação dos partidos..." (GLOBONEWS, 2016). Cabe ressaltar a dúvida sobre qual o termo correto não se restringe ao nosso país. Conforme Sancho (2000, p.123, tradução nossa, grifos nossos) afirma:

Ao se referir a infográficos, frequentemente se pensa em grandes e complexas infografias coletivas, que podemos chamar megainfografias, embora alguns chamem 
de megagráficos e que nem em Inglês fica claro com gráficos; de qualquer forma, há alguma confusão com este termo mesmo em livros e dissertações ${ }^{22}$.

Sobre o uso equivocado da palavra infográfico para peças que não são exatamente um infográfico jornalístico, Sancho declara que:

o infográfico jornalístico tem suas próprias características que pouco se assemelham a outras formas ou produtos comumente chamados infográficos. Este termo usado em diferentes direções, anarquicamente, não provoca nada além de confusão e imprecisões, muitas vezes de grande calibre... gostaria de ver estudos de certa magnitude sobre a justificativa do termo infográfico ${ }^{23}$ (SANCHO, 2000, p.131, tradução nossa).

Nota-se, pelos trechos supracitados, que a imprecisão do uso do termo gera insegurança e confusão por parte dos profissionais, da academia e, consequentemente, do público. $\mathrm{O}$ autor aponta, inclusive, indícios de problemas em línguas diferentes. Devemos, portanto, investigar a origem do termo, bem como algumas das principais definições propostas por pesquisadores.

O termo infográfico, segundo Cairo (2008, p.21), deriva da aglutinação das palavras informação e gráfico, de forma análoga ao original em inglês infographics (information + graphics). Sua popularização originou-se no meio jornalístico, no fim da década de 1980. O desenvolvimento tecnológico e a ampliação do uso da informática pelos profissionais da área editorial (jornalistas visuais, designers, artistas gráficos) deram origem a um ambiente propício para a elaboração de representações gráfico-visuais da informação em tempo hábil para o uso em periódicos, revistas e jornais. A palavra traz consigo uma ambiguidade na língua original, pois além de remeter a uma representação diagramática ou gráfico-visual de informações, também pode se associar ao uso da informática (computadores) para confeccionar essas representações visuais. Em Infografía 2.0, Cairo (2008, p.21) refere-se a "visualização de informação" para descrever a atividade de produzir infográficos, com o fim de evitar equívocos com o termo.

${ }^{22}$ No original "Al referirse a los infográficos, a menudo se piensa en las grandes y complejas infografías colectivas, que podemos llamar megainfografías aunque algunos les llaman megagráficos y tampoco en inglés queda aclarado con the graphics; de todas maneras, hay una cierta confusión con este término incluso en libros y tesis doctorales."

${ }^{23}$ No original “...la infografía de prensa tiene sus propias características que poco se asemejan a otras formas o productos denominados comúnmente infográficos. Este término utilizado en distintas direcciones de manera anárquica no suscita otra cosa que confusión e imprecisiones, a menudo, de gran calibre... me gustaría que se realizaran estudios de cierta envergadura sobre la justificación del término infografía. 
Para Ribas (2000), o cerne da questão em relação à palavra infográfico está no fato de traduções terem sido feitas de forma imprecisa. O termo informational graphics teria se tornado "gráfico informativo". Segundo a autora, a palavra diagrama, que significa a representação gráfica por meio de figuras geométricas (linhas, pontos, áreas), de fatos, fenômenos, grandezas ou das relações entre eles (RIBAS, 2000, p.4), seria adequada para gerar os termos infodiagrama ou diagrama informativo. Estes termos sugeridos seriam mais precisos para representar o conceito de infografia como desenho que mostra parte de algo, seu funcionamento, operação ou processos.

Para Kanno e Brandão (1998), em uma das primeiras publicações nacionais sobre o assunto, o Manual de infografia da Folha de S. Paulo, lançado em 1998, a infografia é "o recurso gráfico que se utiliza de elementos visuais para explicar algum assunto ao leitor. Esses elementos visuais podem ser tipográficos, gráficos, mapas, ilustrações ou fotos" (KANNO e BRANDÃO, 1998, p.2). Essa definição sem maiores restrições, apesar de não permitir uma visão clara dos limites entre o que é ou não uma infografia, ao menos proporciona a possibilidade de incorporar ao vocábulo infográfico variados tipos de intervenções gráficas que tenham a função de enriquecer o texto. O manual possui exemplos de diversos tipos de infográficos (Figura 7) dentro das categorias estabelecidas pelos autores, bem como orientações de uso e aplicação.

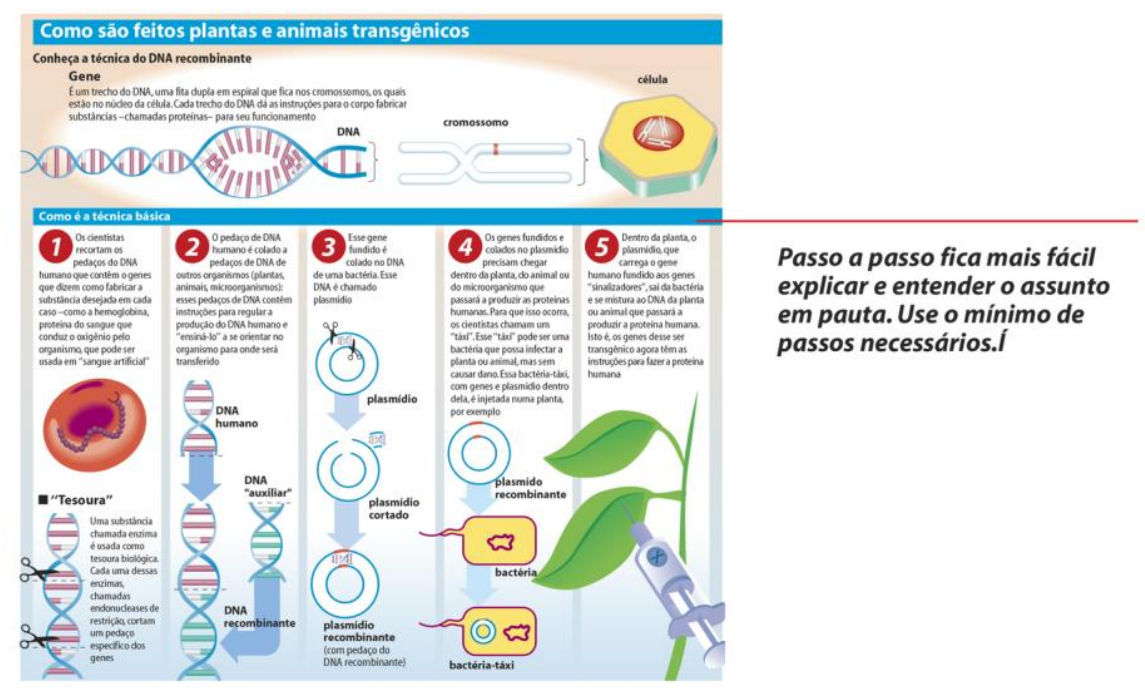

Figura 7 - Exemplo de infográfico do tipo "passo a passo", da categoria Visuais, com dicas e orientações de uso, presente no Manual de infografia da Folha de S. Paulo, de 1998. Fonte: KANNO e BRANDÃO (1998, p.28). 
Para Moraes, a infografia se inscreve no design da informação e relaciona-se com o jornalismo em sua essência. Preza pela responsabilidade na investigação dos fatos e dados, bem como pela função informativa (não opinativa) dos mesmos. Para o autor, o termo infografia se dissemina no jornais, na década de 1980, como resultado da expansão do uso de gráficos informativos derivado da concorrência entre os veículos (MORAES, 2013, p.32). A palavra teria sua origem na língua espanhola, infografía, mais precisamente em um seminário promovido pela Universidad de Navarra, em 1988, sendo fruto da aglutinação de information graphics (infographics) advindo do inglês. A infografia seria, então, uma "combinação de texto e imagem com o objetivo de esclarecer ao leitor assuntos cuja complexidade ultrapassa os limites do repertório das pessoas comuns" (MORAES, 2015, p.40). O autor menciona que o que orienta a infografia é "a harmonia entre a imagem e a palavra de modo que sejam complementares e objetivas, sem deixar dúvidas quanto ao conteúdo" (MORAES, 1998, p.113). A infografia, portanto, destacou-se dos sistemas definidos nos jornais e revistas impressos nos anos 1980, quando a linguagem verbal (textos) era hierarquicamente superior à não verbal (fotografia e ilustrações). Já os infográficos integrariam, fundamentalmente, texto e imagem de forma complementar, sem subjugar hierarquicamente nenhuma linguagem:

Os infográficos representariam uma transição por se constituírem em sistemas híbridos, multimodais, que congregam ao mesmo tempo texto e imagem, linguagem verbal e não verbal numa relação em que se complementam mutuamente. Apontam para uma realidade comunicacional diferente daquela de onde se originaram (MORAES, 2013, p.17).

Para Cairo (2008, p.21), que prefere o termo information graphics, "um infográfico é uma representação diagramática de dados", ou seja, "qualquer informação apresentada em forma de diagrama é uma infografia" e não precisa ser publicado em uma revista ou jornal para ser considerado como tal. Um desenho onde se mostram as relações entre as diferentes partes de um conjunto ou sistema é um infográfico. Ele não depende de um computador para ser gerado ou exibido; não precisa ter a interatividade característica de computadores, seja com filtros, animações ou quaisquer outras características dinâmicas virtuais; nem existe a necessidade de estar em um meio jornalístico. Um infográfico pode ser totalmente confeccionado de forma artesanal, usar papel como suporte e, ainda assim, cumprir 
as exigências que a denominação infografia demanda. Para o autor, em uma afirmação que o próprio categoriza como não ortodoxa, os “infográficos e visualizações existem em um continuum" (CAIRO, 2013, p.xvi). As definições servem como uma forma de referência que demonstre uma tendência maior em apresentar, expor; ou uma tendência maior em fazer com que os dados sejam explorados pelo leitor, de modo que o processamento se conclua com a sua participação ativa. Assim, todos os gráficos apresentam os dados e também permitem um certo grau de exploração desses mesmos dados, em maior ou menor grau. Os gráficos que são quase exclusivamente "apresentados", sem dar muita possibilidade de exploração, possuem uma característica mais infográfica. Já os gráficos que são intensamente focados em deixar o leitor explorá-los teriam uma característica mais ligada a uma visualização de informação.

No que diz respeito a uma não exigência de aparatos informáticos para que um infográfico seja considerado como tal, Sancho corrobora com Cairo (2008). Apesar de uma presente associação a suportes e interfaces de alta tecnologia, tais como desktops, tablets e smartphones, para Sancho (2001, p.25, tradução nossa), um infográfico não depende do meio virtual/interativo para acontecer, pois é muito anterior ao computador: "desde que se realizam desenhos informativos, existem infografias; e estas apareceram nos jornais há 200 anos $^{24 "}$. Segundo o autor, uma definição para o termo infográfico seria:

Uma contribuição informativa, concebida no jornal escrito, realizada com elementos icônicos e tipográficos, que permite ou facilita a compreensão dos acontecimentos, ações ou coisas da atualidade ou alguns de seus aspectos mais significativos e acompanha ou substitui o texto informativo (SANCHO, 2000, p.124, tradução nossa).

Para De Pablos (1999, p.19), uma infografia ${ }^{25}$ é a apresentação impressa de um binômio imagem + texto (bI+T), qualquer que seja o suporte onde se apresenta essa união informativa: tela, papel, plástico, barro, pergaminho, papiro ou pedra. Desvincula, portanto, o surgimento da infografia ao meio jornalístico, apesar da relevância deste para o seu desenvolvimento, e, consequentemente, amplia o espectro da "linha do tempo" da infografia. Assim como Sancho (2001, p.104), De

${ }^{24}$ No original "desde que se realizan dibujos informativos ha habido infografias y éstas aparecieron en los periódicos desde hace 200 años."

${ }^{25}$ De Pablos (1999, p.40) distingue infografia (a peça gráfica ou o procedimento) de infográfico (relativo à infografia). Analogamente, indica que fotográfico não é uma fotografia, mas algo relacionado à fotografia. 
Pablos também se refere ao termo infograma como parte de uma infografia ou unidade elementar e explica o elo entre ambos:

Entenderemos um infograma em relação a uma infografia a mesma coisa que aceitamos por um fotograma em relação à fotografia de uma produção cinematográfica: uma imagem, cuja soma é o trabalho total e comercializável ou pronto para exposição ao público. Assim, às vezes encontramos infografias que são um conjunto de vários infos juntos em uma unidade de aparência singular. A cada uma dessas imagens podemos chamar infogramas, quadros diferenciados que em momentos de dificuldade podem ser realizados por diferentes artistas gráficos, para, no final, serem reunidos e apresentar a infografia combinada e única (DE PABLOS, 1998, p.23, tradução nossa, grifos nossos).

Para Peltzer, o termo infograma é sinônimo de infográfico, descrevendo-o como "expressões gráficas, mais ou menos complexas, de informações cujo conteúdo são fatos ou eventos, a explicação de como algo funciona ou a informação de como é alguma coisa ${ }^{26 "}$ (PELTZER, 1991, p.135, tradução nossa). Dessa forma, Peltzer não respalda a opinião de De Pablos (1999) e Sancho (2001), no que diz respeito a um infograma ser uma unidade elementar ou parte de um infográfico. Peltzer (1991, p.125) difere o conteúdo das mensagens iconográficas em sete códigos visuais ou gêneros: gráficos, infográficos, mapas, símbolos, ilustrações, comics e iconografia animada. Reduz-se, assim, equívocos causados pelo uso indiscriminado do termo infográfico ou infografia ao se referir a qualquer informação gráfica. Como forma de se diferenciar de demais peças gráficas, De Pablos (1999, p.82) comenta que infografias possuem uma estrutura específica e contêm elementos básicos como: título; porta de entrada, semelhante ao lead jornalístico, que pode ser suprimido em alguns casos; texto, apoiando a construção de sentido; fonte( $(s)$ de consulta e assinatura, com os colaboradores. Portanto, um texto com uma ilustração que não contenha esses elementos não seria caracterizado ou confundido como uma infografia.

Já em relação ao uso de computadores para o desenvolvimento de infográficos, Peltzer está de acordo com Cairo (2008), De Pablos (1998) e Sancho (2001), como se pode observar em seu comentário sobre o trabalho de Peter Sullivan, que atuou por 25 anos no The Sunday Times, de Londres, um dos grandes nomes da infografia mundial:

\footnotetext{
${ }^{26}$ No original "Son expresiones gráficas, más o menos complejas, de informaciones cuyo contenido son hechos o acontecimientos, la explicación de cómo algo funciona, o la información de cómo es una cosa."
} 
Sullivan nunca usou um computador para fazer seus trabalhos informativos, algo que, mesmo que signifique mais tempo de trabalho, faz com que seus gráficos e desenhos sejam completamente originais, criativos... Este fato também mostra que não é necessário usar computadores para fazer informação gráfica ${ }^{27}$ (PELTZER, 1991, p.161, tradução nossa).

De Pablos (1998, n.p) também deixa claro o desvínculo entre o surgimento da infografia e os computadores. Ao abordar o tema da presença da infografia ao longo da história da comunicação impressa, o autor afimra que:

Ninguém acredita que a infografia jornalística é a filha da informática e muito menos que seja produto do computador Macintosh, da Apple, lançado no mercado em dezembro de 1984 - janeiro de 1985. Antes dessa data, encontramos infográficos em jornais e revistas espanhóis e de outros países ${ }^{28}$ (DE PABLOS, 1998, n.p., tradução nossa).

No Brasil, observando a definição do dicionário Houaiss (2001, p.1615), em que a infografia é "gênero jornalístico que utiliza recursos gráfico-visuais para apresentação sucinta e eficiente de determinadas informações", percebe-se a associação direta com o jornalismo informativo, corroborado por Teixeira:

Definimos esse termo como uma modalidade discursiva, ou subgênero do jornalismo informativo, na qual a presença indissociável de imagem e texto - e imagem, aqui, aparece em sentido amplo - em uma construção narrativa que permite a compreensão de um fenômeno específico como um acontecimento jornalístico ou o funcionamento de algo complexo ou difícil de ser descrito em uma narrativa textual convencional (TEIXEIRA, 2010, p.18)

É habitual encontrar definições onde haja indicação de uma exigência associativa entre texto e imagem para que uma determinada visualização seja considerada um infográfico (principalmente em relação aos infográficos em meio jornalístico). No entanto, de acordo com Cairo (2008, p.21), não há uma obrigatoriedade de relação texto-imagem para que um infográfico tenha seu conteúdo compreendido. Um exemplo dessa possibilidade são os infográficos com total ausência de texto produzidos por Nigel Holmes, em seu livro intitulado Wordless Diagrams. A inspiração de Holmes foi Otto Newrath, sociólogo austríaco

27 No original "Sullivan no ha utilizado nunca un ordenador para hacer sus trabajos informativos, algo que, aunque le suponga más tiempo de trabajo, consigue que sus gráficos y dibujos sean completamente originales, creativos... Este hecho demuestra también que no es necesario utilizar ordenadores para realizar información gráfica."

${ }^{28}$ No original "Que nadie crea que la infografía en prensa es hija de la informática y mucho menos que es producto del ordenador Macintosh, de Apple, lanzado al mercado en diciembre de 1984 - enero de 1985. Antes de esa fecha encontramos infográficos en diarios y revistas, españoles y de otros países." 
criador do Isotype (International System of Typographic Picture Education), um tipo de linguagem baseada em ícones e pictogramas simples, com o objetivo de comunicar mensagens complexas com o mínimo de texto possível. O infográfico de Holmes (2005, p.94) How to slice an avocado and remove the pit (Figura 8) é uma demonstração da possibilidade de se compreender um conteúdo de uma visualização de dados sem a exigência da presença do texto verbal.

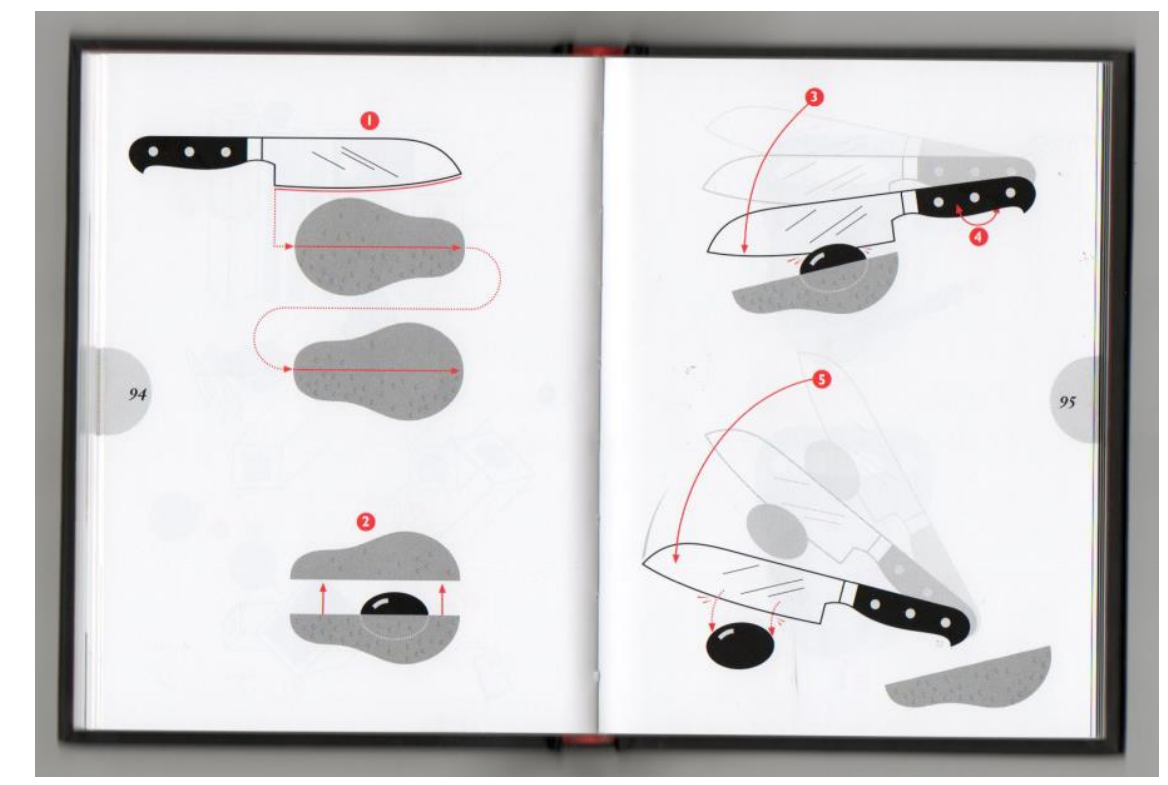

Figura 8 - Wordless diagrams - How to slice an avocado and remove the pit, de Nigel Holmes, como possível exemplo de infografia com ausência de texto. Fonte: HOLMES (2005, p.94).

Por outro lado, a publicação de dados e gráficos simples, com o objetivo de ressaltar alguma informação ou de transmitir uma mensagem rápida e prática a uma audiência que não demanda aprofundamento frequentemente é confundida com um infográfico. É o tipo de artefato gráfico que Dino Citraro (2013, n.p.), fundador da Periscopic, empresa especializada em visualização de dados, denomina digital posters (Figura 9). Esses artefatos se caracterizam por imagens normalmente verticalizadas, que demandam $\operatorname{scroll}^{29}$, com números e textos acompanhados de artes complementares. Essas peças com informações simples, listas, muitas vezes imprecisas e sem apuração de fontes, também são identificadas pela alcunha de infauxgraphics, ou seja, seriam falsos infográficos e encaradas por jornalistas

${ }^{29} \mathrm{O}$ termo scroll pode ser traduzido como o ato de rolagem na tela para acessar o resto do conteúdo que não está visível. 
visuais e infografistas com um tom pejorativo. Uma diferença fundamental entre um digital posters e um infográfico é não contextualizar a informação de uma forma que permita a compreensão mais profunda da mensagem.

Esse tipo de peça pode ser observado no comentário de Paiva (2017), durante o encontro de infografistas no $2^{\circ}$ In.Rio, realizado na ESPM, ao falar sobre o fato de a infografia não ser um "combo de números bonitinhos, bem tratados tipograficamente, com pictogramas":

Hoje, se você dá um google (faz uma busca por) "infographic", você vai ter um monte de imagens, principalmente enfiletadas, bem compridinhas já para ficar scrollando, que são combos de pictogramas bem simplificados com números, combos numéricos para entregar números com bonequinhos em volta para tentar entregar aquele monte de números. Inclusive, o conceito do que é o tal infográfico ficou diluído, perdido em uma série de grafismos que poderíamos chamar de infográficos, mas não são infográficos no sentido clássico, no sentido de pegar uma quantidade de números e relacionar eles, criar comparativos que façam sentido (PAIVA, 2017).

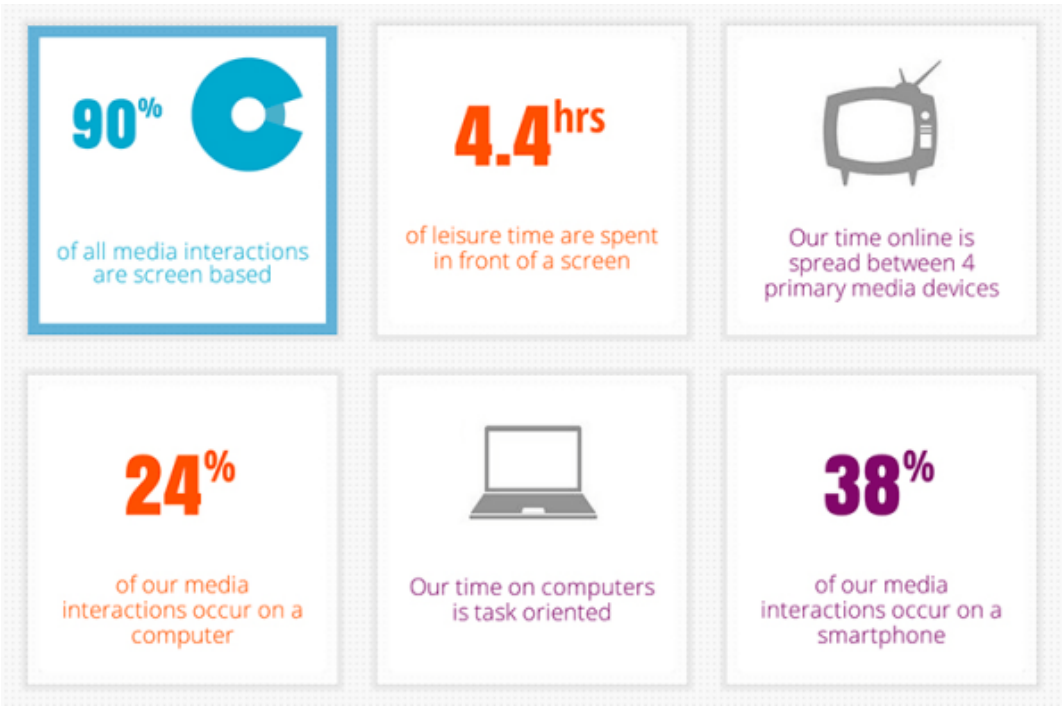

Figura 9 - Parte de um digital poster ou infaxgraphics, peças que são confundidas com infográficos por usarem texto e imagem (CITRARO, 2013) (Disponível em: <https://www.fastcodesign.com/ 1673113/the-difference-between-infographics-and-their-simpler-cousins> Acesso em: 22 mar. 2018)

Apesar do uso trivial de dados, Citraro (2013, n.p.) comenta que os digital posters teriam o seu valor em alguns casos, pois são coleções simples de declarações gráficas. Ou seja, se a audiência e a mensagem não são complexas, os digital posters podem ser uma ferramenta de comunicação excelente. Eles não sobrecarregam o leitor, são rápidos e possuem um apelo visual, características eficazes em um momento em que as mídias sociais, posts em blogs e listas de 
curiosidades em sites como Buzzfeed, competem pela atenção dos leitores das mídias jornalísticas tradicionais.

Mesmo reconhecendo a funcionalidade dos digital posters, o termo cunhado para esse tipo de peça não é adequado. A denominação remete a outro tipo de peça gráfica (posters ou cartazes), mas incorporando-se o vocábulo digital para trazer a alusão ao suporte virtual. No entanto, afasta-se da tentativa de que esse tipo de peça tem de emular um infográfico. Dessa forma, aumenta-se a confusão ao introduzir uma nova expressão para se referir a uma peça que, sob a ótica do público e profissionais de outras áreas, parece um infográfico. Portanto, acreditamos que um termo que deixe mais claro que esse tipo de ferramenta tenta se aproximar de uma infografia, mas não o é, seria mais útil. O termo infauxgraphics nos parece bastante irônico ou pejorativo, mesmo sendo objetivamente claro. Um outro problema é o fato de infographics e infauxgraphics serem homônimas homófonas, ou seja, com a diferenciação na grafia, mas pronúncias similares, fato que leva a uma possível confusão em uma referência verbal não escrita. Dessa forma, consideramos o uso do termo pseudo-infográficos, como forma de solucionar o problema. Dependendo do contexto, o prefixo pseudo é usado para denotar algo que superficialmente parece ser uma coisa, mas, em realidade, é outra. Esse prefixo representa, de forma precisa, o caso dessas peças que se assemelham a um infográfico, mas, sob uma análise mais apurada, não possuem as características necessárias.

\section{4 . Infográfico digital}

Ao abordarmos as diferenças impostas na transição da infografia impressa para a digital, pode-se notar que elas vão desde fatores estruturais como, por exemplo, a forma como percebemos as cores nos suportes (luz refletida no papel e luz emitida pelos displays digitais) até detalhes de ordem conceitual, como a possibilidade de adição de dimensão do tempo (é possível incluir animações, vídeos, áudios etc.); variados graus de interatividade e, ainda, questões de complexidade técnica, como a diversidade de plataformas, múltiplas resoluções de tela, proporções, capacidade de processamento, sistemas operacionais, integração de câmeras para realidade aumentada (augmented reality). 
É importante frisar que o advento da infografia digital não levou a infografia impressa a perder o seu papel informativo, nem a relegou a um grau de menor apuro. A infografia digital apenas possui características distintas em relação à impressa, devido às possibilidades de exploração tecnológica e interações inerentes ao ambiente online. Como exemplo, o infográfico "Es war nicht immer der Osten" (Nem sempre foi o Leste, em tradução livre), do jornal alemão Berliner Morgenpost, mostra, em sua versão impressa, a prevalência de partidos populistas e de extrema direita na Alemanha. Publicado em 23 de janeiro de 2017, realizado em conjunto com a equipe interativa, possui, também, uma versão interativa online, na qual os leitores podem rastrear a distribuição dos eleitores no mapa, com dados, porcentagens, imagens das cidades, indicadores de tendência etc. O gráfico impresso recebeu a maior premiação no Malofiej, em 2018, sendo agraciado com o "best of show".

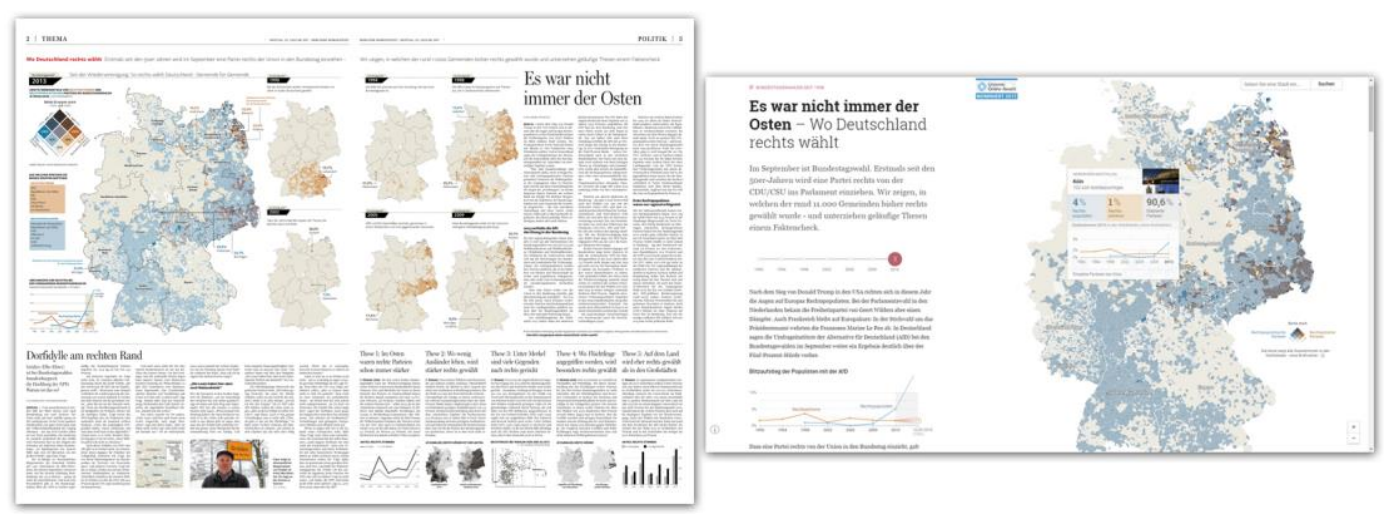

Figura 10 - Versões impressa (à esquerda) e online (à direita) do infográfico Es war nicht immer der Osten, do jornal alemão Berliner Morgenpost, edição de 23 de janeiro de 2017. Cada versão explora as características específicas e vantagens do seu suporte (físico ou digital). (Disponível em: <https://interaktiv.morgenpost.de/wo-deutschland-rechts-waehlt/> Acesso em: 28 mar. 2018)

De acordo com Sancho (2008, p.494), o surgimento dos infográficos digitais, a partir da consolidação da internet, aumentou a complexidade das peças com a adição de recursos multimidiáticos. Os infográficos digitais se diferenciam dos infográficos impressos, que usam os instrumentos clássicos de desenho como forma original de comunicação:

A forte implementação da Internet por alguns anos influenciou o surgimento de novas mídias digitais e a aparência incipiente de uma nova proposta de infográfico 
digital. Suas características são diferentes, pois permite o uso de uma infinidade de novas formas de se comunicar ${ }^{30}$ (SANCHO, 2008, p.494, tradução nossa).

Com a ampliação de recursos disponíveis para o uso e combinação, Sancho afirma que a infografia digital aumenta significativamente a densidade de informação e define-a como:

O infográfico digital, em seu sentido jornalístico, é uma apresentação informativa (não necessariamente do campo do jornalismo), que na maioria dos casos mostra os infogramas em sequência sucessiva ou mista, preparados para publicações digitais audiovisuais, cujas linguagens não são necessariamente lingüísticas, realizadas por meio de unidades icônicas elementares (fotografias) ou complexas (mapas ou gráficos), dinâmicas ou não, completadas com tipografias, sinais gráficos e/ou links auditivos, geralmente verbais e interconectados, como legendas, citações e notas de hipertexto $^{31}$ (SANCHO, 2008, p.494, tradução nossa).

Os infográficos digitais, de fato, são produtos diferentes dos infográficos em mídia impressa. O suporte digital permite que o usuário observe e interaja com reproduções em movimento de representações de fenômenos naturais, ambientes, lugares, objetos etc. Além do movimento, é possível amplificar a experiência por meio de áudio, modelos tridimensionais navegáveis, recursos de realidade virtual e outras dinâmicas que a natureza bidimensional e estática do impresso não permitiam. Sancho $(2008$, p.495) afirma que a peculiaridade do suporte torna a infografia digital diferente e que é comum que alguns infografistas prefiram "gráficos interativos na internet" ao termo infográfico. O autor declara que "Talvez tenha chegado a hora de mudar o nome, já que eles não são os mesmos produtos, embora pretendamos vê-los como iguais ou em diferentes estágios do mesmo 32 ", (SANCHO, 2008, p.495) e faz uma analogia sobre a distância entre a fotografia e o cinema ser menor que a distância entre a infografia impressa e a online.

${ }^{30}$ No original "La fuerte implantación de Internet desde hace unos años ha influido en la aparición de unos nuevos soportes digitales y en la incipiente aparición de una nueva propuesta infográfica que es la digital. Sus características son distintas ya que permite el empleo de multitud de formas nuevas de comunicar."

31 No original "La infografía digital, en su sentido periodístico, es una presentación informativa (no necesariamente del ámbito del periodismo), que en la mayoría de los casos muestra los infogramas en secuencia sucesiva o mixta, elaborados para las publicaciones digitales audiovisuales, cuyos lenguajes no son necesariamente lingüísticos, realizados mediante unidades icónicas elementales (fotografías) o complejas (mapas o gráficos), dinámicas o no, completadas con tipografías, signos gráficos y/o auditivos normalmente verbales y enlaces interconectivos como leyendas, citas y notas hipertextuales..."

${ }^{32}$ No original "Quizá le ha llegado el momento de cambiarle el nombre, puesto que no son los mismos productos aunque pretendamos verlos como iguales o en estadios distintos de lo mismo." 
Um ponto de reforço que a infografia digital é um produto diferente do impresso é justamente o surgimento de um novo problema de nomenclatura. A aparição de termos diversos como infográfico digital, infográfico de internet, infográfico interativo, infográfico animado, infográfico jornalístico digital animado, infográfico multimídia, infográfico online, flash infographics e interaction graphics são alguns exemplos. No entanto, o fato de os infográficos digitais serem recentes, em comparação aos impressos, torna a questão menos passível de críticas em relação ao uso de vocábulos diferentes, já que esse tipo de produto está em desenvolvimento, ainda sem um formato consolidado.

Nichani e Rajamanickam (2003) preferem o termo interactives (interativos) para se referirem aos primeiros experimentos no jornalismo interativo. O que, para os autores, são dispositivos interativos baseados em internet para explicação visual. O termo corporifica o conceito de interação, sem carregar as noções advindas do meio impresso. Cabe apontar, entretanto, que os autores consideram a diferença entre os interactives e o que definem como infográficos estáticos baseados em web (static Web-based infographics). Portanto, ambos existem em ambiente digital, sendo um estático e, outro, interativo. A palavra interação também é usada por Cairo (2008, p.62), referindo-se aos infográficos digitais como visualización interactiva de información. Assim como o faz em visualização de informação, utiliza uma denominação de forma ampla, sem delimitações rígidas.

O termo infográfico online é recorrente, usado, inclusive, na categorização dos prêmios internacionais do Malofiej. No maior prêmio mundial de infografia, desde 2002, são distintas as categorias impressos e online.

Para Ribas (2004, p.5), a denominação adequada seria infografia multimídia, pois seria a que melhor representaria o modelo de formatação do discurso na internet, sem excluir as características referentes aos termos digital, interativo ou animado, presentes no meio. Segundo a autora:

A infografia multimídia mantém as características essenciais da infografia impressa, mas ao ser realizada através de outros processos tecnológicos, agregar as potencialidades do meio e ser apresentada em outro suporte, estende sua função, altera sua lógica, incorpora novas formas culturais (RIBAS, 2004, p.2).

O termo online, apesar de não causar incômodo, não nos parece totalmente preciso, pois, apesar de presente nas versões online dos jornais, uma vez carregado, o infográfico não demanda conexão para ser funcional, apenas para ser acessado. 
Já os infográficos com atualização constante, por meio de acesso a bases de dados (da Bolsa de Valores, por exemplo), teriam uma identificação maior com o termo. No entanto, esse é um tipo específico de peça comunicacional, e não é um atributo característico a todos os infográficos.

Consideramos que a mesma inadequação se aplica ao termo multimídia, pois boa parte dos infográficos digitais não necessita de recursos como áudio, vídeo, animações ou interações para estarem nas versões online dos jornais. Neste trabalho, a acepção do termo multimídia significa a combinação de pelo menos um tipo de mídia estática (texto, fotografia, gráfico, figura) com pelo menos um tipo de mídia dinâmica (vídeo, áudio, animação, 3D), em meio digital (computadores pessoais, smartphones, tablets e afins), onde as diferentes linguagens não devem ser apenas justapostas, e sim integradas (DÍAZ NOCI, 2009, p.214). Dessa forma, assim como infográficos digitais podem ser similares aos infográficos impressos, inclusive sendo uma imagem estática em alguns casos, esta possibilidade enfraquece o conceito associado ao termo "multimídia", a partir do qual se espera a integração de diferentes recursos. Cairo $(2008$, p.80) afirma que todo infográfico online é multimídia, em algum grau, mas conclui que é o grau de multimidialidade e a sua qualidade que realmente importam.

Também consideramos impreciso o vocábulo interativo, pois um infográfico pode se apresentar na versão online de um jornal e possuir graus de interação variados. Um infográfico digital pode se diferenciar do impresso apenas pelo fato de ser exibido por meio de uma tela de um smartphone, tablet ou desktop. De acordo com Cairo (2008, p.63), interação "não significa mais que a relação que um usuário estabelece com um objeto (físico ou virtual) para conseguir um objetivo". A palavra “interativo" remete a um intenso nível de interatividade efetiva com os dados e informações no infográfico, por meio de filtros, ações, digitação de dados, cliques, swipes $^{33}$ e diversas outras possibilidades, o que, no entanto, nem sempre ocorre.

Portanto, nossa concepção é que os termos infográfico digital e infografia digital, são mais adequados para representar infográficos que dependam de aparatos tecnológicos, tais como monitores, telas de dispositivos móveis ou projetores para exibição. A essência desses infográficos é a natureza digital envolvida no método de saída, no suporte à visualização, do ambiente virtual onde os seus arquivos

\footnotetext{
${ }^{33}$ Interação ativada ao deslizar o dedo em dispositivos com tela interativa.
} 
existem. Todos os vocábulos anteriores são englobados pelo termo infográfico digital, que pode representar um infográfico que tenha características de ser online, interativo, animado, multimídia etc. sem enfatizar quaisquer dessas qualidades.

Dentre as principais possibilidades passíveis de exploração na infografia digital em relação a impressa, proporcionando uma experiência distinta, podemos destacar, de forma sucinta:

- Interatividade - enquanto o impresso permite a interação física com o papel e o layout direciona o olhar pela narrativa ou para a página seguinte, a interatividade no meio digital já se dá além dos cliques do mouse (PCs e notebooks) ou do swipe e scroll dos dedos (tablets e dispositivos mobile), podendo acontecer por meio de fixações do olhar (em dispositivos com eyetracking), comandos de voz, ativação por sons e/ou gestos.

- Filtros - a quantidade de informações é superior, pela falta de limitação física da página impressa. Os filtros dão a oportunidade de o leitor escolher quais dados são relevantes para a sua busca naquele infográfico. Ele pode cruzar dados conforme a sua pesquisa de forma mais fácil, apenas exibindo ou escondendo determinados campos ou informações.

- Animações, áudios e vídeos - a página impressa é estática, o que exigiu a criação de recursos para emular a passagem do tempo nesse meio (linhas do tempo, sequências de desenhos, setas indicativas, quadrinhos etc.). No meio digital esses recursos podem ser ampliados e exibidos com o uso da dimensão do tempo. Além da possibilidade de inclusão de esquemas diagramáticos animados, tais como o funcionamento de uma máquina ou a sequência dos fatos de um acontecimento.

- Tridimensionalidade - a interação com objetos tridimensionais permite a visualização de mapas, ambientes e objetos de uma forma mais completa que o meio impresso. Se usada em conjunto com filtros, interações e animações, as simulações podem ter seu potencial informativo ampliado. 
- Imersão e VR (Virtual Reality) - a realidade virtual, recentemente remodelada com tecnologia derivada da indústria dos videogames, tal como o oculus rift, é um campo importante para o desenvolvimento de simulações, treinamentos, prototipagem e tratamentos cognitivos. A infografia está diretamente relacionada a interface, dados e informações disponibilizadas aos usuários, a partir da relação dos objetos com o ambiente.

- Alimentação de dados em tempo real - a conexão com bases de dados de instituições, centrais de informação, governos, dentre outros, permite que uma visualização de dados seja atualizada em tempo real. A forma de se lidar com esse tipo de dado real time demanda um planejamento técnico específico. Também é necessário estabelecer elementos estéticos ou atributos visuais que mantenham a legibilidade em caso de variação excessiva de informações.

\section{5 . \\ Considerações sobre os termos essenciais}

A discussão acerca de uma terminologia definitiva ainda está longe de ser encerrada, mesmo em relação a termos fundamentais. Para fins objetivos, no entanto, este trabalho buscou revisar um amplo leque de autores relevantes que tenham realizado investigações e propostas terminológicas, por meio da análise de termos por eles utilizados. Ao fim, corroboramos com algumas definições, com a consequente discordância de outras. Com isso, visamos enriquecer o debate acerca do tema. Oferecemos um resumo com a nossa concepção dos termos essenciais para este trabalho, a partir dos conceitos que consideramos coerentes para cada um, a seguir:

- Gráfico: representação diagramática de dados, normalmente provenientes de tabelas ou dados estatísticos, que podem ser aglutinados em unidades a serem comparadas entre si. Dentre suas variedades mais comuns, estão os gráficos de barra, pizza e linha. 
- Visualização de dados: representação visual diagramática de dados quantitativos ou qualitativos elaborada com o intuito de auxiliar a exploração, a análise, a compreensão e a comunicação dos dados;

- Infográfico: representação diagramática de dados em linguagem multimodal, que possui o objetivo de esclarecer, por meio de uma narrativa, o acontecimento ou o funcionamento de algo específico que seria muito complexo de se descrever apenas por meio de texto verbal;

- Infográfico digital: infográfico natural de ambiente virtual, digital, que depende de aparatos tecnológicos, tais como monitores (desktops, notebooks), telas de dispositivos móveis (smartphones, tablets) ou projetores para sua exibição. Utiliza linguagem multimodal e pode possuir características como interatividade, filtros, animações, recursos multimídia, ambientação tridimensional, realidade virtual, realidade aumentada, acesso a bases de dados, dentre outras características derivadas de tecnologias digitais;

- Pseudo-infográfico: coleção de declarações gráficas usada como meio de comunicar informações não complexas com apelo visual, comumente encontrada em mídias sociais e portais informativos de listas de curiosidades e afins.

Aqui, buscamos elucidar questões relacionadas aos termos estruturais (gráficos, visualizações de dados, infográficos e infográficos digitais) e consolidar uma terminologia de forma didática. Para compreender a infografia contemporânea, no entanto, é importante revisitar suas origens, sua evolução e seus suportes. No capítulo a seguir, observaremos diferentes propostas de linhas de evolução da linguagem infográfica e, a partir do cruzamento de seus dados, elaboramos uma linha do tempo para este trabalho. 


\section{3 Das origens à infografia contemporânea: a construção de
uma linha do tempo}

Para contextualizar a infografia, convém observar suas origens e como chegaram à forma tal como se reconhece na atualidade, tendo em vista que não se pode afirmar que a linguagem infográfica deriva de uma única fonte. Ela surge de forma pluridisciplinar, com influência de fontes como a cartografia, a estatística, a medicina, a ilustração científica, o jornalismo e a literatura. Seu meio de difusão hegemônico foi a imprensa jornalística, principalmente nas décadas de 1980 e 1990. O surgimento dos infográficos digitais e a disponibilização de dados em larga escala, disseminados de forma mais evidente a partir dos anos 2000, propiciaram uma amplificação no potencial de uso desse tipo de linguagem para comunicar, analisar dados e gerar novo conhecimento. Atualmente, com a massiva popularização dos smartphones e facilidade de acesso a dados e de consultas a informações por meio desses dispositívos, superando os jornais impressos ou suas versões para os desktops, as visualizações de dados e infográficos estão disponíveis a qualquer momento em dispositivos que cabem na palma da mão.

Uma forma eficaz de se iniciar a elucidação da evolução dos infográficos até o estágio atual e a melhor compreensão da complexa variedade de recursos gráficovisuais que são usados como ferramenta ou fazem parte de infográficos, é investigar as suas fontes de origem e traçar uma linha do tempo da comunicação por meio de artefatos gráficos ou diagramas informativos até o presente. $\mathrm{O}$ fato de a infografia usar diferentes modais combinados para comunicar uma mensagem, tais como textos, diagramas, mapas, gráficos etc. amplia a dificuldade em se definir exatamente o que é um infográfico, sob o ponto de vista do público geral. A compreensão de como as variadas fontes se aglutinaram em determinados momentos da história, bem como os benefícios proporcionados pelo resultado dessas peças, podem amparar o entendimento da relevância da visualização de dados e da infografia como ferramentas de auxílio à construção do saber ao longo do tempo, de seus primórdios aos dias de hoje. De acordo com Tufte (2001, p.15) 
os exemplos listados no percurso histórico disponibilizado em The Visual Display of Quantitative Information, publicado em 1983, sustentam diversos propósitos, tais como: fornecer exemplos de alta qualidade para discussão e construção de uma teoria de gráficos de dados; ajudar a demonstrar a terminologia; contar, de forma breve, uma história do desenvolvimento dos gráficos e mostrar como gráficos estatísticos podem ser bons. Portanto, antes de nos aprofundarmos nas demais questões relevantes para este trabalho, estabeleceremos uma linha do tempo da infografia e da visualização de dados, por meio do cruzamento dos históricos apresentados por alguns dos principais pesquisadores do campo e adicionaremos marcos extras que julgamos fundamentais.

Este capítulo aborda, então, a comunicação de informações por meios gráficovisuais ao longo da história, como forma de contextualizar as origens, os campos do saber envolvidos e a evolução dos gráficos e infográficos. Foram revisados e analisados os percursos históricos elaborados por alguns dos principais autores de referência. Os dados obtidos foram comparados, como forma de auxiliar a escolha de marcos fundamentais por meio da identificação de exemplos recorrentes. Uma vez estabelecida uma estrutura básica, eventos ou itens relevantes (mencionados pelos autores ou não) foram adicionados para o desenvolvimento de uma linha histórica específica para este trabalho. Foi realizada uma descrição mais detalhada dos exemplos selecionados, de modo a contextualizá-los. Ao final, uma linha do tempo gráfico-visual foi elaborada e disponibilizada para consulta rápida aos marcos descritos.

\section{1.}

\section{Percurso(s) histórico(s): cruzando óticas variadas}

Diversos autores buscaram traçar, em suas obras, uma breve história das visualizações de dados, da infografia ou sobre a evolução dos gráficos. Campos do saber distintos influenciaram e apoiaram-se em variados tipos de gráficos para o registro, a análise e a difusão de seus dados e conquistas. Observar as origens e a evolução do uso de gráficos e infográficos ao longo da história, identificando os seus principais marcos, autores, obras e casos exemplares, permite que se compreenda com maior clareza a importância e o porquê desse tipo de linguagem ser amplamente usada por diversos meios nos dias de hoje. 
O método de seleção dos autores de referência essenciais se baseou em obras (1) que tenham reconhecida relevância para a área da infografia, nacionais e internacionais e (2) que tenham discorrido sobre o tema da evolução dos gráficos, visualizações de dados ou infográficos ou elaborado linhas do tempo e/ou revisões históricas em suas obras. A partir da lista inicial de autores obtida, foram aplicados critérios adicionais para a seleção final. Foram escolhidos os autores que (a) realizaram uma narrativa baseada em marcos fundamentais da evolução histórica, (b) que descreveram os itens ou indivíduos, (c) que explicitaram as razões pelas quais os marcos foram incluídos e (d) que tenham disponibilizado imagens. As narrativas que não disponibilizaram imagens da totalidade ou maioria dos exemplos e as catalogações temporais sem a inclusão de uma revisão crítica dos elementos presentes nelas foram eliminadas.

Na primeira etapa, a partir da revisão bibliográfica, chegou-se a dez autores: Tufte (2001), Peltzer (1991), Cairo (2008), Few (2009), Friendly e Denis (2001), Holmes (2011), Kanno (2013), Moraes (1998), Ribeiro (2008) e Teixeira (2010). Após a aplicação dos criérios da segunda etapa, selecionamos para este trabalho os históricos traçados por três autores: Tufte (1983), Few (2009) e Cairo (2008), que disponibilizam conteúdo para a construção de uma linha do tempo capaz de abordar tanto gráficos quanto infográficos. Para cada autor, buscou-se descrever de forma sucinta os marcos e as razões de terem sido mencionados, bem como organizar sua cronologia. Ao fim de cada resumo, apresenta-se uma tabela ou listagem para tratamento dos dados obtidos. Apesar de não se adequarem aos critérios iniciais, foram escolhidos como linhas auxiliares os trabalhos de Kanno (2013), que sintetizou parte do trabalho de Friendly e Denis (2001) e Holmes (2011), que realizou uma linha do tempo sobre as raízes da infografia na peça Infographia, presente em Rendgen (2012). Posterioremente, os dados obtidos foram analisados e comparados, dando origem a uma linha do tempo que visa reunir o cruzamento dos conteúdos selecionados.

\subsection{1.}

\section{Tufte: a referência na esfera da visualização de informações}

O professor emérito de estatística, design gráfico e economia política, Edward Tufte, da Universidade de Yale, é uma das personalidades mais importantes no 
âmbito da visualização de dados, na área de design da informação. Em seu livro, The Visual Display of Quantitative Information, publicado em 1983, Tufte dedica a primeira parte da obra a uma revisão detalhada sobre a evolução de séculos da prática da elaboração de gráficos, divididos em quatro tipos, cada qual com seus exemplos: mapas de dados, séries temporais, narrativas de espaço-tempo e gráficos relacionais.

O primeiro grupo é o de mapas de dados, chamados de mapas temáticos na Cartografia, que tem suas origens nos primeiros mapas desenhados em tabuletas de argila, há 5 mil anos. Após um hiato de alguns milênios, e com um salto para o ano de 1137, surgem obras cartográficas altamente detalhadas, como o mapa chinês Yü Chi Thu (traduzido como "mapa das trilhas de Yü, o grande”). Em 1546, em Cosmographia, de Petrus Apianus, são encontrados exemplos de mapas europeus que se aproximam da estrutura de gráficos estatísticos. No entanto, o mapa de dados de Edmond Halley, de 1686, é o que podemos considerar, efetivamente, um dos primeiros exemplos de mapa com gráfico estatístico, monstrando ventos alísios e monções em um mapa mundi. Já como mapa temático, um exemplar valioso para exibir padrões é o que aponta as mortes por cólera, do Dr. John Snow, de 1854. Uma década mais tarde, o mapa de Charles Joseph Minard adicionou quantidades e direções no mapa mundi, em uma peça sobre a exportação de vinhos franceses, em 1864. Acerca dos mapas gerados por computador pela cartografia moderna, Tufte (2001, p.26) cita um aumento na densidade de informação, na ordem de 5 mil vezes, em relação aos gráficos de Halley. Tais como o mapa de galáxias do hemisfério norte, que mostra a distribuição de 1,3 milhão de elementos, citado em um artigo de 1977.

Resumindo-se o grupo dos mapas de dados exemplificados e ordenando-os cronologicamente, temos:

\begin{tabular}{cll} 
Ano & \multicolumn{1}{c}{ Marco } & \multicolumn{1}{c}{ Autor/Instituição } \\
\hline 3400 a.C. & primeiros mapas em tabuletas de argila & $\mathrm{n} / \mathrm{d}$ \\
\hline 1137 & mapa de Yü Chi Thu & $\mathrm{n} / \mathrm{d}$ \\
\hline 1546 & mapa estatístico no Cosmographia & Petrus Apianus \\
\hline 1686 & mapa de dados & Edmond Halley \\
\hline 1854 & mapeamento do cólera & John Snow \\
\hline 1864 & mapa de exportação de vinhos franceses & C. J. Minard \\
\hline 1977 & mapeamento de galáxias por computador & M. Seldner et al \\
\hline
\end{tabular}

Quadro 1 - Exemplos de mapas de dados mencionados por Tufte. Fonte: do autor. 
Sobre gráficos de séries temporais, Tufte afirma que o arranjo dos dados onde uma das dimensões se dedica a um ritmo regular de tempo, como segundos, minutos, dias, meses, anos etc. permite uma eficiência interpretativa que se sobrepõe a outros tipos de gráfico, e essa é uma das razões pelas quais os gráficos de séries temporais serem os mais comuns (TUFTE, 2001, p.28). O autor afirma que esses gráficos são melhor aproveitados quando há grandes conjuntos de dados variados, que usem material estatístico complexo e rico. Tufte (2001, p.32) destaca que os dois grandes criadores dos gráficos modernos foram Johann Heinrich Lambert (1728-1777), cientista e matemático suíço-alemão, e William Playfair (1759-1823), engenheiro e economista político escocês. Um dos exemplos mais antigos desse grupo é um gráfico sobre a inclinação das órbitas planetárias, do século X ou XI. É uma tentativa de se mostrarem graficamente variáveis em relação ao tempo, provavelmente parte de um texto para escolas de mosteiro. Saltando-se para o século XVIII, há o aparecimento de gráficos temporais em textos científicos, como o de Lambert, publicado em 1779, que mostra a variação de temperatura do solo em relação a diferentes profundidades ao longo de quatro anos. Em 1979, o gráfico temporal multivariado sobre emissões de rádio de Júpiter, coletados pela sonda Voyager 2, realizado por D. A. Gurnett e outros autores, mostra 18,9 mil pontos de dados sobre a distância do planeta, datas, orientação relativa e latitudes. Outro gráfico que demonstra a eficiência no uso de vários dados é o sumário do clima da cidade de New York, de 1980, que exibe 1.888 números sobre as temperaturas mínima e máxima, precipitações e umidade relativa do ar ao longo do ano. Tufte (2001, p.31) afirma que um gráfico com força similar é o do itinerário de partidas de trens de Paris para Lyon, de 1885, desenvolvido por E. J. Marey (1830-1904). A eficiência é tamanha que, cem anos depois, em 1981, foi possível indicar um novo trem expresso mais rápido, no mesmo display, apenas adicionando uma nova linha. Na sequência, são apresentados três gráficos de Playfair: o primeiro gráfico temporal a usar dados econômicos, o primeiro gráfico de barras, com dados sobre as importações escocesas, ambos publicados no The Commercial and Political Atlas, em 1786 e um gráfico que compara os preços do trigo, os salários e monarcas no poder, por um período de 250 anos, publicado em 1821. Como exemplo de gráfico temporal que demonstra claramente situações de antes/depois, existe a peça de um engenheiro francês, Charles Joseph Minard, acerca do colapso 
da ponte sobre o Rhône, publicado em 1856. Também são destacados o gráfico de Marey sobre a genealogia da realeza inglesa, publicado em La Méthode Graphique, em 1885, bem como o seu pioneirismo no desenvolvimento de gráficos relativos à fisiologia humana e animal, publicados no Movement, de 1895.

Organizando a narrativa de Tufte em ordem cronológica, temos, abaixo, os tópicos identificados sobre séries temporais:

\begin{tabular}{cll} 
Ano & \multicolumn{1}{c}{ Marco } & \multicolumn{1}{c}{ Autor/Instituição } \\
\hline Séc. X & gráfico de inclinações orbitais planetárias & n/d \\
\hline 1779 & variação de temperatura do solo & J. H. Lambert \\
\hline 1786 & The Commercial and Political Atlas & W. Playfair \\
\hline 1821 & dados de 250 anos dos preços do trigo & W. Playfair \\
\hline 1856 & colapso da ponte sobre o Rhône & C. J. Minard \\
\hline 1880 & itinerário de trens de Paris para Lyon & E. J. Marey \\
\hline 1885 & gráfico da genealogia da realeza inglesa & E. J. Marey \\
\hline 1895 & gráficos no Movement & E. J. Marey \\
\hline 1979 & gráfico com dados da Voyager 2 & D. Gurnett et al \\
\hline 1980 & gráfico do clima de New York. & NYT \\
\hline
\end{tabular}

Quadro 2 - Exemplos de gráficos de séries temporais mencionados por Tufte. Fonte: do autor.

O terceiro grupo é o dos gráficos narrativos de espaço e tempo, que possuem a adição da dimensão espacial em relação aos gráficos temporais. De acordo com Tufte (2001, p.40), essa adição aprimora o potencial explicativo do gráfico ao mover os dados pelo espaço em duas ou três dimensões. O autor cita três exemplos nessa categoria: o clássico gráfico de Minard sobre a campanha do exército de Napoleão na Rússia, de 1869; o gráfico do Los Angeles Times, de 1979, sobre os níveis de três poluentes presentes no ar, ao longo do dia, em condados no sul da Califórnia e, finalmente, o gráfico sobre o ciclo de vida do besouro japonês, de L. Hugh Newman, publicado no Man and Insects, em 1965. O gráfico de Newman demonstra as fases do ciclo do besouro exibindo os dados sobre o tempo e o espaço na horizontal, de forma criativa, ao longo dos meses.

Os gráficos com narrativas de espaço e tempo ficam organizados a seguir:

\begin{tabular}{cll} 
Ano & \multicolumn{1}{c}{ Marco } & Autor/Instituição \\
\hline 1869 & campanha do exército de Napoleão & C. J. Minard \\
\hline 1965 & ciclo de vida do besouro japonês & L. H. Newman \\
\hline 1979 & níveis de poluentes no sul da Califórnia & L. A. Times \\
\hline
\end{tabular}

Quadro 3 - Exemplos de gráficos narrativos de espaço e tempo mencionados por Tufte. Fonte: do autor. 
O último grupo, o de gráficos relacionais, caracteriza-se pelo uso de representações abstratas, não diretamente relacionadas a analogias geográficas ou do mundo físico, tais como as coordenadas de latitude e longitude dos mapas estatísticos. Segundo Tufte (2001, p.46), graças ao trabalho de Lambert e Playfair, a libertação das analogias ao mundo físico, no princípio do século XVIII, fez com que os gráficos pudessem usar quaisquer variáveis quantificáveis em relação a outras, medidas pelas mesmas unidades de observação. Um gráfico que demonstra os avanços dos gráficos relacionais é o elaborado por Lambert, em 1771, a respeito da taxa de evaporação da água em função da temperatura. Outro exemplo são os gráficos presentes na obra mais teórica de Playfair, o livro The Statistical Breviary, publicado em 1801, que possuem analogias menos relacionadas ao mundo real que as do seu atlas, de quinze anos antes. No gráfico Principal Nations of Europe, notase o uso de dados multivariados, de áreas para representar quantidades e de um gráfico de pizza, o que Tufte $(2001$, p.44) afirma parecer ser a primeira aplicação desses dispositivos. Outros cinco gráficos são listados, mostrando a diversidade de temas e variáveis passíveis de serem observadas e transformadas em gráficos relacionais, tais como a comparação entre pesquisas sobre condutividade do cobre, o crescimento de sementes de pinho de acordo com elementos presentes no solo, dentre outros. De acordo com o Tufte (2001, p.47), o scatterplot (gráfico de dispersão) e suas variantes são os melhores designs de gráficos e, não coincidentemente, respondem por $40 \%$ dos gráficos em literatura científica.

Os gráficos relacionais ficam organizados em ordem cronológica de acordo com o quadro a seguir:

\begin{tabular}{cll} 
Ano & \multicolumn{1}{c}{ Marco } & \multicolumn{1}{c}{ Autor/Instituição } \\
\hline 1771 & taxa de evaporação da água & J. H. Lambert \\
\hline 1801 & Principal Nations of Europe & W. Playfair \\
\hline 1939 & o crescimento de sementes de pinho & H.L. Mitchell \\
\hline 1964 & gráfico do relatório Smoking and Health & n/d \\
\hline 1974 & condutividade térmica do cobre & C.Y. Ho et al \\
\hline 1976 & Catastrophe Theory, Scientific American & E. C. Zeeman \\
\hline 1977 & gráficos relacionais sobre desemprego & P. McCracken et al \\
\hline
\end{tabular}

Quadro 4 - Exemplos de gráficos relacionais mencionados por Tufte. Fonte: do autor. 
A narrativa de Tufte apresenta ricos exemplos em uma ordem lógica, com categorias distintas que cobrem um amplo espectro de atuação das visualizações de dados. Apesar de não ter como foco o tema exato da infografia, os elementos apresentados, descritos e criticados pelo autor fornecem subsídios essenciais para o campo. O fato de a linha se encerrar na década de 1980, dada a publicação da obra, em 1983, não impede que os exemplos incluam tecnologias recentes.

\subsection{2.}

\section{Few: o caminho da visualização das informações}

O professor Stephen Few, da University of California, atuou por 30 anos na elaboração e na teoria da visualização de dados com foco em análise e comunicação de informações quantitativas para negócios. É autor de quatro livros de referência para visualização de dados. Em uma de suas obras fundamentais, Now You See It: Simple Visualization Techniques for Quantitative Analysis, publicada em 2009, Few propõe uma linha do tempo com os principais marcos que pavimentaram o caminho para a visualização de informação contemporânea, mais exatamente em relação às visualizações de dados quantitativos.

A proposta de Few $(2009$, p.14) inicia-se no século II, com as tabelas que organizam dados em um arranjo simples de colunas e linhas. Essas primeiras tabelas foram encontradas no Egito e eram usadas para organizar informações astronômicas no auxílio às navegações. Após um longo período sem inovações, apenas no século XVII surgem os gráficos bidimensionais ${ }^{34}$, de Descartes. A diferença nos gráficos cartesianos foi o propósito de tornar visíveis os dados matemáticos, por meio de coordenadas em eixos verticais e horizontais. $\mathrm{O}$ autor afirma que a maior parte dos gráficos que conhecemos hoje foram inventados apenas no fim do século XVIII e início do século XIX (FEW, 2009, p.15), aprimorados ou criados por Playfair, como o gráfico de barras, os que usam linhas para mostrar mudanças ao longo do tempo e o gráfico pizza. Um marco interessante, relativo à educação superior, é a criação da primeira graduação com foco na prática da elaboração de gráficos, oferecida pela Iowa State University, em 1913. O autor, no entanto, ressalta que existem poucos cursos atualmente, excetuando-se os incluídos nos programas de estudos em

\footnotetext{
${ }^{34}$ No capítulo anterior esclarecemos que as bases para os gráficos de coordenadas surgiram antes de Descartes, por meio de Nicole d'Oresme, no século XIV.
} 
estatística. Três obras são relacionadas em sequência: o livro de Jacques Bertin, Sémiologie Graphique, publicado em 1967, que aborda como a percepção visual opera na expressão visual da informação; o livro Exploratory Data Analisys, de John Tukey, de 1977, que ofereceu uma nova abordagem à estatística e o principal título de Tufte, The Visual Display of Quantitative Information, de 1983. Few, então, ressalta o lançamento do Macintosh, da Apple, em 1984, por permitir a interação direta com a visualização de dados em um computador. O ano de 1985 tem como marco a publicação do livro de William Cleveland, The Elements of Graphing Data, que refina e expande o uso de visualizações em estatística. No ano seguinte, em 1986, houve o surgimento de uma nova especialidade em pesquisa acadêmica, por meio da National Science Foundation (NSF), a partir do lançamento de uma iniciativa que encorajou o uso de computadores para o processamento de dados científicos. O último marco na linha do tempo de Few $(2009$, p.16) é o livro Readings in Information Visualization: Using Vision to Think, de 1999, que reúne as melhores pesquisas sobre o tema, até então.

A partir da narrativa de Few, temos então:

\begin{tabular}{cll} 
Ano & \multicolumn{1}{c}{ Marco } & \multicolumn{1}{c}{ Autor/Instituição } \\
\hline Séc. II & tabelas de dados no Egito & $\mathrm{n} / \mathrm{d}$ \\
\hline Séc. XVII & gráficos bidimensionais de Descartes & R. Descartes \\
\hline Séc. XVIII & gráficos de barra, linha sobre tempo e pizza & W. Playfair \\
\hline 1913 & primeira graduação & lowa St. University \\
\hline 1967 & Sémiologie Grafique & J. Bertin \\
\hline 1977 & Exploratory Data Analisys & John Tukey \\
\hline 1983 & The Elements of Graphing Data & W. Cleveland \\
\hline 1984 & Lançamento do Macintosh & Apple \\
\hline 1986 & dados em nova especialidade de pesquisa & NSF \\
\hline 1999 & Readings in Information Visualization & Card et al \\
\hline
\end{tabular}

Quadro 5 - Marcos históricos apontados por Few. Fonte: do autor.

Apesar de sucinta, a linha do tempo de Few disponibiliza autores e obras imprescindíveis para a compreensão da evolução da composição de gráficos como disciplina e o seu auxílio a outros campos do saber. Com isso, ele demonstra o potencial de geração de novo conhecimento a partir dos dados por meio gráficovisual. 


\subsection{3.}

\section{Cairo: as fontes de origem da infografia}

Um dos nomes mais influentes no mundo da infografia, o professor doutor Alberto Cairo, da University of Miami, atuou como jornalista de dados em publicações como o jornal espanhol El Mundo e foi diretor de infografia e multimídia da Editora Globo, no Brasil. Seus livros, Infografía 2.0 visualización interactiva de información en prensa (2008), The Functional Art: an introduction to Infomation Graphics and Visualization (2012) e The Truthful Art: Data, Charts, and Maps for Communication (2016) trazem uma análise do cenário da visualização de informação mundial. Em Infografía 2.0, Cairo (2008, p.39) traça um percurso da visualização de informações na história. Para esta pesquisa, esse percurso será usado como referência central para a construção da linha do tempo, principalmente pelo fato de a sua abordagem contemplar variadas fontes de origem e não se restringir em demasiado às visualizações de dados, imergindo-se, também, na esfera da infografia.

O caminho descrito por Cairo desenvolve-se originalmente em seis partes: cartografia e estatística; ilustração científica; infografia jornalística; a revolução da década de 1980; a era dos conflitos e, finalmente, jornalismo de precisão e visualização analítica. Para este trabalho, aglutinamos as três últimas partes em uma, devido ao fato de os exemplos estarem diretamente relacionados ao jornalismo (impresso ou digital). Dessa forma, depuramos cada uma das linhas de construção dessas seções e observamos como se constituíram para elaborar uma linha do tempo baseada no conteúdo disponibilizado pelo autor.

Em cartografia e estatística, são apresentadas as origens fundamentais das visualizações de informação. Cairo (2008, p.39) afirma que os mapas são a origem da apresentação visual de informações, por meio de representações esquemáticas relacionadas a elementos, geralmente, geográficos. Para o autor, há indícios de mapas usados no berço das civilizações, como no Egito, Babilônia e China, séculos antes de Cristo. Esse início da cartografia ocorreu em diversas culturas, em momentos distintos, mesmo sem contato entre elas. O primeiro exemplo ilustrado pelo autor são os mapas usados pelos nativos das Ilhas Marshall, compostos por gravetos e conchas, que representam os arquipélagos e correntes marinhas. Com abstração similar, destaca-se o mapa das rotas do Império Romano, identificados 
na Tabula Peutingeriana, do século IV ou V. O mapa da epidemia de cólera em Londres, do Dr. John Snow, destaca-se como exemplo da cartografia temática, em 1854. Antes do mapa de Snow, no entanto, houve casos notáveis de experimentação de representações estatístico-cartográficas, como os mapas de Frére de Montizon, os quais representaram a densidade populacional da França por meio de pontos, em 1830 e o mapa de incidência de hérnia na França, de J. F. Malgaigne, de 1840. Cairo destaca William Playfair como o inventor da representação estatística e declara que "se a cartografia é filha de muitos pais, as representações estatísticas contam com um único inventor ${ }^{35 "}$ (CAIRO, 2008, p.43, tradução nossa). Cita que suas duas obras, o The Commercial and Political Atlas (1786) e Statistical Breviary (1801), contêm os primeiros exemplos de gráficos de barras e pizza. $\mathrm{O}$ último exemplo de gráfico estatístico é o mapa de C. J. Minard, sobre a campanha do exército de Napoleão, de 1869, descando-o como nome chave na história das representações estatísticas e da cartografia temática.

\begin{tabular}{cll} 
Ano & \multicolumn{1}{c}{ Marco } & \multicolumn{1}{c}{ Autor/Instituição } \\
\hline $\mathrm{n} / \mathrm{d}$ & mapas no Egito, Babilônia e Egito & $\mathrm{n} / \mathrm{d}$ \\
\hline $\mathrm{n} / \mathrm{d}$ & mapas das Ilhas Marshall & $\mathrm{n} / \mathrm{d}$ \\
\hline Séc. IV/V & Tábula Peutingeriana de Roma & $\mathrm{n} / \mathrm{d}$ \\
\hline 1786 & The Commercial and Political Atlas & W. Playfair \\
\hline 1801 & Statistical Breviary & W. Playfair \\
\hline 1830 & mapa da densidade populacional da França & F. de Montizon \\
\hline 1840 & mapa de incidência de hérnia na França & J. F, Malgaigne \\
\hline 1854 & mapeamento do cólera & John Snow \\
\hline 1869 & campanha do exército de Napoleão & C. J. Minard \\
\hline
\end{tabular}

Quadro 6 - Marcos históricos da Cartografia e Estatística, apontados por Cairo. Fonte: do autor.

Sobre a ilustração científica, Cairo (2008, p.45) afirma que ela nasce historicamente séculos antes do método científico. Inicia os exemplos com os tratados de anatomia de Claudius Galenus (129-209 d.C.), que influenciou médicos ao longo de séculos até o Renascimento. Em seguida, o autor apresenta imagens dos desenhos anatômicos de Leonardo da Vinci, de 1510-1511. Destaca que "nenhuma história da visualização de informação, por mais breve que seja, estaria

\footnotetext{
${ }^{35}$ No original "Si la cartografía es hija de muchos padres, la representación estadística cuenta con un único inventor, el ingeniero, matemático y economista escocês William Playfair."
} 
completa sem mencionar Leonardo da Vinci ${ }^{36 "}$ e afirma, ainda, que Da Vinci, tal como Playfair, "intuiu o poder dos olhos não apenas para ver, mas para

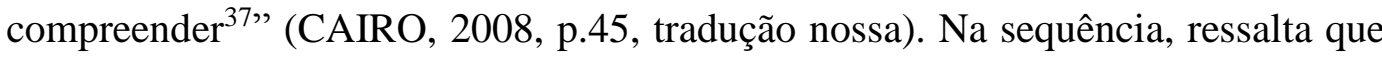
Andreas Versalius, apesar de menos famoso que Da Vinci, é autor do tratado de anatomia mais influente de todos os tempos, o De humani corporis fabrica, de 1543. Por último, evidencia que a ilustração tem sido usada como ferramenta para a ciência desde o Renascimento e que não era necesário exímio talento artístico ou desenhos muito elaborados para criá-las, como se nota, por exemplo, no desenho da árvore da evolução, presente na obra A origem das espécies, de Charles Darwin, de 1859.

\begin{tabular}{cll} 
Ano & \multicolumn{1}{c}{ Marco } & \multicolumn{1}{c}{ Autor/Instituição } \\
\hline Séc. II & tratados de anatomia & Claudius Galenus \\
\hline 1510 & desenhos anatômicos & Da Vinci \\
\hline 1543 & De humani corporis fabrica & Andreas Versalius \\
\hline 1859 & desenho da árvore da evolução & C. Darwin \\
\hline
\end{tabular}

Quadro 7 - Marcos históricos da ilustração científica, apontados por Cairo. Fonte: do autor.

Em infografia jornalística, o autor afirma que é possível identificar as tendências fundamentais que influenciaram a sua evolução até o presente. $\mathrm{O}$ exemplo inicial é o mapa da invasão da baía de Cádis pelas tropas britânicas, do The Daily Courant, edição de 12 de setembro de 1702. Pode-se notar falta de precisão cartográfica, prática comum nos primeiros mapas em mídia jornalística, que geralmente não eram desenvolvidos por cartógrafos. Cairo $(2008$, p.50) reforça que o início da infografia se caracterizou por uma abordagem mais artística e com menos rigor jornalístico, pois o objetivo primário era chamar a atenção por meio dos recursos visuais em detrimento ao conteúdo. O item seguinte, considerado um dos primeiros infográficos jornalísticos, é a cobertura do assassinato do Mr. Blight, publicado na capa do The Times, em 7 de abril de 1806. O autor também destaca o infame infográfico com informações incorretas sobre a explosão no encouraçado Maine, no porto de Havana, publicado pelo New York Journal, na edição de 17 de fevereiro de 1898. Quase um século depois, o surgimento do jornal USA Today, em

\footnotetext{
${ }^{36}$ No original "Ninguna historia de la visualización de información, por breve que sea, estaría completa sin mencionar a Leonardo da Vinci."

${ }^{37}$ No original "el maestro del Renascimiento intuyó el poder de los ojos no sólo para ver, sino para compreender."
} 
15 de setembro de 1982, é um marco em função do seu conteúdo conciso, diagramação dinâmica e amplo uso da infografia. Na mesma década, o autor frisa a importância da implementação da informática no desenvolvimento de infográficos, com o surgimento dos computadores Macintosh, da Apple (CAIRO, 2008, p.53). Na sequência, há uma análise da infografia em cobertura de períodos de conflitos, tais como na Guerra do Golfo, em 1991, e são expostos exemplos de infográficos da Guerra das Malvinas, no The Sunday London Times, em 1982, e do conflito no Afeganistão, no San José Mercury News, em 2001. Os dois últimos exemplos abordam a mudança do foco para visualizações analíticas no que o autor denomina “jornalismo de precisão", tais como a cobertura do Miami Herald sobre a destruição causada pelo furacão Andrew, em 1992, e os infográficos sobre a eleição presidencial americana, em 2004, do New York Times.

\begin{tabular}{cll} 
Ano & \multicolumn{1}{c}{ Marco } & \multicolumn{1}{c}{ Autor/Instituição } \\
\hline 1702 & mapa da invasão da baía de Cádis & The Daily Courant \\
\hline 1806 & assassinato do Mr. Bright & The Times \\
\hline 1898 & infográficos sobre o encouraçado Maine & New York Journal \\
\hline 1982 & infográfico sobre a Guerra das Malvinas & TS London Times \\
\hline 1982 & surgimento do USA Today & USA Today \\
\hline 1984 & lançamento do Macintosh & Apple \\
\hline 1991 & guerra do Golfo & n/d \\
\hline 1992 & infográfico sobre o furacão Andrew & Miami Herald \\
\hline 2001 & infográfico sobre conflito no Afeganistão & SJ Mercury News \\
\hline 2004 & infográficos sobre a eleição nos EUA & NYT \\
\hline
\end{tabular}

Quadro 8 - Marcos da infografia jornalística apontados por Cairo. Fonte: do autor.

A apresentação de Cairo, com exemplos separados por diferentes origens, proporciona uma visão ampla das raízes, dos autores e das mudanças de paradigmas no campo da infografia. Seus apontamentos reforçam tópicos mencionados por Tufte (2001) e Few (2009), mas adicionam conteúdo diverso e possibilitam uma clara percepção do papel da infografia na difusão de informações e a sua presença em mídias jornalísticas impressas e digitais, de sua origem até os dias de hoje.

\subsection{4.}

\section{Linhas adicionais: Holmes e Kanno}

Dois percursos históricos não se adequaram aos critérios iniciais de seleção e, portanto, não foram detalhados neste trabalho. No entanto, pelo fato de exibirem 
exemplos relevantes com ilustrações que os representam, apesar de as descrições serem menos aprofundadas em alguns casos, foram usados como apoio aos dados coletados dos autores listados anteriormente. São eles: a linha do tempo de Nigel Holmes, em Infographia, de 2011, encartado no livro Information Graphics, de Sandra Rendgen (2012) e Mario Kanno, no livro Infografe, de 2013.

Holmes traça uma linha sucinta com as raízes da infografia, desde as pinturas rupestres até 1984, com o lançamento do Macintosh, da Apple; Kanno faz uma revisão do trabalho de Friendly e Denis (2001), professores da York University, no Canadá, presente no Milestones in the History of Thematic Cartography, Statistical Graphics, and Data Visualization: An illustrate chronology of innovations. Abaixo, seguem os dados extraídos de ambos os trabalhos:

\begin{tabular}{cll} 
Ano & \multicolumn{1}{c}{ Marco } & \multicolumn{1}{c}{ Autor/Instituição } \\
\hline 32.000-16.000 a.C. & pintura rupestre & $\mathrm{n} / \mathrm{d}$ \\
\hline 3.000 a.C. & pinturas em paredes egípcias & $\mathrm{n} / \mathrm{d}$ \\
\hline 150 a.C. & mapas com informações de clima, população & Ptolomeu \\
\hline 1066 & narrativas pictóricas, primeiros quadrinhos & The Bayeux Tapestry \\
\hline 1250 & visualizações estatísticas & Roger Bacon \\
\hline 1485 & artes nas informações visuais & Da Vinci \\
\hline 1637 & gráficos cartesianos & R. Descartes \\
\hline 1637 & enciclopédia pictórica & Jan Amos Comelius \\
\hline 1760 & gráficos de barra, linha e pizza & W. Playfair \\
\hline $1920-1940$ & Statistical Accountability & Otto Neurath \\
\hline 1930 & mapa do metrô de Londres & Harry Beck \\
\hline 1967 & Sémiologie Graphique & Jacques Bertin \\
\hline 1984 & surgimento do Macintosh & Apple \\
\hline
\end{tabular}

Quadro 9 - Raízes da infografia extraídos do Infographia, de 2011, de Holmes. Fonte: do autor.

\begin{tabular}{cll} 
Ano & \multicolumn{1}{c}{ Marco } & \multicolumn{1}{c}{ Autor/Instituição } \\
\hline 30.000 a.C. & pinturas rupestres & $\mathrm{n} / \mathrm{d}$ \\
\hline 6.200 a.C. & primeiro mapa babilônico gravado em pedra & $\mathrm{n} / \mathrm{d}$ \\
\hline 550 a. C. & mapa do mundo segundo Anaximandro & Anaximandro de Mileto \\
\hline 150 & primeira projeção esférica da Terra & Ptolomeu \\
\hline 1350 & primeiros gráficos de barras & Nicole d'Oresme \\
\hline 1500 & ilustrações de anatomia, máquinas e movimentos & Da Vinci \\
\hline 1595 & primeiro mapa múndi & Rumold Mercator \\
\hline 1669 & gráfico de função & Christiaan Huygens \\
\hline 1782 & primeiro mapa topográfico & M. du Carla-Boniface \\
\hline 1786 & gráficos de barras e linhas com dados econômicos & W. Playfair \\
\hline 1801 & gráfico de pizza & W. Playfair \\
\hline 1819 & cartograma sobre analfabetismo na França & B. Pierre Charles Dupin \\
\hline
\end{tabular}




\begin{tabular}{cll}
1820 & gráficos e diagramas em textos científicos & Michael Faraday \\
\hline 1855 & mapa da epidemia de cólera em Londres & John Snow \\
\hline 1857 & campanha para melhorias sanitárias no exército & Florence Nightingale \\
\hline 1869 & campanha do exército de Napoleão & C. J. Minard \\
\hline 1920 & diagramas com setas & Sewall Wright \\
\hline 1924 & Isotype & Otto Neurath \\
\hline 1933 & mapa do metrô de Londres & Harry Beck \\
\hline 1976 & surgimento da "arquitetura de informação" & Richar Saul Wurman \\
\hline 1977 & Explanation graphics, Holmes entra na Times & Nigel Holmes \\
\hline 1982 & mapa do tempo no USA Today & George Rorick \\
\hline 1999 & livro Understanding USA & Richard Saul Wurman \\
\hline 1999 & visualizações interativas na internet & El País e El Mundo \\
\hline 2000 & palestras, incluindo no Brasil, nos anos 2000 & Alberto Cairo \\
\hline
\end{tabular}

Quadro 10 - Origens da infografia extraídos do livro Infografe, de 2013, de Kanno. Fonte: do autor.

\subsection{5. \\ Resultados obtidos pelo processamento dos dados}

Após a coleta, os dados de cada autor foram organizados e codificados por meio de cores, ordenação e posicionamento espacial, para que fosse possível a distribuição em ordem cronológica dos variados eventos, marcos e exemplos identificados. Uma vez dispostos em ordem, foram destacados os itens citados que obtiveram menções por dois ou mais autores. Pelo fato de os autores não abordarem exatamente os mesmos temas, exemplos relevantes pontuados por apenas um autor também foram identificados com um código, apesar de classificados em uma posição hierárquica inferior. Ao final, foram adicionados elementos ausentes entre os autores revisados, mas considerados marcos na infografia para este trabalho. Esses itens podem não estar incluídos nos históricos de seus autores por uma questão de escolha ou, ainda, por uma questão cronológica, tendo em vista que a obra analisada de Tufte fora publicada em 1983, por exemplo.

Os dados e a lista final, ainda em formato tabular, ordenados e codificados por cores, para fins ilustrativos sobre o processo, ficam de acordo com o exemplo na figura abaixo: 


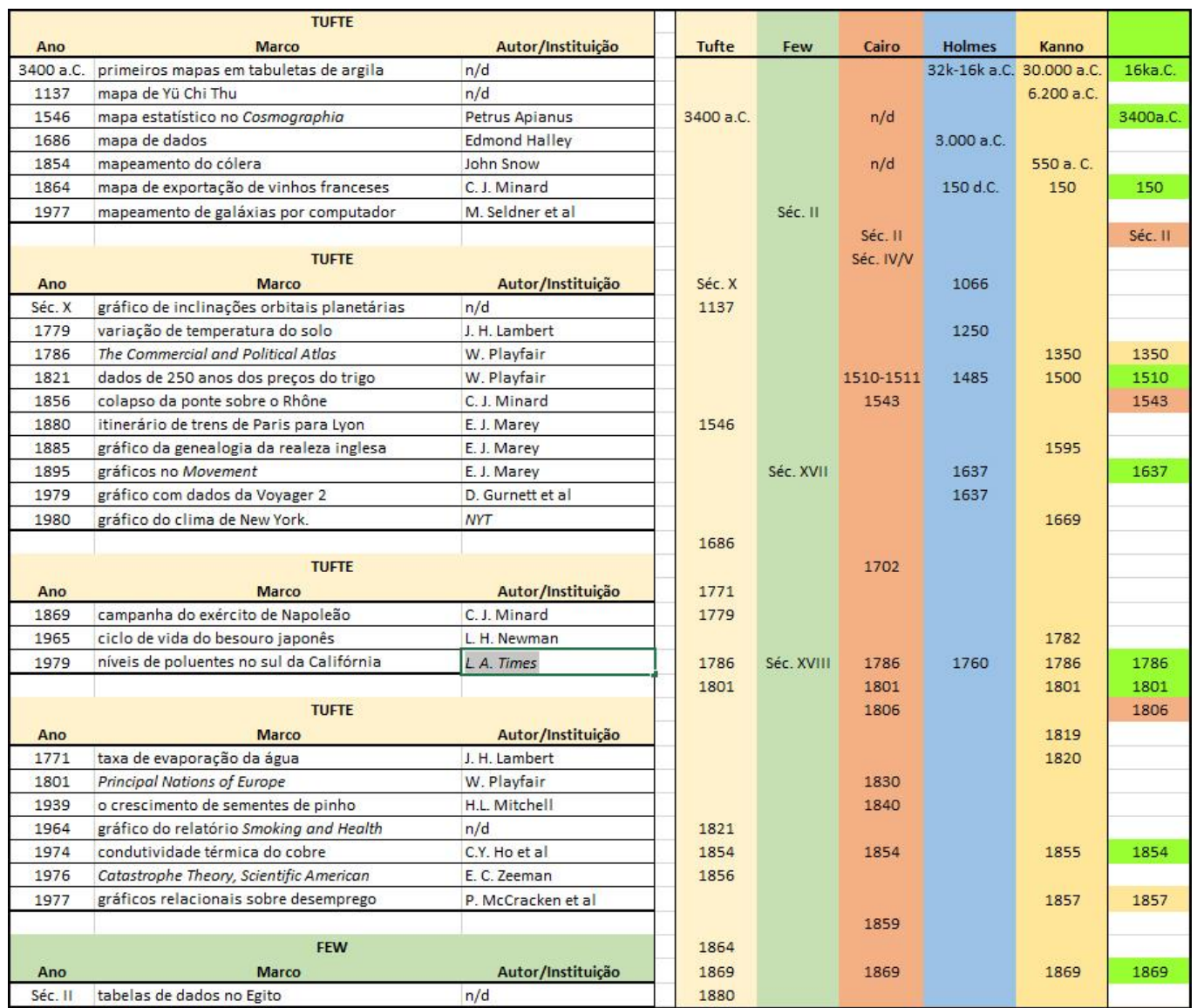

Figura 11 - Imagem de pequena parte do processo de codificação de cores dos dados para a obtenção dos marcos selecionados. Fonte: do autor.

A coluna de dados selecionados (Figura 12), uma vez organizada e colapsada, revela uma escala de tempo dentro do esperado, com itens capazes de alimentar uma linha do tempo pertinente. Os itens em verde vibrante revelam dados mencionados por dois ou mais autores; os dados com datas em cores e títulos em células brancas indicam a menção de um único autor, mas com relevância suficiente para inclusão; os itens totalmente em branco são elementos não mencionados pelos autores, mas considerados relevantes por este trabalho. 


\begin{tabular}{|c|c|c|}
\hline \multicolumn{3}{|c|}{ SELECIONADOS } \\
\hline Ano & Marco ou exemplo & Autor \\
\hline \multicolumn{2}{|c|}{16.000 a.C. pinturas rupestres } & $\mathrm{n} / \mathrm{d}$ \\
\hline 3.400 a.C. & mapas no Egito e Babilônia & $\mathrm{n} / \mathrm{d}$ \\
\hline Séc. II & tratados de anatomia & Claudius Galenus \\
\hline 150 & primeira projeção esférica da Terra & Ptolomeu \\
\hline 1350 & primeiros gráficos de barras & Nicole d'Oresme \\
\hline 1510 & desenhos anatômicos & Da Vinci \\
\hline 1543 & De humani corporis fabrica & Andreas Versalius \\
\hline 1637 & gráficos cartesianos & R. Descartes \\
\hline 1786 & The Commercial and Political Atlas & W. Playfair \\
\hline 1801 & Statistical Breviary & W. Playfair \\
\hline 1806 & primeiro infográfico: o assassinato do Mr. Bright & The Times \\
\hline 1854 & mapeamento da epidemia de cólera em Londres & John Snow \\
\hline 1857 & campanha para melhorias sanitárias no exército & Florence Nightingale \\
\hline 1869 & campanha do exército de Napoleão na Rússia & C. J. Minard \\
\hline 1885 & gráfico da genealogia da realeza inglesa & E. J. Marey \\
\hline 1899 & mapas de navegação dos nativos das Ilhas Marshall & $\mathrm{n} / \mathrm{d}$ \\
\hline 1924 & Isotype & Otto Neurath \\
\hline 1933 & mapa do metrô de Londres & Harry Beck \\
\hline 1967 & Sémiologie Graphique & J. Bertin \\
\hline 1982 & surgimento do USA Today & USA Today \\
\hline 1984 & lançamento do Macintosh & Apple \\
\hline 1991 & cobertura infográfica da guerra do Golfo & vários veículos \\
\hline 1992 & Infografia espanhola nos Jogos de Barcelona & vários veículos \\
\hline 1994 & Del arte del Toreo & Mario Tascón \\
\hline 1995 & infográfico La Ballena Franca é publicado no Clarín & Jaime Serra \\
\hline 2007 & sector snapshot com atualização de dados constante & NYT \\
\hline 2011 & Manifesto sobre erros em infográficos & Giner e Cairo \\
\hline 2016 & mobile vira o principal meio de acesso a informações & PEW Research \\
\hline
\end{tabular}

Figura 12 - Itens selecionados, organizados em ordem cronológica. Fonte: do autor.

\section{2. \\ Breve história da infografia: das cavernas aos smartphones}

Uma vez estabelecidos os marcos fundamentais para nossa proposta de linha do tempo, buscou-se desenvolver um detalhamento de cada exemplo em uma ordem lógica, construindo uma narrativa capaz de apresentar a evolução da infografia, desde suas origens até a contemporaneidade, de acordo com a nossa ótica. Foi possível, então, discorrer sobre a evolução da infografia em um percurso com origens múltiplas, abordando cada uma das principais áreas de influência (cartografia, estatística e ilustração científica) e culminando em um breve histórico do seu suporte essencial (jornal impresso), e do surgimento das visualizações digitais e online. 


\subsection{1. \\ Cartografia e estatística}

Os mapas são representações visuais de determinadas regiões. São uma das mais antigas formas de comunicação, precedendo a linguagem escrita e sistemas numéricos. Eles funcionam "como mediadores entre um mundo mental interior e um mundo físico exterior, mapas são ferramentas fundamentais que ajudam a mente humana a dar sentido ao seu universo em várias escalas"38 (HARLEY e WOODWARD, 1987, p.2, tradução nossa). Há registros arqueológicos que indicam a existência de mapas celestes pré-históricos nas pinturas das cavernas de Lascoux, com aproximadamente 16.500 anos de idade. Compreender os mapas celestes era importante para prever a chegada do inverno e a migração de manadas de animais que eram fontes de alimento. Elementos gráficos entre os desenhos dos animais pintados indicam estruturas visíveis no céu noturno, tais como constelações, ciclos lunares e outros agrupamentos de estrelas (Figura 13). Por exemplo, de acordo com Rappenglück (2004, p.19), uma pintura encontrada na câmara denominada Shaft of the Dead Man possui marcações que representam o Triângulo do Verão. A forma triangular composta pelos olhos do homem-pássaro, do pássaro e do bisão equivalem às estrelas Vega, Altair e Deneb, que formam uma estrutura muito brilhante visível nas primeiras horas da noite, no hemisfério norte, durante o verão. Outra evidência da existência de mapas celestes é a pintura do grande auroque ${ }^{39}$, na câmara chamada Hall of the Bulls. Os seis pontos acima do animal indicam o aglomerado estelar de Plêiades, da constelação de Touro, e o conjunto de pontos ao redor do olho do animal delineariam Hyades, ao redor da estrela Aldebaran (RAPPENGLÜCK, 2004, p.102).

\footnotetext{
${ }^{38}$ No original "As mediators between an inner mental world and an outer physical world, maps are fundamental tools helping the human mind make sense of its universe at various scales."

${ }^{39}$ Espécie de bovino selvagem extinto que habitou a Europa, a Ásia e o norte da África.
} 

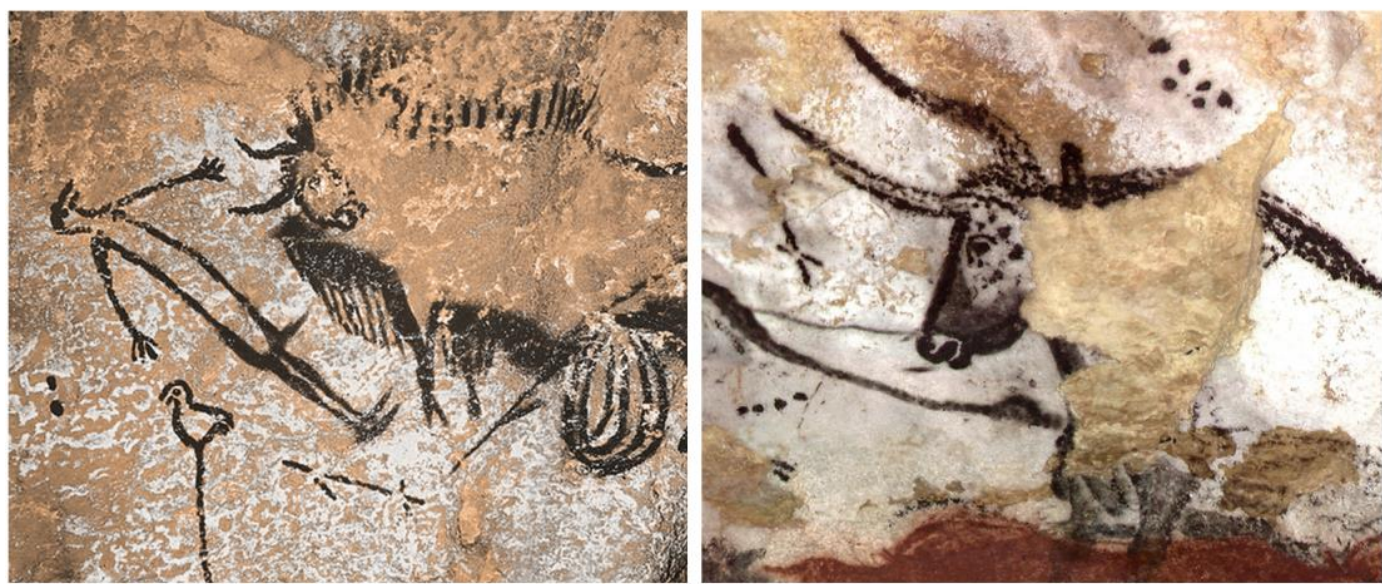

Figura 13 - Parte da câmara Shaft of the Dead Man (esquerda) e detalhe do auroque no Hall of the Bulls (direita). Elementos nas pinturas indicam a presença dos mais antigos mapas celestes já registrados nas cavernas de Lascoux. (Disponível em: <http://donsmaps.com/images25/ manbisonrhinosm.jpg> Acesso em: 20 fev. 2018)

Milênios se passaram até a invenção da escrita e a inclusão de elementos textuais integrados a estruturas gráficas. Foram encontrados artefatos com mapas que indicam representações complexas de informação, como a tabuleta em argila babilônica com escritas cuneiformes e um mapa do mundo mesopotâmico (700-500 a.C.), recuperados na região que hoje é o sul do Iraque e o mapa em papiro de Turim (1160 a.C.), registro topográfico egípcio que indica a localização de minas de ouro e prata, bem como rotas para o porto no Mar Morto (Figura 14). Eles podem ser considerados exemplos de primeiros indícios de uso de representações esquemáticas de informação e relação entre elementos visuais e texto.
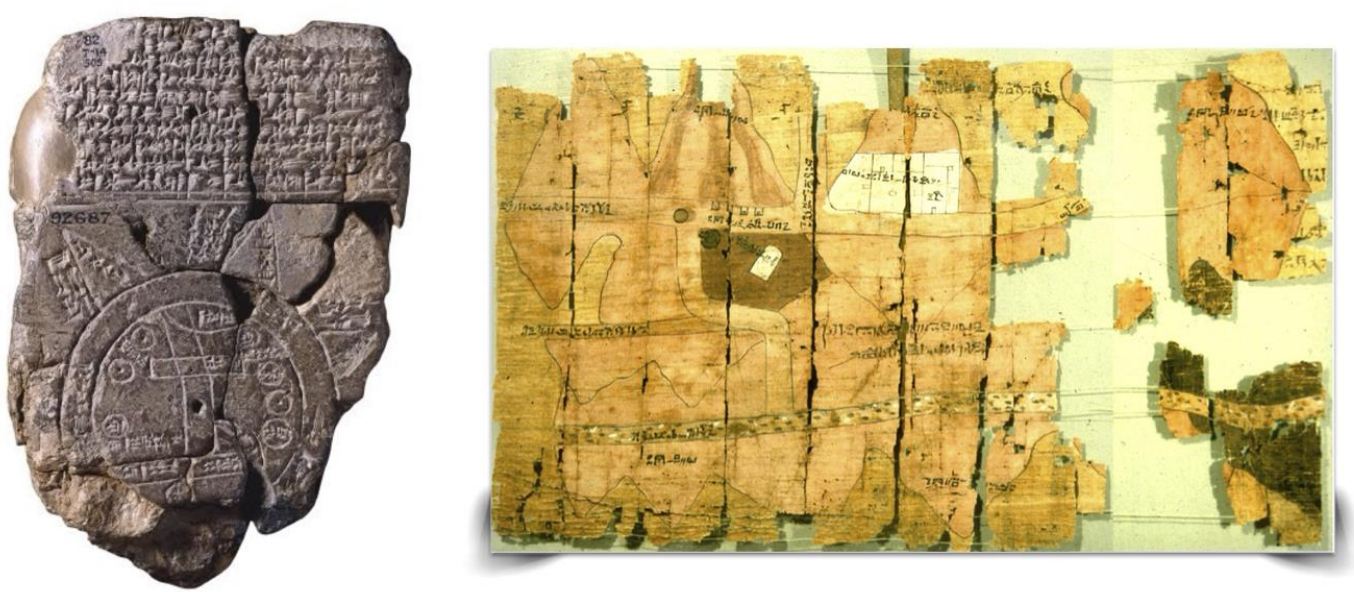

Figura 14 - (1) Mapa babilônico em tabuleta de argila (esq.) e (2) mapa egípcio em papiro (dir.). 1 - (Disponível em: <http://www.ancient.eu.com/image/526/> Acesso em: 15 mar. 2018) 
2 - (Disponível em: <http://traveltoeat.com/wp-content/uploads/2012/10/wpid-Photo-Oct-23-2012844-AM1.jpg > Acesso em: 15 mar. 2018)

O desenvolvimento da cartografia como disciplina baseia-se no fato de o cérebro humano ser naturalmente capacitado a visualizar mentalmente espaços físicos - o registro em um suporte bidimensional seria fruto de um consequente esforço de coordenação entre o cérebro e as mãos. Entretanto, a prática passou por períodos de lenta progressão ao longo dos séculos, assim como outros campos do saber. O mapa de projeção cônica equidistante meridiana, inventado por Claudius Ptolemaeus (90-168 d.C.), permaneceu sendo reproduzido como referência até o século XIV. O mapa baseia-se nas descrições do mundo conhecido pelos gregos no século II, presentes na obra Geography, de 150 d.C. Ou seja, a projeção na qual as distâncias ao longo dos meridianos (retas) e de paralelos (círculos), com escalas constantes, permaneceu viva após mais de um milênio, como pode ser observado na reprodução do século XV (Figura 15). Uma cópia da obra de Ptolomeu foi traduzida do grego para o latim, em 1407, revolucionando a forma como os cartógrafos faziam mapas medievais, dando ênfase aos cálculos matemáticos e de medições precisas no lugar de representações gráfico-visuais influenciadas pela importância dos locais. Com o estudo de obras da antiguidade, no século XVI, o Geography torna-se referência da Renascença na cartografia europeia (HARLEY e WOODWARD, 1987, p.7, tradução nossa).

Após longa estagnação, a prática da cartografia viria a dar saltos com o desenvolvimento das ciências (matemática, geometria, astronomia) e de inovações técnicas na navegação (bússola, astrolábio e caravela) (CAIRO, 2008, p.39).

Tudo confluiu na ideia de que era possível realizar um modelo em escala de qualquer região da superfície do mundo por meio de uma simplificação sistemática: a complexidade infinita da realidade ao nosso redor é reduzida a uma abstração em que os elementos não relevantes são eliminados para que aqueles que tem a ver com o propósito do mapa (convenientemente simbolizados) sejam ressaltados ${ }^{40}$ (CAIRO, 2008, p.39, tradução nossa).

\footnotetext{
${ }^{40}$ No original "Todo ello confluyó en la idea de que es posible realizar un modelo a escala de cualquier región de la superfície del mundo por medio de una simplificación sistemática: la complejidad infinita de la realidad circundante es reducida a una abstración en la que los elementos no relevantes son eliminados para que aquéllos que sí tienen que ver con el propósito del mapa (convenientemente simbolizados) sean resaltados".
} 


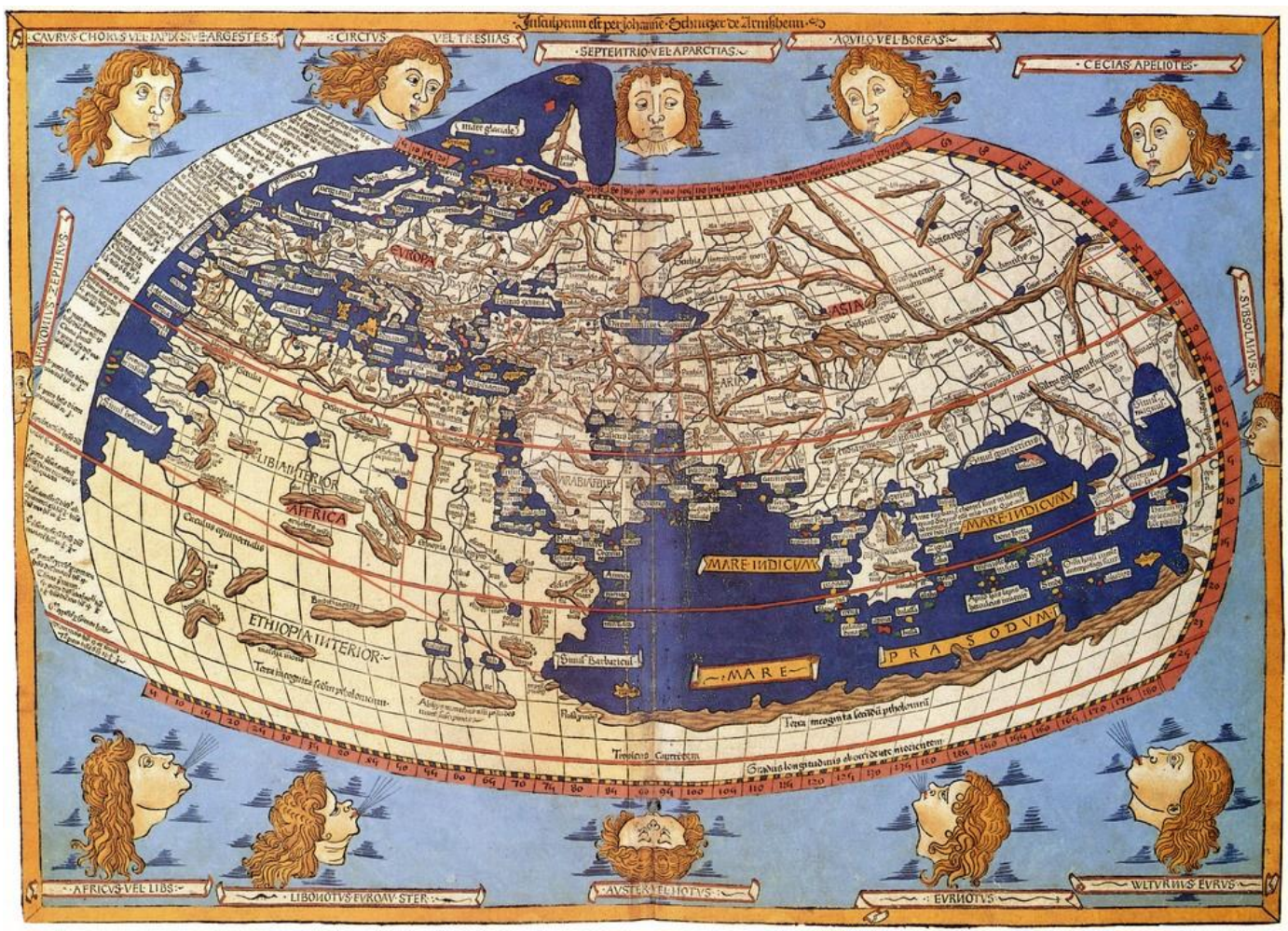

Figura 15 - Reprodução do mapa de Ptolomeu da Leinhart Holle, impressa em 1482. A aplicação de cálculos matemáticos e medidas precisas modificou a prática da cartografia medieval europeia, na qual a importância dos lugares influenciava a representação de suas dimensões. (Disponível em: < http://www.bl.uk/learning/timeline/item126360.html> Acesso em: 10 fev. 2018)

Harley e Woodward (1987, p.3) argumentam que o significado dos mapas e muito do seu sentido no passado - deriva do fato de as pessoas fazerem-nos para contar às outras pessoas sobre lugares ou espaços que tenham experimentado. Para Wurman (2000, p.157, tradução nossa), os mapas "são os meios metafóricos pelos quais podemos entender e agir de acordo informações de fontes externas ${ }^{41}$ ”, ou seja, são meios que permitem compartilhar as percepções de outrem. Vestígios de mapas encontrados de diferentes culturas manifestam a natureza abstrata, simbólica e relacional da cartografia. Nativos das Ilhas Marshall desenvolveram mapas de navegação de arquipélagos no Oceano Pacífico, com representações simbólicas para ilhas, costas e correntes marítimas (Figura 16). Peças construídas com galhos, gravetos, búzios e conchas amarradas com fibras de folhas de palmeira eram memorizadas. Esses mapas auxiliavam a navegação, permitindo viagens de aproximadamente $1.000 \mathrm{~km}$ (LYONS, 1928, p.325). Os nativos conseguiram

\footnotetext{
${ }^{41}$ No original "Maps are the metaphoric means by which we can understand and act upon information from outside sources."
} 
desenvolver abstrações da região de forma visual e tátil, complementadas por relatos orais, com associações simbólicas que substituíam as semelhanças físicas com os elementos naturais locais.
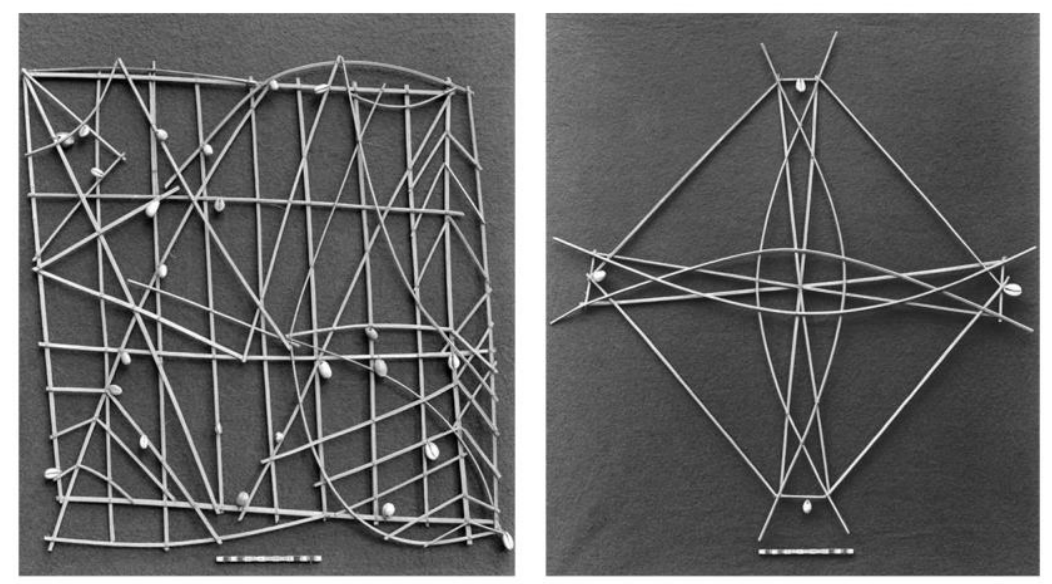

Figura 16 - Exemplares de mapas dos nativos das llhas Marshall, confeccionados com gravetos, conchas e fibras de palmeira, coletados no fim do Século XIX. (Disponível em: <http://www.lib.cam.ac.uk/collections/departments/royal-commonwealth-society/collections/marshal I-island-sailing-charts> Acesso em: 15 jun. 2016)

Sob influência do Iluminismo, no século XVIII, desponta a vontade de tentar compreender o mundo por meio da razão e pela quantificação das observações, essência do método científico de Descartes (CAIRO, 2008, p.41). Deriva desse pensamento uma nova categoria cartográfica: a cartografia temática. O mapeamento das mortes ocasionadas por um surto de cólera em Londres, feito pelo Dr. John Snow (Figura 17), em setembro de 1854 (TUFTE, 2011, p.24), é um exemplo desse novo ramo. Analisando o padrão formado pelos pontos escuros espalhados no mapa (cada ponto representava um óbito), foi possível notar a proximidade de um grande número das ocorrências com uma determinada estação de água. Não se sabia como o cólera se disseminava, se pelo ar, pelo contato físico ou por alimentos, por exemplo. O Dr. Snow levou os investigadores a uma associação entre mortes e a estação de água. $\mathrm{O}$ conhecimento originado pelo mapa levou à interrupção da distribuição de água da estação contaminada, encerrando o surto de forma eficaz. 


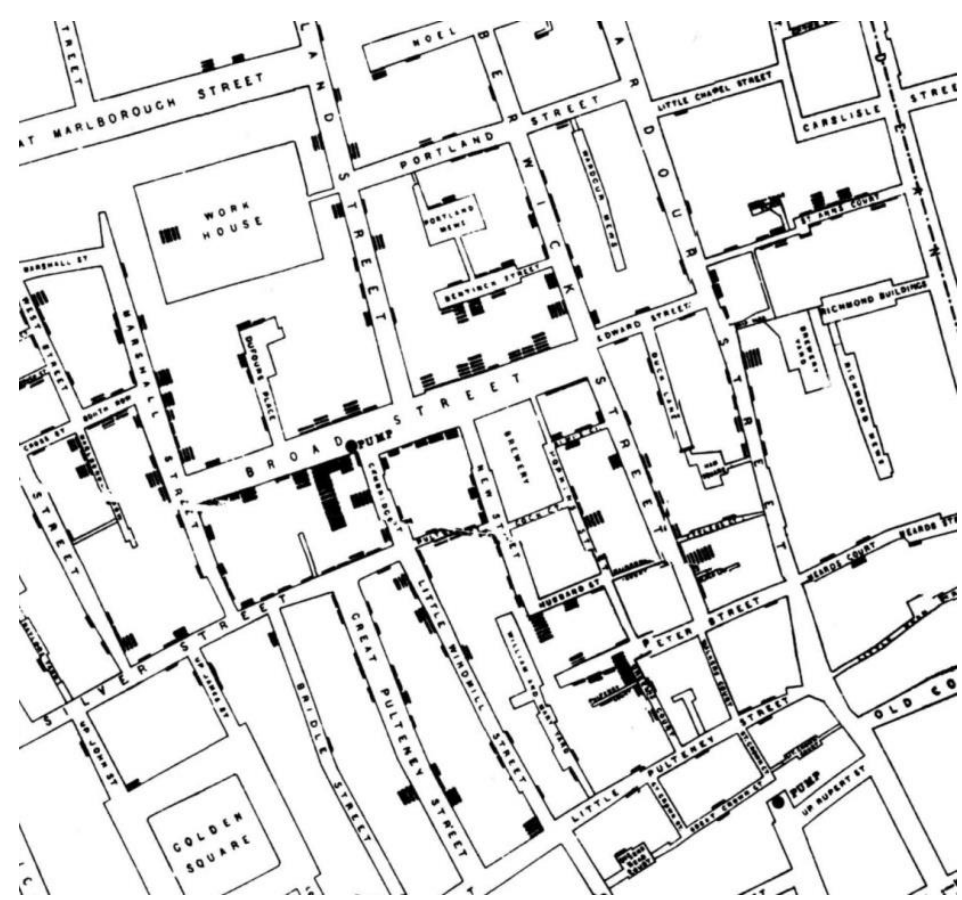

Figura 17 - Mapeamento do surto de cólera em Londres realizado pelo Dr. John Snow, 1854. Fonte: TUFTE (2011, p.24).

As representações visuais em diagramas estatísticos, originadas no início do século XIX, também contribuíram com o desenvolvimento das visualizações de dados tal como se conhece hoje. Para Michael Friendly e Daniel J. Denis, pesquisadores da Universidade do Canadá responsáveis pela cronologia Milestones in the History of Thematic Cartography, Statistical Graphics, and Data Visualization, de 2001, o nascimento do pensamento estatístico foi acompanhando pelo progresso de um "pensamento visual". Diagramas foram usados para ilustrar provas matemáticas e funções, bem como diversos gráficos foram inventados para comunicar mais facilmente e ressaltar propriedades de números empíricos, tais como distribuições e tendências. Para Friendly e Denis (2001), a "Era de ouro" dos gráficos estatísticos ocorreu no período entre 1850 e 1899. As condições para um rápido crescimento das visualizações de dados haviam sido estabelecidas com o reconhecimento da importância de dados numéricos para a industrialização, o transporte, o comércio e o planejamento social. Escritórios oficiais de estatística se estabeleceram na Europa e "a teoria estatística, iniciada por Gauss e Laplace e estendida ao campo social por Guerry (1833) e Quetelet (1831), forneceu os meios para dar sentido a grandes conjuntos de dados" (FRIENDLY e DENIS, 2001). 
O engenheiro, matemático e economista escocês William Playfair foi o autor do The Commercial and Political Atlas, em 1789, e do Statistical Breviary, de 1801, livros que contêm os primeiros exemplos publicados dos tipos mais comuns de gráficos estatísticos. Playfair preferia os gráficos às tabelas porque eles mostravam a forma dos dados em uma perspectiva comparativa (TUFTE, 2011, p.32). O engenheiro introduz fundamentos de design gráfico na visualização de dados com representações visuais esquemáticas, trazendo novidades à forma de se construir conhecimento a partir de dados que não eram percebidos por meio de análise bruta. De acordo com Tufte, ao longo do tempo, Playfair eliminou elementos que não fossem dados relevantes, em favor de um design mais limpo (Figura 18). O princípio "acima de tudo, mostre os dados"42 (TUFTE, 2011, p.92, tradução nossa) estabelece uma base para uma teoria dos gráficos de dados:

[Nos gráficos] as tendências, diferenças e associações se percebem em um piscar de olhos. O olho percebe de forma instantânea o que o cérebro levaria segundos ou minutos inferindo a partir de uma tabela de números... Gráficos permitem que os números falem com todos... não há outra forma de comunicação humana que mereça de forma mais apropriada ser chamada de linguagem universal (PLAYFAIR apud CAIRO, 2008, p.43 tradução nossa).

No Statistical Breviary, mais especificamente na página 48, Playfair apresenta três tipos novos de diagramas estatísticos: os gráficos de pizza, os gráficos circulares e gráficos similares a diagramas de Venn, que usam curvas fechadas e suas relações para simbolizar relações entre conjuntos (Figura 19). Além de introduzir essas inovações, de acordo com Spence e Wainer (2005, p.227), o gráfico com dados sobre as principais nações na Europa é especial pois provê dados sobre o tamanho físico de cada país, o tamanho de sua população, sua carga de impostos e como eles interagem, de forma engenhosa, em apenas uma visualização.

${ }^{42}$ No original "Above all else show the data". 


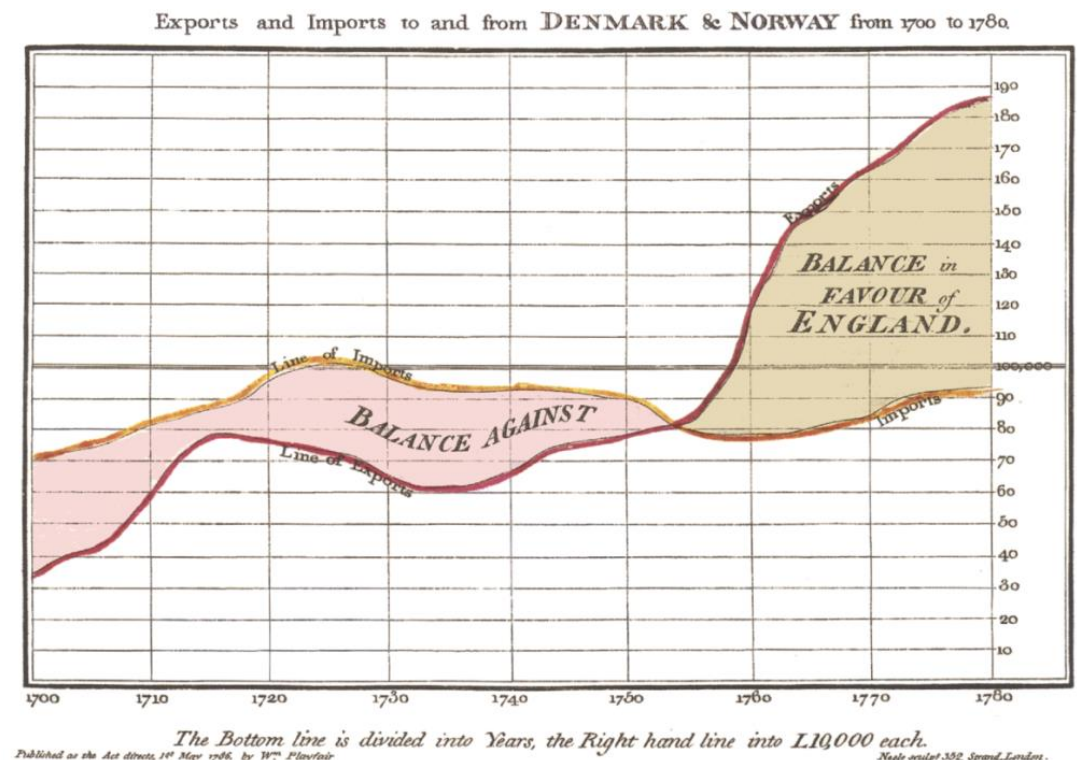

Figura 18 - Representações visuais esquemáticas no lugar de tabelas, William Playfair, Londres, 1786. Fonte: TUFTE (2011, p.92).

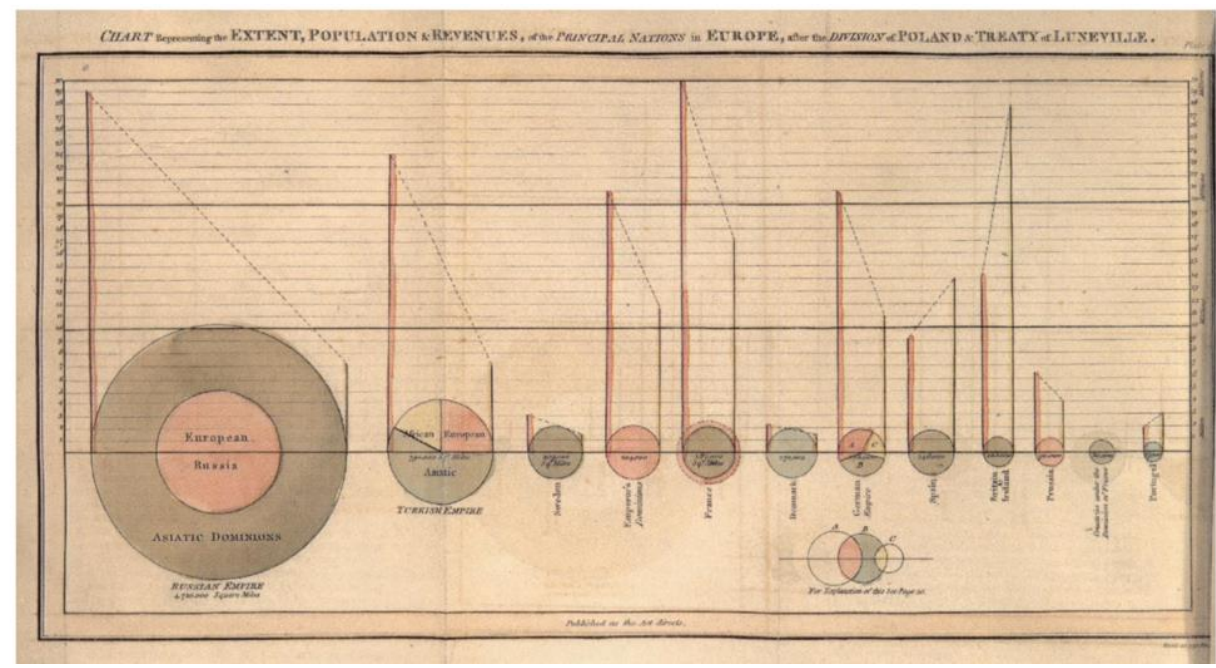

Figura 19 - Gráfico multivariado Principal Nations of Europe, da página 48 do Statistical Breviary, de William Playfair, contendo a primeira aparição de gráficos pizza, dentre outras inovações. Fonte: SPENCE e WAINER (2005, p. 227).

Apesar de Playfair ter publicado, em 1801, o gráfico circular, também conhecido como gráfico polar, a popularização desse tipo de representação ocorreu por meio dos gráficos de Florence Nightingale, em 1857. A enfermeira britânica foi uma das pioneiras no uso de métodos de representação visual de informações e criou gráficos que indicavam que o número de mortes de soldados provocadas por doença era maior que o de derivadas dos combates nas frentes de batalha da guerra 
da Criméia (Figura 20). Nos gráficos setoriais de Nightingale estão indicadas as mortes a cada mês, em que o azul representa as mortes ocasionadas por doenças, o vermelho indica mortes por ferimentos de combate e o preto a morte por outras razões. Percebe-se, claramente, o volume superior de mortes por doença em relação às demais causas. Esses dados foram usados para a melhoria das condições sanitárias no exército, aprimorando a higiene nos hospitais de campanha e casernas. Dada a importância e a popularidade desses gráficos, alguns autores atribuem, de forma equivocada, a invenção dos gráficos setoriais a Nightingale.

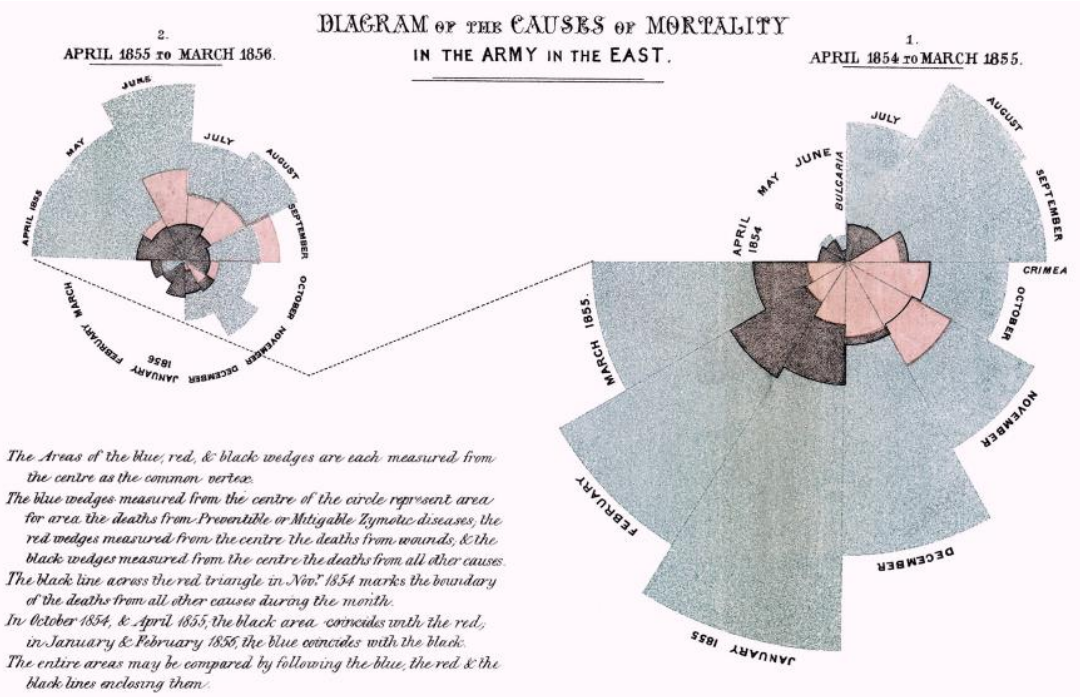

Figura 20 - Diagrama das causas de mortalidade do exército britânico desenvolvido por Florence Nightingale, em 1857, que popularizou os gráficos setoriais e auxiliou a melhorar as condições sanitárias dos soldados. (Disponível em: <https://www.smithsonianmag.com/history/surprisinghistory-infographic-180959563/>. Acessado em: 12 dez. 2017)

O gráfico sobre a campanha de Napoleão na Rússia, de Charles Joseph Minard (1781-1870) foi responsável por uma das grandes referências para a evolução da infografia (Figura 21). Elaborado em 1869, o gráfico envolve informações quantitativas sobre tempo e espaço. Nota-se as perdas dos soldados de Napoleão durante a campanha de 1812. A linha grossa que se inicia à esquerda, na Polônia, representa a quantidade de componentes da tropa. De acordo com o avanço da campanha pelo território russo até Moscou, a linha se estreita, indicando as mortes ao longo do trajeto. Há também marcações sobre o período do ano e a temperatura em cada marco, mostrando a influência do tempo e do clima no exército francês em movimento. Para George Rorick, criador dos gráficos do tempo do USA 
Today, ao selecionar esse infográfico como o mais importante da história, descreveo como sendo "um mapa, uma linha do tempo, um gráfico e uma ilustração, tudo em um" (MALOFIEJ, 2002, p.48).

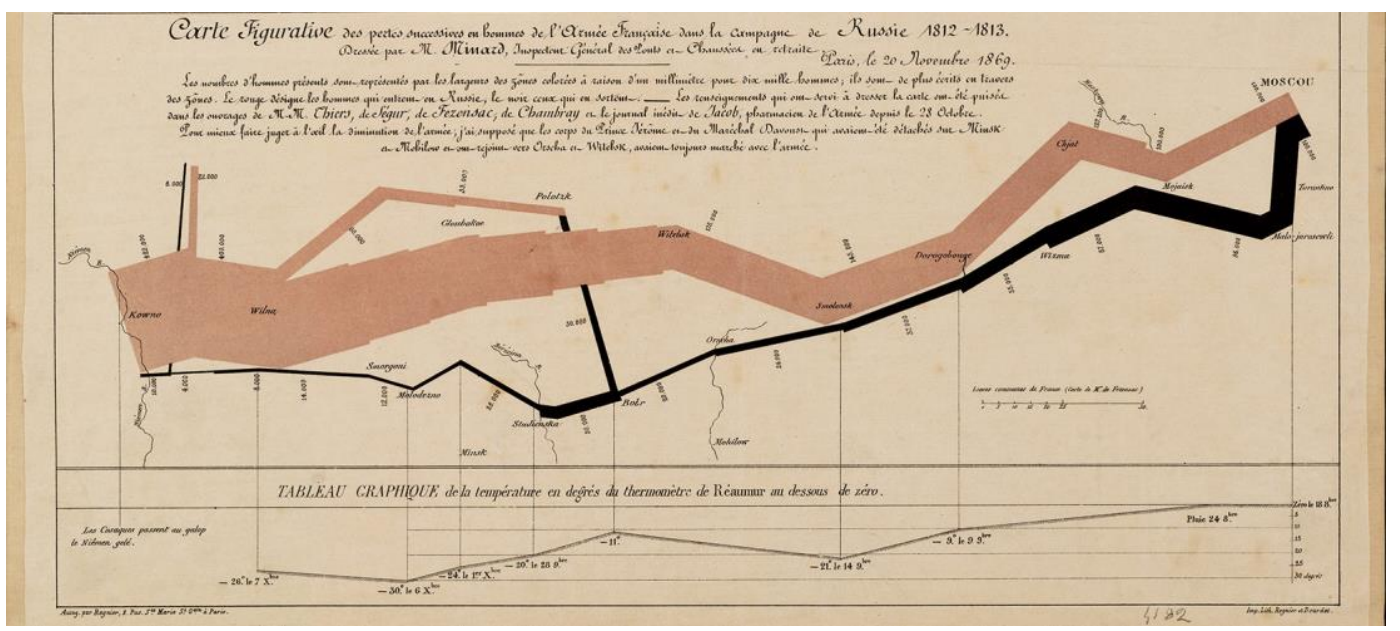

Figura 21 - Infográfico sobre a marcha de Napoleão na Rússia, Charles Joseph Minard, 1869. (Disponível em: < https://news.nationalgeographic.com/2017/03/charles-minard-cartographyinfographics-history/>. Acessado em: 16 dez. 2018)

O período posterior à "era de ouro" das visualizações, no início do século XX, foi marcado pela ausência de inovações gráficas. No entanto, houve uma popularização no uso de gráficos estatísticos, com o estabelecimento de padrões e modelos formais nas instituições, nos governos, no comércio e na ciência. Se a criatividade não se destacou no período entre 1900 e 1949, batizado como Modern Dark Ages das visualizações de dados (FRIENDLY e DENIS, 2001), a difusão e uso dos gráficos estatísticos auxiliou descobertas e teorias em astronomia, física, biologia e outras ciências. Um dos destaques da época é o mapa do metrô de Londres, confeccionado por Harry Beck, em 1933 (Figura 22). Desenhado como uma placa de circuito elétrico, usando linhas verticais, horizontais e em $45^{\circ}$, ainda permanece como padrão dos mapas do metrô londrino e influencia diversos sistemas de transporte ao redor do mundo. Apesar de não ser preciso geograficamente, desvinculando o design dos trajetos da topografia local, o mapa agiliza o processo de encontrar rotas desejadas entre as estações. 


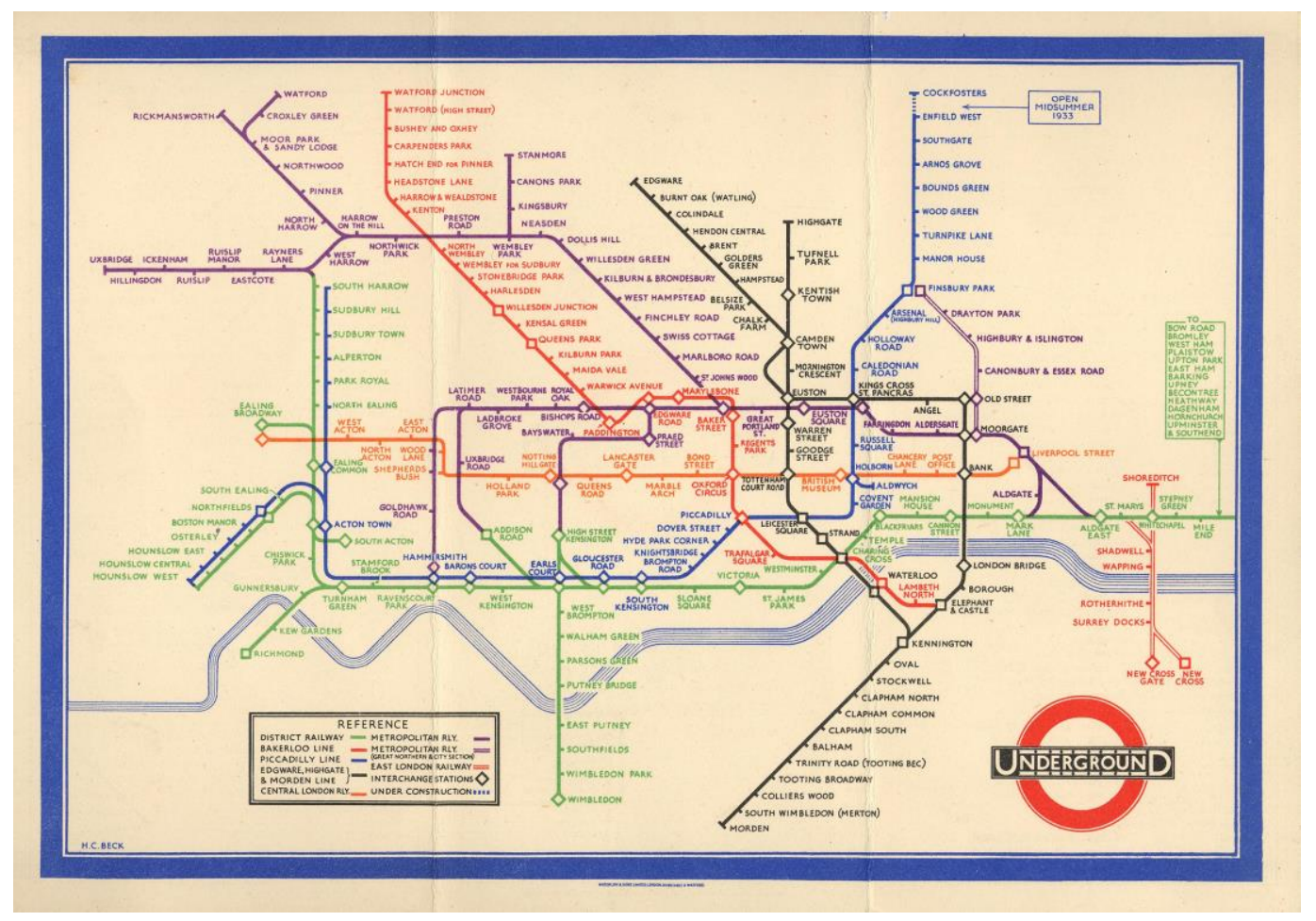

Figura 22 - Clássico mapa do metrô de Londres realizado por Harry Beck, em 1933. (Disponível em: <http://www.twohundredby200.co.uk/london-tube-map-designer-honoured/> Acesso em: 19 jun. 2016)

Em meados do século XX, de acordo com Friendly e Denis (2001), as inovações gráficas estavam à espera de novas ideias e tecnologias. A nova onda de desenvolvimento das visualizações de dados seria subsidiada pelo processamento por computadores, pelo reconhecimento da importância da análise gráfica de dados e pela publicação da teoria da Semiologia Gráfica, de Jacques Bertin, em 1967.

\subsection{2. \\ llustração científica}

O surgimento da imprensa com caracteres móveis, em meados do século XV, propiciou o desenvolvimento das ciências naturais. Eliminaram-se o acúmulo de erros derivados das cópias manuais dos copistas medievais nos textos e nas figuras por meio da tipografia e da gravura. Dessa forma, foi possível manter o rigor e a credibilidade das imagens, que não mais sofriam de deformações cumulativas excessivas. Paralelamente ao aumento na precisão das cópias, houve uma redução de custos e a rapidez na produção dos impressos, facilitando a divulgação científica por meio de imagens. 
Até a Renascença, os tratados de anatomia humana baseados em observações de Claudio Galeno (129-209) influenciaram a medicina. No entanto, nesse período, houve um desenvolvimento nos estudos anatômicos a partir da disseminação da prática de dissecação de corpos, mesmo com a enfática proibição dessa atividade por parte da Igreja. Um dos expoentes do Renascimento, Leonardo de Ser Piero da Vinci (1452-1519), realizou diversos desenhos minuciosos, combinando-os com textos complementares, em que o poder descritivo de um era reforçado pelo outro (Figura 23). A observação sistemática de seus temas, com a tentativa de representálos com maior fidelidade visual possível e com anotações descritivas detalhadas, tornaram-no referência no campo da ilustração científica.
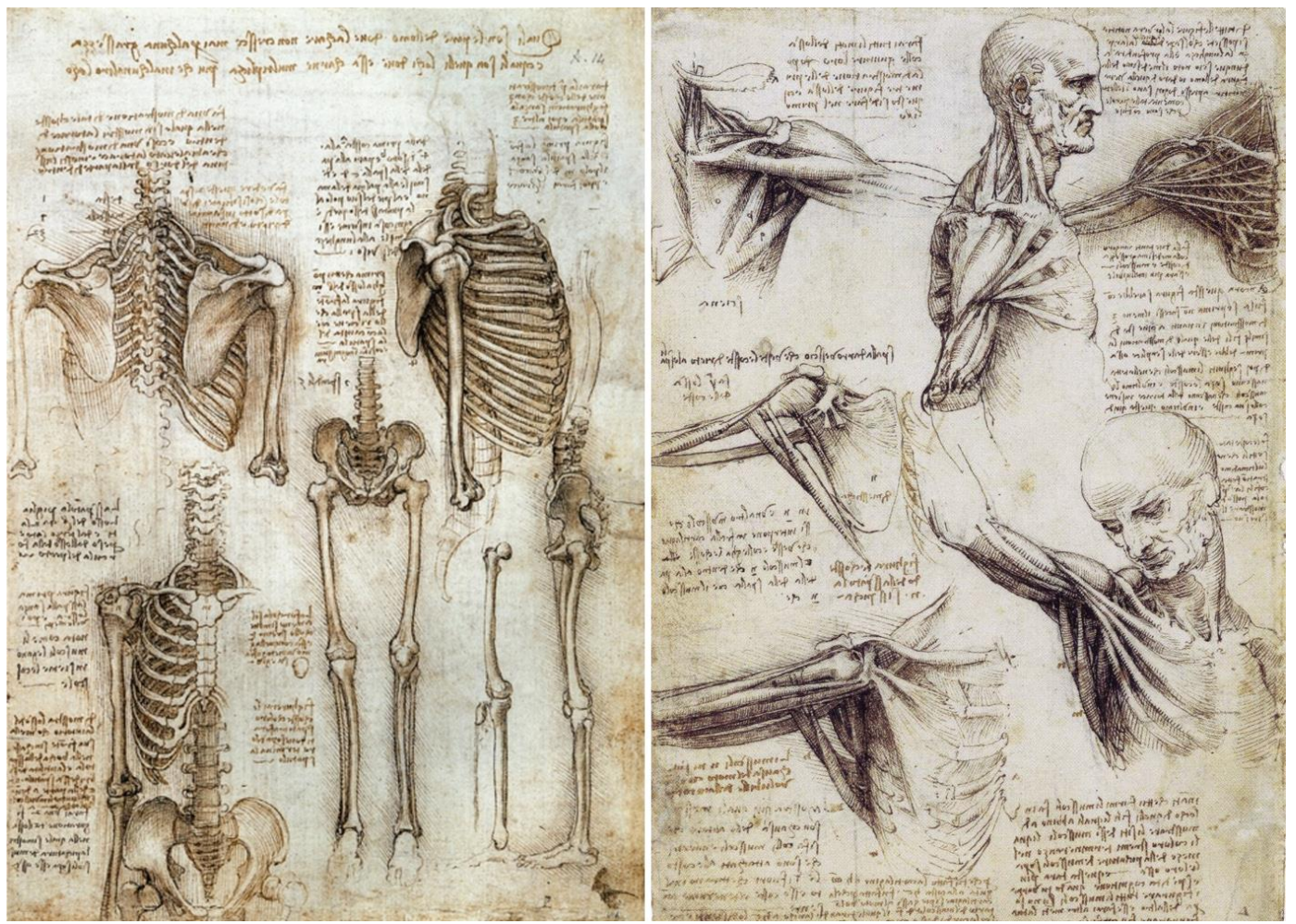

Figura 23 - Studies of the Shoulder and Neck, Leonardo da Vinci, 1509-1510. (Disponível em: <http://www.drawingsofleonardo.org> Acesso em: 17 jun. 2016)

O cânone das proporções do corpo humano descritos pelo arquiteto romano Marcos Vitrúvio Polião (80-15 a.C.), na obra De Architectura, de aproximadamente 27 a 16 a.C., foi usado por diversos artistas renascentistas como exemplo do ideal clássico de beleza. Assim como Leonardo da Vinci, Albrecht Dürer (1471-1528) aprofundou-se nos estudos dos sistemas de proporções da anatomia humana. Ambos os artistas desenvolveram esquemas que se baseiam nos conceitos de 
Vitrúvio, em que se observam suas proporções no homem inscrito em um quadrado e com os membros estendidos inscritos em um círculo, no qual o centro do quadrado se localiza no púbis e o do círculo se aproxima ao umbigo (KEELE, 2014, p.251). Exemplos de trabalhos publicados podem ser vistos nas ilustrações de Da Vinci para o livro do matemático Luca Pacioli, Da divina proportione, em 1509, e os experimentos desenvolvidos por Dürer na obra Vier Bücher von menschlicher Proportion, publicada em 1528, poucos meses após sua morte. Ao observarmos lado a lado o Homem Vitruviano de Da Vinci, de 1490, e o Homem inscrito em um círculo, de Dürer, de 1521, excluindo-se as proporções faciais, é possível notar a semelhança estrutural das ilustrações e os esquemas sobrepostos (Figura 24). De acordo com Elam (2014, p.15) "quando comparamos esses desenhos com a ajuda de sobreposições transparentes, constatamos que ambos refletem as proporções vitruvianas e são, na verdade, quase idênticos". Os desenhos esquemáticos são um exemplo de que a ilustração científica não se refere especificamente a um desenho hiper-realista; trata-se de uma ferramenta visual com enfoque na precisão da informação.
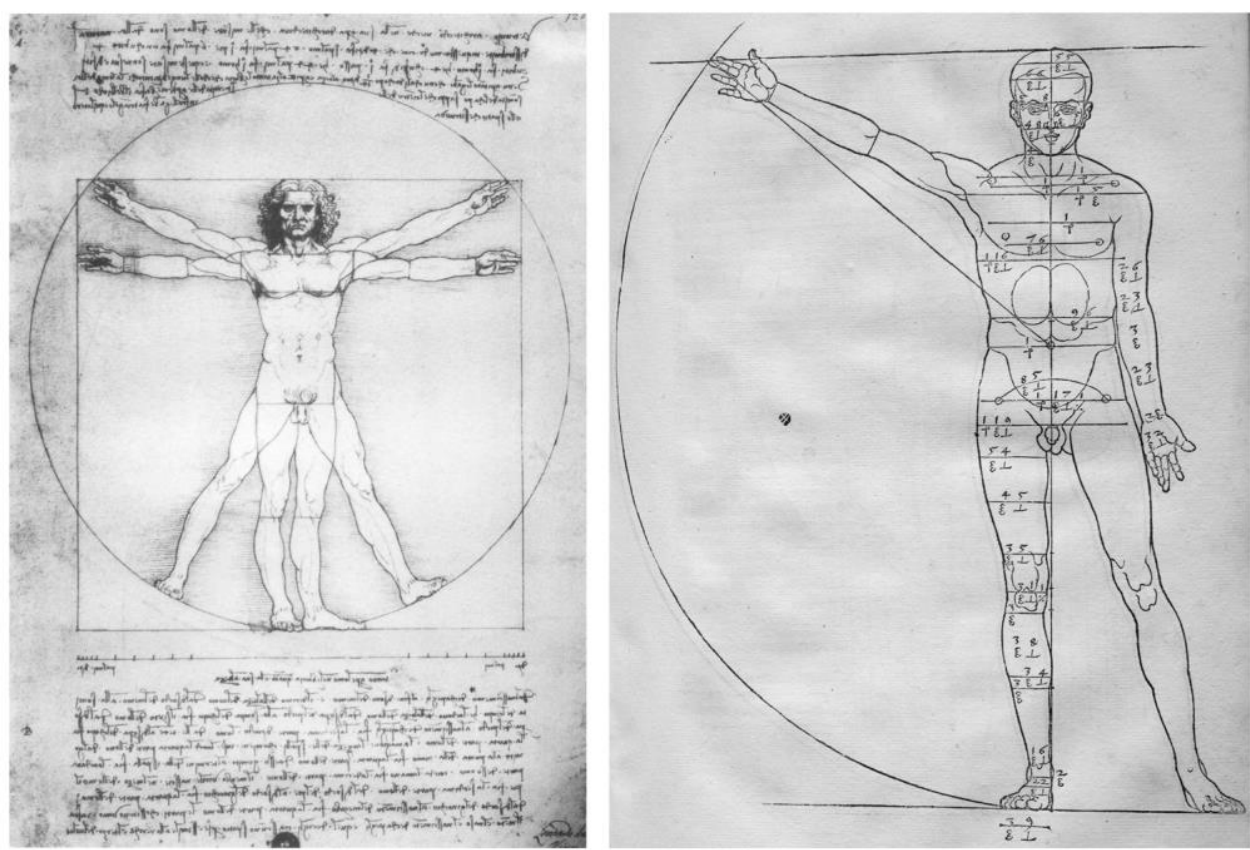

Figura 24 - Reproduções do Vitruvian Man, de Leonardo da Vinci, de 1490 (à esq.) (Disponível em: <http://www.drawingsofleonardo.org> Acesso em: 10 ago. 2017) e do Homem inscrito em um círculo, no Vier Bücher von menschlicher Proportion, de Albrecht Dürer, de 1528 (à dir.) (Disponível em: <https://brbl-dl.library.yale.edu/vufind/Record/3783330> Acesso em: 15 ago. 2017)

Finalmente corrigindo erros presentes em clássicos de referência anteriores, o médico belga Andreas Versalius (1514-1564) desenvolveu o tratado de anatomia 
De humani corporis fabrica (Figura 25), publicado em 1543. Cabe destacar que nos volumes de Versalius, os textos que acompanhavam as ilustrações tinham uma relevância secundária, pois o destaque da obra é o detalhamento artístico preciso, presumidamente realizado pelos artistas no momento de dissecações de cadáveres. O atlas do corpo humano confeccionado por Versalius é dividido em sete partes: ossos, músculos, sistema circulatório, sistema nervoso, abdômen, coração e pulmões e cérebro, todas com ilustrações detalhadas e descrições textuais. As imagens presentes no De humani corporis fabrica servem, até os dias de hoje, como referência para o trabalho da ilustração científica. De humani corporis fabrica, ou Fabrica, como é conhecido, demonstra como a ilustração tem sido, desde o Renascimento, um notável instrumento para a ciência (CAIRO, 2008, p.49).
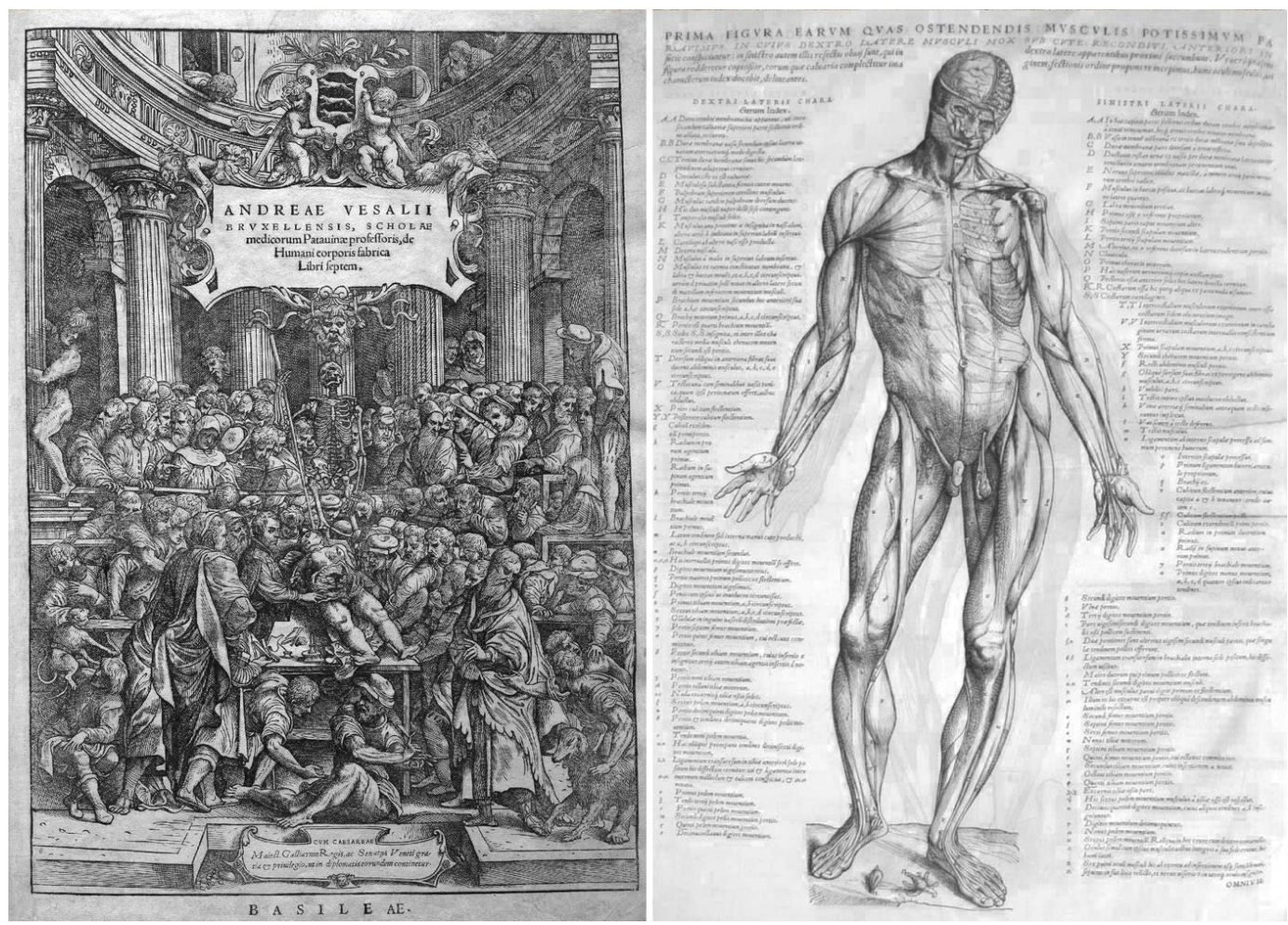

Figura 25 - Capa e exemplo do tratado anatômico De humani corporis fabrica, Andreas Versalis, 1543. (Disponível em: <http://commons.wikimedia.org/wiki/File:Vesalius_Fabrica_fronticepiece.jpg> Acesso em: 19 jun. 2016)

\subsection{3.}

\section{Jornalismo impresso}

As primeiras aparições de peças que viriam a ser precursoras de infográficos na imprensa só foram possíveis a partir dos avanços técnicos na indústria gráfica. 
Elas surgiram por meio de mapas que ilustravam notícias, reduzindo a necessidade de se descrever textualmente os detalhes do terreno ou os acontecimentos em questão. De acordo com Cairo (2008, p.50), era possível identificar a falta de formação cartográfica por parte dos autores. O papel dessas ilustrações era cativar o leitor, chamar a sua atenção em um grau superior ao objetivo de informar precisamente. Por ser hierarquicamente inferior ao texto, aparentemente não demandava a mesma precisão em relação aos fatos. Assim, os gráficos informativos nos jornais surgem mais como arte que como jornalismo. Segundo afirmado por Peltzer:

[...] a informação gráfica apareceu na imprensa praticamente com os primeiros jornais, mas sempre foi considerada mais como uma arte decorativa, ou como simples complemento da informação textual do que como informação em si mesma (PELTZER, 1992, p.75).

Em meio a autores que se debruçaram em investigar o surgimento da infografia, é comum observar a menção ao gráfico impresso no britânico The Times, em abril de 1806 (Figura 26). Ele foi publicado na capa do jornal, descrevendo como ocorreu o assassinato de Isaac Blight. O artigo exibe os planos da casa, os passos do assassino, a trajetória da bala e o local onde o corpo foi encontrado, explicando-os com associação entre texto e imagem diagramática (PELTZER, 1992, p.21). É reconhecido por muitos como um dos primeiros infográficos ou diagramas informativos publicados em um meio de comunicação.

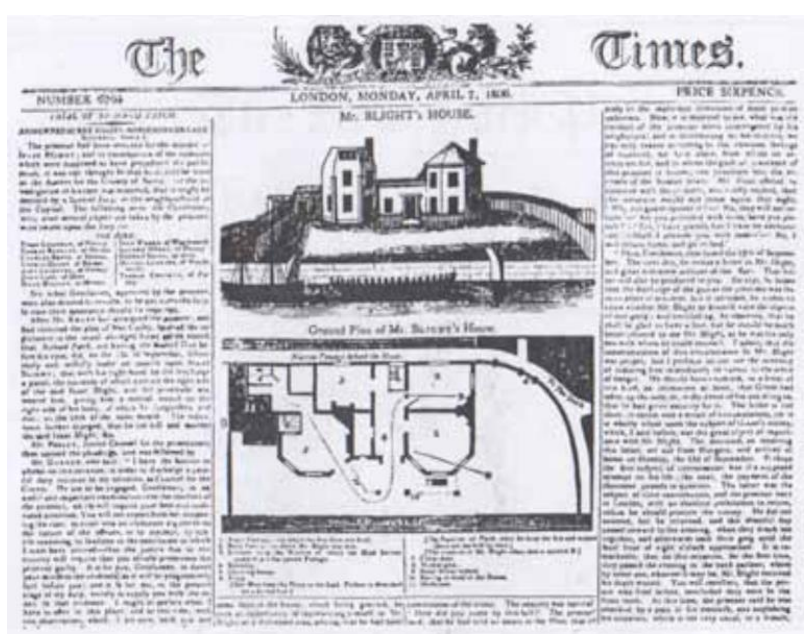

Figura 26 - Capa do The Times com um dos primeiros infográficos publicados em jornal, edição de 7 de abril de 1806. Fonte: SKIRBEKK (2011, p.16). 
Ao longo de um século e meio as características gerais dos gráficos informativos permaneceram similares. Mudanças socioeconômicas e políticas tornaram os jornais diários atores fundamentais na difusão de informações na sociedade moderna. $\mathrm{O}$ aumento da população urbana, das taxas de alfabetização, da quantidade de eleitores, bem como o impacto no cotidiano ocasionado por duas guerras mundiais foram preponderantes para a evolução indústria jornalística. Aliado a evoluções técnicas, com aumento da tiragem e redução de custo por exemplar, o jornal sofreu mudanças significativas após um longo período de suposta estagnação. De uma forma sucinta, é possível notar, a partir de capas de períodos distintos do jornal The Guardian (1821, 1972 e 2012), a redução da quantidade de texto por chamada de notícia, aumento da área dedicada a imagens, redução do número de destaques na capa e aprimoramento visual-estético conforme a tecnologia de produção com o passar do tempo (Figura 27).
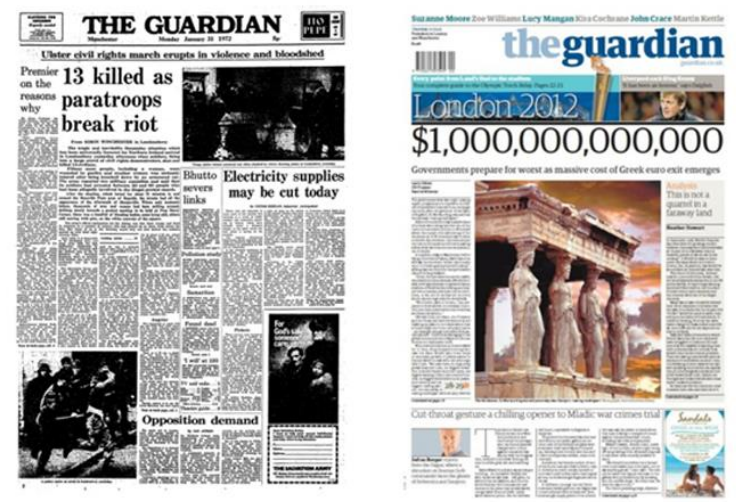

Figura 27 - Capas do jornal Londrino The Guardian em diferentes épocas 1821, 1972 e 2012. (Disponível em: <http://guardian.newspaperdirect.com/epaper/viewer.aspx>. Acesso em: 14 jun. 2016)

A competição com a TV foi um importante fator de influência no jornalismo impresso. O surgimento do diário USA Today, em 1982, revolucionou o jornalismo mundial - sendo ele frequentemente citado como o primeiro jornal a fazer alterações em seu conteúdo de forma a se orientar a um leitor com menos tempo para dedicar à leitura de um jornal tradicional. O jornal passava a ser visto, além de lido. Seus artigos eram curtos, com conteúdo conciso; buscou-se uma diagramação dinâmica, diferenciando-o dos demais jornais. Segundo Lupton (1993, p.226, tradução nossa) "a substituição do discurso linear por hieroglifos visuais e verbais na mídia noticiosa é exemplificada pelo jornal USA Today, que privilegia 
ilustrações sobre texto e serve seus artigos em porções de tamanho de TV ${ }^{43}$ ”. De acordo com Moraes:

Colorido e repleto de imagens, o USA Today contrastava com o cinza então característico de seus pares, um símbolo da sobriedade inerente ao papel cívico dos jornais. Além disso, seus textos curtos e objetivos o aproximavam mais da TV que de seus pares, predominantemente dissertativos (MORAES, 2013, p.31).

Dentre diversas inovações implementadas pelo USA Today, constantemente o associamos à plataforma do surgimento do "mapa do tempo" colorido, de George Rorick (Figura 28). Cairo (2008, p.52) afirma que esse mapa é "uma das infografias jornalísticas mais imitadas de todos os tempos", enquanto Jeff Goertzen o considera o melhor infográfico da história, corroborando com Cairo no sentido de que tenha sido "o mais copiado por periódicos e emissoras de televisão" (MALOFIEJ, 2002, p.39).
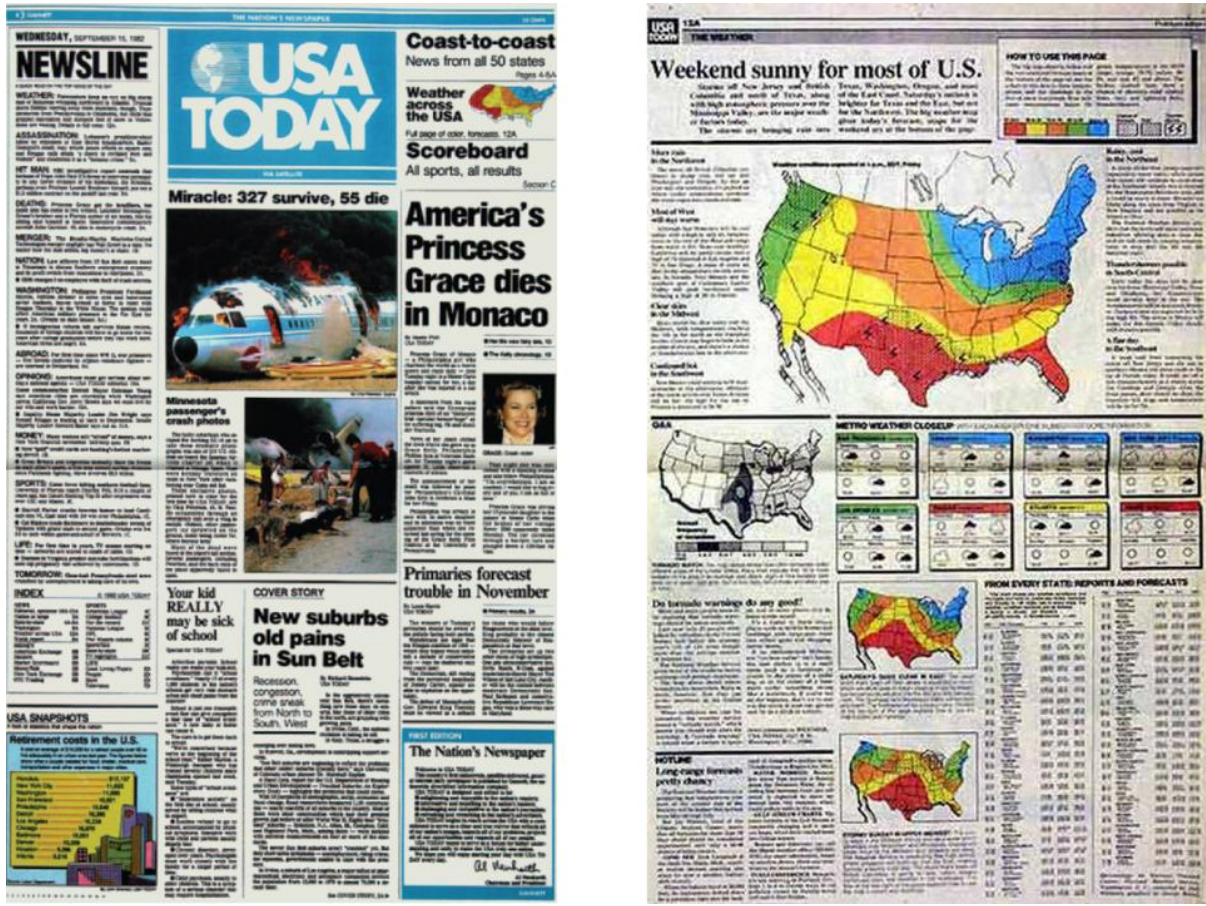

Figura 28 - Capa e mapa colorido do clima nos EUA, de George Rorick, no USA Today em 1982. (Disponível em: <http://datavis.ca/milestones//admin/uploads/images/rorick1982-weathermaplg.jpg> Acesso em: 14 jun. 2016)

${ }^{43}$ No original "The replacement of linear discourse with visual and verbal hieroglyphs in the news media is exemplified by the newspaper USA Today, which favors illustrations over text and serves up its articles in TV-sized portions." 
Ficou claro o impacto causado pela busca de uma intensificação do apelo visual de suas páginas. Regularmente, o USA Today recebe a alcunha de ter sido responsável pelo surgimento dos infográficos nos jornais e outras inovações. Apesar das notáveis experimentações, é necessário frisar que outros jornais e veículos como a Time e Newsweek, anteriores ao ano de lançamento do USA Today, já faziam uso de diversos elementos nele explorados. Segundo apontado por Moraes

As edições do anuário com as melhores peças de design de jornais organizados pela Society for News Design (SND) publicadas entre 1978 e 1982... já atestam o uso de ilustrações coloridas em grandes dimensões, o emprego da tipografia fora dos limites da hierarquização tão característicos do meio jornal, ou ainda o uso de infográficos, o que derruba a tese de que estes teriam surgido com o USA Today (MORAES, 2013, p.31).

O diário USA Today é reconhecido pelo uso de diversas novas tecnologias em meio jornalístico, com inovações tanto técnicas, quanto conceituais. No entanto, também foi um grande responsável pela associação da infografia à arte em primeiro lugar, e não à informação jornalística. O conceito de infográfico como elemento prioritariamente estetizante, com o intuito de chamar atenção, vender e entreter, diminuía a impressão geral de sua importância como veículo informativo.

A década de 1980 foi um período inovador de informatização nas redações. O surgimento das interfaces gráficas (Graphical User Interface ou GUI) no Macintosh, da Apple (Figura 29), em 1984, foi um ponto chave do desenvolvimento tecnológico nas editorias. Derivados do projeto desenvolvido na Xerox Palo Alto Reseach Center (Xerox PARC), os aplicativos permitiram uma nova relação entre os indivíduos e as visualizações de dados por meio da informática (FEW, 2009, p.16). Os softwares para criação de peças gráficas, como o QuarkXPress, permitiam a visualização do layout instantaneamente. Assim, acelerou-se o processo de produção de mapas, diagramas, infográficos e da editoração em si. Ao longo da década, os sistemas de produção espaçosos e extremamente caros, em termos comparativos, foram sendo substituidos - bem como ferramentas e métodos de produção praticamente artesanais com o uso de réguas, decalques em letraset, facas olfa, dentre outros materiais. Além disso, as interfaces com metáforas visuais tornaram a interação com os computadores uma tarefa mais amigável que a digitação de linhas de comando de sistemas anteriores. 


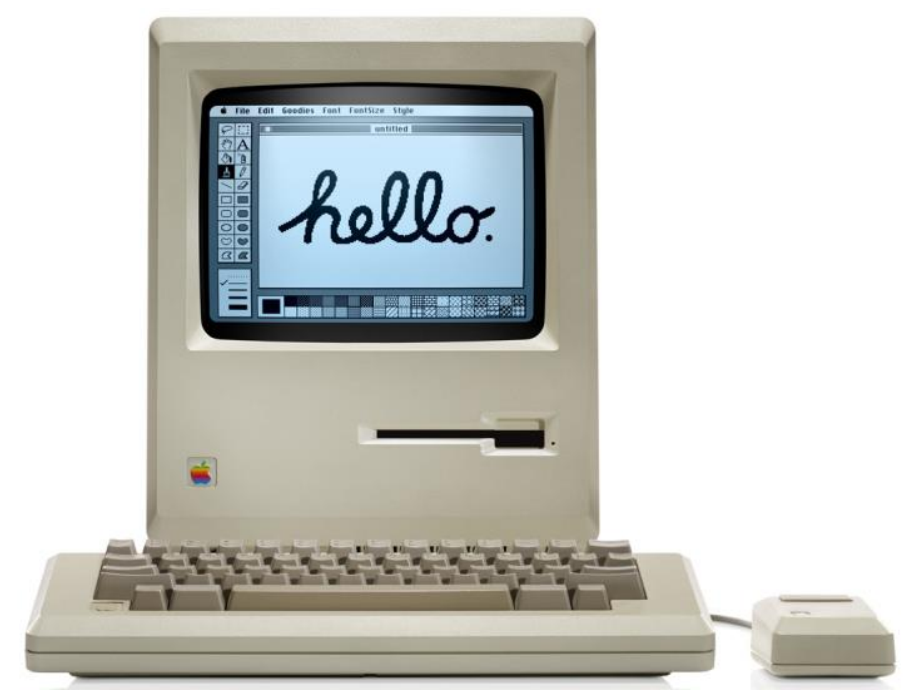

Figura 29 - A interface gráfica e o Macintosh agilizam e reduzem custos no processo de produção na década de 1980. Fonte: Divulgação/Apple.

Apesar dos avanços promovidos pela informática, foi durante a cobertura da Guerra do Golfo, em 1991, que se pôs à prova todo o desenvolvimento técnico dos anos anteriores. O combate foi um momento marcante para a evolução do uso da linguagem infográfica nos jornais e revistas, nos quais se expandiram os limites conceituais e construtivos da infografia existentes até então. O conflito era transmitido pela TV dia e noite ${ }^{44}$, quase em tempo real, por meio de imagens a distância, terrestres ou aéreas. A escassez de repórteres e fotógrafos de campo com capacidade de registrar as mazelas da guerra in loco geravam, propositalmente, imagens a distância que reforçam a impressão de uma guerra "limpa". Coube, então, a jornais e revistas detalhar procedimentos, providenciar explicações técnicas sobre equipamentos, mostrar movimentos de tropas pelos mapas, relatar ataques aéreos, elucidar o funcionamento de aviões, tanques e bombas inteligentes, dentre outros assuntos (Figura 30). Os veículos de informação impressos encontraram na infografia um meio apropriado de publicação, dada a falta de imagens fotográficas relevantes e coberturas de histórias no front. Essa realidade corrobora com De Pablos (1992, p.271, tradução nossa), que afirma que "quando não há fotografia, há ou pode haver infográficos", ou seja, que "de fato, quando não há documento

${ }^{44}$ A cobertura do conflito alavancou o estilo de jornalismo $24 \mathrm{~h}$ realizado pela rede de TV americana CNN. Mesmo após a ordem de retirada dos jornalistas de Bagdá, antes do bombardeio inicial, equipes de reportagem da emissora permaneceram no hotel al-Rashid, na capital. O material produzido e transmitido ao vivo por jornalistas como Peter Arnett, Bernard Shawn e John Holliman deu ao canal vasto conteúdo exclusivo, que as três grandes redes ABC, CBS e NBC não obtiveram. 
gráfico analógico, pode haver infografia para explicar as causas do evento ${ }^{45}$ ". Assim, a infografia ocupou um bom espaço nos veículos jornalísticos durante a guerra.

Entretanto, mesmo com o desenvolvimento técnico, a cobertura ressaltou o uso da infografia como ferramenta estética, não como ferramenta de comunicação efetiva. Na visão de Cairo, o espaço ocupado pela infografia só existiu de forma ampla exatamente pela ausência de informação. Caso houvesse informação suficiente, a comunicação infográfica provavelmente não teria tido o espaço que lhe foi aberto. Ela foi usada como ferramenta que primava pela espetacularização do conflito. Segundo Cairo:

[...] os gráficos da primeira Guerra do Golfo estavam repletos de meias verdades, exageros e detalhes completamente inventados. Estilisticamente eles eram muito sofisticados: a qualidade das ilustrações atingia níveis nunca antes vistos. Éticamente, no entanto, a Guerra do Golfo de 1991 foi um ponto obscuro do jornalismo visual que marcaria todos os conflitos subsequentes até hoje, especialmente fora da imprensa "de elite" americana ${ }^{46}$ (CAIRO, 2008, p.55, tradução nossa).
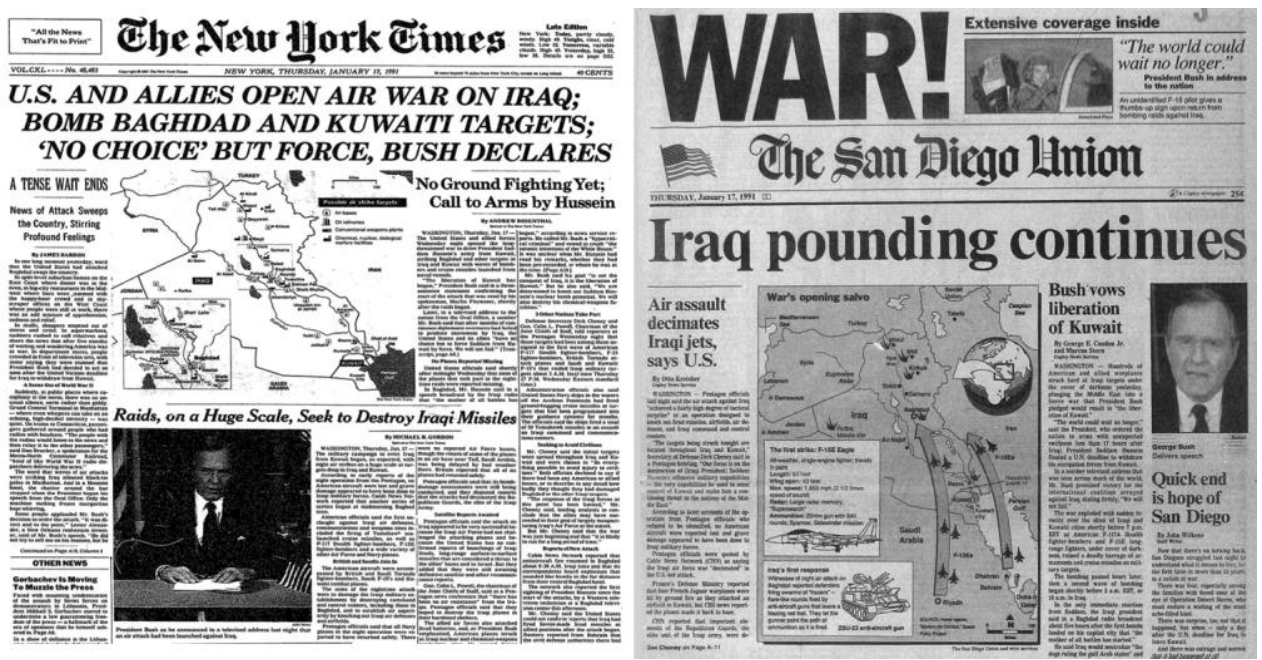

Figura 30 - Capas dos jornais The New York Times e The San Diego Union, ambas edições do dia 17 de janeiro de 1991, com mapas infográficos explicando possíveis alvos de ataques aéreos na

${ }^{45}$ No original "Cuando no hay fotografia, hay o puede haber infografia" e "Efectivamente, cuando no hay documento gráfico analógico, puede haber infografia, para explicar las causas del hecho acontecido..."

${ }^{46}$ No original “...los gráficos sobre la primera Guerra del Golfo estaban llenos de medias verdades, exageraciones y detalles completamente inventados. Estilísticamente eran muy sofisticados: la calidad de las ilustraciones alcanzó cotas nunca vistas hasta el momento. Éticamente, sin embargo, la Guerra del Golfo de 1991 fue un ponto oscuro del periodismo visual que habría de marcar todos los conflictos posteriores hasta nuestros días, especialmente fuera de la prensa "de elite" estadunidense." 
Guerra do Golfo. (Fonte: The New York Times Archives e <http://www.sandiegouniontribune.com/ news/150-years/sd-me-150-years-january-17-htmlstory.html> Acesso em: 18 dez. 2017)

Cabe aqui um contraponto em relação ao afirmado por Cairo: é necessário refletir se seria possível realizar outro tipo de cobertura do conflito, tendo em vista que as informações disponíveis eram insuficientes. Seria possível realizar uma cobertura a partir de briefings dos órgãos de defesa americanos? Como fazer a cobertura de um evento sem acesso a informação? Ou seja, apesar das críticas e da espetacularização, os infográficos publicados durante a cobertura da Guerra do Golfo possuem um valor de registro, pois são uma narrativa pertinente ao período e fizeram parte da evolução da linguagem infográfica em diversos meios informativos.

É prudente ressaltar que eventos de destaque e com as dimensões de uma guerra estão caracteristicamente presentes nas primeiras páginas dos jornais. A virtude da linguagem infográfica em explicar por meio de diferentes modais integrados, não apenas pelo texto ou foto com legenda, já era explorada anteriormente à Guerra do Golfo e permanece útil até os dias de hoje. Pode-se observar que a tentativa de integrar mapas, indicações gráficas, números, comparativos, entre outros elementos, já estava presente na capa de jornais há décadas. Um exemplo disso é a capa do jornal americano The Anderson Independent, hoje conhecido como Independent Mail, publicada em 7 de dezembro de 1941. A capa destaca o ataque surpresa japonês à frota americana, estacionada em Pearl Harbor, oferece mapas com dados sobre a frota japonesa, seu raio de alcance, diferentes classes de navios de batalha e traça um comparativo entre as frotas americana e japonesa com as dimensões, silhuetas e quantidades de cada unidade (Figura 31). Portanto, o que se critica em relação à cobertura da Guerra do Golfo é a espetacularização e o preenchimento de espaços realizado pela infografia. Isso, no entanto, não deve ofuscar a utilidade dos infográficos para contar histórias e esclarecer fatos em determinados casos - antes e depois desse período. 


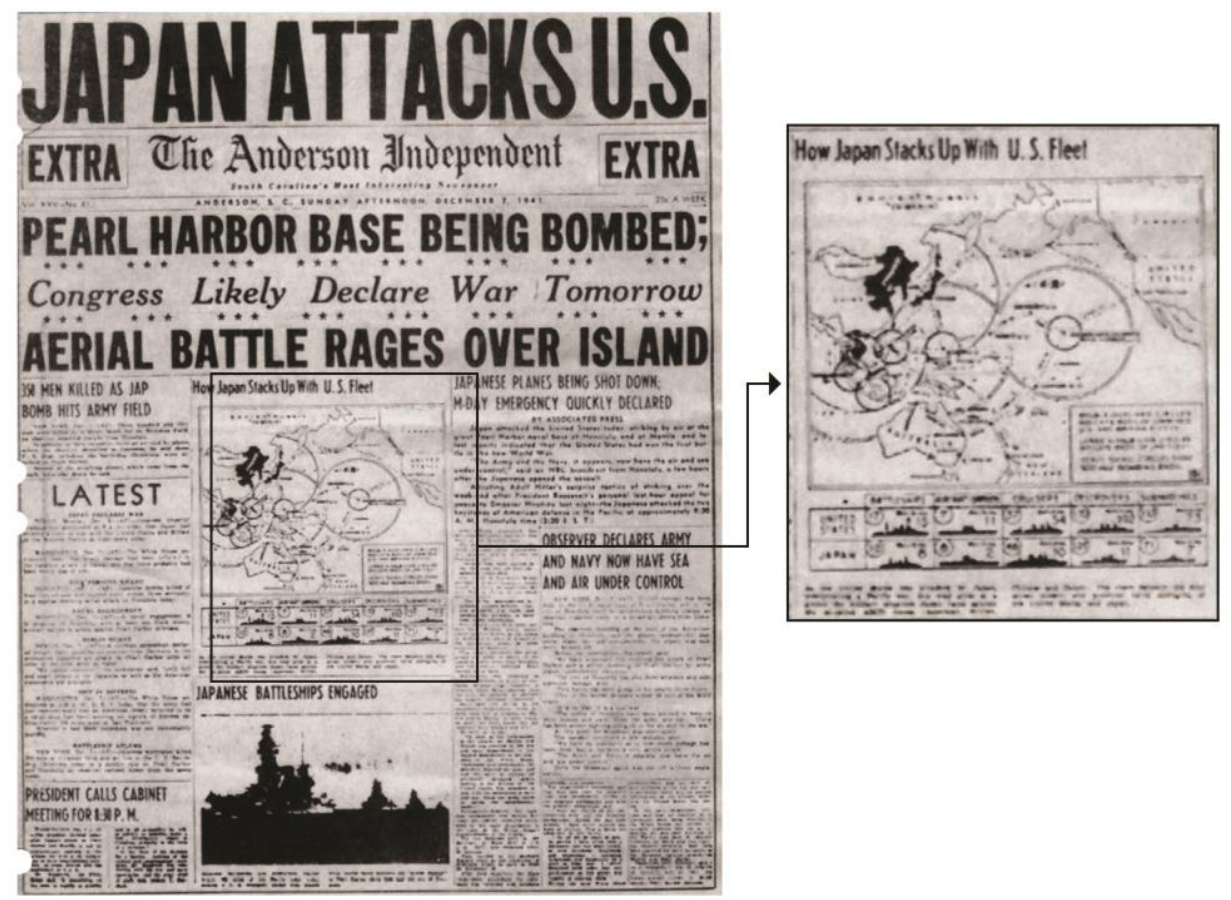

Figura 31 - Uso de recursos gráficos combinados (mapa, setas, diagramas, silhuetas, texto e números) para comparar as frotas japonesa e americana, no The Anderson Independent, edição de 7 de dezembro de 1941. (Disponível em: <https://digital.scetv.org/teachingAmerhistory/pdfs/ JapanAttacks266.pdf> Acesso em: 18 dez. 2017)

O nome infografía surge, como palavra, na Espanha, em 1988, durante seminário na Universidad de Navarra (MORAES, 2013, p.32). Após as reformas gráficas na década de 1990, os EUA e, posteriormente, a Espanha foram vetores de difusão do uso da infografia nos veículos jornalísticos impressos, principalmente por meio de consultorias prestadas a editorias em jornais de diversos países (dentre eles o Brasil). Houve um pesado investimento por parte das editorias espanholas na questão gráfica em função dos Jogos Olímpicos de Barcelona, em 1992, proporcionando uma oportunidade de desenvolvimento no uso da linguagem infográfica. A infografia espanhola promove uma tendência diferente da americana: enquanto os infográficos americanos possuíam um caráter tecnicista, com vistas explodidas, raios-x de aparelhos, construções etc., na Espanha, sob pioneirismo de Mario Tascón, do diário El Mundo, essas características técnicas seriam adaptadas às questões cotidianas das condições humanas presentes nos diários. De acordo com Moraes (2013, p.33), essa tendência se propagou nos seminários promovidos pela Universidade de Navarra, que tinha Tascón como um de seus colaboradores. Um dos exemplos da abordagem diferenciada é a reportagem visual sobre as touradas, 
intitulada Del arte del toreo (Figura 32), publicada na revista de domingo do El Mundo, chamada Magazine, em 15 de maio de 1994. O infográfico apresentava a dinâmica da tourada em 6 partes distintas que, apesar de serem dispostas em sequência, poderiam ser compreendidas individualmente. Com autoria de Tascón, ilustrada por Victoria Martos e com gráficos de Fran Álvarez e Modesto Carrasco, a reportagem viria a ser premiada na $16^{\mathrm{a}}$ edição do The Best of Newspaper Design, da SND, e no Malofiej, em 1994 (COPER, 1999, n.p.).

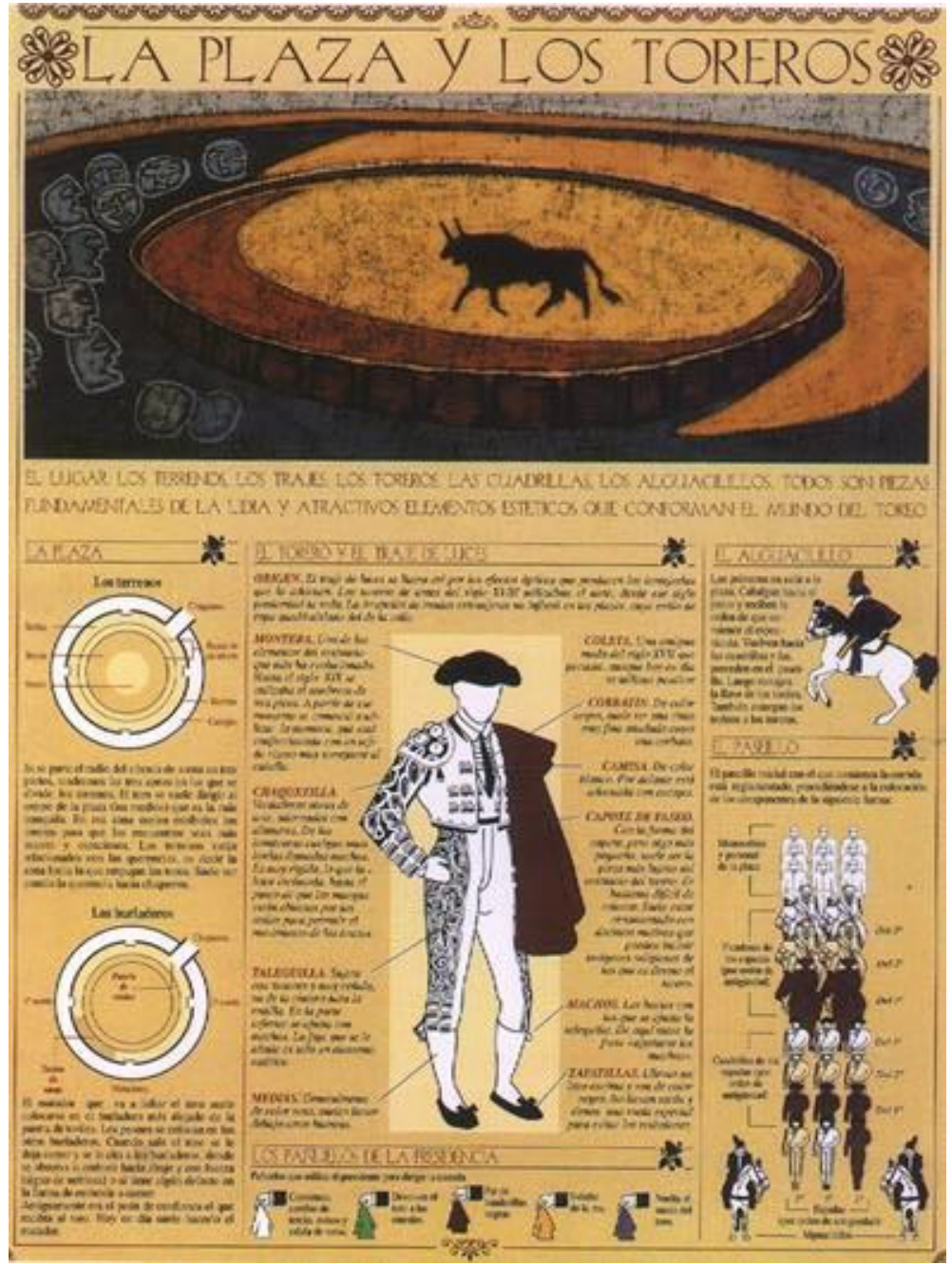

Figura 32 - A infografia espanhola influenciou diversos veículos de comunicação, na década de 1990. No exemplo, uma das lâminas do infográfico Del arte del toreo, publicada na revista Magazine, do diário El Mundo, edição de 15 de maio de 1994. (Disponível em: <http://www.revistalatinacs.org/ a1999hmy/97info/coper.htm > Acesso em: 17 dez. 2018)

Em 1995, o jornal argentino Clarín publica, em sua revista Viva, o infográfico La ballena Franca, de Jaime Serra (Figura 33). Utilizando recursos criativos, tal 
como a transferência de fotocópias para um papel antigo por meio de solvente, Serra deixou o seu estilo pessoal na peça e trouxe alegorias referentes ao mar, nem sempre relacionadas com a informação em si. O período de atuação do infografista catalão no Clarín (1995-2001) é considerado uma revolução na linguagem infográfica, tanto pela estética, quanto pela abrangência de temas abordados. No ano seguinte, o Clarín foi premiado com uma medalha de prata no Malofiej. Entretanto, em 2012, no Malofiej 20, o La ballena Franca foi escolhido o infográfico mais influente dos últimos 20 anos (1992-2012). Na mesma edição, Serra foi escolhido o editor de infografia mais infuente do mesmo período, tendo superado nomes como John Grimwade, Nigel Holmes, Fernando Baptista e Archie Tse. De acordo com Moraes (2013, p.34) a grande contribuição de Serra foi, por meio de suas técnicas de representação variadas, libertar a infografia do desenho vetorial, associação que reforçava a falsa crença de que os infográficos eram desenhados por computador. Serra desenvolveu uma linguagem e abordagem próprias, incluindo temas do cotidiano e não se limitanto à informação, segundo o infografista "Nunca me satisfiz em simplesmente informar. Também busquei transmitir emoções. É fundamental emocionar os leitores se queremos cativá-los." (O GLOBO, 2018b). Em 28 de abril de 2018, Serra estreou uma coluna infográfica mensal no jornal $O$ Globo, denominada "Segundo Caderno +".

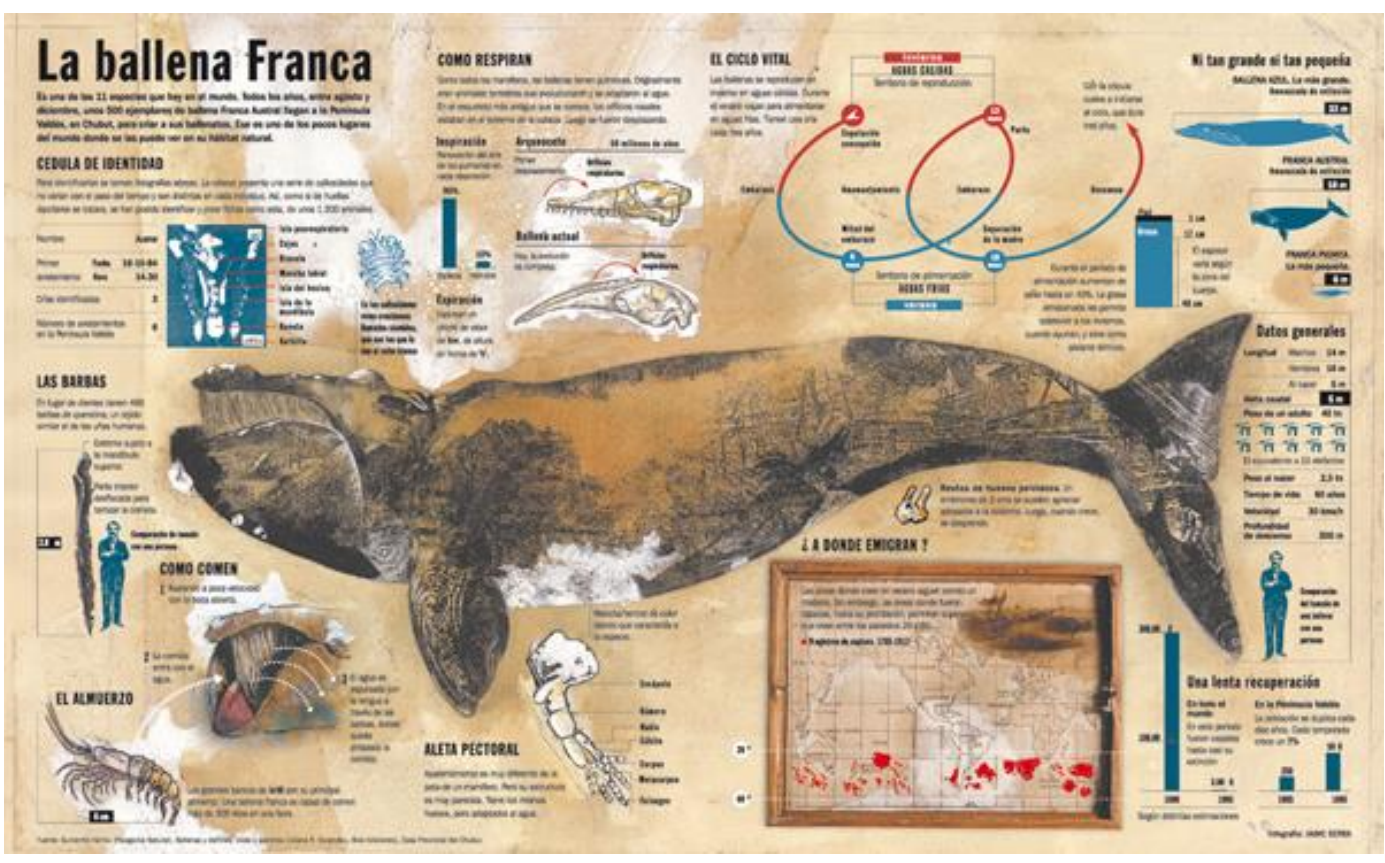

Figura 33 - Infográfico La ballena Franca, de Jaime Serra, publicado no Clarín, em 1995 (Disponível em: < https://jaimeserra-archivos.blogspot.com/p/la-ballena-franca.html> Acesso em: 19 mar. 2018) 
Apesar de um período profícuo, com infográficos criativos e esteticamente memoráveis, com influência de infografistas como Mário Tascón e Jaime Serra, percebe-se uma tendência a um tipo de infografia mais analítica, nos anos 2000. No jornalismo impresso, hoje em dia, há um número maior de visualizações analíticas e uma menor quantidade de visualizações estetizantes, como se nota no jornalismo de elite americano, em mídias como o The New York Times. A tendência também é observada por meio dos principais prêmios de infografia, tal como o Malofiej, em que peças de cunho analítico passaram a obter prêmios subsequentes. Cairo (2008, p.57) aponta como razões do aumento do uso de infográficos analíticos mais precisos nos últimos quinze anos: a crescente disponibilidade de acesso a bases de dados públicas, por meio de agências governamentais e organizações privadas; a consolidação dos valores de um jornalismo preocupado com a precisão dos dados e a efetiva incorporação de profissionais especializados nas redações, tais como desenvolvedores, profisionais de multimídia, cartógrafos, estatísticos, dentre outros.

\subsection{4. Infografia digital ou online}

A transição da infografia do suporte impresso para o digital ocorreu de forma gradativa, pois, em um primeiro momento, as versões online das publicações faziam apenas "traduções" do que havia sido planejado para o impresso. Estima-se que as primeiras versões projetadas de forma prioritária para o meio digital tenham sido desenvolvidas em meados de 1998. No entanto, grandes eventos como os Jogos Olímpicos de Sydney, em 2000, e a Copa do Mundo no Japão e na Coreia, em 2002, proporcionaram a exploração e a experimentação da infografia no meio online. Apesar dos eventos esportivos, foi o ataque às Torres Gêmeas do World Trade Center, em 11 de setembro de 2001, que causou grande impacto e obteve extensa difusão nos meios de comunicação mundiais no início da década. A contínua cobertura do atentado foi um momento em que houve um aumento quantitativo e qualitativo na forma de se detalhar o ocorrido por meio de infografias, explorando recursos multimidiáticos variados combinados. De forma progressiva, a infografia digital conquistou o seu espaço e obteve seu aval de autoridade em 2007, quando o 
maior prêmio de infografia do Malofiej daquele ano foi concedido apenas a uma peça online ${ }^{47}$. O prêmio foi concedido ao New York Times (online), pelo Snapshot Sector: Retailing, de Peter Sullivan (Figura 34). O uso de interações e a sua atualização constante, a partir da base de dados com informações sobre a Bolsa de Valores S\&P, trouxe novas possibilidades de se apresentarem dados para a análise e a interpretação dos leitores/usuários.

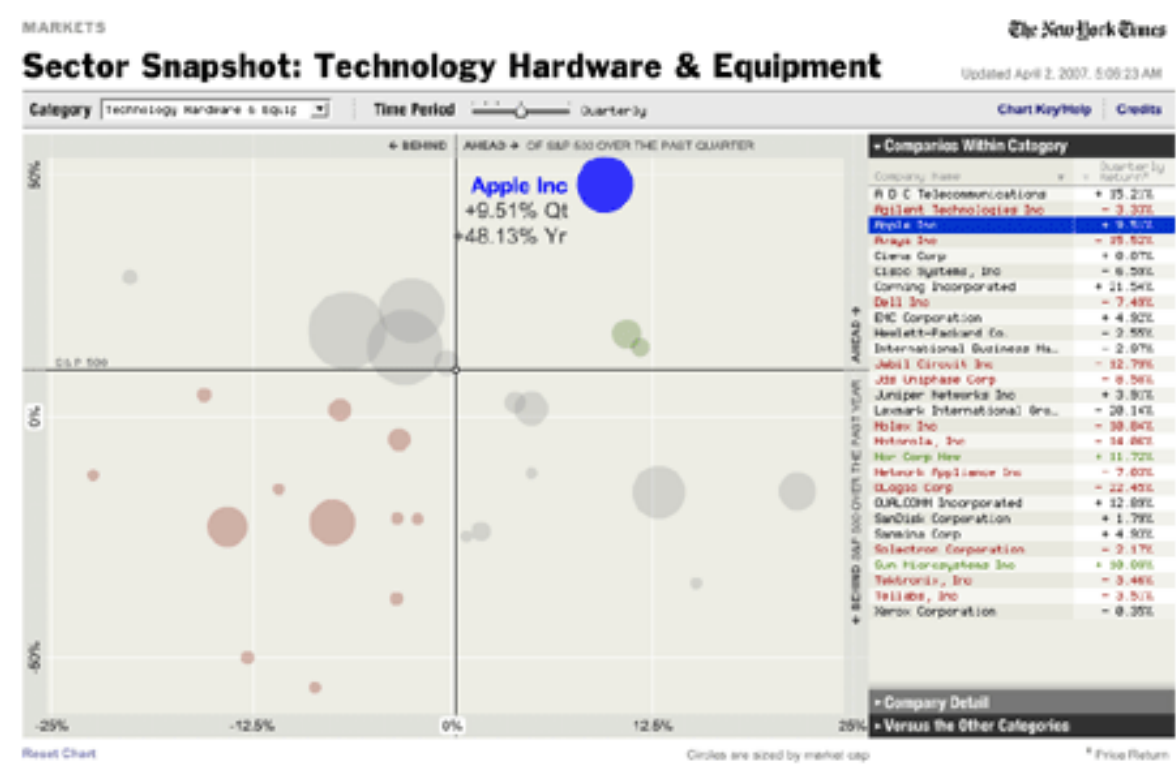

Figura 34 - Imagem de exemplo do Sector Snapshot, do NYT, que permitia atualização constante dos dados da Bolsa de Valores S\&P, premiado em 2007, no Malofiej. (Disponível em: < https://archive.nytimes.com/www.nytimes.com/packages/khtml/2006/04/02/business/20060402_SE CTOR_GRAPHIC.html > Acesso em: 20 mar. 2018)

\subsection{5.}

\section{Um momento de reflexão necessário}

Após a Guerra do Golfo, em 1991, houve um incremento nos padrões éticos adotados pelos meios de imprensa norte americanos, na tentativa de buscar a redução do uso da linguagem infográfica como reforço na espetacularização de eventos. Curiosamente, duas décadas depois, a infografia voltou ao centro das atenções, durante a cobertura da perseguição e morte de Osama Bin Laden, em 2011. Infográficos publicados em jornais em diversos países não se limitaram aos fatos e tornaram as peças sensacionalistas, publicando ficção como fato. Um infográfico que pode ser tomado como exemplo foi o publicado no jornal El País,

\footnotetext{
${ }^{47}$ A categoria de infográficos online estava presente há cinco anos no Malofiej, desde 2002.
} 
em 2 de maio de 2011. Dentre os graves erros encontrados na peça, há o tipo errado de aeronaves usadas na operação, a aproximação das equipes e a representação do terreno onde se situava o complexo no qual houve a incursão - ilustrado como um ambiente semelhante a montanhas, sendo que a localização era em meio urbano, no Paquistão (Figura 35). A cobertura fantasiosa dos infográficos sobre a operação levou à publicação de um manifesto amplamente endossado por profissionais, redigido por Juan Antônio Giner e Alberto Cairo, referências indiscutíveis no campo. O texto, publicado em 9 de maio de 2011, menos de uma semana após o ocorrido, ressaltou a importância da credibilidade para a prática do jornalismo. De acordo com os autores: “O jornalismo é um negócio sério, onde a credibilidade é fundamental. Os editores precisam, em primeiro lugar, obter os fatos certos, tanto em gráficos quanto em texto e vídeo ${ }^{48 "}$ (GINER \& CAIRO, 2011, tradução nossa). $\mathrm{O}$ artigo com o manifesto expôs os problemas em diversos infográficos e tornou-se um momento de grande reflexão sobre a questão dos preceitos éticos relacionados ao jornalismo visual ao redor do mundo. Os autores concluem o texto postulando seis regras a serem conferidas por infografistas:

1. Um infográfico é, por definição, uma exibição visual de fatos e dados. Portanto, nenhum infográfico pode ser produzido na ausência de informações confiáveis.

2. Nenhum infográfico deve incluir elementos que não sejam baseados em fatos conhecidos e evidências disponíveis.

3. Nenhum infográfico deve ser apresentado como sendo factual quando for fictício ou baseado em suposições não verificadas.

4. Nenhum infográfico deve ser publicado sem creditar sua(s) fonte(s) de informação.

5. Profissionais de gráficos informativos devem se recusar a produzir qualquer apresentação visual que inclua componentes imaginários projetados para torná-la mais "atraente" ou "espetacular". Os editores devem abster-se de pedir gráficos que não se atenham às evidências disponíveis.

\footnotetext{
${ }^{48}$ No original "Journalism is a serious business where credibility is paramount. Editors need, first and foremost, to get the facts right, in graphics as well as text and video."
} 
6. Infográficos não são ilustrações nem "arte". Infográficos são jornalismo visual e devem ser regidos pelos mesmos padrões éticos que se aplicam a outras áreas da profissão.

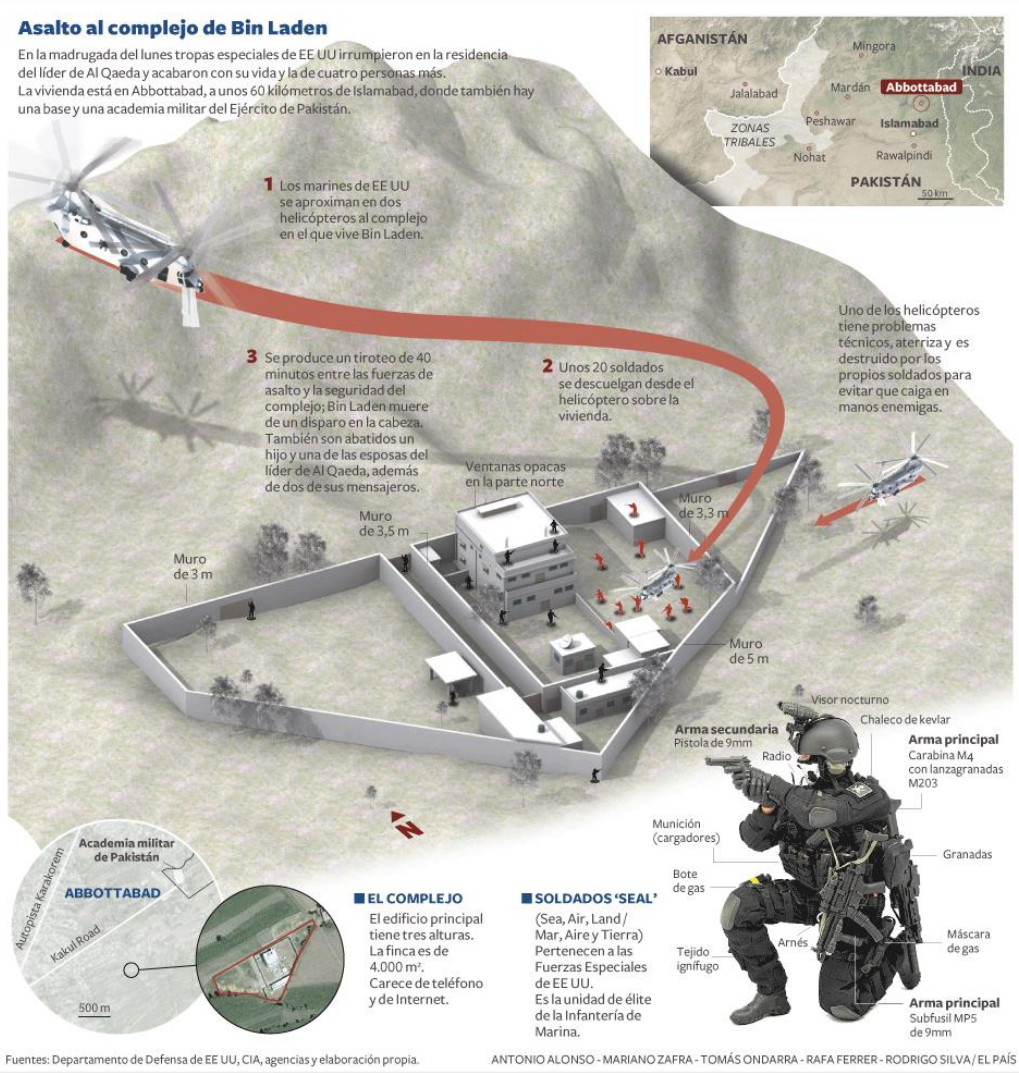

Figura 35 - Infográfico publicado pelo jornal El País, em 2 de maio de 2011, onde há grave erro em relação ao tipo de terreno do teatro de operações, que se situava em ambiente urbano. (Disponível em: <https://elpais.com/elpais/2011/05/02/media/1304302211_720215.html> Acesso em: 20 dez. 2017)

O manifesto, apesar de buscar a valorização de questões éticas relacionadas ao jornalismo visual, também acarretou uma restrição no escopo da infografia. Ao considerar a imposição de limites rígidos, as recomendações serviram, também, como conteção às possibilidades criativas dos infográficos.

\subsection{6.}

\section{O mobile first torna-se realidade}

Em 2016, os dispositivos móveis, ou mobile devices, consolidaram-se como um dos principais meios de acesso à informação. De acordo com o relatório anual sobre dados relativos ao acesso aos meios de informação nos EUA, o State of the News Media, realizado em 2017 pelo Pew Research Center, apesar de a TV 
permanecer em primeiro lugar, o único meio que obteve crescimento no ano foi o online, seguido pelo rádio, e, em quarto e em declínio, o jornal impresso (PEW, 2017). Segundo os dados do Pew Research Center, em 2016, foi possível notar a superação do consumo de informações por meio dos dispositívos móveis em relação aos PCs e laptops. Os números mostram uma ampliação dessa tendência em 2017 (PEW, 2017). Em pesquisa conduzida entre maio e outubro de 2017, os resultados indicam que seis a cada dez americanos adultos acessam notícias por meio de dispositivos móveis (PEW, 2018). O que antes era considerado como previsão, em 2016, é confirmado. Ou seja, a estratégia denominada mobile first, ou mobile imperative, na qual a prioridade do suporte passa a ser o planejamento para smartphones e tablets, torna-se imprescindível para o futuro dos meios de comunicação jornalística focados no ambiente online. A infografia presente nesses veículos acompanha a evolução do suporte. Ou seja, se, em um primeiro momento, houve uma transição do impresso para o digital, para desktops, agora, os dispositivos móveis superaram os computadores e notebooks. No presente e iminente futuro, portanto, os infográficos e visualizações de dados possuem as vantagens de processamento, resolução, conexão e recursos multimidiáticos dos dispositivos móveis, mas, também, as restrições das dimensões dos displays (o que dificulta a visualização de detalhes e interações complexas, como as possíveis nas telas maiores dos desktops) e desafios tecnológicos inerentes ao desenvolvimento de peças eficazes para esse suporte (como os custos para a produção de peças que funcionem bem em variadas plataformas e sistemas, tempo de produção, versões de aplicativos, dentre outros).

\section{3.}

\section{Linha do tempo em formato gráfico-visual}

Uma vez consolidados os marcos, foi elaborada uma linha do tempo com o objetivo de reunir de forma sintética as informações coletadas. Além de disponibilizar as informações em formato gráfico, a linha do tempo permite posicionar diferentes categorias em paralelo, observando-se as relações temporais entre os diferentes marcos.

A seguir, apresentamos a linha do tempo reduzida e em sua versão para impressão com as informações derivadas da investigação realizada neste capítulo. 


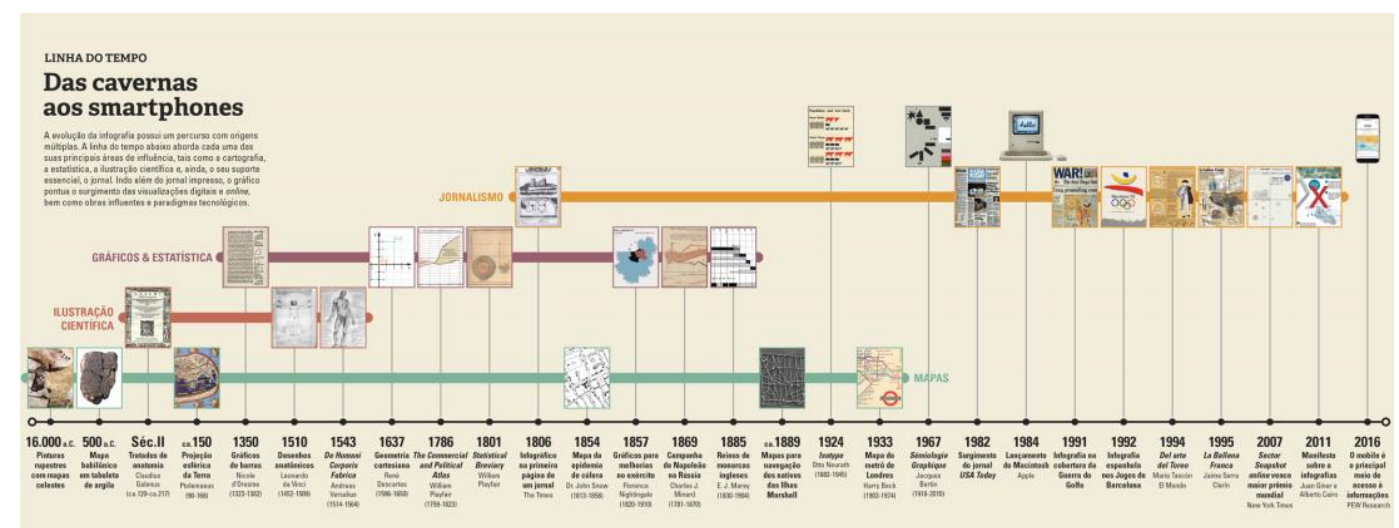

Figura 36 - Proposta gráfica reduzida da linha do tempo com as principais origens e marcos da infografia, de 16.000 a.C. aos dias de hoje. Fonte: do autor. 


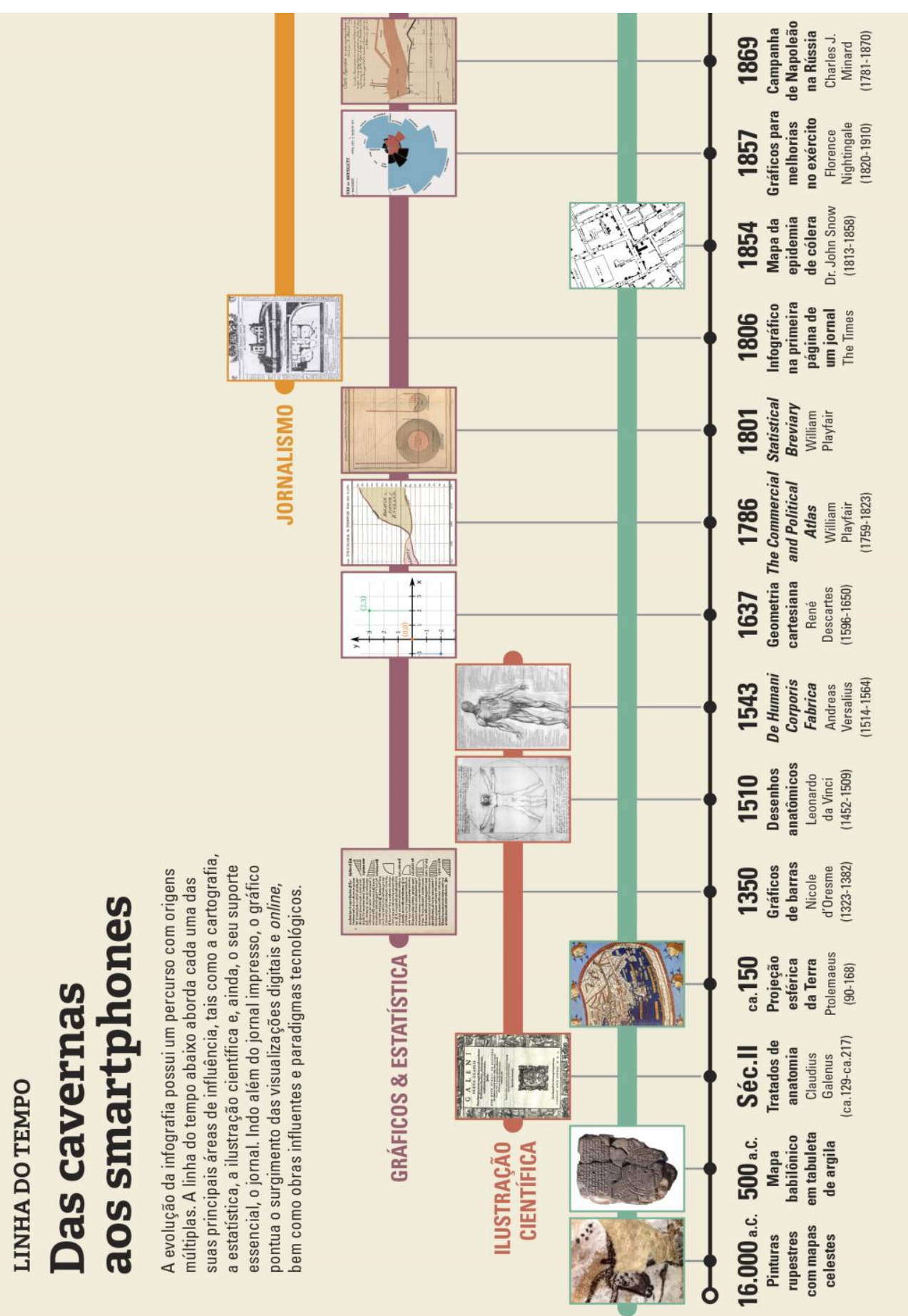

Figura 37 - Imagem da primeira parte da linha do tempo da infografia no tamanho original para impressão. Fonte: do autor. 


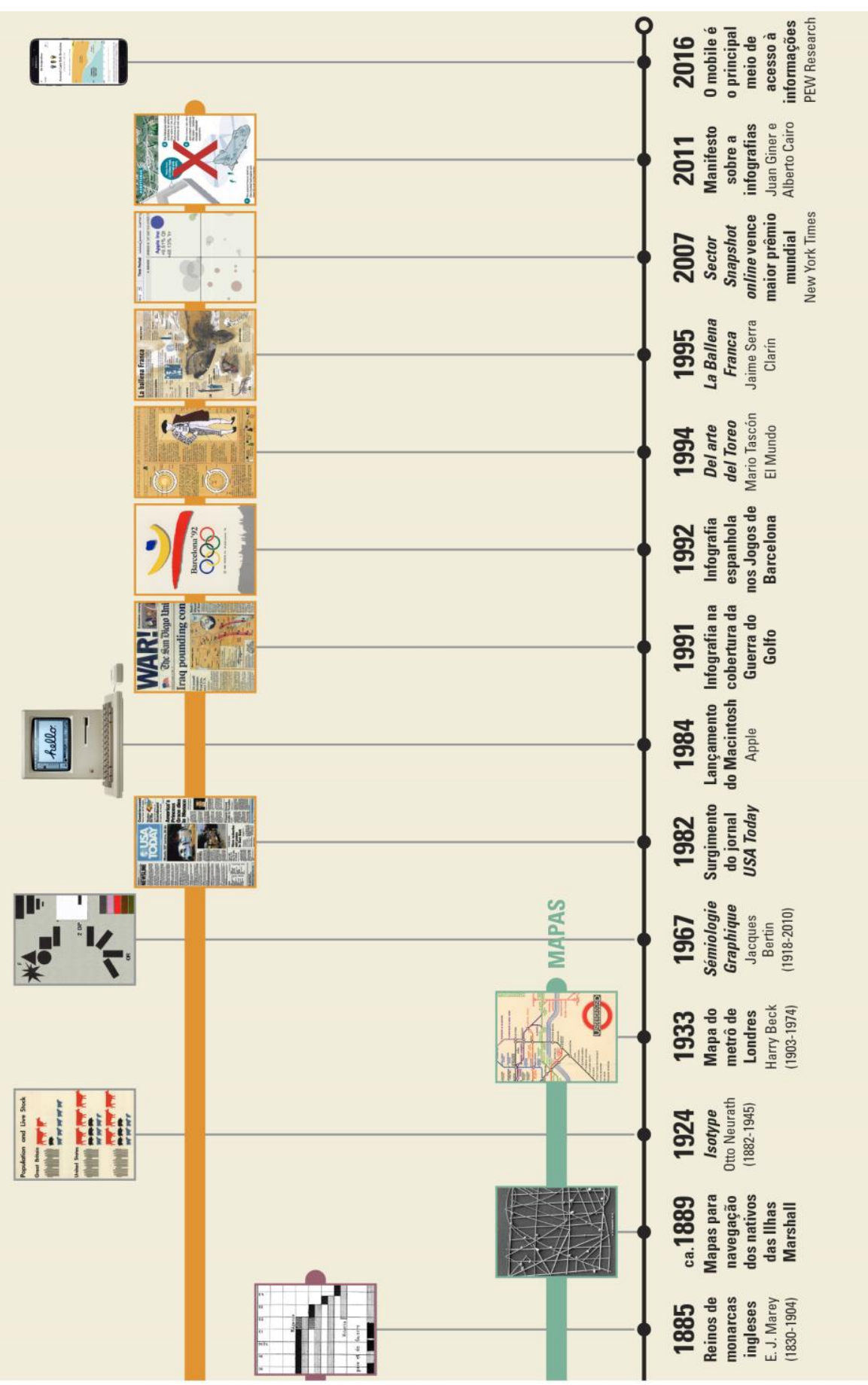

Figura 38 - Imagem da segunda parte da linha do tempo da infografia no tamanho original para impressão. Fonte: do autor.

Cabe ressaltar que o formato final ocupará dimensões maiores que o tamanho A4 $(210 \times 297 \mathrm{~mm})$, preenchendo uma área de aproximadamente 500x200mm. Portanto, a imagem precisou ser dividida para ser visualizada com uma legibilidade mínima no formato deste documento. 
Hoje, a variedade de profissionais que atuam no domínio da infografia, com equipes de origens diversas e campos do saber heterogêneos, bem como o aumento da demanda por qualidade e precisão tornam mais evidentes problemas como a ausência de uma nomenclatura "universal", o que dificulta a denominação padronizada de cada elemento. Para nos aprofundarmos em relação à infografia contemporânea, no entanto, não devemos nos restringir aos termos e seus problemas. Devemos, também, observar as funções e as abordagens conceituais ou "ideológicas" que podem ser aplicadas aos diferentes tipos de peças que usem a linguagem infográfica. Tema para o capítulo a seguir. 


\section{4 \\ Dos dados ao conhecimento, suas abordagens e categorias}

Até o momento, observamos o desenvolvimento da infografia ao longo da história, suas origens, sua participação como ferramenta de apoio cognitivo ao desenvolvimento das ciências e à difusão de informações em meios de comunicação. Também investigamos a diversidade de termos circulantes no universo dos infográficos e estabelecemos nossas definições. No entanto, para que possamos construir fundamentos para analisar o panorama da infografia no Brasil, é necessário abordar questões relativas ao papel da linguagem infográfica, suas funções essenciais, abordagens e propostas tipológicas. Ressaltamos que questões relevantes como o papel da percepção visual e da retórica na construção do discurso dos infográficos já foram abordadas em trabalho anterior ${ }^{49}$ e, neste documento, serão mencionadas apenas pontualmente.

\section{1. O processo de esclarecer: dos dados não estruturados ao conhecimento}

O infográfico não trata apenas de eliminar a quantidade de texto que se refere a uma determinada informação, com o objetivo de reduzi-lo ou simplificá-lo. Trata de integrar o texto e as informações visuais adicionais, os esquemas diagramáticos, as imagens ilustrativas, os dados e outras formas não verbais com o objetivo de estimular o leitor a melhor assimilar o conteúdo da notícia. Ele não simplifica informações complexas, mas deixa-as mais claras do que se elas fossem transmitidas de maneira apenas textual, tabular, numérica etc. De acordo com Moraes (1998, p.117), a infografia "age no sentido de informar sem deixar espaço para dúvida ou diferenças de interpretação. Isto porque trabalha a partir da articulação de duas linguagens distintas: ilustração e palavra”. Para Cairo (2008,

${ }^{49} \mathrm{O}$ tema da retórica e da percepção visual no âmbito dos infográficos pode ser consultado em Nogueira (2014). 
p.32, tradução nossa) a infografia jornalística "não consiste em simplificar a informação no sentido de reduzi-la artificialmente, de modo que ela possa ser apreendida rapidamente por leitores pouco esclarecidos ${ }^{50}$ ". Portanto, o infográfico traz determinados assuntos à luz da compreensão por meio da integração de diferentes modais, de forma que o conjunto da obra conte a história permitindo que a interpretação seja mais palatável ao leitor - e isso não é o mesmo que "simplificar", no sentido de tornar simples ou de fazer necessariamente uma "leitura rápida", como um passe de mágica. Significa, sim, que a sua narrativa deve ser adequada à percepção e à cognição humanas, proporcionando a apresentação de dados e/ou fatos em um ambiente no qual o leitor tenha a capacidade de absorver o conteúdo sem ambiguidade. Em diversos casos, um infográfico demanda amplo esforço cognitivo e atenção por parte do leitor, de forma que concatene as ideias e explore os dados para que extraia conteúdo novo das informações fornecidas. Esse esforço e essa participação do leitor, certamente, não significam que a leitura seja sempre "mais rápida" ou "simples".

O diagrama de hierarquia DIKW (Data, Information, Knowledge, Wisdom ou Dados, Informação, Conhecimento, Sabedoria, em tradução livre) apresentado por Cairo (2013, p.16) é capaz de demonstrar as etapas do processo de transição de informações não estruturadas até se tornarem conhecimento e, potencialmente, em sabedoria (Figura 39). O diagrama assemelha-se ao An overview of understanding, proposto por Nathan Sherdoff (1994, p.3), e mostra as etapas entre as pontas da proposta de arquitetura da informação de Wurman ${ }^{51}$. Conforme Cairo $(2013$, p.16), apesar de esses tipos de modelos de estruturação terem sido criticados por serem considerados vagos e simplistas, eles são úteis para explicar para que servem gráficos e infográficos.

${ }^{50}$ No original "La visualización en prensa no consiste en simplificar la información en el sentido de reducirla de modo artificioso para que pueda ser aprehendida con rapidez por los lectores poco ilustrados."

${ }^{51}$ O professor de arquitetura Richard Saul Wurman, nos anos 1970, previu a necessidade de se desenvolverem formas de organizar e dar sentido à grande quantidade de dados que seriam gerados em um futuro iminente. $\mathrm{O}$ autor denomina de arquitetos da informação os profissionais que seriam responsáveis por essa organização e por apaziguar a sensação que ele batiza de ansiedade de informação. Para Wurman, a solução para a ansiedade de informação é o acesso à compreensão. (WURMAN, 2001, p.21) 


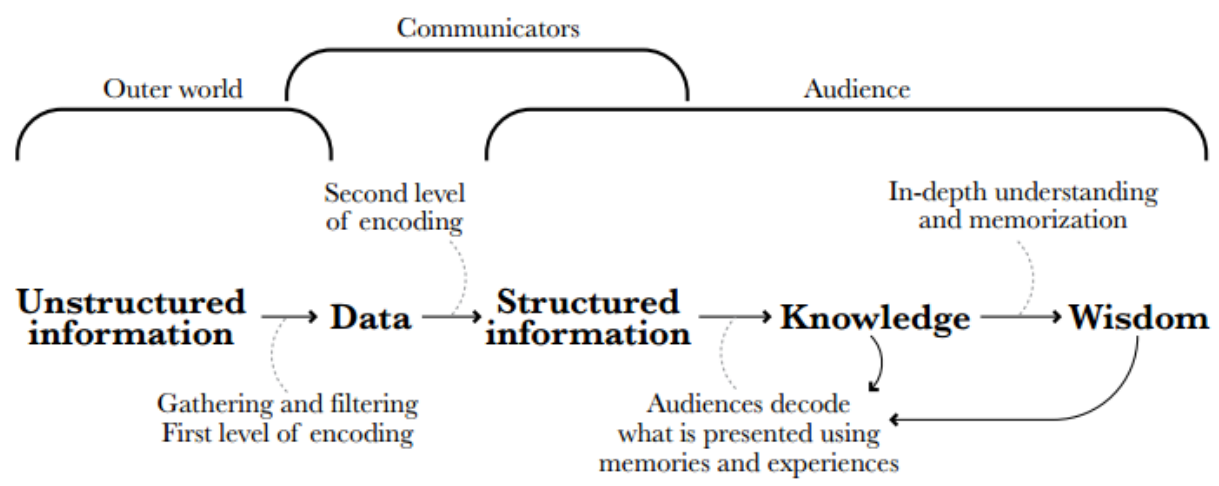

Figura 39 - Gráfico DIKW identificando as etapas de transição de informações não estruturadas até se tornarem conhecimento. Fonte: CAIRO (2013, p.16).

No diagrama, as informações não estruturadas referem-se à realidade, aos fenômenos que podem ser percebidos e medidos; dados são os registros de observações que podem ser codificados em símbolos como números e palavras (primeiro nível de codificação); as informações estruturadas são as representações dos dados de forma significativa por meio de texto, imagens etc., realizadas por um comunicador, tal como um pesquisador, jornalista, designer etc. Nessa etapa, os dados ganham forma, de maneira que os padrões relevantes se tornem visíveis (resultado de um segundo nível de codificação); o conhecimento é atingido quando a audiência é capaz de perceber os padrões ou o significado dos dados, relacionando-os com as suas memórias e experiências; a sabedoria ocorre quando há uma compreensão profunda do conhecimento adquirido, não apenas com o entendimento da informação, mas com sua assimilação de forma que ela seja útil para tomada de decisões em situações similares no futuro. Sobre o fato de a sabedoria ser um processo que não se transmite, Sherdoff (1994, p.5, tradução nossa) afirma que:

[sabedoria] é o resultado da contemplação, avaliação, retrospecção e interpretação todos os quais são processos particularmente pessoais. Não podemos criar sabedoria como dados e informações, e não podemos compartilhá-la com outras pessoas como podemos com conhecimento. Só podemos criar experiências que ofereçam oportunidades e descrevam processos. Em última análise, é um entendimento que deve ser adquirido por si mesmo ${ }^{52}$.

52 No original "It is the result of contemplation, evaluation, retrospection, and interpretation - all of which are particularly personal processes. We cannot create wisdom like we can data and information, and we cannot share it with others like we can with knowledge. We can only create experiences that offer opportunities and describe processes. Ultimately, it is an understanding that must be gained by one's self." 
Cairo (2013, p.17) ressalta que nem toda informação apreendida torna-se conhecimento e nem todo conhecimento adquirido torna-se sabedoria. Para o autor, o cérebro impõe, de forma inconsciente, uma organização e hierarquia às informações não estruturadas que coletamos do mundo ao nosso redor. Ademais, afirma que "o papel de um arquiteto de informação é antecipar esse processo e gerar ordem antes que os cérebros das pessoas tentem fazê-lo por si próprios" (CAIRO, 2013, p.17). Ou seja, o papel das visualizações é justamente traduzir esse processo e apresentá-lo por meio da integração de códigos verbais e não verbais, em consonância com o repertório do jornalista visual ou designer que o confecciona e seu auditório. Moraes (1998, p.120), por sua vez, afirma que:

Codificar um infográfico corresponde a escolher e articular imagens e palavras de modo a que possam informar o leitor sem colidir com o seu repertório. Os infos devem facilitar a recepção e o entendimento ds informações que transmitem, mesmo quando se reportam a alguma coisa totalmente desconhecida por parte dos leitores.

Como mencionado por Wurman (2001, p.20), “ordem não é garantia de compreensão". Portanto, infográficos são ferramentas que auxiliam parte do processo. Então, o fato de as informações estruturadas tornarem-se conhecimento e/ou sabedoria dependerá do cruzamento da bagagem cultural do leitor na identificação dos códigos estabelecidos pelo infografista na peça em questão. $\mathrm{Ou}$ seja, o discurso construído pelo jornalista visual deve ser orientado ao repertório de seu auditório, e sua aderência só será obtida se houver códigos suficientemente comuns a ambos na argumentação.

É importante ressaltar que ordenar ou organizar os dados não é sinônimo de impor uma linearidade rígida à narrativa. Infográficos ou visualizações de dados, digitais ou impressos, podem fazer a integração entre blocos de informação em uma diagramação que permita a exploração dessas unidades por meio de diferentes sequências, de acordo com a vontade ou objetivo do leitor/usuário. A forma como os dados são organizados também impõe um significado. De acordo com Sherdoff, o primeiro passo para se transformar dados em informação é explorar a sua organização e comenta que "é importante perceber que a própria organização das coisas afeta a maneira como interpretamos e entendemos suas partes separadas ${ }^{53}$, (SHERDOFF, 1994, p.5). Essa organização ocorre em um nível estrutural relativo

\footnotetext{
${ }^{53}$ No original "It is important to realize that the very organization of things affects the way we interpret and understand their separate pieces."
} 
à escolha dos argumentos que serão explorados pelo orador, filtrando dados e selecionando índices e valores referenciais no campo estatístico, por exemplo; e, posteriormente, por meio de um planejamento da peça gráfica com regras naturais e conceitos do design gráfico. Na esfera da comunicação visual, fundamenta-se a aplicação de conceitos da psicologia da gestalt, semiótica, ergonomia, dentre outros, para que a diagramação no suporte seja otimizada em relação ao públicoalvo, reforçando os argumentos e dados do discurso desejado.

Além do seu sistema lógico interno, a infografia deve se integrar com a diagramação da página, relacionando elementos variados em um conjunto, proporcionando maior efetividade na transmissão do conteúdo, ao mesmo tempo que mantém a identidade do veículo no qual se encerra. Kanno (2013, p.28) aponta resultados de pesquisas realizadas pelo Poynter Institute, em 2008, que indicam que o uso de recursos infográficos auxiliam os leitores a memorizar e compreender os fatos da matéria jornalística. Nos testes realizados, a diagramação em tópicos, unindo recursos visuais e textos obtiveram melhores pontuações em avaliações qualitativas que modelos com apenas o texto e narrativa "tradicionais". Para que seja efetivo, deve-se pensar no ecossistema em que habita, ou seja, o infográfico deve conversar com a diagramação do suporte como um todo, sendo a harmonia elemento fundamental para a percepção do conjunto. Nota-se a relação intrínseca da infografia com a diagramação da página no comentário de Kanno (2013, p.60) "uma página bem editada e desenhada pode salvar um infográfico ruim, mas mesmo um excelente infográfico não salva uma página ruim". Portanto, em uma publicação impressa ou digital, é preponderante considerar o projeto gráfico do veículo, seu grid, a tipografia, as cores e outros elementos como ponto de partida para a elaboração de infográficos que farão parte da edição.

A construção de uma narrativa por meio da integração entre diferentes blocos, de acordo com o seu planejamento, proporciona uma leitura de forma distinta da de um texto corrido ou de um vídeo, os quais dependem de uma sequência sucessiva de seus argumentos. Ou seja, se lermos o penúltimo parágrafo de um texto, ou iniciarmos um vídeo a partir de um ponto aleatório, certamente perderemos a essência da argumentação, fugindo da experiência esperada pelo orador.

Já um infográfico pode ser capaz de ser lido de forma não-linear ou, em determinados casos, de maneira multilinear, se vários caminhos paralelos forem disponibilizados de acordo com as escolhas e interações. O leitor pode retornar e 
consultar informações presentes em setores específicos rapidamente, indo e voltando pelas informações disponíveis. É interessante ressaltar que essa característica se exacerba ou expande suas possibilidades em ambiente hipertextual, natural da internet. Contudo, a navegação não-linear não se ausenta em meio impresso estático. Esse tipo de navegação pelo conteúdo, de forma modular, segmentada, permite uma apreensão por blocos de informação menores que os textos corridos de narrativas tradicionais em colunas. Além de permitir que o leitor explore e acesse o conteúdo disponível de acordo com o seu interesse, essa abordagem proporciona uma leitura mais adequada ao cérebro humano do que longas sequências de palavras, dados e tabelas. Com isso, exige-se menos armazenagem na memória de curto prazo e usam-se elementos visuais para representar dados e realizar conexões lógicas.

O processo de esclarecer informações por meio da infografia, portanto, ocorre em vários níveis. O resultado final, a peça gráfica em si, seja um infográfico, uma visualização de dados, uma infografia digital, é a parte visível de um intrincado procedimento que vai desde a escolha do tema, da identificação da mensagem que se deseja transmitir, da coleta de dados não estruturados, da sua filtragem, organização e disposição até a articulação entre texto, dados, imagens, diagramas, interações e demais elementos que constituem um discurso capaz de fornecer informações ao leitor de forma clara, sem ambiguidade. A partir daí, em uma relação íntima com o que apreendeu, gera-se no leitor, a possibilidade de a informação se transformar em sabedoria.

\section{2.}

\section{Entre a estética e a objetividade}

A afirmação de Kanno (1998, p.2) de que a função primária da infografia é enriquecer o texto, auxiliando a compreensão de uma reportagem, e a secundária é "embelezar" a pauta para torná-la mais atrativa fundamenta um princípio essencial para o design da informação: o que importa, em primeiro lugar, é a informação a ser transmitida ao leitor/usuário. Entretanto, pode-se observar uma acentuada característica estética em determinados infográficos, mesmo que essa atitude vá de encontro aos princípios de simplificação sem elementos decorativos que muitos autores relevantes sugerem, como Tufte (2011) ou Wong (2013). Para Cairo (2008, 
p.28) é possível estabelecer dois grupos com abordagens, ou "ideologias", distintas que separam as funções dos infográficos em jornais e revistas: o primeiro seria o grupo dos infográficos estetizantes e o segundo, o grupo dos infográficos analíticos.

As visualizações estetizantes possuem a função de atrair o leitor, de induzi-lo a ler um determinado artigo ou consumir o jornal ou revista. Possuem um apelo estético intenso e costumam fazer uso de ilustrações, apesar de não "informar melhor" ou facilitar a compreensão de algum assunto necessariamente de forma mais eficiente. A abordagem estetizante enfatiza o aspecto de apresentação, o teor visual, e tem a infografia como elemento ornamental e informativo. $\mathrm{O}$ impacto visual é mais importante que a clareza em transmitir conteúdo informativo de forma sintética ou prática. As visualizações estetizantes servem, também, para preencher um espaço destinado à fotografia quando ela não está disponível ou quando não é possível ilustrar com imagens fotográficas uma história da forma desejada pelo jornalista.

Já as visualizações analíticas são usadas para complementar uma história de forma mais eficaz do que se fossem usados apenas textos acompanhados de fotografias ou ilustrações. As visualizações com essa tendência têm a capacidade de explicar visualmente relações entre elementos, com grande poder sintético, o que facilita a compreensão e reduz a quantidade de texto descritivo necessário. É uma abordagem que deriva da incorporação de profissionais especializados nas redações, com crescente uso de bases de dados, ferramentas e técnicas advindas de visualizações científicas. Segundo Cairo, de acordo com esse conceito que ele denomina visualização analítica, determina que:

a visualização da informação na imprensa é entendida como apoio à compreensão: aumenta a capacidade cognitiva dos leitores por meio da revelação de evidências, de mostrar o que permanece oculto, seja por trás de um conjunto caótico de dados, em uma lista de números, ou em um objeto cuja estrutura interna é excessivamente complexa $^{54}$ (CAIRO, 2008, p.29).

${ }^{54}$ No original "la visualización de información en prensa se entiende como soporte de la comprensión: incrementa la capacidad cognitiva de los lectores por medio de la revelación de evidencia, de mostrar aquello que permanece oculto, ya sea tras un conjunto caótico de datos, en una lista de números, o en un objeto cuya estructura interna es excesivamente compleja." 

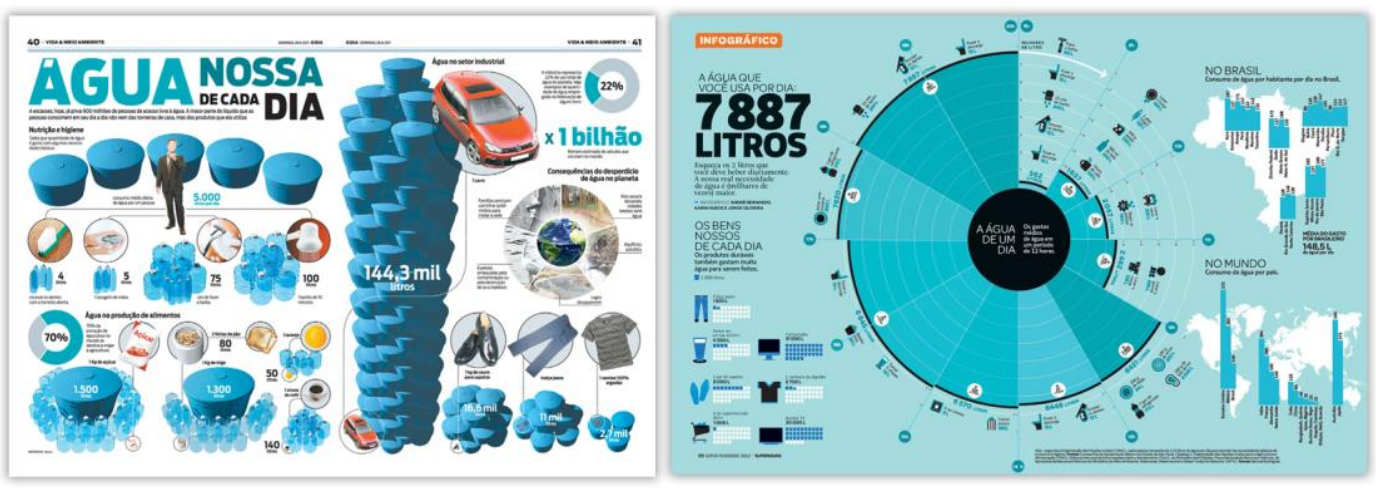

Figura 40 - Exemplos de infográficos analíticos e estetizantes sobre o mesmo tema. Enquanto no infográfico à esquerda as imagens e montagens fotográficas exacerbam o impacto por meio de caixas d'água empilhadas - demonstrando o volume gasto, o infográfico à direita busca tornar os dados de diversas entidades (ONU, Sabesp etc.) em gráficos exploratórios. Fonte: INFOLIDE (2012, p.31) e Revista SUPER INTERESSANTE, ed. fevereiro de 2012, p.26. (Disponível em: $<$ https://super.abril.com.br/blog/superlistas/o-melhor-do-ano-10-melhores-infograficos-da-superem-2012/> Acesso em: 22 jan. 2019)

Cairo ressalta que as abordagens chamadas de "visualizações estetizantes" ou "visualizações analíticas" são conceitos teóricos e manifestam a forma como os departamentos de infografia abordam seus produtos, mas que não são precisos para classificar peças concretas e avaliar o trabalho de um determinado meio de comunicação (CAIRO, 2008, p.29). De fato, a escolha de uma determinada publicação por uma ou outra abordagem depende de fatores complexos que podem ser de variáveis tecnológicas (como a resolução para impressão ou servidores específicos para peças online), disponibilidade de tempo e investimento (para pesquisa e apuração, acesso a bancos de dados, quantidade de profissionais envolvidos etc.), capacitação técnica da equipe (presença de especialistas, estatísticos, desenvolvedores, ilustradores, designers etc.) e o cruzamento desses fatores com o público-alvo, leitores e usuários, para que se decida a melhor forma de tornar a mensagem atrativa e eficiente.

Cabe aqui um debate entre o purismo informativo e os excessos artísticos, extremos opostos em abordagens infográficas. Cairo (2013, p.61) considera que profissionais de origem mais técnica (estatística, cartografia, ciência da computação e engenharia) seriam mais adeptos de uma abordagem racional, propensos a desenvolver infográficos que enfatizem a funcionalidade. Já os profissionais com formação em design gráfico, artes ou jornalismo tenderiam a uma abordagem mais artística, enfatizando o lado estético e emocional das peças (Figura 41). 

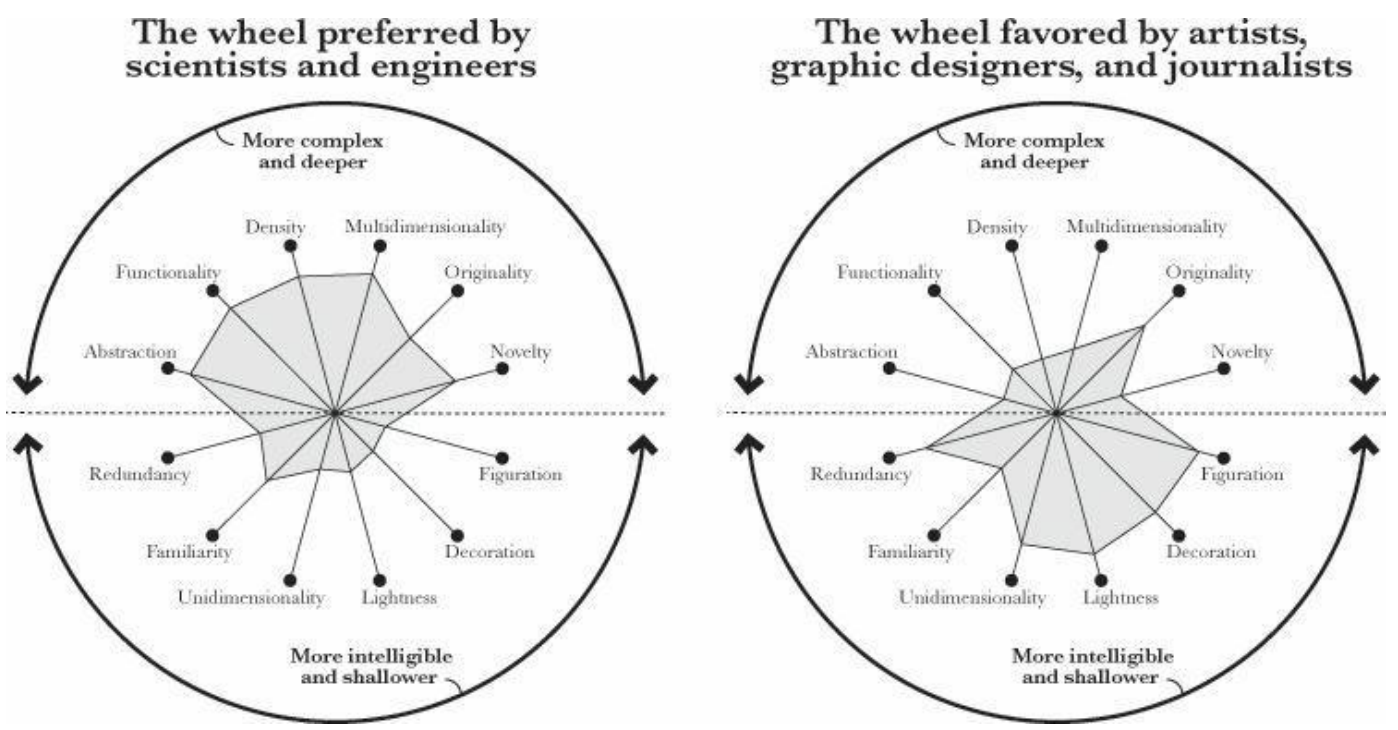

Figura 41 - Gráfico de análise de preferências na abordagem projetual entre profissionais com diferentes backgrounds. Fonte: CAIRO (2013, p.62).

Para Sancho, a estética deve estar a serviço do rigor, precisão e princípios de funcionalidade jornalística. $\mathrm{O}$ autor afirma que o jornalista visual ou infografista deve ser capaz de "coletar informações, acessar fontes, entender dados, processálos e expressar o resultado de uma forma muito visual, para que seja facilmente compreendido por todos ${ }^{55 "}$ (SANCHO, 2008, p.499, tradução nossa). Ainda, declara que o infografista não deve ser apenas um ilustrador que serve o jornalista (responsável pelo texto) de uma forma marginal, como mero apoio visual. Em um momento em que a infografia digital oferece inúmeras possibilidades estéticas e experiências de ordem tecnológica e interativa, Sancho afirma que o jornalismo digital "Embora seja uma ferramenta que permita licenças artísticas específicas para entretenimento, ficção ou publicação, deve-se evitá-las em benefício do rigor, funcionalidade, precisão e tempo para melhorar a qualidade geral ${ }^{56 "}$ (SANCHO, 2008, p.499, tradução nossa).

Em relação ao trabalho do infografista não ser marginal, um mero apoio de ilustração ao texto, o relato de Moraes (1998) sobre a investigação jornalística auxilia a esclarecer a profundidade do processo:

\footnotetext{
${ }^{55}$ No original "capaz de reunir información, recurrir a fuentes, entender los datos, procesarlos y plasmar de forma muy visual el resultado, de forma que pueda ser fácilmente entendido por todos."

56 No original "Aunque es una herramienta que permite licencias artísticas propias del entretenimiento, ficción o publigrafía, debe evitarlas en beneficio del rigor, funcionalidad, veracidad y consecución de tiempo para mejorar la calidad general."
} 
A produção de uma infografia supõe o trabalho de investigação jornalística. Quer dizer, para se fazer um info é necessário ao infografista mais que uma pesquisa de referências, como é comum na produção de ilustrações. Há que se levantar e apurar informações; dimensioná-las de acordo com o objetivo do trabalho; traduzi-las o máximo possível para a linguagem não-textual e relacioná-las de forma clara com o elemento textual, que também deve ser levantado, pelo menos em parte, pelo infógrafo. Não se trata de fazer uma "arte" que apenas complemente uma matéria apurada, escrita e editada por outros. Trata-se, sim, de um trabalho jornalístico no exato sentido do termo, onde as informações apuradas são apresentadas com base em técnicas de ilustração, complementadas por palavras (MORAES, 1998, p.121).

Portanto, o rigor jornalístico na apuração dos dados e informações, bem como a responsabilidade e ética em todo o processo de desenvolvimento, são questões que devem se sobrepor a quaisquer outras, inclusive estéticas. Ao ignorar os limites impostos por uma investigação precisa, pode-se incorrer em resultados infames, tais como os mencionados anteriormente, sobre a caça a Osama Bin Laden, que resultaram o manifesto de Giner e Cairo (2011). No entanto, isso não significa que um infográfico não possa dispor de uma estética apurada.

Sobre os objetivos ao se usar o infográfico como ferramenta comunicacional, Leite (2018), em entrevista para esta pesquisa, afirma que ele não deve ser usado de forma supérflua, quando não é necessária:

Porque, na eterna luta entre artistas de redação e jornalistas de redação, há muito uma briga para que o infográfico seja usado como um adorno. E esse é um momento que o infográfico não deve ser usado. Por quê? Porque eu sou contra adornar uma página? Não. Eu acho o belo, belo, eu fiz Escola de Belas Artes. Mas eu preciso saber se aquele momento que eu estou usando a infografia, ela está sendo um decodificador, um facilitador de entendimento, ou se ela simplesmente está ali como um mais uma trave na frente do que é preciso ser visto (LEITE, 2018).

Ainda, sobre a responsabilidade jornalística ao pensar o objetivo de determinados infográficos, Damian (2016), comenta que se deve priorizar a audiência no momento de decidir a pauta e a forma como ela será desenvolvida, um papel importante do editor. Isso pode ser ilustrado pelo relato sobre uma proposta de pauta sobre o Bóson de Higgs. Na época, não havia uma compreensão clara do que seria, devido à complexidade do material disponível para apuração. Isso poderia prejudicar o infográfico:

[...] (chegou alguém para dizer) "vamos fazer um infográfico sobre o Bóson de Higgs!". E você fala: "Você leu essa tratado científico aqui. Você trouxe ele para mim, eu li. Eu não entendi, você não entendeu. Você quer que eu embrulhe essa desinformação e repasse para o pobre do coitado leitor que está do outro lado? A gente não entendeu e, mesmo assim, quer levar adiante? Não dá." Acho que isso é importante, também, pensar muito na sua audiência, com quem você está falando (DAMIAN, 2016). 
Há uma longa linha entre os extremos excessos estéticos e objetividade absoluta. O clássico embate entre Tufte e Holmes é um exemplo desse contraponto. Tufte demanda um rigor informativo, em contraste com o apelo "artístico-visual" presente em obras de infografistas premiados como Jaime Serra ou abordagens bem humoradas e criativas de Nigel Holmes. Para Tufte, qualquer tipo de ilustração seria considerada mero elemento decorativo e, portanto, inútil. É preponderante a eliminação do chartjunk, termo cunhado por Tufte que define os pictogramas e ilustrações como o conjunto de elementos desnecessários em uma determinada visualização de dados. Ao criticar o infográfico Diamonds were a girls 's best friend (Figura 42), a respeito do preço médio de diamantes ao longo dos anos, desenvolvido por Holmes, Tufte deixa clara a sua opinião ao sugerir que aqueles que promovem o chartjunk não possuem os dados corretos e usam subterfúgios para dar vida ao gráfico:

Promotores do chartjunk imaginam que números e detalhes são chatos, enfadonhos, tediosos, requerendo ornamentos para avivarem. Decoração cosmética, que frequientemente distorce os dados, nunca salvará uma falta de conteúdo subjacente. Se os números são entediantes, então você tem os números errados ${ }^{57}$ (TUFTE, 1990, p.34, tradução nossa).

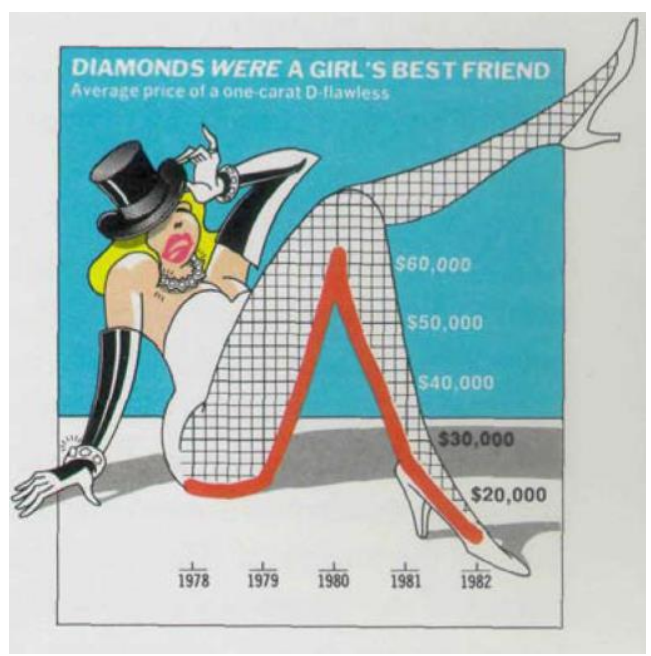

Figura 42 - Infográfico desenvolvido por Holmes, criticado e usado por Tufte como exemplo de chartjunk, no livro Envisioning Information. Fonte: TUFTE (1990, p.34).

${ }^{57}$ No original "...imagine that numbers and details are boring, dull, and tedious, requiring ornament to enliven. Cosmetic decoration, which frequently distorts the data, will never salvage an underlying lack of content. If the numbers are boring, then you've got the wrong numbers." 
Há, no entanto, questões estéticas que não podemos desconsiderar em uma infografia, tal como o seu apelo visual como recurso para atrair o leitor ao assunto. Mesmo as abstrações exploradas nas visualizações de dados podem ser visualmente agradáveis, não apenas por quesões de contraste, tamanho, posicionamento espacial, proporção e demais atributos estudados pela percepção visual, mas também por fatores culturais, que revelam possíveis qualidades ou características em um recorte temporal. Holmes faz alusão aos termos e às teorias analíticas de Tufte, defendendo uma abordagem que chame a atenção do leitor como forma de fazer com que a mensagem seja lida:

Uma boa abordagem para gráficos informativos inclui um apelo ao leitor, imediatamente seguido por um verdadeiro relato da história, seja ela estatística, geográfica ou diagramática. Essa é a diferença entre a abordagem de Tufte e a minha: sua ciência pura versus meu mix de ciência e cultura. Eu quero dar espaço para o prazer, satisfação, apreciação estética e sagacidade, e uma abordagem "você pode entender isso" amigável (HELLER, 2006, p.78).

Uma abordagem analítica não exclui a exploração da dimensão estética em um infográfico, mas subordina-a à clareza e busca a eliminação de elementos supérfluos e decorativos. Tufte leva essa abordagem a um extremo, com um purismo acadêmico que pode não ser adequado em todos os casos. De acordo com Cairo (2008, p.35), um profissional experiente "sabe que, às vezes, e de acordo com o tema, um gráfico que faz uso de bom humor e elementos lúdicos pode ser muito eficaz”. Para Heller, Holmes faz uso de um método que nem sempre é capaz de comunicar qualquer tipo de informação, mas crê "no poder da ilustração e do humor para ajudar o leitor a compreender números abstratos e conceitos científicos complicados” (HELLER, 2006, p.xxii). É fundamental, então, identificar as oportunidades de uso de recursos "não estritamente relacionados a algum dado ou informação", mas que sejam úteis para ambientar ou atrair o leitor, potencializando as chances de que ele leia, efetivamente, o infográfico.

Portanto, neste trabalho, considera-se que, desde que obedecidos princípios éticos no que diz respeito à qualidade investigativa, apuração de dados, clareza e manutenção estrita a fatos, as características estéticas presentes em infográficos ou gráficos possuem funções que vão além da representação nominal de números e descrições. Elas detêm um discurso intrínseco, reforçam argumentos e trazem o leitor a uma narrativa que o conduz à descoberta de novos conhecimentos e à compreensão de fatos. Se os elementos forem minimalistas, com ausência de 
grafismos ou elementos desnecessários, ainda assim, ele está "dizendo" algo por meio de sua aparência ao leitor. Por exemplo, um infográfico mais analítico (menos estetizante) sobre dados econômicos em uma publicação voltada a um público de economistas pode ser adequado para transmitir suas mensagens de forma a apresentar a esse grupo de leitorer um discurso de "seriedade". Seria possível que esse direcionamento encontrasse fundamentação nos princípios de Tufte e não coubesse, no exemplo, toques do humor de Holmes. No entanto, não se questiona a seriedade do trabalho La Ballena Franca, de Serra, apesar de todo o seu apelo estético. Apenas é possível afirmar que o seu leitor é outro. Tudo é uma questão de discurso e de como ele é apresentado ao seu auditório. Seja de forma analítica, por meio de recursos com apelo estético ou mesmo de forma híbrida, o objetivo final é informar o leitor.

\section{3. \\ Categorias}

Se notamos a ausência de consenso em relação ao termo infográfico, no que tange à concordância em relação a classificações, o problema é ainda mais complexo. Há diversas propostas apresentadas por pesquisadores e profissionais, mas, conforme se aumenta a tentativa de enclausurar e detalhar categorias específicas em listagens complexas, maior é a dificuldade aparente na aceitação ou reconhecimento. Algumas propostas oferecem classificações que funcionam de forma didática, como um meio de identificar modalidades e classes, inserindo-as de forma organizada em um discurso acadêmico. Entretanto, há classificações que pecam em aplicabilidade no cotidiano ou tornam-se anacrônicas por não serem capazes de acompanhar o fluxo de inovações próprio de uma linguagem híbrida como a infografia. Para Lima (2015, p.121), uma determinada classificação de infográficos "baseada em tipo de conteúdo deve estar relacionado a um momento histórico específico, ou se arrisca a ignorar as constantes mudanças do design jornalístico.”

A falta de termos coesos dificulta a interação dos responsáveis pela elaboração dos infográficos com os demais profissionais e, em certos casos, gera interferências em conversas entre os próprios infografistas, como podemos atestar no relato de Tarso Silva, infografista do GloboEsporte.com: "as vezes é complicado 
conversar até mesmo com um outro infografista, pois se eu uso o livro do Kanno como referência e ele usa outro autor, a gente pode estar se referindo a um mesmo tipo de gráfico, mas com nomes diferentes. Isso atrapalha” (SILVA, 2018).

Nota-se, portanto, que a busca por uma classificação suficientemente reconhecida e coerente pode auxiliar tanto a academia quanto os profissionais. É importante frisar que há inúmeras tentativas de classificação realizadas nos últimos anos. Em alguns casos, como em relação às visualizações de dados, há propostas de taxonomias que estão bem difundidas e são úteis como fonte de consulta e referência. Como as ferramentas de visualização de dados são muitas vezes usadas de forma combinada ou mesmo como elementos centrais em infográficos, a consolidação de termos é muito proveitosa para o campo como um todo.

Apesar de o foco desta pesquisa não ser elaborar uma nova classificação, nem detalhar demasiadamente cada uma das categorizações relatadas, é necessário observarmos a lógica envolvida em algumas das principais propostas identificadas em nossa investigação por meio de revisão bibliográfica, entrevistas e experiência no campo. Com isso será possível melhor compreender tanto a profusão de termos quanto as principais abordagens usadas na elaboração de infográficos.

\subsection{1. Categorias por forma}

Sancho propôs categorias, desde os anos 2000, como forma de distinguir o que é ou não um infográfico. Sua classificação inicial era composta por infografias individuais (divididas em comparativas, documentales, escénicas e ubicativas), infografias coletivas e megainfografias. As infografias individuais seriam sintéticas, cumpririam uma função de complemento e apoio aos textos e poderiam: comparar diagramas e dados estatísticos, dados e representações (comparativas); oferecer um conteúdo didático, demonstrando o desenvolvimento de eventos, fenômenos ou objetos, baseado em documentos (documentales); abordar relatos, narrações de fatos, descrições de locais ou objetos que representem a informação (escénicas) ou com conteúdo referente a espaços físicos, locais, mapas e espaços geográficos (ubicativas). Já as infografias coletivas ou megainfografias poderiam substituir textos, como um sistema fechado em que podem combinar mais de uma 
infografia em uma unidade discursiva de maior complexidade (SANCHO, 2001, p.148).

Há exemplos de divisões em categorias gerais, tais como a proposta de Kanno (2013, p.60), artes-texto, gráficos, mapas e diagramas ilustrados que são detalhados em subitens como cronologias, fichas, tabelas, gráficos pizza, barra, mapas de localização, mapas não geográficos, organogramas, storyboard etc. As categorias gerais de Kanno possuem alguma semelhança com a separação de elementos imagéticos na linguagem jornalística, de Peltzer (1991, p.125), mencionados no capítulo anterior, que os divide em gráficos, infográficos, mapas, símbolos, ilustrações, quadrinhos informativos (comics) e iconografia animada. Já De Pablos (1999) organiza os grupos em (gráficos de) barras, pizza, tabela numérica, sumário infográfico e diagrama jornalístico. Ou seja, os grupos de cada autor, apesar de usarem termos similares, possuem diferenças no modo de escolha de categorização.

Uma categorização detalhada e, curiosamente, formatada como um infográfico, é o poster explicativo Infographia, de Nigel Holmes (2011). Descrito como "uma taxonomia idiossincrática", o diagrama permite a exploração das classificações listadas, partindo de grandes grupos denominados impressos, tridimensionais, web/motion, visualizações de dados e aprofundam-se em diversas subcategorias e detalhamentos em vários níveis (Figura 43). O poster também disponibiliza informações sobre as razões pelas quais os gráficos informativos são usados, as suas raízes, as escolas de pensamento, os autores e as obras de referência para o campo. O conteúdo, como esperado, acompanha toques do humor de Holmes sem sacrificar a precisão ou a compreensão das informações disponíveis. 


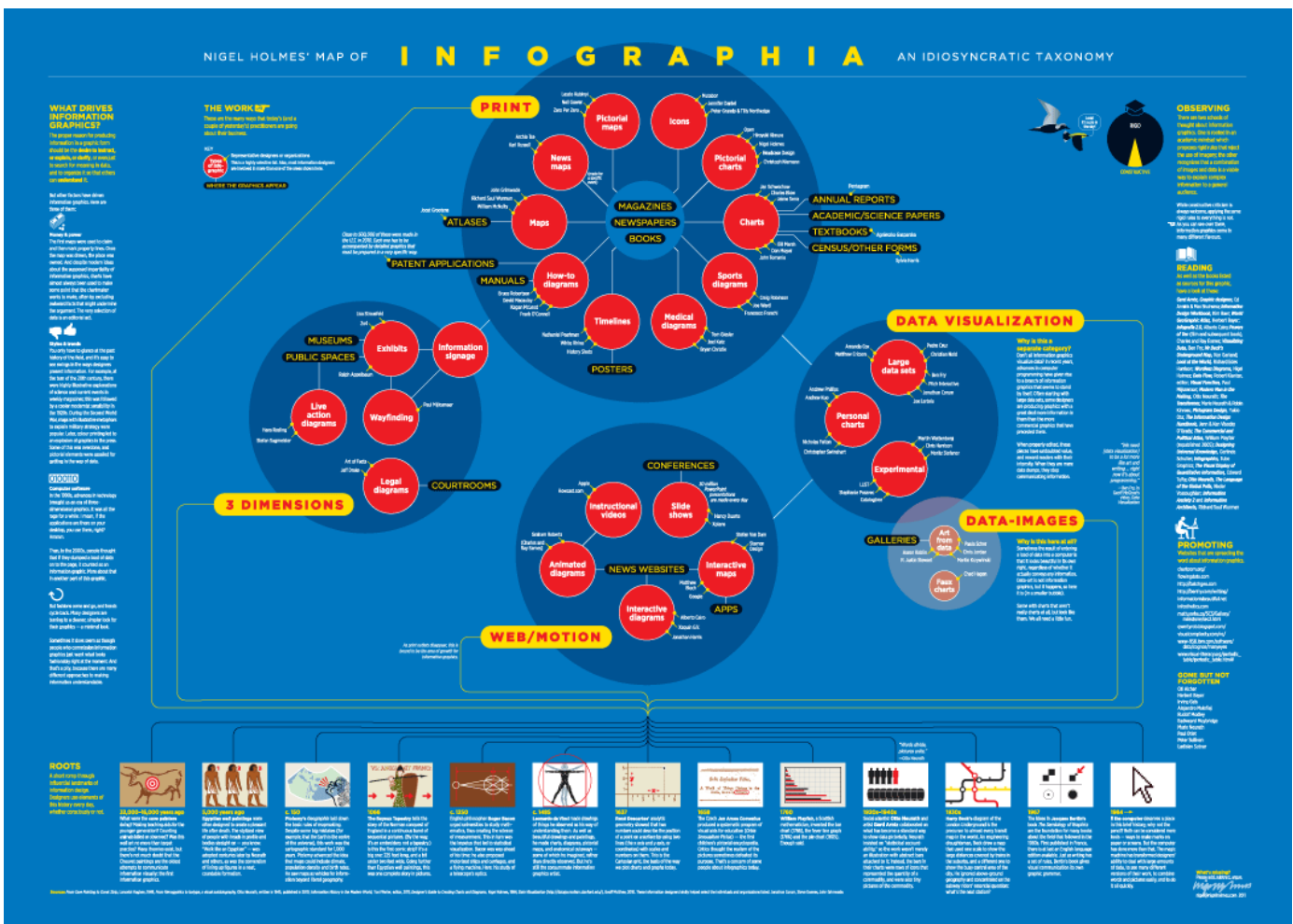

Figura 43 - Infographia, poster com mapeamento das categorias de Nigel Holmes. Fonte: RENDGEN (2012, n.p.).

\subsection{2. \\ Categorias orientadas pelo lead jornalístico}

Como forma de classificação em função do conteúdo, os modelos de Roam (2008) e Ruys (2013) possuem uma associação ao lide jornalístico (ou lead, em inglês), que deve responder às perguntas: o quê (ação), quem (agente), quando (tempo), onde (lugar), como (modo) e por quê (motivo) do fato central da história da matéria. Portanto, a forma ou tipo de gráfico ficam subjugados ao tipo essencial de pergunta, influenciando a classificação. Os autores sugerem arquétipos de gráficos para cada uma das situações, nas quais o resultado varia dependendo da estrutura dos dados e da combinação de questões a serem respondidas. Como pode se observar no quadro proposto por Ruys (Figura 44), há 21 opções de gráficos distintos para as respostas, bem como combinações entre elas. 


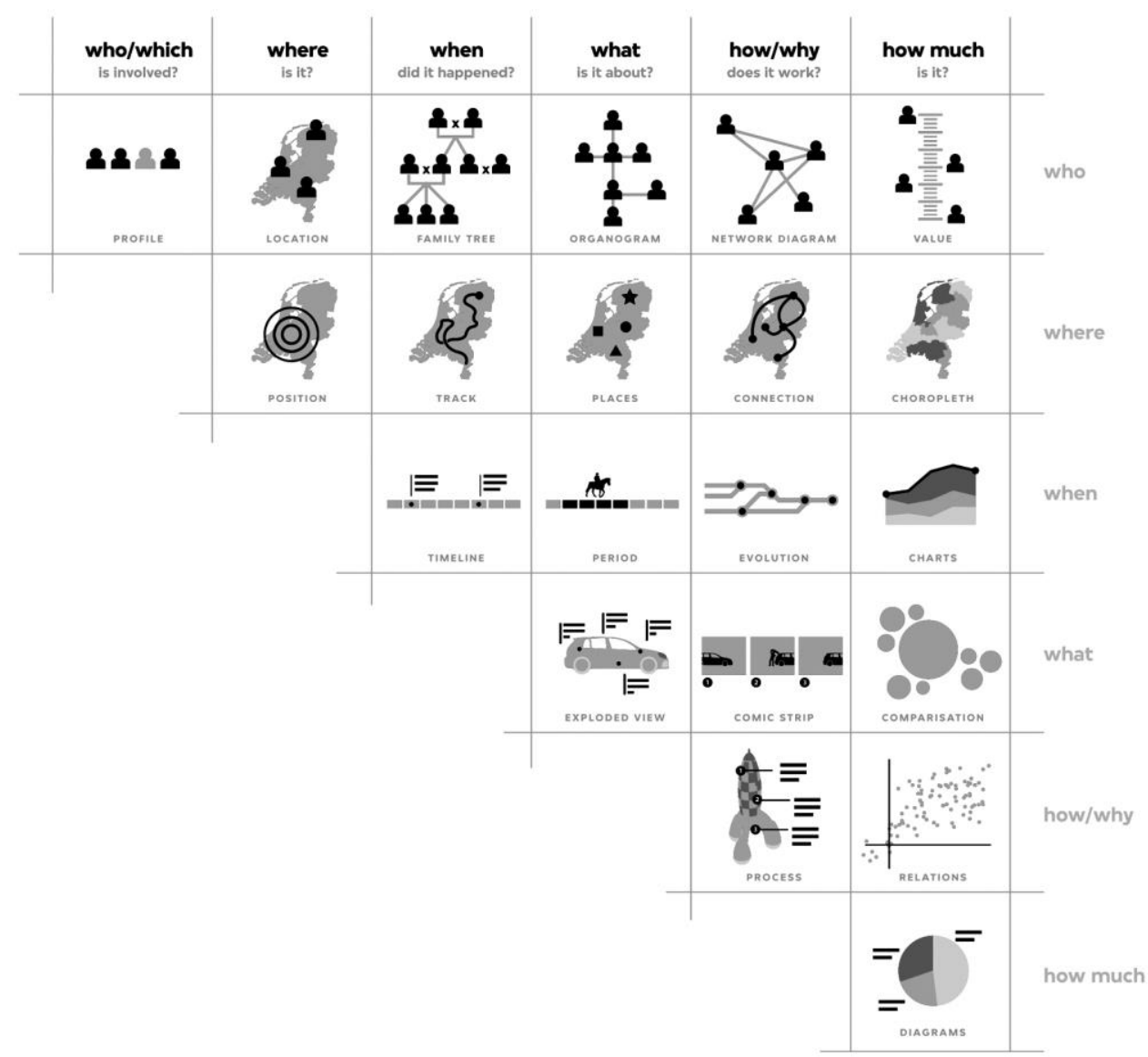

Figura 44 - Gráfico com proposta de taxonomia de infográficos baseado no lead jornalístico. Fonte: RUYS (2013, n.p.)

Para Moraes (2013, p.73), a elaboração de um infográfico depende do tipo de pergunta a ser respondida. Os infográficos podem ser de três tipos, de acordo com as perguntas as quais se relacionam: exploratórios, explanatórios ou historiográficos. O tipo exploratório refere-se às perguntas o que?, quem? ou onde?. Ocupam-se em descrever objetos, pessoas ou lugares e possuem um baixo grau de complexidade em relação às ferramentas visuais para exibição de informações (mapas, plantas, vistas explodidas, gráficos estatísticos, fotos etc.). Os infográficos explanatórios têm por objetivo responder às perguntas como? e por $q u \hat{e}$ ? Buscam explicar o funcionamento de objetos ou fenômenos, demonstrando relações de causa e efeito, conexões entre os elementos, organizações etc. ou como se desenvolveu um determinado evento. Além disso, demandam mais tempo para o desenvolvimento e fazem uso de diagramas, quadros tipo passo a passo, fluxogramas, dentre outras ferramentas que auxiliem a estabelecer uma narrativa de fatos ou relações. Já os infográficos historiográficos são aqueles que 
contextualizam um determinado elemento, fato ou pessoa, em relação a uma sequência de eventos históricos por meio de linhas do tempo e cronologias. Estes propõem-se a responder à pergunta quando? Requerem uma intensa pesquisa e, de acordo com o autor, devem ser produzidos sob supervisão de especialistas (MORAES, 2013, p. 76).

Uma vantagem de uma abordagem que tenha relação direta com o lead jornalístico é que ela facilita a atuação da equipe de infografia junto aos demais profissionais. $\mathrm{O}$ uso de uma linguagem familiar torna mais eficaz a conversa e troca de informações com o jornalista responsável pelo texto, tendo em vista que o repertório deste, em termos de soluções visuais, costuma ser mais restrito que as soluções gráficas que podem ser sugeridas por um infografista ou jornalista visual que atue junto com a equipe de arte (SILVA, 2018). Assim, o debate para a solução em equipe fica concentrada em quais questões devem ser respondidas, e menos em uma longa lista de termos e classificações que, nem sempre, serão compreendidas por todos os atores.

\subsection{3. \\ Catalogação de ferramentas}

Apesar de uma ampla variedade, o campo das visualizações de dados possui diversas soluções interessantes de classificação de métodos de visualização. As ferramentas classificadas nesse espectro, tais como variados tipos de gráficos de barra, pizza, linhas do tempo, organogramas etc. são habitualmente usadas como parte de infográficos. Portanto, classificações organizadas podem servir de referência para infografistas, tanto para ampliarem o seu repertório, quanto para exibirem como exemplo de possíveis soluções gráficas aos demais profissionais envolvidos antes de despender tempo em prototipação.

Um extenso trabalho de pesquisa e catalogação enciclopédica de gráficos informativos foi desenvolvido por Harris (1999), publicado com o título Information Graphics: A Compreensive Illustrated Reference. O trabalho busca definir, categorizar e ilustrar mais de 850 itens entre gráficos, mapas, diagramas e tabelas. A busca por uma terminologia coerente fica evidente no título de definição de cada item, pois não apenas existe o nome em destaque, mas também são mencionadas suas variações. Por exemplo, sobre os gráficos tipo pizza, o autor 
menciona que podem ser referidos como gráficos tipo torta, círculo dividido, gráfico de porcentagem circular, gráfico de setor, diagrama de círculo, sectograma, gráfico círculo ou gráfico segmentado, complementando que os gráficos pizza são membros da família de gráficos de área proporcionais (HARRIS, 1999, p.281). Ou seja, apesar de não ser um sistema prático de consulta, a catalogação de Harris é um dos primeiros trabalhos mais completos no campo.

A Tabela periódica de métodos de visualização, desenvolvida por Lengler e Eppler (2007), é um projeto que propõe definir e compilar 100 métodos de visualização existentes de forma a desenvolver um sistema que sirva para consulta e facilitação de escolha de determinadas visualizações adequadas a diferentes contextos. O gráfico (Figura 45) assemelha-se, em aparência e lógica, à clássica tabela periódica elaborada pelo químico Dmitri Mendeleev, publicada em 1869. A tabela separa as visualizações em seis grupos: visualizações de dados, com representações esquemático-visuais de dados quantitativos; visualizações de informações, que se referem ao uso de representações de dados interativas como forma de ampliar a cognição; visualizações de conceitos, que auxiliam a elaborar conceitos qualitativos, ideias, planos e análises; visualizações de estratégia, usadas para análise, desenvolvimento, formulação de estratégias em organizações; visualizações metafóricas, usadas para organizar e estruturar graficamente as informações por meio de metáforas visuais e visualizações compostas, com o uso de diferentes representações gráficas em conjunto (LENGLER e EPPLER, 2007, p.85).

Para Few (2007), a tabela possui um design que comunica de forma pobre, apesar do tema, e questiona a utilidade em se adaptar o resultado da pesquisa a uma tabela que não foi criada para tal propósito. No entanto, este autor menciona que a separação em categorias (dados, informações, conceitos, estratégia, metafóricas e compostas) exibe uma organização útil. De qualquer forma, a tabela foi difundida em meio acadêmico e blogs especializados, talvez justamente pela semelhança com a tabela periódica clássica, estimulando o interesse no resultado. 


\section{A PERIODIC TABLE OF VISUALIZATION METHODS}

\begin{tabular}{|c|c|c|c|c|c|c|c|c|c|c|c|c|c|c|c|c|c|}
\hline$\underset{\text { continum }}{\mathbf{S}}$ & & & \multicolumn{4}{|c|}{ 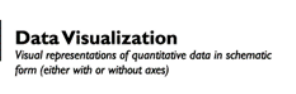 } & & \multicolumn{4}{|c|}{ 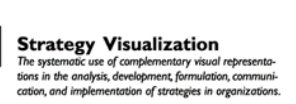 } & & & & & & 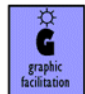 \\
\hline >io & 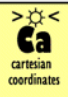 & & \multicolumn{4}{|c|}{ 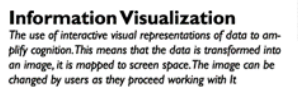 } & & \multicolumn{4}{|c|}{ 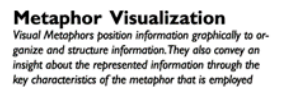 } & 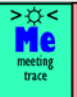 & 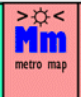 & im & $\underset{\substack{\text { story } \\
\text { template }}}{<-3}$ & ifree $_{\text {tree }}^{>c t<<}$ & $\underset{\text { artion }}{\mathbf{G t}}$ \\
\hline $\begin{array}{c}>\phi<<< \\
P^{\prime}\end{array}$ & $>x$ & & \multicolumn{4}{|c|}{ 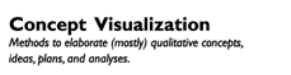 } & & \multicolumn{4}{|c|}{ 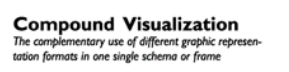 } & $\begin{array}{c}>+\infty< \\
\text { C0 }\end{array}$ & $>$ & $\begin{array}{l}>0< \\
\text { \&s }\end{array}$ & Brp & $\begin{array}{l}>+x^{2}< \\
\text { Funet }\end{array}$ & Ri \\
\hline 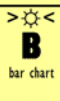 & $>0<$ & $\prod_{\substack{\text { ndar chart } \\
\text { cobmeb }}}^{>+\infty<<<}$ & 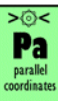 & $\begin{array}{l}>0<< \\
11 y\end{array}$ & $\begin{array}{c}>0+<< \\
\mathbf{G y} \\
\text { gree } \\
\text { diagram }\end{array}$ & 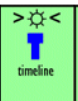 & $\begin{array}{l}>0,<< \\
\text { Vean } \\
\text { diagram }\end{array}$ & ili & 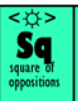 & \begin{tabular}{|c|}
$>0+<$ \\
$\Theta \Theta$ \\
concentric \\
circtes
\end{tabular} & 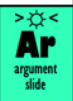 & $\underset{\substack{\text { swim the } \\
\text { diggram }}}{>+0<}$ & $\begin{array}{c}>0+1< \\
\text { Ge } \\
\text { gantt } \\
\text { chart }\end{array}$ & $\underset{\substack{\text { perpectives } \\
\text { diagram }}}{\mathrm{Pej}}$ & $\sum_{\substack{\text { dikmma } \\
\text { diagram }}}^{>\odot<<}$ & $\underset{\substack{<p r a p \\
\text { parater } \\
\text { ruler }}}{<p}$ & 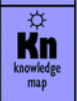 \\
\hline$\underset{\text { histogram }}{>0<<}$ & $\underset{\text { scatterpot }}{>+\infty}<$ & 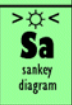 & $\begin{array}{l}>0< \\
\text { information } \\
\text { lense }\end{array}$ & $\sum_{\substack{\text { entiyy } \\
\text { reationship } \\
\text { diagram }}}^{>\mathrm{M}<}$ & $\begin{array}{l}>\text { pot< } \\
\text { Pt } \\
\text { petri net }\end{array}$ & $\underset{\text { flow chart }}{>10<}$ & 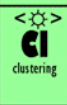 & कर & & 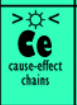 & 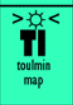 & $\begin{array}{l}>0< \\
\text { Det } \\
\text { decision } \\
\text { tree }\end{array}$ & 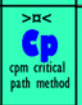 & $\underset{\text { concept an }}{<j<>}$ & $\begin{array}{l}>0< \\
\mathbf{f o r} \\
\substack{\text { concept } \\
\text { map }}\end{array}$ & le & \begin{tabular}{|c|} 
ga \\
Ging \\
cognitive \\
mapping
\end{tabular} \\
\hline $\begin{array}{l}>0<< \\
\text { Thk } \\
\text { twkey } \\
\text { box plot }\end{array}$ & 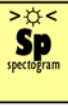 & $\begin{array}{l}>><< \\
\text { Data map } \\
\text { data }\end{array}$ & $\begin{array}{l}>0< \\
\text { Treemap }\end{array}$ & $\begin{array}{l}>0< \\
\text { Cone tree }\end{array}$ & 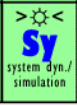 & 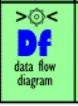 & 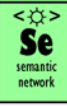 & \begin{tabular}{|l|}
$>0<$ \\
So \\
solt yptem \\
modeding
\end{tabular} & $\underbrace{0}_{\text {sypergy map }}$ & 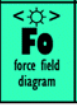 & 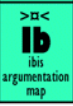 & 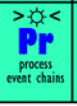 & 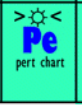 & 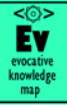 & $\prod_{\text {Vee diagram }}^{>0<}$ & 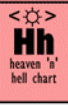 & $\prod_{\text {intomaral }}^{0}$ \\
\hline & Visu & tion & & & $\begin{array}{l}\text { Note: Depe } \\
\text { (c) Ralph }\end{array}$ & $\begin{array}{l}\text { ending } \\
\text { Lengle }\end{array}$ & 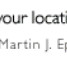 & $\begin{array}{l}\text { on and conn } \\
\text { pler, www.vis }\end{array}$ & $\begin{array}{l}\text { nection spe } \\
\text { isual-literacy }\end{array}$ & $\begin{array}{l}\text { eed it car } \\
\text { y.org }\end{array}$ & sor & to load & po & ure. & & & ersion 1.5 \\
\hline 好 & $\begin{array}{l}\text { Struct } \\
\text { Visuali } \\
\text { Overvi } \\
\text { Detail }\end{array}$ & ion & & 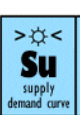 & 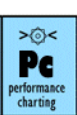 & $\left|\begin{array}{c}>0 \\
\mathbf{S} t \\
\text { stratteg map }\end{array}\right|$ & 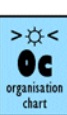 & 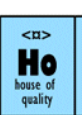 & 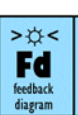 & $\underset{\text { tailure tree }}{\mathbf{F}}$ & 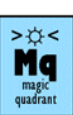 & 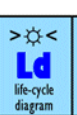 & $\begin{array}{c}>><< \\
\text { Po } \\
\text { porters } \\
\text { fire loces }\end{array}$ & $\underset{\text { s. odde }}{\mathbf{S}}$ & 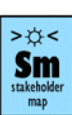 & $\underset{\substack{\text { Ishikam } \\
\text { diagram }}}{0}$ & 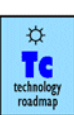 \\
\hline $\begin{array}{l}0 \\
<>\end{array}$ & $\begin{array}{l}\text { Detail } \\
\text { Diverg } \\
\text { Conver }\end{array}$ & $\begin{array}{l}\text { ND Ove } \\
\text { ent think } \\
\text { gent thir }\end{array}$ & iew & $\begin{array}{c}d \\
\text { edgewerth } \\
\text { box }\end{array}$ & $\begin{array}{l}>>0< \\
\text { Pff } \\
\text { portolio } \\
\text { diagram }\end{array}$ & 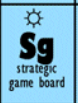 & 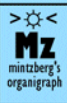 & $\underset{\substack{\text { zwick's } \\
\text { morphologial } \\
\text { box }}}{\mathbf{Z}}$ & 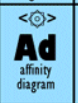 & $\begin{array}{c}\text { a } \\
\text { Dee } \\
\text { deccion } \\
\text { diccover } \\
\text { diagram }\end{array}$ & $\begin{array}{l}>0<< \\
\mathbf{B m} \\
\text { beg matrix }\end{array}$ & 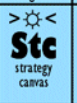 & $\begin{array}{l}>0<< \\
\text { value chain }\end{array}$ & Hy & 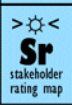 & $\begin{array}{c}>0<< \\
\text { Taps } \\
\text { taps }\end{array}$ & 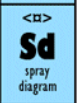 \\
\hline
\end{tabular}

Figura 45 - Imagem da Tabela periódica dos métodos de visualização. Fonte: LENGLER e EPPLER (2007, p.88).

Um projeto em andamento, em sua versão beta, que vale ser mencionado é o proposto pelo Datavizproject, sendo desenvolvido pela Ferdio, agência que realiza projetos no campo da infografia. A iniciativa disponibiliza uma taxonomia de ferramentas usadas para visualizações de dados e infográficos, tentando estabelecer uma nomenclatura com exemplos visuais claros (Figura 46). A visualização dos modelos pode ser filtrada por família (chart, diagram, geospatial, plot, table), por input (a forma como os dados estão oganizados na matriz), por função (comparison, concept visualisation, correlation, distribution, geographical data, part to whole, trend over time) ou por forma (com ícones relacionados ao formato do gráfico, como barras, círculos, mapas etc.). Até o momento, o projeto disponibiliza espécimes de 154 tipos de ferramentas de representações gráfico-visuais em sua base. O fato de o Datavizproject estar aberto para consulta online, bem como de dispor uma vasta investigação e oferta de exemplos, torna-o uma fonte útil de difusão de uma taxonomia e de conceitos que podem auxiliar o estabelecimento de termos mais homogêneos. 


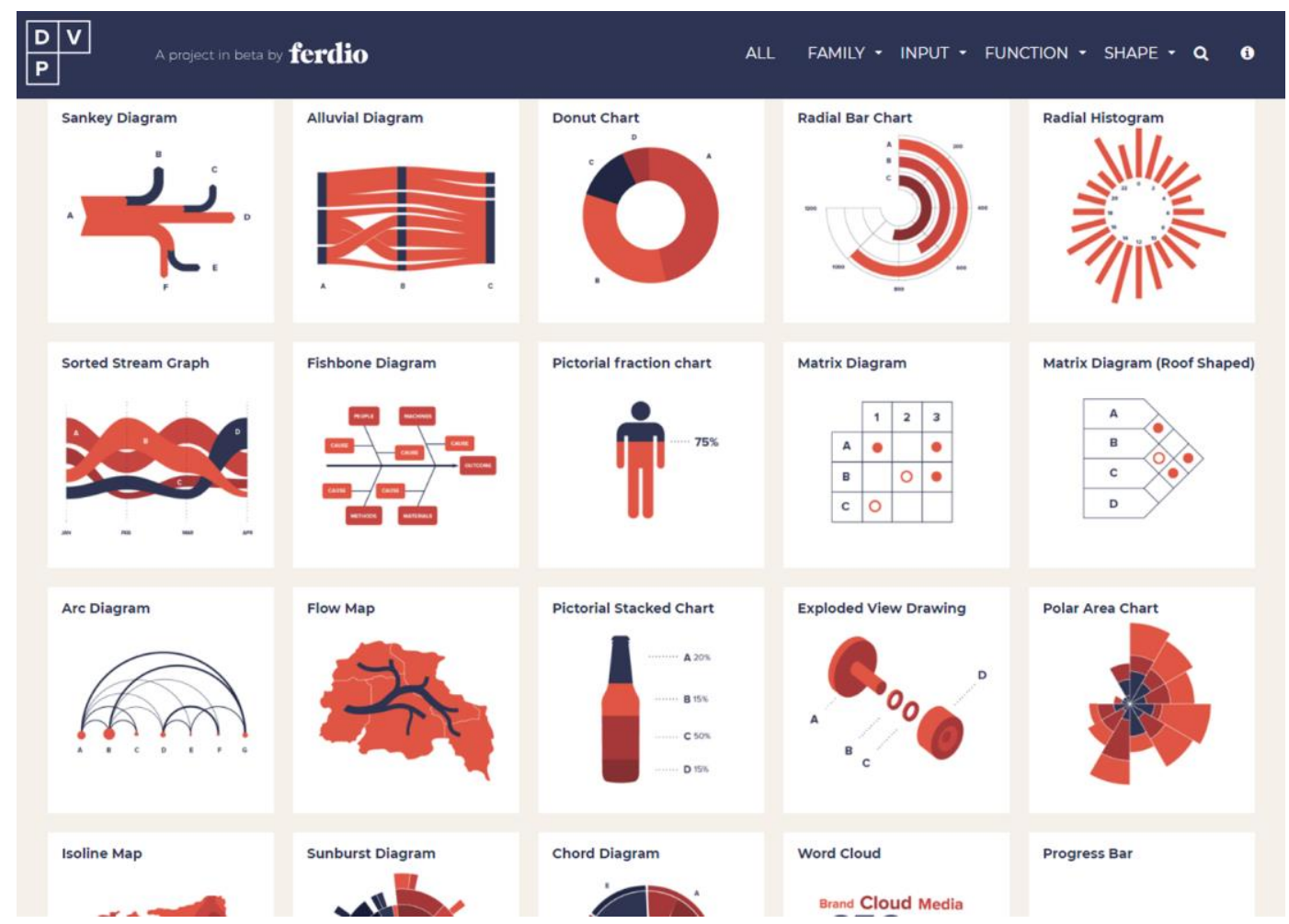

Figura 46 - Imagem do Datavizproject exibindo parte dos exemplos catalogados. Fonte: DVP.

Há diversas propostas taxonômicas complexas realizadas por pesquisadores, profissionais e empresas, porém mais conflitos surgem entre as diferentes terminologias a partir do excesso de detalhamento. Para este trabalho, consideramos que elementos diversos podem ser usados como ferramentas para codificar a informação em um infográfico, sejam eles mapas, gráficos estatísticos, listas, diagramas explicativos, fotografias, animações, vídeos, áudios, interações com bancos de dados, virtual reality, augmented reality, dentre outros meios para transmissão de mensagens de uma forma integrada e complementar. O que caracterizará se "é um infográfico ou não" será a forma como esses elementos se interrelacionam e fazem parte de um sistema, em uma peça que possa ser considerada uma infografia. O que importa é se, utilizando elementos originais e inovadores ou não, a história é contada por meio da integração de vários modais atuando de forma hierarquicamente equilibrada e de maneira complementar, o que caracteriza um infográfico. 


\section{4.}

\section{Conclusões sobre o capítulo}

Neste capítulo, observou-se o papel da infografia no processo de transformação de dados não estruturados em informações que podem vir a se tornar conhecimento. Apresentamos reflexões sobre abordagens estetizantes e analíticas, a fim de identificar a relevância do rigor da investigação jornalística, bem como seu processo de trabalho, como elemento prioritário na elaboração de infográficos. Revisamos, ainda, propostas de categorização diversas, elaboradas por autores relevantes ou projetos que obtiveram ampla difusão no campo.

As questões abordadas levaram-nos a gerar subsídio para a estruturação e a análise dos dados coletados ao longo da pesquisa. Os dados qualitativos e quantitativos foram obtidos por meio de investigação documental, revisão de literatura, consultas a Instituições de Ensino Superior em território nacional e entrevistas realizadas com profissionais e docentes atuantes no espectro da infografia no Brasil.

No próximo capítulo, o foco será direcionado para a trajetória da infografia no Brasil, observando-se marcos relevantes, desde suas origens até o momento atual. Será analisada a participação do país na maior premiação internacional de infografia, como forma de observar a atuação e relevância da infografia brasileira nos cenários interno e externo, ao longo das últimas três décadas. 


\section{5 Infografia no Brasil: a participação no Malofiej}

Para traçarmos um panorama da infografia no Brasil, devemos investigar e relatar, mesmo que de forma breve, o histórico do uso da linguagem infográfica no país, resgatando suas origens e sua evolução. Dessa forma estabelecemos não apenas um retrato da situação atual, mas uma linha progressiva que facilita a visualização de momentos significativos no desenvolvimento da infografia no país. Assim, podemos atribuir a influência de fatores de ordem tecnológica, econômica, cultural e acadêmica a uma cronologia, oferecendo subsídios para a identificação de novos dados e pesquisas subsequentes no campo.

Para a identificação de marcos históricos em uma linha do tempo da infografia em meio jornalístico nacional, foi realizada uma pesquisa bibliográfica sobre o tema, concentrando o foco nas obras de Cairo (2008, 2013), Kanno (1998, 2013), Moraes $(1998,2013,2015)$ e Teixeira (2010), com destaque especial aos dois últimos - autores de obras essenciais para a compreensão da história da infografia nacional. Foram mapeados os principais conceitos, nomenclaturas, pressupostos teóricos e identificadas pesquisas relevantes ao campo. Dessa maneira foi possível delimitar um recorte temporal de referência, para direcionar a busca por dados mensuráveis.

Em paralelo, como forma de balizar a importância do Brasil e de seus veículos de comunicação no espectro internacional, buscou-se identificar os principais prêmios internacionais de infografia, selecionando o de maior importância e longevidade para prospecção de dados. O evento escolhido foi o Malofiej, realizado pela SND-E (o setor espanhol da Society for News Design), em Pamplona, Espanha, que possui mais de 25 anos de existência e é considerado o principal evento de infografia mundial. A coleta dos dados ocorreu por meio de consulta aos relatórios de premiação e press releases do Malofiej (online e impressos), acervos de notícias publicadas em jornais acerca do evento (O Globo, Folha de S. Paulo, Estado de S. Paulo, El Mundo, Clarín, El País e New York Times), revistas (Superinteressante, Mundo Estranho e Veja), portais de comunicação (Abril, Europapress, IG e 
Universidade de Navarra), bem como relatos de infografistas brasileiros agraciados com medalhas da premiação e de pesquisadores do campo. Devido à intensa fragmentação dos dados e à ausência de uma padronização consistente ao longo dos anos, optou-se por organizar, apurar, analisar e formatar os dados consolidados em gráficos comparativos ${ }^{58}$, de acordo com o objeto das informações obtidas. Com esses dados foi possível identificar os principais veículos de difusão de informação por meio da linguagem infográfica no país, traçar um panorama da participação brasileira no evento ao longo do tempo, bem como observar o volume de inscrições, veículos participantes, medalhas recebidas, a transição de relevância da infografia impressa para a digital, dentre outros aspectos detalhados adiante.

Antes de nos direcionarmos aos dados coletados e gráficos confeccionados, como forma de contextualização, convém observarmos as origens da linguagem infográfica no país, para que a linha do tempo não se delimite apenas ao recorte temporal do Malofiej e exclua marcos fundamentais anteriores.

\section{1. \\ Origens}

Não há acordo sobre qual foi efetivamente o primeiro infográfico publicado no Brasil. Pesquisadores buscam estabelecer diferentes marcos que indiquem, pelo menos, o princípio de uma história da infografia nacional. Para Moraes (2013, p.23), apesar de partir de uma generalização com objetivos didáticos, sua divisão histórica indica uma fase que antecede a infografia - entre o período da implantação da imprensa no Brasil, datada de 1808, e as mudanças tecnológicas ocorridas na década de 1980. Essa delimitação, de uma fase quase que "pré-infografia", ocorre pela inexistência do reconhecimento da infografia como sistema até então. Segundo Moraes (2013, p.23), a união de palavras e imagens de forma intuitiva em uma peça gráfica, sem preconizar objetivos formais que um infográfico deve cumprir, diferese do uso da infografia como ferramenta jornalística. Para o autor, se uma peça gráfica foi criada com o objetivo de esclarecer uma determinada informação por

${ }^{58}$ Cabe ressaltar que foram indicados, neste trabalho, dados obtidos por meio de diversos canais, documentos, relatórios, relatos de profissionais e pesquisadores, tendo em vista que nem sempre as fontes oficiais disponibilizaram dados completos consolidados sobre cada ano de premiação, principalmente em edições anteriores a 2004. Portanto, dados sem confirmação até a data de publicação deste trabalho podem não estar incluídos, e casos importantes serão pontuados em cada caso. 
meio da combinação de linguagens verbal e visual, em um sistema fechado, um infográfico, ela ocorreu a partir da década de 1980, pois só nessa época houve a definição do conceito do que seria a infografia. Ou seja, tudo antes disso, apesar de assemelhar-se a um infográfico, seriam peças com outras definições e determinações, que posteriormente entrariam no campo da infografia.

De acordo com Teixeira (2010, p.24), uma das peças que pode ser considerada pioneira no uso de recursos gráficos semelhantes a um infográfico na imprensa brasileira foi publicada no jornal $O$ Estado de $S$. Paulo, em 18 de agosto de 1909 (Figura 47). O gráfico aborda o tema do aumento da navegação no Brasil e assemelha-se a um gráfico de barras, mas com o uso de ilustrações de embarações indicando o aumento ao longo de um eixo de tempo. Outro exemplo pioneiro é o infográfico sobre o aumento da quantidade de automóveis no Rio de Janeiro, publicado na primeira página de $O$ Globo, na edição número 1, em 29 de julho de 1925 (Figura 48). Este seria um gráfico ilustrado no qual é possível identificar, ainda que de forma simples, uma complementação entre o texto verbal e as imagens ilustrativas representativas do aumento do número de veículos entre os anos de 1922 e 1923. Deve-se considerar, também, no âmbito dos periódicos, os gráficos que aliam dados estatísticos e ilustração identificados na revista Veja, na década de 1970, bem como versões embrionárias de infográficos, na década de 1980 (TEIXEIRA, 2010, p.24).

A NAVEGAÇÃO BRASILEIRA

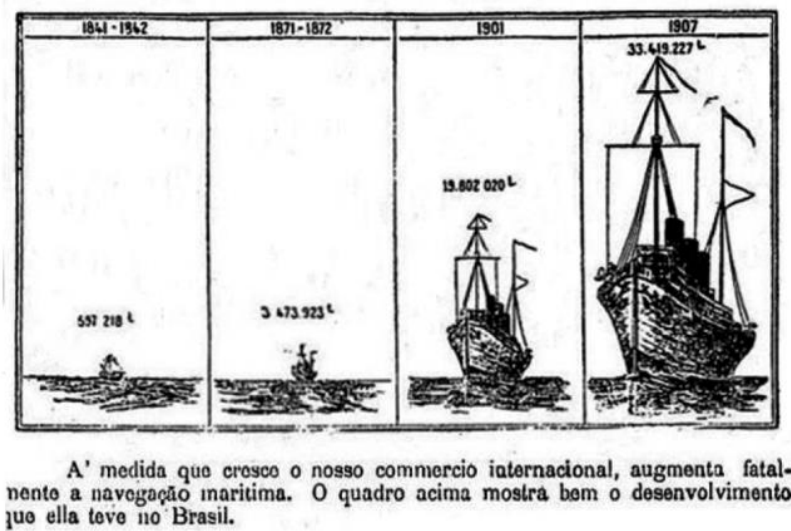

Figura 47 - Gráfico A Navegação Brasileira, publicado no jornal O Estado de S.Paulo, edição de 18 agosto de 1909. Fonte: TEIXEIRA (2010, p.24). 


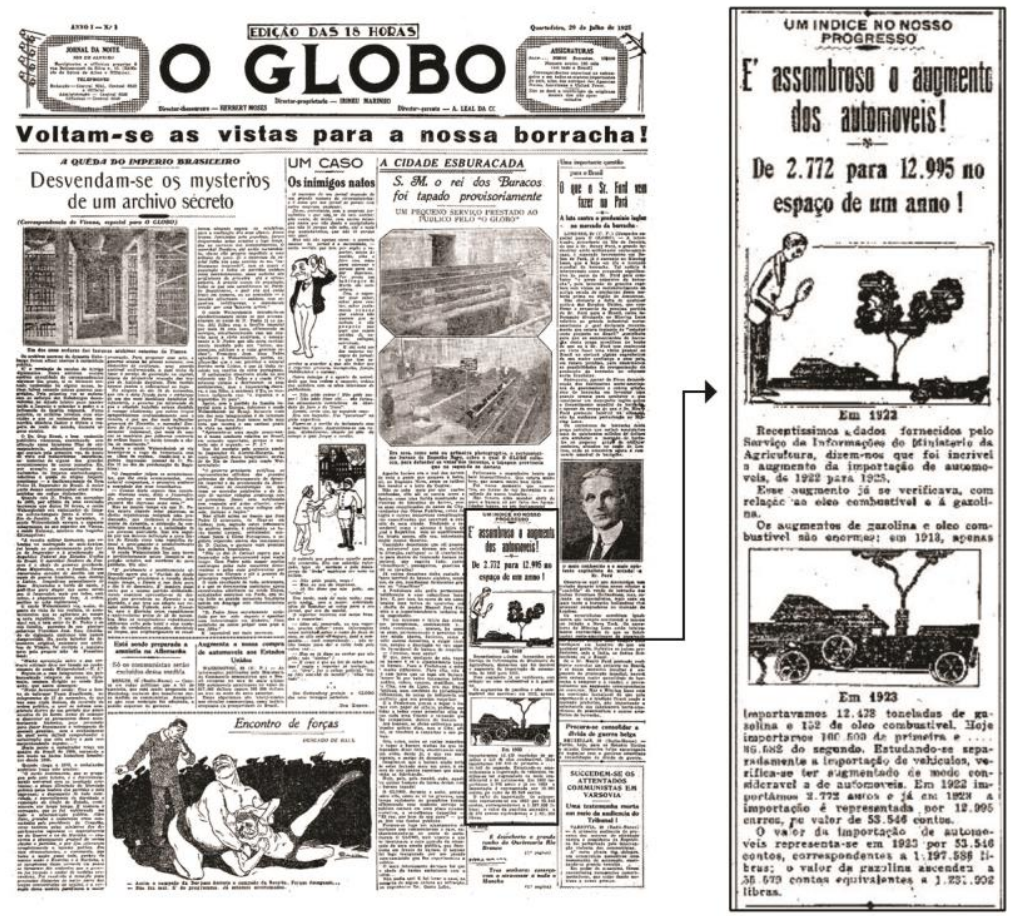

Figura 48 - Primeiro infográfico publicado no jornal $O$ Globo, na capa da edição número 1 de 29 de julho de 1925. (Disponível em: <http://memoria.oglobo.globo.com/linha-do-tempo/o-globo-eacutelanccedilado-9196292> Acesso em: 12 dez. 2017)

Uma outra indicação da falta de consenso sobre o surgimento da infografia no Brasil é notada por meio do trecho do livro A Revista no Brasil "a infografia apareceu nas revistas e nos jornais no final dos anos 70 como uma resposta da imprensa escrita ao impacto visual que a televisão e o computador trouxeram ao universo da notícia" (A REVISTA NO BRASIL, 2000, p.76 apud TEIXEIRA, 2010, p.25). A afirmação de Massimo Gentili, editor de arte da Folha de S. Paulo durante o período do Projeto Folha de 1985-86, de que o jornal foi o primeiro a usar infográficos no Brasil reforça o desencontro de informações acerca do período inicial da infografia nacional.

De acordo com Kanno (2013, p.69), "não existe uma fronteira que delimita a diferença entre a diagramação e infografia. Nem no impresso, nem na web". Ou seja, ainda existe uma dificuldade em se estabelecer o que efetivamente é ou não uma infografia. Se considerarmos essa questão nos estágios primordiais do jornalismo visual no país, a identificação de um infográfico pioneiro torna-se uma tarefa aberta ao debate. No entanto, os exemplos supracitados apontam uma experimentação, mesmo com limitações técnicas, e revelam a tentativa de complementar texto verbal com imagens ilustrativas que se assemelham a 
infográficos simples. Essas peças foram publicadas em veículos de grande circulação nacionais e, portanto, são suficientemente relevantes para serem considerados parte do "grupo de infográficos pioneiros" no Brasil.

Optamos, para este trabalho, por seguir a linha de pensamento de Moraes (2013), segundo a qual o estabelecimento da definição do que seria a infografia na década de 1980 estrutura uma argumentação lógica que simplifica didaticamente a questão. Tomamos também os exemplos pioneiros como marcos históricos na construção do que viria a se tornar a infografia contemporânea.

\section{2.}

\section{Reformas editoriais e intercâmbio de conhecimento}

Poucos jornais sobreviveram à crise da década de 1970, com o abrupto aumento do preço do papel. Na década de 1980, apenas três jornais diários concentravam cerca de $80 \%$ dos leitores cariocas (RIBEIRO, 2006, p.430) e essa distribuição do share de mercado por poucos veículos refletia uma realidade nacional. A concorrência e a busca pela otimização das empresas em busca de permanência no mercado levou à reformulação de diversas editorias dos jornais nacionais, pautadas, de uma forma geral, pelas diretrizes implementadas pela imprensa dos EUA - com grande influência da mídia televisiva. De acordo com Moraes (2015, p.41), o USA Today impulsionou o debate sobre o uso de imagens na construção de discursos jornalísticos e a predominância hierárquica do texto. Para aumentar a área destinada ao uso de imagens, o espaço do texto é reduzido, o que leva a textos mais curtos e diretos. Com essa abordagem sendo assimilada pela concorrência, deflagra-se uma série de reformulações gráficas e editoriais nos jornais americanos. Nasce aí, uma nova atividade:

Esse contexto favoreceu o desenvolvimento de um setor da economia ligado aos jornais: as consultorias em design (editorial) jornalístico, responsáveis pelos projetos de reformulação gráfica e editorial - chamados redesign (MORAES, 2015, p.41).

Essas consultorias se multiplicaram durante a década de 1990, principalmente com o auxílio de seminários e cursos promovidos pela Society for News Design (SND) ou pelas associações de empresas jornalísticas, dado o interesse comercial envolvido em reformulações dessa ordem. As reformulações não se limitam a um novo desenho da página ou mudanças estéticas superficiais. São mudanças muitas vezes estruturais e, até mesmo, sobre a filosofia de trabalho envolvida na 
abordagem do jornal $^{59}$. Para contextualizar a dimensão de um projeto de reformulação, vejamos a descrição de Moraes em relação ao processo:

Fazer o processo de redesign significava atualizar o produto (o jornal) em relação ao mercado, o que representava a aquisição de equipamentos (hardwares e softwares, especialmente); o reaparelhamento do parque gráfico; o treinamento ou a eventual substituição de pessoal; a reorganização da empresa, em alguns casos, e o redesenho do fluxo de produção em todos eles; além de investimentos em publicidade e marketing. $\mathrm{O}$ custo dessa empreitada seria dividido entre com os novos anunciantes e parceiros comerciais interessados em atingir o público do jornal [...] (MORAES, 2015, p.41)

O design ganha relevância na página jornalística, dado o debate no exterior (particularmente pela SND) sobre o uso da impressão off-set em quatro cores e a intensificação do uso de infográficos - sobretudo durante a Guerra do Golfo, no início da década de 1990, quando infográficos preenchiam os jornais impressos devido à escassez de imagens da cobertura do conflito (como vimos anteriormente). Entretanto, apesar do intenso uso na Guerra do Golfo, a real difusão do recurso infográfico ocorreu nos Jogos Olímpicos de Barcelona, em 1992. Moraes (2015, p.42) descreve que os Jogos Olímpicos foram fundamentais para a projeção mundial da Universidade de Navarra como centro de estudos em infografia, pois ela foi sede de um seminário internacional sobre design jornalístico, no qual os gráficos informativos foram apresentados aos espanhóis, desseminados pelo país e foram batizados de infografía. A experiência adquirida na produção de infográficos para os Jogos e sua difusão mundial deram o aval para que as consultorias espanholas se tornassem referência para a América Latina e países em desenvolvimento na Europa e Ásia (MORAES, 2015, p.43).

Portanto, um dos catalizadores do desenvolvimento da infografia no país foi a troca de conhecimento proporcionada pela contratação de consultores internacionais. Segundo Teixeira (2010, p.25), as reformas editoriais “...muitas vezes com a contratação de consultorias internacionais, passaram a ser comuns e, graças a elas, a presença de infografia se tornou mais corriqueira nas páginas de diversos diários". A expressão infografia, inclusive, passou a ser usada no Brasil

${ }^{59}$ A greve dos jornalistas, em 1979, foi um evento que gerou consequências importantes para o futuro dos jornais nacionais. Uma "resposta" ao movimento foi a criação da Associação Nacional de Jornais (ANJ), entidade que congregava os empresários do setor e que, de acordo com Moraes (2015, p.67), foi criada com interesse no desenvolvimento tecnológico, industrial, comercial e empresarial dos jornais de seus afiliados. A ANJ promoveu cursos, seminários e ações que levaram os jornalistas brasileiros a conhecer as propostas gráficas e editoriais americanas e européias, principalmente a partir da década de 1990. 
no fim da década de 1980 justamente pelos poucos profissionais que possuíam contato com a SDN. De acordo com Moraes (1998, p.68), foi "trazida pelos poucos iniciados" e o "seu uso limitava-se ao círculo dessas pessoas".

Em relação ao Brasil, conforme Moraes (2013, p.48), destaca-se a reformulação realizada pelo jornal Folha de S. Paulo, em 1984, denominada Projeto Folha. Dentre inúmeras medidas de controle de produção, com normatizações por meio de manuais, modelos e padrões, a eliminação de quaisquer práticas que não constassem nos parâmetros definidos pelo projeto mostra uma busca sistemática pela eficiência. Em 1988, a Folha implementou o redesign de suas páginas, acentuando o fator gráfico, com destaque aos gráficos informativos, ainda sob influência das tendências iniciadas pelo USA Today alguns anos antes.

No início da década de 1990, o jornal O Dia tornou-se referência nacional por conta do redesign de suas páginas, destacando-se o uso de cores e da infografia. O impacto da influência de profissionais estrangeiros fica evidente no relato de Moraes (2013, p.50):

A Infografia chegou no jornal no final de junho de 1992, trazida por dois jornalistas ligados a Universidad de Navarra - Juan Corrales, professor da instituição, e Mario Tascón, editor de infografia do jornal El Mundo, que ministraram um curso sobre o tema. O foco desse curso foi a inclusão dos designers no centro de decisões da redação, interferindo na fase inicial da produção, quando se decide que assuntos farão parte da edição e que recursos serão utilizados para apresentá-los aos leitores. Em 23 de junho de 1992, foi publicado o que pode ser considerado o primeiro infográfico do jornal.

O jornal O Dia, mesmo não sendo um jornal "de elite", se comparado a Folha de S. Paulo, O Globo e Estado de S. Paulo, destacou-se por ter mais liberdade para experimentar e testar novas ferramentas. Em 1994, O Dia cria um departamento de infografia, que posteriormente se tornaria editoria, em 1996, a primeira do Brasil. Também em 1996, torna-se o primeiro veículo nacional a ganhar a maior distinção no campo da infografia, conquistando o prêmio Malofiej ${ }^{60}$ para o Brasil com o infográfico sobre o pugilista Myke Tyson, de autoria de Ary Moraes em parceria com o repórter Renato Ribeiro, publicado na edição de 13 de agosto de 1995 (Figura 49).

${ }^{60}$ Malofiej é uma premiação internacional de infografia, criada pelos professores da Universidad de Navarra Juan Antonio Giner e Miguel Urubayen, em 1993. É conferida aos jornais e revistas que se destacam com melhores infográficos. 


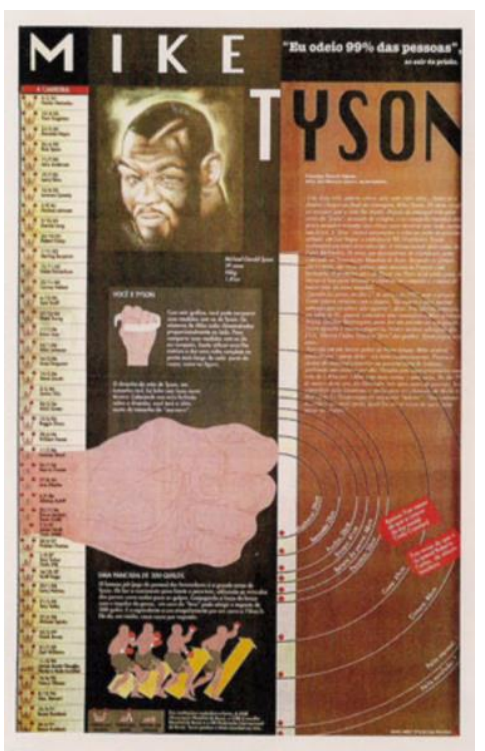

Figura 49 - Infográfico Mike Tyson, responsável pelo primeiro prêmio Malofiej do Brasil (medalha de bronze), publicado no jornal O Dia, edição de 13 agosto de 1995. Fonte: MORAES (2013, p.51).

A Abril, uma das empresas de maior porte no setor jornalístico, também passou a investir em infografia no início da década de 1990. A revista Veja, a publicação semanal de maior circulação do país ${ }^{61}$, obteve seu primeiro Malofiej em 1997. A revista Superinteressante, outra referência nacional em infografia, conquistou seu primeiro Malofiej em 1998, tornando-se uma das publicações mais premiadas posteriormente. Segundo Teixeira (2010, p.26), a Abril criou um grupo de autotreinamento, integrado por membros de algumas revistas. Conforme relato de Eugenio Bucci, da secretaria editorial da empresa no período, à pesquisadora Mayara Rinaldi, "começamos a mandar profissionais para o exterior e a convidar especialistas de fora que nos orientavam nesta busca pelo estabelecimento de uma linguagem infográfica" (TEIXEIRA, 2010, p.26).

$\mathrm{Na}$ década de 1990, alguns fatores foram imprescindíveis para tornar o ambiente propício para o desenvolvimento da linguagem infográfica nacional: a implementação de reformas editoriais, os avanços tecnológicos das ferramentas de confecção (tanto hardware quanto em relação aos softwares), as rupturas no equilíbrio hierárquico na relação entre texto e imagem ${ }^{62}$, o intercâmbio de

${ }^{61}$ A revista Veja lidera o ranking das publicações semanais no país, com 1.195.386 exemplares em média em maio de 2017, de acordo com os dados auditados pelo Instituto Verificador de Circulação - IVC (Disponível em: <https://www.ivcbrasil.org.br> Acesso em: 18 dez. 2017).

${ }^{62}$ Nota-se a divisão de importância entre texto e imagem no trecho do relato de Ricardo Noblat acerca das premissas nas reformas gráfica e editorial do Correio Braziliense, na década de 1990: "No novo jornal: o que importa é comunicar bem ao leitor o que se quer comunicar. Se um 
conhecimento com o exterior, os investimentos em busca de eficiência e inovação para enfrentar as crises e concorrência, dentre outros. Em 1998, ainda em meio a uma época de afirmação e compreensão da infografia como linguagem ${ }^{63}$, Mario Kanno e Renato Brandão lançaram o Manual de infografia da Folha de S. Paulo. No guia é possível observar uma das primeiras definições publicadas no país sobre o que seria infografia no jornalismo impresso:

É o recurso gráfico que se utiliza de elementos visuais para explicar algum assunto ao leitor. Esses elementos visuais podem ser tipográficos, gráficos, mapas, ilustrações ou fotos. A função básica da infografia é enriquecer o texto, permitindo que o leitor visualize o assunto em pauta. Sua função secundária é "embelezar" a pauta,tornando-a mais atrativa (KANNO, 1998, p.2).

A publicação indica a seriedade com a qual a infografia nacional estava se desenvolvendo com uma personalidade própria. Por ser uma novidade, a infografia não fazia parte dos cursos de jornalismo e design, na década de 1990.

...a Infografia, porém, era algo novo, que ainda não fazia parte dessa cultura e, assim, encontrava dificuldades em se disseminar, sobretudo pelo limitado investimento em treinamento por parte das empresas jornalísticas, praticamente as únicas responsáveis pela formação em infografia no Brasil dos anos 1990 (MORAES, 2013, p.59).

Coube às próprias empresas realizar treinamentos e investimentos em consultorias e palestras para que suas redações passassem a compreender o sistema de uso e aplicação da linguagem infográfica em seus veículos. Esse investimento no intercâmbio de profissionais se manteve ao longo da década de 1990 e adiante. Podemos destacar a vinda do infografista norte-americano Jeff Goertzen para implementar o trabalho de infografia na redação do Estado de S. Paulo, em 1993; o ciclo de palestras com Nigel Holmes, reconhecido pelo seu trabalho junto a revista Time, realizado pelo O Globo, em 1994; o workshop promovido pela Associação Nacional de Jornais (ANJ), com Jeff Goertzen, em 1996; o seminário de infografia com a participação de Goertzen, Tascón, dentre outros consultores internacionais, organizado pelo $O$ Globo, em 2003. Ou seja, no Brasil, em função do atraso em relação às implementações e reformas realizadas pelas empresas no exterior, foi possível desenvolver sua linguagem infográfica a partir da contratação e

gráfico, em determinados casos, comunica melhor, publique-se o gráfico, subrtraia-se o texto (NOBLAT, 2002, p.152).

${ }^{63}$ Segundo Kanno (2013, p.33), não havia consenso terminológico: "na imprensa brasileira, é comum que a infografia e a diagramação sejam chamados de Editoria de Arte, ou Departamento de Arte, mas eles não devem se deixar seduzir pela denominação. Não é 'arte' o que fazem". 
treinamentos realizados por profissionais que possuíam experiência consolidada no campo.

Devido à novidade e aos altos custos envolvidos nesse tipo de investimento, as maiores empresas puderam realizar com mais celeridade reformas e implementações tanto em relação ao design das páginas quanto à infografia. No entanto, o processo em redações de menor porte se mostrou mais lento quanto a resultados referentes aos departamentos de infografia. Moraes (2013, p.59) exemplifica com a diferença da qualidade entre o excelente design das páginas de jornais como O Povo (CE), Jornal do Commercio (PE), Diário de Pernambuco (PE), A Tarde (BA), Correio (BA), O Popular (GO), as quais, no entanto, não possuem o mesmo nível de excelência quando se trata de infografia. Um reflexo dessa diferença pode ser notado na intensa concentração das premiações do Malofiej a veículos de comunicação da região Sudeste, principalmente no eixo RioSão Paulo, excetuando-se ocorrências no Paraná e Distrito Federal, como veremos adiante.

\section{3. \\ O Malofiej em dados}

Um fenômeno que auxiliou a reflexão acerca do design de informação nas páginas jornalísticas foi o surgimento de premiações internacionais relevantes. Duas premiações podem ser consideradas mais abrangentes e longevas: o "Best of News Design", da Society for News Design ${ }^{64}$ (SND), desde $1979^{65}$, que premia o design de página de notícias e o Malofiej, do capítulo espanhol da SND, iniciado em 1993, focado especificamente em infografia. Os eventos podem não ter elucidado de forma definitiva e consensual questões como nomenclaturas, taxonomia, o estabelecimento de fronteiras exatas entre o que é ou não é um infográfico, tampouco qual a melhor forma de exibir determinados dados ou contar histórias. No entanto, estimularam o intercâmbio de informações e o

${ }^{64}$ A Society for News Design (SND) é uma organização internacional sem fins lucrativos fundada nos Estados Unidos, em 1979, que reúne profissionais de mídia jornalística e comunicadores visuais. Com mais de 1.500 membros no mundo, organiza anualmente a premiação internacional Best of News Design, que visa congratular as melhores páginas de notícias de jornais e revistas. A SNDE é a sua seção baseada na Espanha.

${ }^{65}$ Inicialmente o nome da premiação era "Best of Newspaper Design” Creative Competition. O título foi alterado para "Best of News Design" e aberto para todas as revistas em 2009. (Fonte: https://www.snd.org/competitions/print/) 
estabelecimento de parâmetros de avaliação. De acordo com a declaração de George Rorick, autor dos mapas climáticos do USA Today, um dos jurados da quinta edição do Malofiej, em 1997, o "Malofiej ajuda a distinguir o que é um gráfico bom e um gráfico ruim. Entretanto, esse não é o objetivo final, mas mais um processo de aprendizado"66(MALOFIEJ, 1997, tradução nossa). Ressaltamos que as premiações também forneceram bases comparativas entre jornais de diversos países e culturas distintas, bem como fomentaram o investimento em linguagem infográfica nas editorias, validando o esforço de profissionais e veículos premiados.

A premiação mundial mais importante, frequentemente referenciada em notícias como o Pulitzer ou o Oscar da infografia, é o Malofiej, criado pelos professores Juan Antonio Giner e Miguel Urabayen, da Universidade de Navarra, em 1993. O prêmio é batizado em homenagem ao cartógrafo argentino Alejandro Malofiej (1938-1987), considerado um pioneiro na infografia. Desde então, em Pamplona, na Espanha, organizado pela seção espanhola da Society for News Design (SNDE) e pela Faculdade de Comunicação da Universidad de Navarra, realiza-se um evento que busca premiar as melhores peças infográficas no mundo.

Já em sua primeira edição, o Malofiej obteve 800 trabalhos inscritos, procedentes de 11 países. Os infográficos enviados para avaliação eram publicações de 100 diferentes veículos de comunicação jornalística. Se levarmos em conta o estágio ainda inicial da difusão da infografia, os números já demonstravam uma boa variedade de origens e quantidade de peças para a mostra competitiva. Ao fim do primeiro evento, foram distribuídas 20 medalhas: 5 ouros, 7 pratas e 8 bronzes. Se compararmos com os números de 2018, após 26 edições do evento, os relatórios demonstram um aumento significativo. Foram 1320 trabalhos inscritos, de 142 veículos de comunicação diferentes, de 30 países. Ou seja, em 26 anos o número de inscritos teve um aumento de $65 \%$, a quantidade de veículos participantes teve um acréscimo de $42 \%$ e houve um incremento de aproximadamente $272 \%$ de países envolvidos. Mais importante que apenas observar números brutos é notar uma progressiva estabilidade ao longo dos últimos anos, como podemos visualizar nos gráficos ${ }^{67}$ que indicam os números obtidos sobre a quantidade de trabalhos

${ }^{66}$ No original "Malofiej helps to distinguish what is a good and bad graphic. However this is not the final objective but more of a processo of learning."

${ }^{67}$ Cabe ressaltar a indisponibilidade de alguns dados oficiais dos anos 1994, 1995, 1999, 2000 e 2001. Optou-se por não incluir números não passíveis de confirmação. Nota-se, entretanto, que os dados omitidos não interferem significativamente no panorama da série histórica. 
inscritos, de veículos de comunicação e de países de origem dos veículos participantes, a seguir:

\section{Trabalhos}

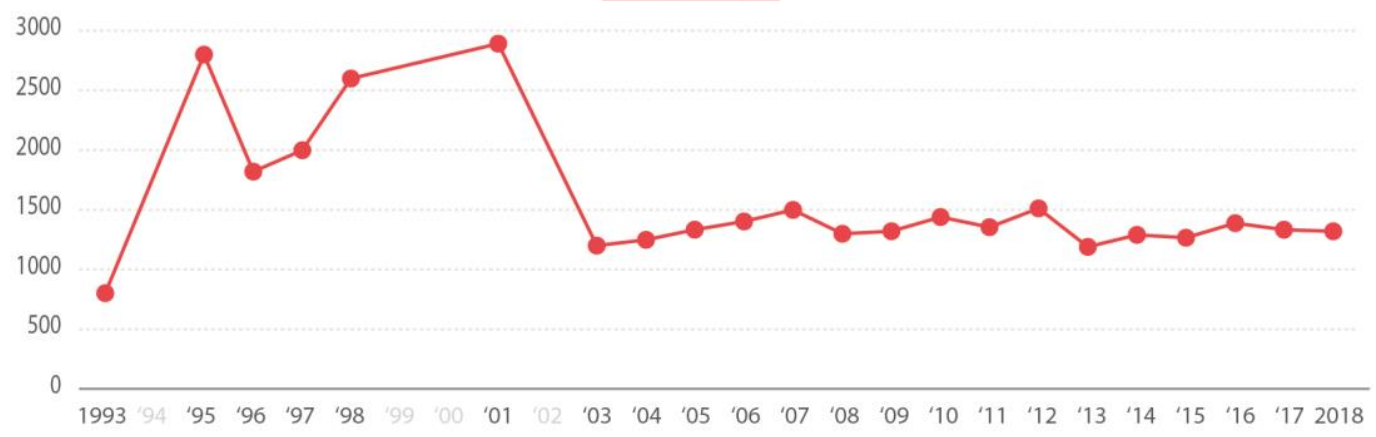

Figura 50 - Quantidade de trabalhos inscritos no Malofiej de 1993 a 2018. Fonte: do autor.

\section{Veículos}

200

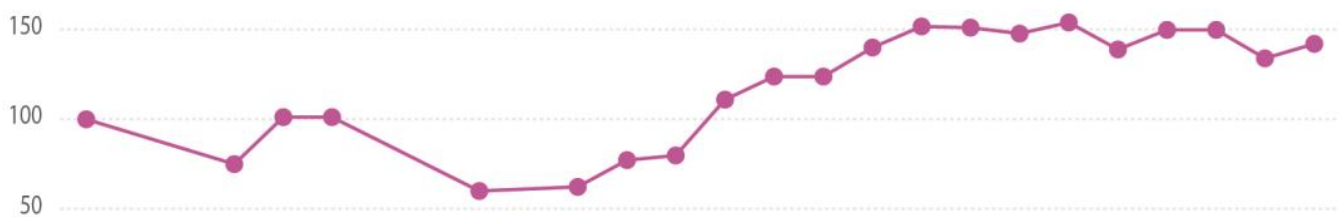

50

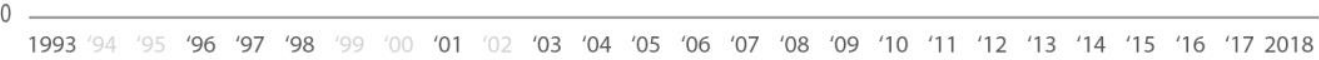

Figura 51 - Quantidade de veículos de comunicação inscritos no Malofiej de 1993 a 2018. Fonte: do autor.

\section{Países}

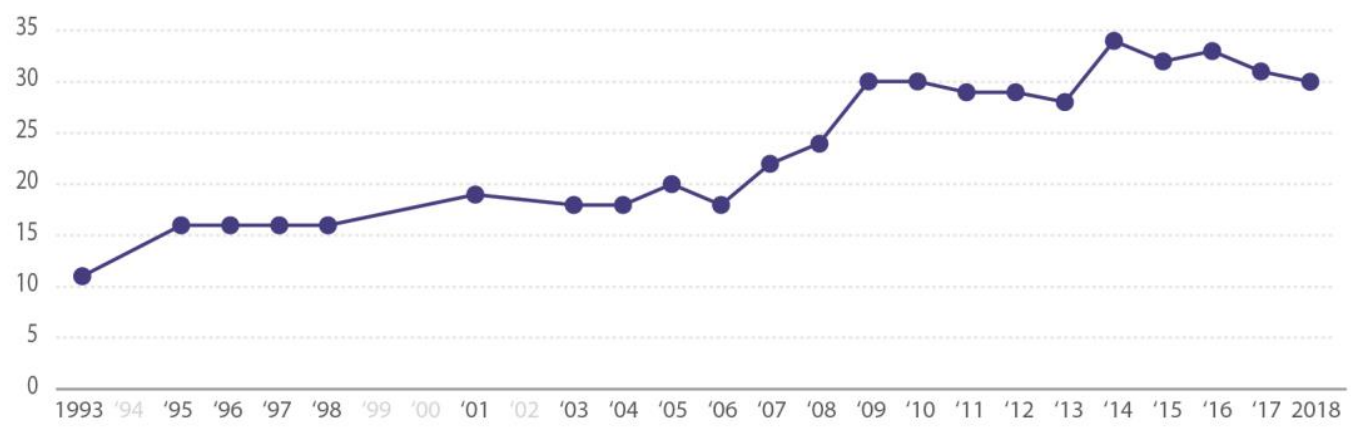

Figura 52 - Quantidade de países participantes no Malofiej de 1993 a 2018. Fonte: do autor.

Os dados demonstram uma quantidade significativa de veículos de comunicação, jornais, revistas, portais etc. participantes atualmente. O número de 
trabalhos inscritos passou por um período de picos no primeiro terço da sequência histórica, atingindo o ápice com 2.910 trabalhos, em 2001. A partir de 2003, no entanto, nota-se uma estabilização na média de aproximadamente 1300 inscritos por ano (Figura 50). Em relação à quantidade de veículos de comunicação participantes (Figura 51), inicia-se com 100, em 1993, e reduz no primeiro terço da série, atingindo o menor número (60) em 2001. Peculiarmente, o ano de 2001 é mesmo com a maior quantidade de trabalhos inscritos. Há um aumento a partir de 2003, estabilizando-se na ordem de 140 veículos inscritos, aproximadamente. O gráfico relativo ao número de países inscritos indica o maior incremento progressivo (Figura 52). Iniciando-se com 11 países, em 1993, e atualmente encontra-se estabilizado na faixa de 30 participantes. O maior número existiu em 2014, com 34 países. A quantidade de países praticamente triplicou desde a primeira edição - o que eleva os premiados a um patamar de notável reconhecimento internacional.

No que tange à quantidade de medalhas, um gráfico de barras foi elaborado, com a indicação das quantidades totais distribuídas por ano ao longo do tempo. No gráfico a seguir (Figura 53), podemos observar que houve um afunilamento na quantidade total de medalhas nos últimos dez anos. No entanto, apesar da tendência, não se pode afirmar a existência de uma estabilização, visto que houve uma queda fora do esperado no número total de medalhas, em 2018. O gráfico indica que não há paridade na proporção de nenhum dos itens avaliados previamente, não se alinhando ao número de trabalhos inscritos, aos veículos de informação ou aos países participantes. 


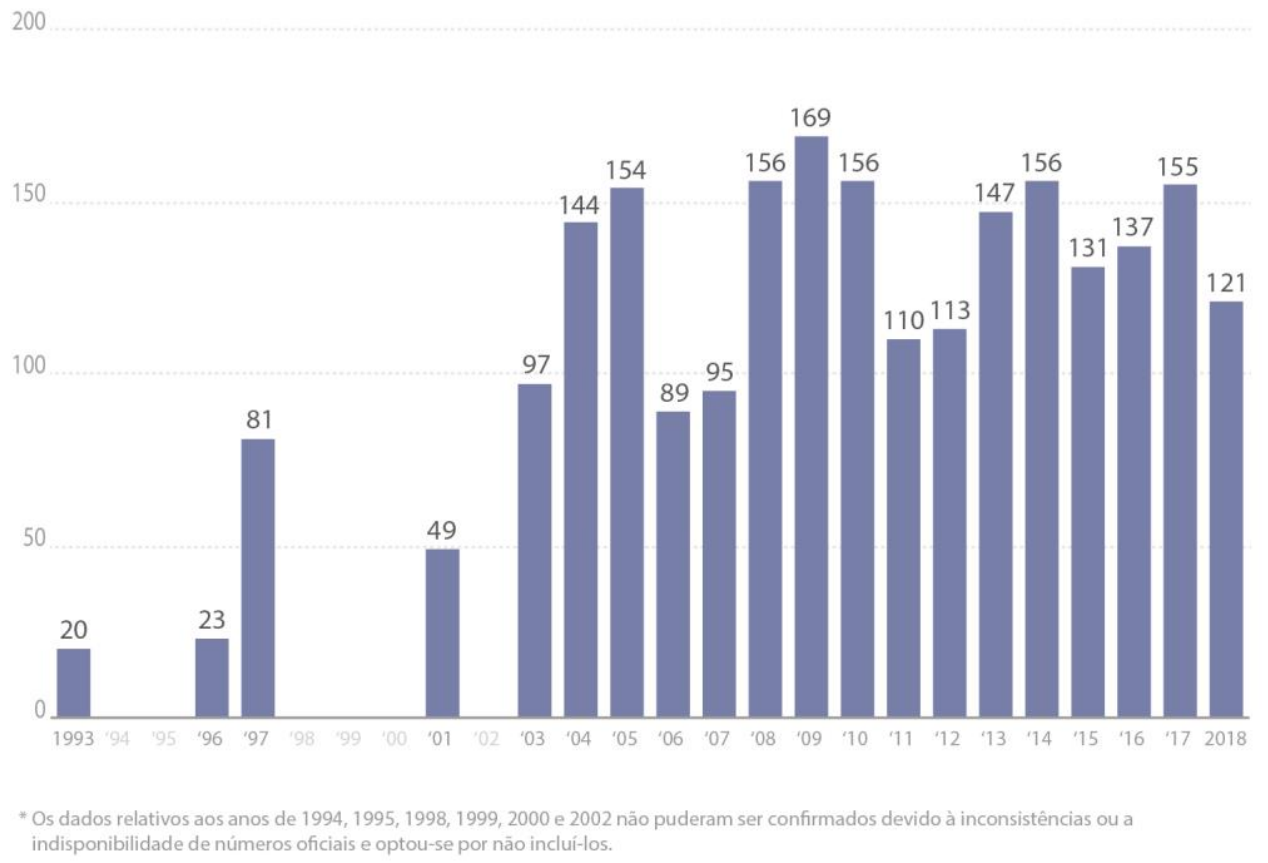

Figura 53 - Número total de medalhas concedidas por ano. Fonte: do autor.

Dentre os diversos fatores que podem influenciar a distribuição de prêmios, salienta-se o fato de o quadro de jurados ser distinto ano a ano. Visões diferenciadas do campo, perspectivas derivadas da origem cultural dos veículos de comunicação dos escolhidos para a avaliação dos trabalhos, tendências surgidas ou saturadas em um determinado período, adoção de novas tecnologias, ou seja, no caso da concessão de medalhas, os números por si só não apontam tendências claras. Seria necessário averiguar os dados com informações de contextos socioculturais ano a ano, o que foge ao escopo dos números aqui compilados.

Já em relação à quantidade de medalhas qualificadas em sua distribuição por ouro, prata e bronze, o gráfico de barras simples não é suficiente. Portanto, um gráfico de barras compostas foi confeccionado para facilitar a visualização. Ao apontarmos a qualidade das medalhas (Figura 54), a visualização da distribuição do tipo de medalhas anualmente torna-se mais clara, visto que cada barra aponta o total de cada ano a partir da soma das barras coloridas que representam cada tipo de prêmio. O gráfico também permite notar os anos em que os dados oficiais não puderam ser confirmados com precisão (1994, 1995, 1998, 1999 e 2002), optando- 
se pela sua exclusão, ou aqueles em que apenas o total foi identificado e exibido (1996 e 2003), sem a confirmação da distribuição por ouro prata e bronze.

\section{No total de medalhas por ano}

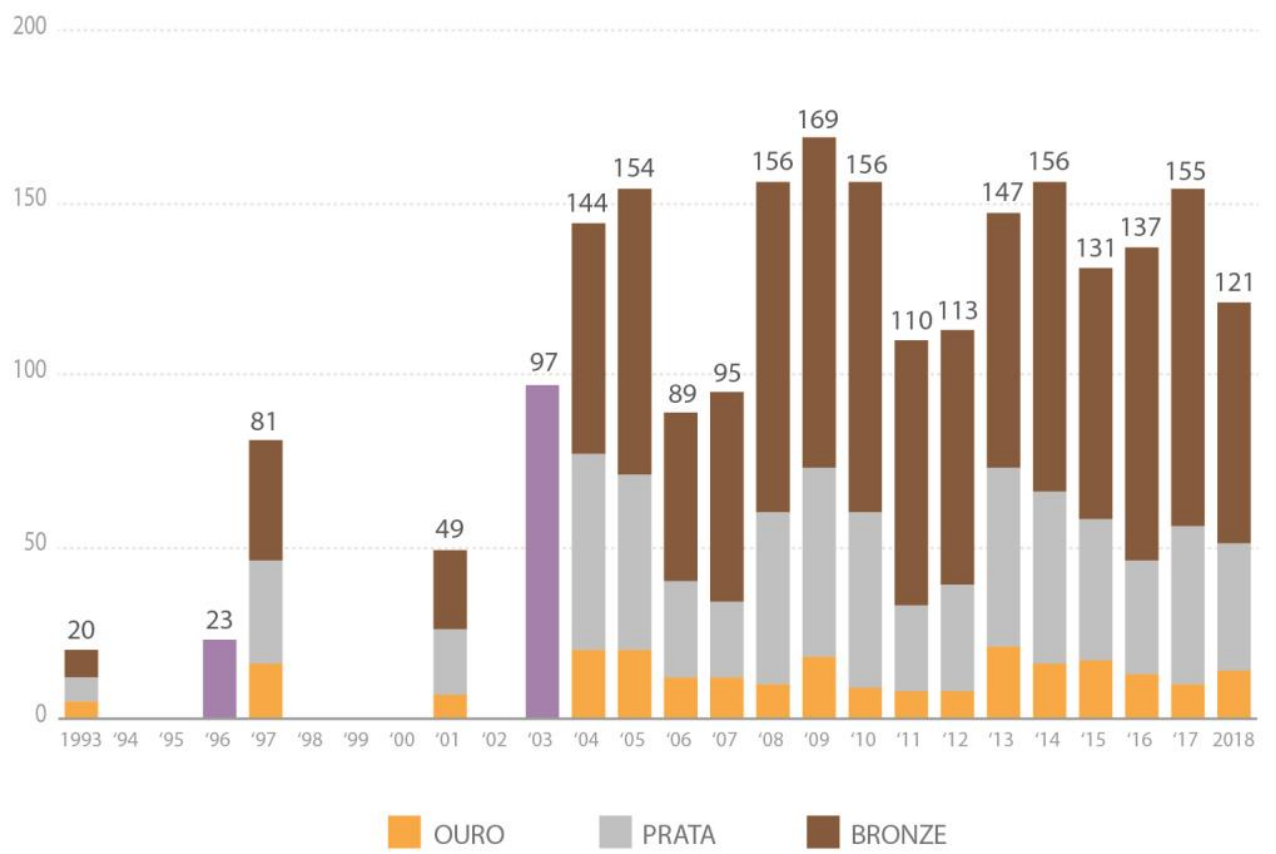

Figura 54 - Número total de medalhas por tipo (ouro, prata e bronze), com os anos de 1996 e 2003 indicando apenas a quantidade total de prêmios distribuídos. Fonte: do autor.

Nos últimos cinco anos analisados nesta pesquisa, o período de 2013 a 2018, observa-se pouca oscilação tanto em números totais quanto em tipo de medalhas. Se levarmos em conta o ponto mais alto e o mais baixo, a variação se mantém dentro de uma faixa entre 156 e 121 unidades. Apesar da redução em 2018, não se esperam quedas bruscas, como nos anos de 2006 e 2007, caso os demais indicadores (números de trabalhos, veículos e países inscritos) também permaneçam em níveis estáveis.

\section{4 .}

\section{Uma análise da participação do Brasil no Malofiej}

Em relação ao Brasil, a relevância das premiações no Malofiej não se restringe à valorização internacional da linguagem infográfica brasileira, mas também fomenta o investimento interno dos próprios veículos de comunicação. As medalhas servem como uma certificação externa da qualidade do trabalho 
desenvolvido, o que possibilita a valorização dos departamentos e dos profissionais envolvidos. Pode-se observar um exemplo dessa situação no relato de Mario Leite, Diretor de infografia do GloboEsporte.com, o veículo brasileiro com maior número de medalhas na categoria online, em entrevista para este trabalho:

São raros os parâmetros de avaliação de trabalhos de infografia no mundo todo. Há dois concursos reconhecidos mundialmente: o Malofiej e o SND. [...] A gente começou a ter muito mais respeito, também da Redação, nesse processo de construção de uma reputação, através desses prêmios (LEITE, 2018).

Sobre o fato de premiações como o Malofiej valorizarem os infografistas e proporcionarem maior reconhecimento, o infografista sênior do GloboEsporte.com, Alexandre Lage, comenta que:

[...] a gente ganhou espaço dentro da empresa e foi crescendo, os trabalhos foram crescendo. Mas o que deu o "boom" mesmo de infografia foram os prêmios. Eu acho que quando a gente ganhou o primeiro prêmio Malofiej, aí que realmente a diretoria olhou para a gente. [...] A gente sabia que os nossos trabalhos eram bons, mas quando tem uma pessoa de fora que fala assim "Pô, esses caras são bons!", os próprios chefes começaram a valorizar (LAGE, 2018).

Em relação à importância do Malofiej como fonte de referência e comparação do próprio trabalho com os demais veículos de excelência do mundo, Lage afirma que:

Sem dúvida, (o Malofiej) é uma grande referência. O que ganhou ouro? Por que ganhou ouro? O que a gente pode fazer para chegar perto... não perto, quais são os lados positivos? (O GE) Faz uma análise de todos os prêmios que são dados. Desde o ouro, bronze, os de excelência... É um norte para a gente, até. De novas tendências, "olha, o pessoal está começando a vir para cá, para lá"... Sempre é usado como referência. É bastante valorizado. Até internamente, por nossos prêmios: "Ah, isso aqui a gente acertou, isso aqui a gente errou"(LAGE, 2018).

Ou seja, as premiações estimulam a busca por uma excelência na qualidade, ao serem fornecidos meios de se balizar um veículo em relação aos demais de diversos países, e resultam em um reconhecimento que pode se transformar em investimento e/ou maior autonomia dos departamentos e profissionais envolvidos na elaboração de infográficos ${ }^{68}$.

Ao fim da década de 1990, o Brasil já possuía cinco medalhas internacionais de infografia no Malofiej. Foram agraciadas três medalhas de ouro, uma de prata e uma de bronze, distribuídas a três veículos nacionais. Dentre os prêmios, destacam-

${ }^{68}$ Cabe mencionar que há um custo para inscrever peças para as premiações do Malofiej. Esses custos nem sempre são acessíveis ou vistos como investimento pelos veículos. Dessa forma, é importante lembrar que o valor das inscrições pode restringir a participação a uma elite de veículos. 
se: $O$ Dia, em 1996, com a primeira medalha brasileira, o bronze no prêmio de infográfico inovador sobre o Mike Tyson, de Ary Moraes (Figura 49); a revista Veja, em 1997, com um ouro no prêmio para melhor infográfico de tema ciência ou saúde "A dor dos ossos do ofício", de Roberto Emílio Nejme (Figura 55) e a revista Superinteressante, em 1998, com a medalha de ouro pelo melhor infográfico esportivo "Golpes de Mestre” (Figura 56), de Luiz Iria, iniciando uma longa lista de premiações posteriores.

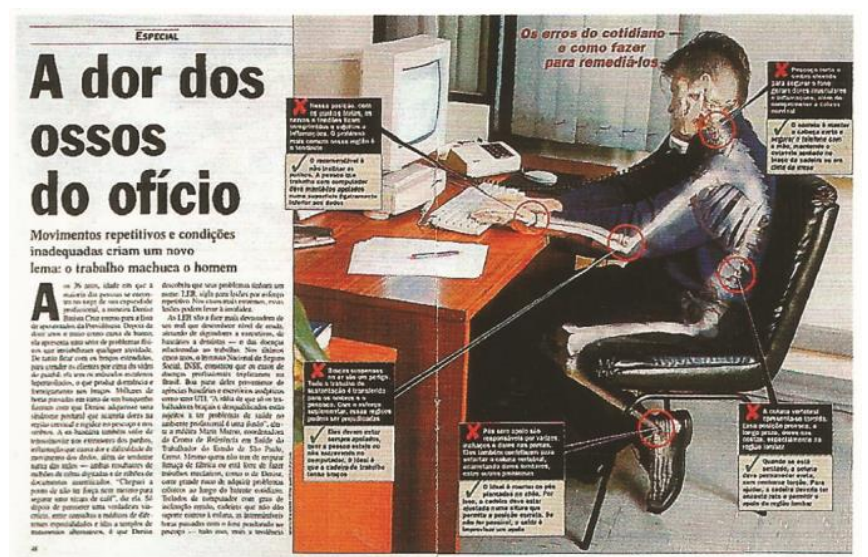

Figura 55 - Infográfico "A dor dos ossos do ofício", da revista Veja. Primeira medalha de ouro brasileira no Malofiej, em 1997. Fonte: MALOFIEJ (1997, p.27). 


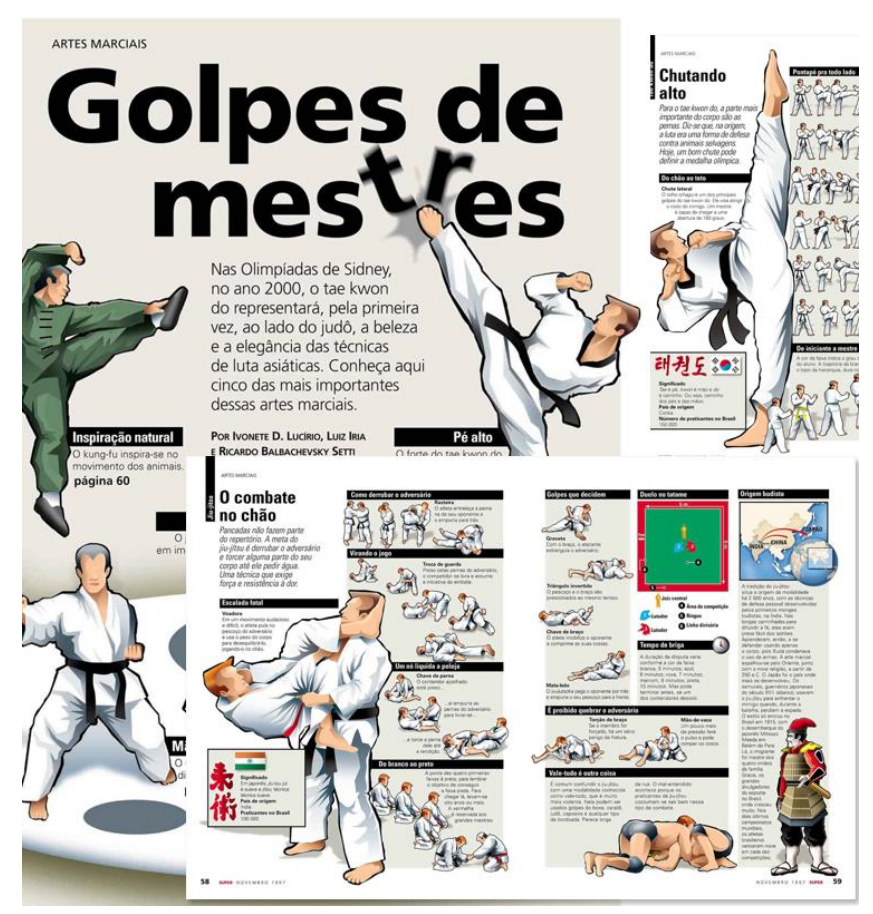

Figura 56 - Infográfico "Golpes de Mestre", publicado na edição de agosto de 1997. Premiado com a medalha de ouro no Malofiej em 1998. (Disponível em: <http://visualoop.com/blog/11928/talkingwith-luiz-iria> Acesso em: 15 dez. 2017)

O Brasil passou a receber prêmios, aumentar sua participação e se destacar no cenário mundial de infografia jornalística. A revista Superinteressante, do grupo Abril, que por uma questão de ordem técnica ${ }^{69}$ teve que desenvolver seu próprio conteúdo, desvinculando-se da publicação original espanhola, a Muy Interessante, teve a oportunidade de explorar a infografia como nenhum outro veículo nacional havia feito até então. Com o intenso investimento e uso de recursos infográficos, na década de 1990, a revista recebeu diversas medalhas no Malofiej, tendo o infografista Luiz Iria como principal destaque. Em 2002, a Superinteressante foi considerada a revista que melhor usou a linguagem infográfica no mundo, prêmio inédito para o mercado editorial brasileiro. A Superinteressante tornou-se ícone da infografia nacional e influenciou spin offs, tais como a revista Mundo Estranho, também agraciada com medalha no prêmio de melhor uso de infografia em revista no mundo, em 2004.

${ }^{69}$ Ao adquirir os direitos, o objetivo era apenas traduzir o conteúdo das matérias da $M u y$ Interessante para o português, mantendo as páginas exatamente iguais. Mas os fotolitos espanhóis possuíam dimensões diferentes dos usados no Brasil. Decidiu-se, então, que a versão brasileira faria suas próprias matérias. (Disponível em: <https://super.abril.com.br/historia/15-anos-de-super/> Acesso em: 16 dez. 2017) 
Levando-se em conta todo o período de existência do prêmio Malofiej, os cinco principais veículos jornalísticos nacionais em número de medalhas são: a revista Mundo Estranho ( $1^{\circ}$ lugar); a revista Superinteressante ( $2^{\circ}$ lugar); o jornal Folha de S. Paulo ( $3^{\circ}$ lugar); o jornal $O$ Globo $^{70}$ (4 $4^{\circ}$ lugar) e o portal GloboEsporte.com ( $5^{\circ}$ lugar). No total, foram 20 veículos laureados, somando-se mais de 126 medalhas identificadas entre categorias impresso e online. Os dados reunidos no gráfico a seguir (Figura 57) facilitam a observação dos títulos dos veículos, a quantidade de medalhas e a categoria (impresso ou online) cujas congratulações foram recebidas, no período entre 1993 a 2018.

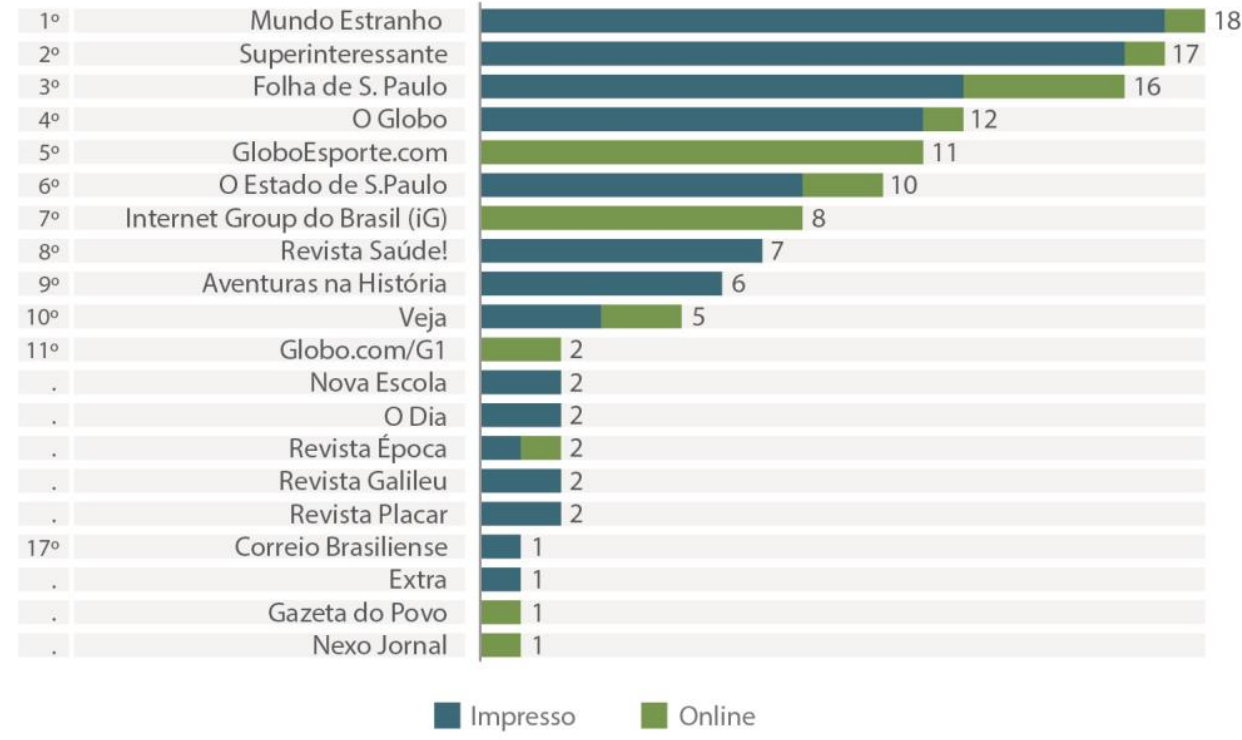

* Em 2003, a Globo.com obteve uma menção especial - categoria Online, Reportagens, Portfólios.

** Em 2006, a revista Mundo Estranho obteve uma menção honrosa - categoria Impresso de Ciência, Tecnologia, Medicina, Saúde.

Figura 57 - Ranking por número de medalhas recebidas por veículos de comunicação brasileiros, soma das categorias impresso e online, de 1993 a 2018. Fonte: do autor.

Em número total de medalhas, as revistas Mundo Estranho e Superinteressante são os veículos mais premiados nacionais. Elas obtiveram 18 e 17 medalhas, respectivamente, nos últimos 26 anos. No entanto, ao observarmos o tipo de medalha (ouro, prata ou bronze), nota-se uma superioridade da Superinteressante (5 ouros, 7 pratas e 4 bronzes) em relação às medalhas da Mundo Estranho (1 ouro, 6 pratas e 10 bronzes). Em ambas, apenas uma do total de

${ }^{70}$ Está em andamento o processo de confirmação de uma medalha recebida pela Globo.com, em 2002, pelo infográfico sobre o porta-aviões Nimitz, de Sérgio Peçanha e Mário Leite. Como a apuração está em andamento, este prêmio não foi incluído nos dados atuais deste trabalho. 
medalhas recebidas pertence à categoria online, predominando os prêmios na categoria de impressos ao longo de suas participações históricas. O gráfico abaixo indica o tipo e a quantidade de medalhas recebidas, separando-se as categorias impresso e online (Figura 58). Dessa forma, é possível identificar quais veículos já conseguiram medalha de ouro, por exemplo, destacando-se dos demais.

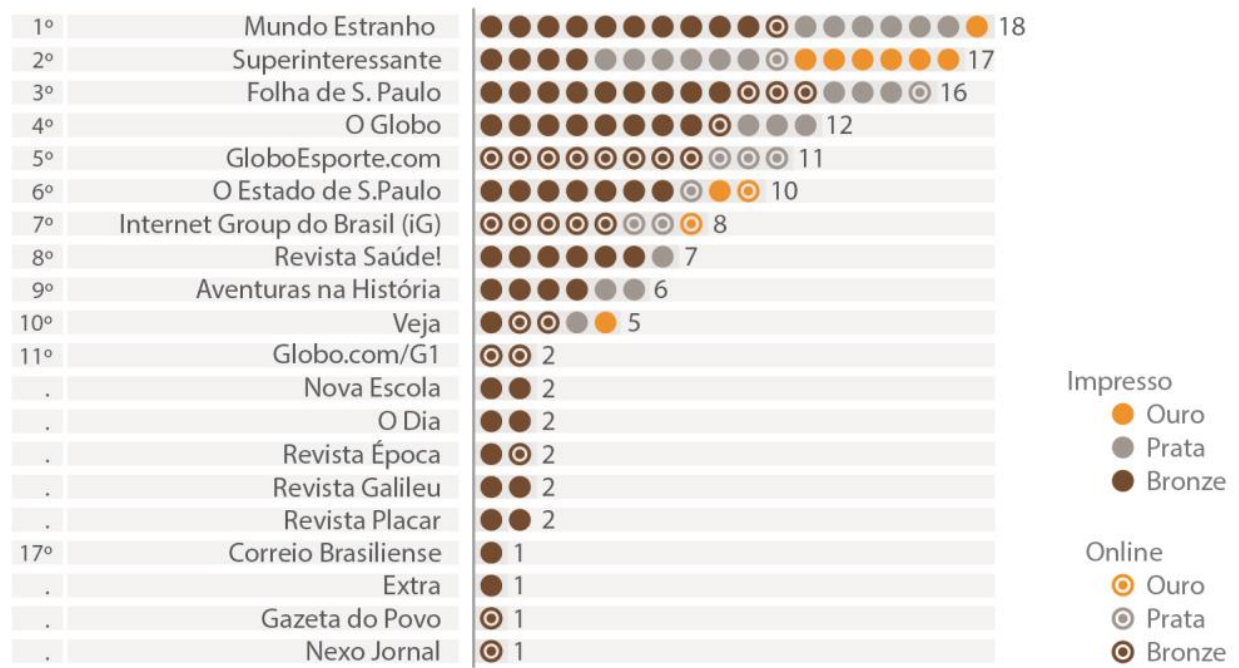

Figura 58 - Ranking por número de medalhas confirmadas (ouro, prata e bronze) por veículo impresso e online - 1993 a 2018. Fonte: do autor.

De acordo com os gráficos por quantidade e qualidade de medalhas de cada veículo, cabe apontar, ainda, dois fatos notáveis além da superioridade da revista Superinteressante em termos de tipo de medalhas. O primeiro é o fato de $O$ Estado de S. Paulo ser o único veículo jornalístico nacional a ter obtido ouro tanto na categoria impresso quando na categoria online, por meio do seu portal Estadao.com.br. O segundo é a hegemonia do portal GloboEsporte.com na categoria online, tendo recebido, nos últimos cinco anos, 11 medalhas, sendo três de prata. Ou seja, uma presença significativa em tempo relativo curto, sendo responsável por aproximadamente um terço das 35 medalhas online confirmadas recebidas por veículos nacionais em toda história do Malofiej.

Uma vez identificados os principais veículos e a quantidade de medalhas recebidas, é interessante posicionarmos os prêmios em uma cronologia. O gráfico abaixo (Figura 59) indica a quantidade total de medalhas recebidas por veículos brasileiros ano a ano em toda a série histórica. 


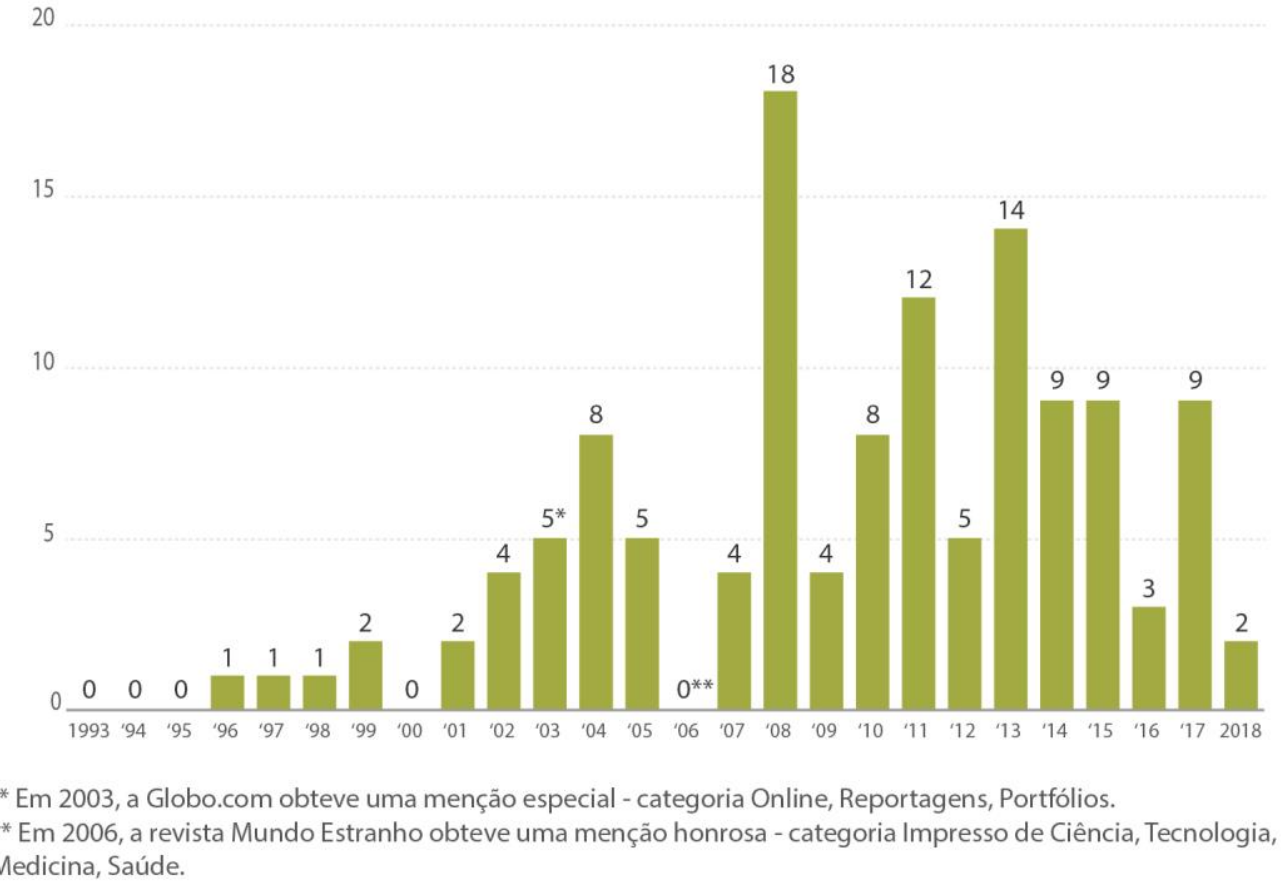

Figura 59 - Número total de medalhas brasileiras confirmadas por ano - 1993 a 2018. Fonte: do autor.

Pela análise do gráfico é possível notar a constante presença dos veículos brasileiros desde a primeira edição, em 1993. Levando-se em conta os anos de 2000 e 2006, em que não houve confirmação de recebimento de medalhas, deve-se, entretanto, citar a menção honrosa recebida pela revista Mundo Estranho, em 2006. Isso revela que a ausência total de indicações de prêmios a brasileiros ocorreu apenas em um ano, desde 1996. Evidencia-se o destaque ao ano de 2008, quando do recebimento de 18 medalhas. É importante ressaltar, no entanto, que no ano de 2018 o desempenho nacional desceu a apenas duas medalhas, um resultado abaixo da expectativa. Cabe listar também os anos com desempenho fora da média: 2011, com 12 prêmios, e 2013, com 14 medalhas.

O número total de medalhas na série histórica acima não diferencia a participação entre as categorias impresso e online. A presença das medalhas de veículos online ao longo do tempo pode ser percebida por meio do gráfico abaixo (Figura 60): 


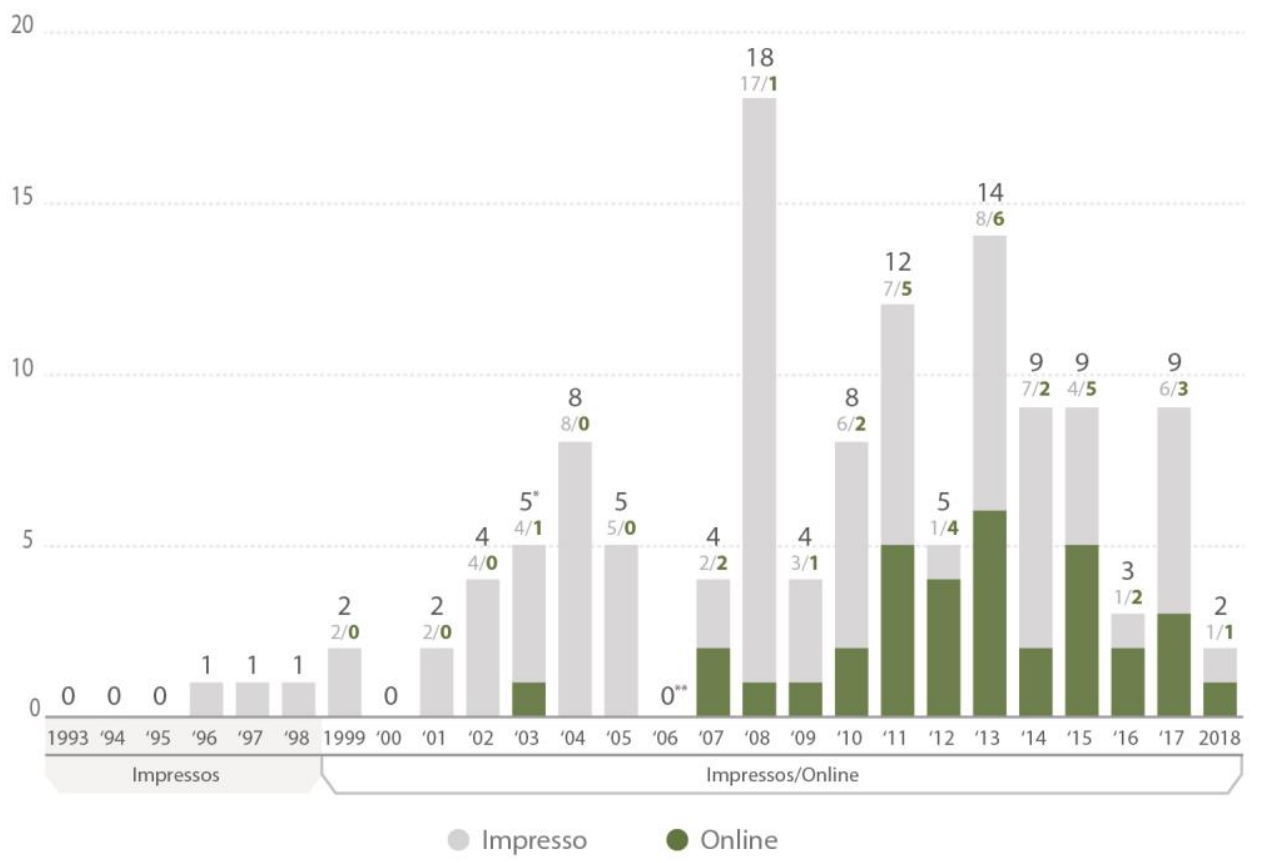

Figura 60 - Número total de medalhas brasileiras confirmadas por ano - 1993 a 2018 - impresso e online. Fonte: do autor.

A categoria online não faz parte da premiação desde sua criação, tendo sido iniciada apenas em 1999. Os prêmios recebidos nesta categoria estão exercendo um papel cada vez mais importante no Malofiej. O ano de 2018, por exemplo, foi o primeiro ano em que o número total de trabalhos inscritos na categoria online superou o da categoria impresso, com 647 impressos contra 674 digitais. O número de medalhas total também reflete esse aspecto: foram concedidas 56 medalhas a trabalhos impressos e 65 a trabalhos online. No caso do Brasil, o gráfico indica que a tendência está presente em veículos nacionais, apesar de não ficar evidente um aumento na presença de medalhas online em questão de números totais. Devido ao recebimento de duas medalhas em 2018, uma na categoria impresso e uma na categoria online, não se deve pontuar que $50 \%$ das medalhas foram online como um indicativo de aumento na série. É mais relevante ressaltar a queda no número de medalhas deste ano e observar, futuramente, as questões que levaram a esse desempenho.

Finalmente, como forma de reunir o máximo de dados em uma visualização, o gráfico seguinte (Figura 61) evidencia o total de medalhas recebidas por veículos brasileiros de comunicação em toda a história do Malofiej, com a indicação do tipo (ouro, prata ou bronze) e da categoria (impresso ou online). 


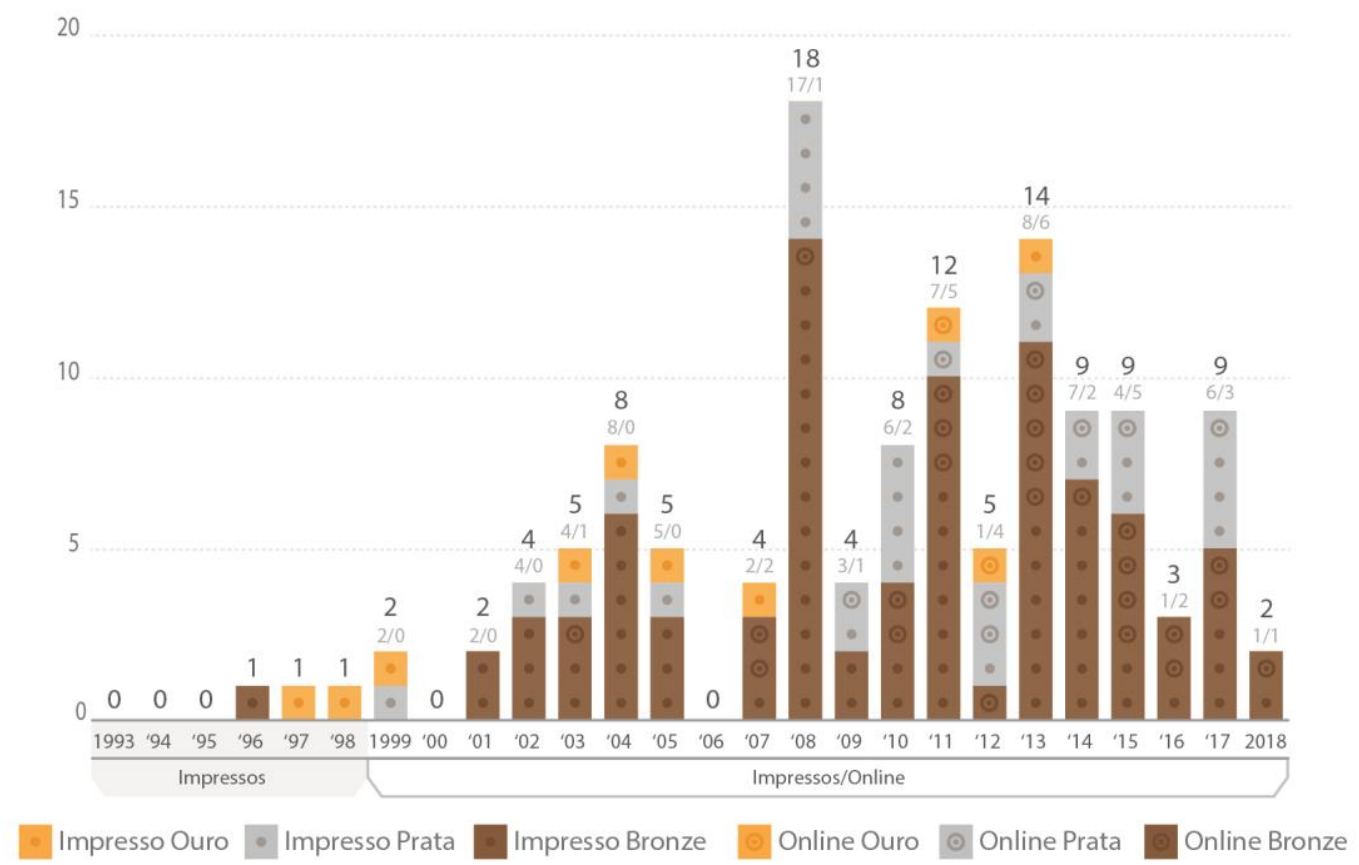

Figura 61 - Número total de medalhas brasileiras por ano, tipo e categoria - 1993 a 2018. Fonte: do autor.

Uma vez identificados os tipos de medalhas, percebe-se que, desde 2013, o Brasil não é laureado com uma medalha de ouro. Nos últimos dez anos, entre os três ouros recebidos, dois pertencem a infográficos online, o que ressalta a crescente importância dessa categoria para o país. Os primeiros prêmios online recebidos por veículos brasileiros, que puderam ser $\operatorname{confirmados}^{71}$ até o momento, foram as medalhas de bronze recebidas pela Globo.com, em 2003, e pelas revistas Veja e Mundo Estranho, em 2007. A primeira medalha de ouro online foi dada, em 2011, para o Estadao.com.br, pelo infográfico sobre o Tapuiassauro. Essa foi a primeira medalha de ouro online para a América Latina, que contou com participação das equipes de arte do impresso e do portal do Estadão. A segunda medalha de ouro da categoria online, em 2012, foi para o IG, pelo infográfico Esquadrilha da Fumaça, em comemoração aos 60 anos do grupamento de pilotos do Esquadrão de Demonstração Aérea da Força Aérea Brasileira (FAB). Cabe mencionar uma medalha de bronze em processo de confirmação para o Globo.com, de 2002, com a participação de Nilo Peçanha e Mario Leite, que viria a ser anterior aos prêmios

${ }^{71}$ Os dados oficiais das premiações online de 1999 a 2004 não são conclusivos, não foram disponibilizados em totalidade em documentação impressa ou online, ou não houve acesso a fontes esgotadas, tais como livros e cd-roms. Optou-se, então, por omitir dados em processo de confirmação. 
supracidados e alteraria o "quadro de medalhas" dos veículos brasileiros, bem como o total de medalhas recebidas.

\section{5.}

\section{Infográfico: O Brasil no Malofiej}

A partir dos dados coletados e analisados, foi elaborado um infográfico com o objetivo de contar, visualmente, a participação brasileira na principal premiação internacional. Abaixo, uma versão reduzida do infográfico, na horizontal.

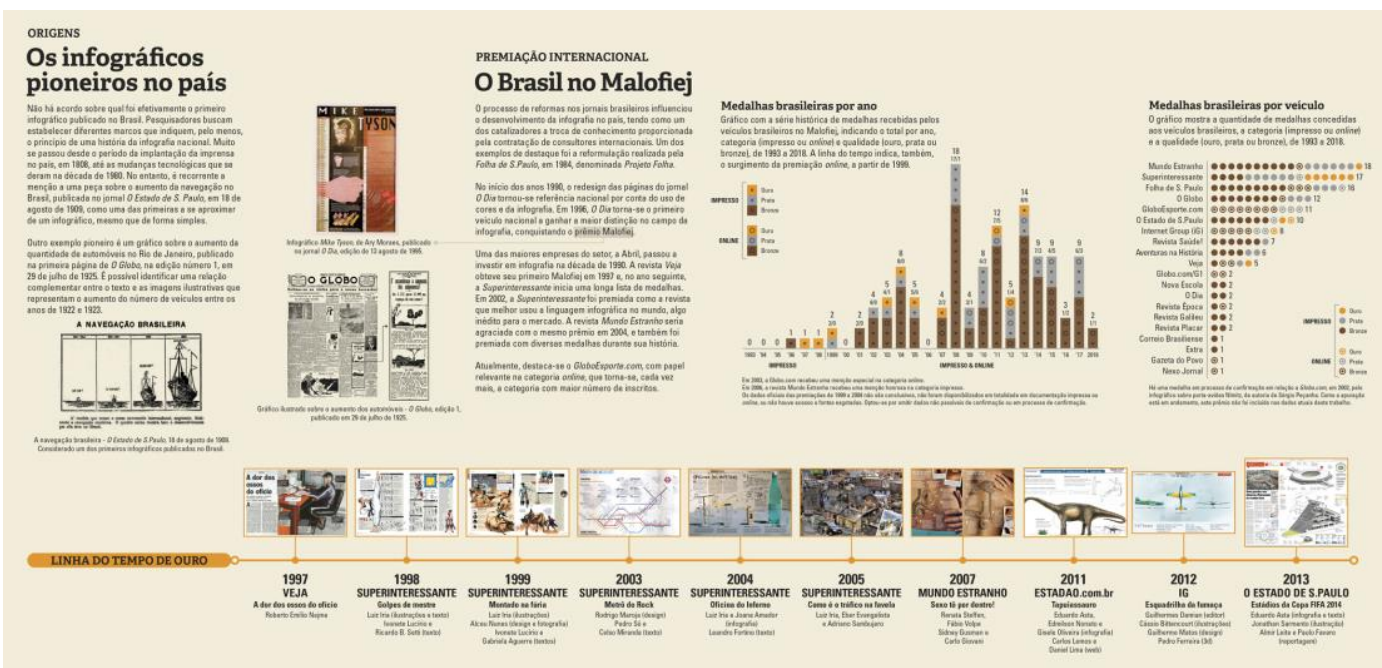

Figura 62 - Versão reduzida da proposta de infográfico sobre a participação da infografia brasileira no Malofiej, junto com uma contextualização de suas origens e uma linha do tempo com todas as medalhas de ouro recebidas por veículos nacionais na premiação. Fonte: do autor.

Na sequência, uma imagem adaptada do infográfico para as dimensões deste trabalho. Cabe lembrar que a versão original possui $50 \mathrm{~cm}$ de largura e altura proporcional. Portanto, a legibilidade sofre prejuízos ao se reduzir para impressão em tamanho A4 $(21 \times 29,7 \mathrm{~cm})$. 


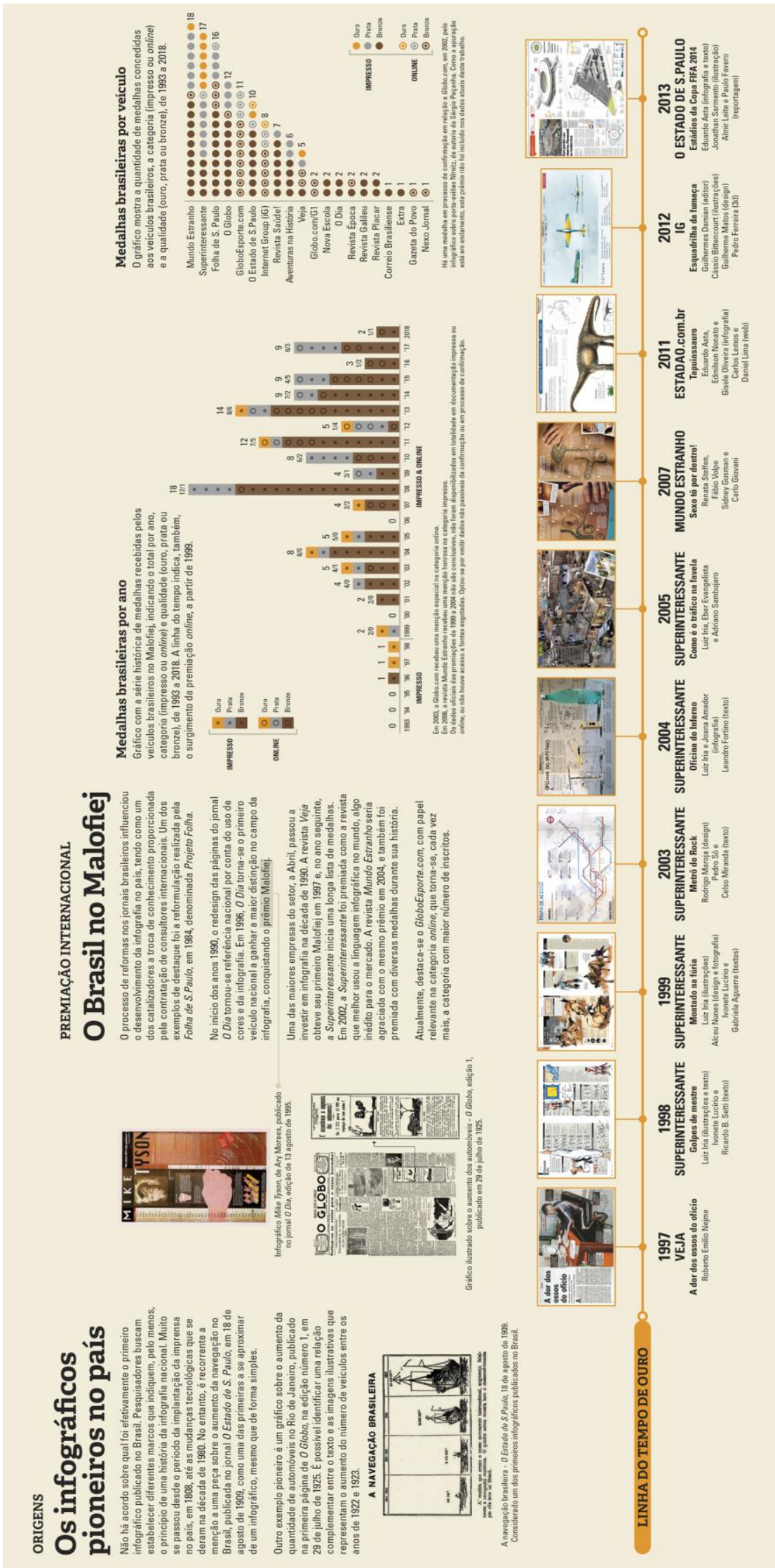

Figura 63 - Proposta de infográfico sobre a participação da infografia brasileira no Malofiej. Fonte: do autor. 


\section{6.}

\section{Conclusões sobre o capítulo}

Uma vez reunidos os dados em gráficos, foi possível notar tendências e destaques do desempenho da infografia nacional no espectro internacional. Os números e gráficos apresentados neste artigo são o resultado de coleta e análise de 26 anos de dados do Malofiej e da participação brasileira no evento. Espera-se que sirvam de apoio à comunidade acadêmica e profissionais do campo, resolvendo a extensa fragmentação e dificuldade em se apurarem dados dessa ordem. Cabe citar o apoio de pesquisadores, professores e profissionais que cederam seus materiais, documentos e prestaram depoimentos para que fosse possível a realização e a apuração dos números que constam neste material. 


\section{6 \\ Dados sobre a infografia no Ensino Superior no Brasil}

Apesar de todo o reconhecimento internacional, prêmios e intenso uso de infografia nos veículos jornalísticos, no Brasil, não há uma graduação específica voltada para as questões relativas ao desenvolvimento teórico e prático da infografia. Tendo em vista a multidisciplinaridade característica envolvida na elaboração de um infográfico, os infografistas são provenientes de diversas formações, tais como estatísticos, cartógrafos, programadores, artistas gráficos, ilustradores, cinegrafistas, jornalistas, designers gráficos, dentre outros que, normalmente, atuam em equipe. Muitos profissionais, inclusive, não possuem formação acadêmica. Como visto anteriormente, para Cairo (2013, p.62), uma das influências da variação das formações dos elaboradores seria a maneira de abordar um projeto com uma tendência ao desenvolvimento de peças mais racionais e voltadas à funcionalidade, no caso de cartógrafos, estatísticos, engenheiros; ou peças mais artísticas e emocionais, no caso de artistas gráficos, jornalistas, designers e afins.

No entanto, ao desenvolver um infográfico jornalístico, deve-se considerar o papel social do comunicador, que não se restringe a uma simples função de noticiar o cotidiano com uma abordagem "mais técnica" ou "mais artística". Os elaboradores de peças infográficas possuem responsabilidades características do jornalismo e sua ética, atuando como mediadores, interpretando, analisando, apurando, editando e apresentando uma narrativa à sua audiência. Dessa forma, por

meio de suas publicações, agem como atores sociais, podendo influenciar pensamentos e atitudes dos membros da sociedade, de acordo com a credibilidade e abrangência de um determinado veículo. Portanto, ao considerarmos os responsáveis pela elaboração do discurso presente nos infográficos, os jornalistas e designers se destacam no uso dessa linguagem, tendo em vista que suas formações, de teor prático e teórico, lidam com a comunicação - social, para o jornalista, e visual, para o designer. Em alguns casos, inclusive, essas formações podem ter disponibilizado alguma oferta de disciplinas específicas sobre infografia, design da 
informação, jornalismo visual, dentre outras ligadas ao tema. Assim, para este trabalho, apesar das variadas origens possíveis, consideramos o recorte nas graduações em jornalismo e design, relacionando-as como os lugares onde subsídios para a formação dos futuros infografistas e pesquisadores sobre o tema deveriam estar disponíveis.

Para que possamos compreender a atual presença de disciplinas sobre temas relacionados à infografia na academia, ou mesmo para observar o grau de ausência deste conteúdo, devemos revisar um breve histórico da evolução dos cursos de jornalismo e design no país - pontuando o início do ensino institucional, o estabelecimento dos diferentes currículos mínimos e as discussões e expectativas a partir da promulgação da nova Lei de Diretrizes e Bases da Educação Nacional $(\mathrm{LDBN})$, Lei $\mathrm{n}^{\circ}$ 9.394/96. Posteriormente, este capítulo disponibiliza os dados apurados sobre as disciplinas relacionadas à infografia nos cursos de jornalismo e design no país, reunido-os em tabelas, mapas e gráficos.

\subsection{Os Currículos Mínimos Profissionais}

Os Currículos Mínimos Profissionais tornaram-se obrigatórios, no Brasil, a partir do momento em que o Conselho Federal de Educação (CFE) passou a ter a atribuição de definir os currículos de todos os cursos de graduação nacionais, existentes e futuros, com a publicação da Lei de Diretrizes e Bases da Educação Brasileira, Lei no 4.024/61 (art.9º), e da Lei 5.540/68 (art.26º). As Instituições de Ensino Superior (IES), então, tornaram-se responsáveis pela seleção e pela oferta de outras matérias ${ }^{72}$ para a formação profissional, disciplinas optativas, complementares, de forma a transformarem os currículos mínimos em currículos plenos.

O modelo, apesar de organizar e padronizar os cursos superiores, foi responsável pelo engessamento do ensino superior no país, focando na disponibilização de disciplinas profissionalizantes dispostas em grades curriculares voltadas ao mercado de trabalho. De acordo com Couto (2008, p.18):

72 De acordo com Souza (1991, p.116) “cada elemento integrante do currículo mínimo denomina-se matéria. A matéria abrange um determinado campo do saber e pode ser seccionada em subcampos a que se dá o nome de disciplina." Continuando, "no currículo mínimo é a matéria que comparece, mas no currículo pleno, quando a matéria se desdobra em especificidades a serem estudadas nas diferentes séries do curso, figuram as disciplinas." 
No modelo do Currículo Mínimo, a inovação e a criatividade das instituições eram inibidas. Não havia espaço e liberdade para reformulações, uma vez que os componentes curriculares e o detalhamento de conteúdos obrigatórios estavam, por Resolução do Conselho Federal de Educação, estabelecidos nacionalmente.

Souza (1991, p.118) afirma que a imposição de um currículo mínimo viola a autonomia das universidades e, ainda, que alguns currículos seriam "tão minuciosos, que deixam de ser mínimos, para serem máximos”. Essas razões geraram críticas do meio acadêmico em relação ao CFE, por meio de questionamentos à fixação dos currículos e às suas possíveis consequências, bem como à limitação da liberdade na organização dos cursos.

Devemos considerar, também, que a realidade do ensino no Brasil possui um vasto cenário de imposições e problemas que impactam a formação dos alunos. De acordo com Couto (2008, p.28), muitas dessas adversidades são atribuídas às deficiências no currículo mínimo vigente, apesar de serem de ordem estrutural, tais como formação inadequada do corpo docente, instalações precárias ou sucateadas, indivíduos que transitaram por um ensino fundamental deficiente, dentre outras. Portanto, antes de seguirmos, faz-se aqui uma ressalva, lembrando que as disfunções no ensino no país não se resumem às questões de ordem curricular.

\subsubsection{No Jornalismo}

Apesar de ser uma profissão regulamentada desde 1938, o jornalismo teve sua formação instituída no sistema de ensino superior no país anos depois, por meio do Decreto-Lei $\mathrm{n}^{\circ} 5.480$, de 13 de maio de 1943. O primeiro curso superior no país foi fundado apenas em 1947, nascido a partir de iniciativa presente no testamento do jornalista paulistano Cásper Líbero, dono do A Gazeta. Após atravessar entraves burocráticos por quatro anos, desde 1943, em 1947 tem inicio a primeira turma na Faculdade de Comunicação Social Cásper Líbero (FCL), em São Paulo (HIME, 2004, n.p). A primeira universidade a disponibilizar o curso na área foi a UFRJ, em 1948, com a UFBA (1950) e a PUC-RS (1951) inaugurando os seus respectivos em seguida. A Associação Brasileira de Imprensa (ABI) havia tentado estabelecer o ensino do jornalismo em 1918, durante o Primeiro Congresso Brasileiro de Jornalistas, contudo, o empreendimento não deu certo. Desde esse período, denomina-se o nome do curso como Comunicação Social com habilitação em Jornalismo. Apesar do mesmo nome, no entanto, o curso já enfrentou diversas 
alterações em sua estrutura curricular, com a determinação de diferentes qualificações ao longo do tempo.

Os cursos de comunicação social passaram por cinco diferentes estruturas de currículos mínimos, com base em diferentes pareceres e resoluções ${ }^{73}$. O primeiro, voltado para a formação de profissionais para imprensa, rádio e TV, foi estabelecido pelo Parecer no 323/62, de 16 de novembro de 1962. Dele originou-se o currículo mínimo com estrutura modular de disciplinas gerais, específicas e técnicas, com duração de três anos letivos, mas sem especificação relativa à carga horária. $\mathrm{O}$ segundo currículo, por meio do Parecer n $n^{\circ}$ 984/65, de 19 de abril de 1966, propôs o ensino com disciplinas em nível cultural (formação humanística), fenomenológico (teorias da comunicação) e instrumental (técnicas). Ampliou a duração do curso para quatro anos letivos e estabeleceu 2.700 horas de carga horária (horas/aula). O terceiro currículo mínimo destina-se à comunicação social, definindo uma base comum, com metade da duração mínima do curso, e ramificações para as diferentes habilitações: publicidade, relações públicas, jornalismo, editoração ou habilitação polivalente. Foi instituído pela Resolução no 11/69, de 6 de agosto de 1969, definiu a estrutura modular em disciplinas básicas, profissionais e de cultura geral, propôs um período mínimo de três anos letivos, com um máximo de seis, e reduziu a carga horária para 2.200 horas/aula. O quarto, implementado pela Resolução nº 03/78, de 12 de abril de 1978, definiu o currículo em disciplinas de fundamentação geral humanística, fundamentação específica e fundamentação de natureza profissional, com a implementação de uma formação em três fases: clássico-humanística, científico-técnica e crítico-reflexiva, de acordo com Moura (2002, p.88). As habilitações se dividiam em jornalismo, publicidade e propaganda, rádio e televisão, cinematografia e relações públicas. Não foram especificadas a quantidade de anos letivos e nem a carga horária mínima. O quinto e último currículo mínimo, afirmado na Resolução nº 02/84, de 24 de janeiro de 1984, aponta uma estrutura modular com disciplinas diversificadas (com base nas diferentes habilitações) e

${ }^{73}$ De acordo com Meirelles (1997, p.166 apud MOURA, 2002, p.81), "Resoluções são atos administrativos normativos expedidos pelas altas autoridades do Executivo (mas não pelo Chefe do Executivo, que só deve expedir decretos), ou pelos presidentes de tribunais, órgãos legislativos e colegiados administrativos, para disciplinar matéria de sua competência específica." e "Pareceres administrativos são manifestações de órgãos técnicos sobre assuntos submetidos à sua consideração. O parecer tem caráter meramente opinativo, não vinculando a Administração ou os particulares à sua motivação ou conclusões, salvo se aprovado por ato subsequente. Já então, o que subsiste como ato administrativo, não é o parecer, mas sim o ato de sua aprovação..." 
projetos experimentais, flexibilizando o ensino. Este currículo incorporou disciplinas classificadas em áreas do conhecimento como: Ciências Humanas, Ciências Sociais Aplicadas, Linguística, Letras e Artes. Estabeleceu um mínimo de quatro anos letivos e um limite máximo de sete, e retomou a exigência mínima de 2.700 horas/aula de carga horária. Este último currículo perdurou até o ano de 1999, quando se instituíram as Novas Diretrizes Curriculares da Área de Comunicação.

O Parecer $n^{\circ}$ 480/83, de 6 de outubro de 1983, em que se reflete a Resolução $n^{\circ}$ 02/84, do quinto currículo, apresenta uma classificação dos antecedentes do Ensino da Comunicação Social no país, dividindo a questão curricular em quatro fases (MOURA, 2002, p.92): fase clássico-humanística, do início dos cursos até a segunda metade da década de 1960, focada em questões humanas, de inspiração europeia; fase científico-técnica, na década de 1960, direcionada a atividades específicas das áreas profissionais, técnicas e instrumentais, com bases no ensino norte-americano de Comunicação; fase crítico-reflexiva, na década de 1970, com um enfoque crítico aos condicionamentos sociais latino-americanos, com distanciamento da prática profissional e melhoria do ensino teórico e fase de crise de identidade, na década de 1980, sem a possibilidade de novos projetos de curso em função de um currículo formal existente e com críticas dos setores empresariais e oficiais ao ensino da Comunicação, além de críticas à qualidade do ensino por parte dos estudantes e profissionais e críticas dos professores à falta de um objeto específico da Comunicação.

Um ponto a se destacar do Parecer $n^{\circ} 480 / 83$, pertinente a este trabalho, está em um dos tópicos das diretrizes para a elaboração do currículo, no subitem 2.3.2. Esse item indica como orientação “incorporar ao currículo novas matérias decorrentes do desenvolvimento de novas áreas dentro da Comunicação", o que mostra, já em meados da década de 1980, a possibilidade de inclusão de disciplinas ligadas à infografia, ferramenta comunicacional que viria a se desenvolver de forma intensa nos veículos jornalísticos impressos na década de 1990.

\subsubsection{No Design}

O ensino de design de forma institucional, no Brasil, inicia-se com a inauguração da Escola Superior de Desenho Industrial, a ESDI, em 1963, no Rio de Janeiro. Sob influência da pedagogia e da metodologia alemãs em seu modelo 
acadêmico, com visitas de professores como Max Bill e Tomás Maldonado, da Hoschschule für Gestaltung Ulm (Hfg-Ulm), a ESDI torna-se paradigma para o ensino do design no país (COUTO, 2008, p.21). Sua grade era composta por disciplinas que abordavam as esferas das ciências humanas e conhecimentos tecnológicos, distribuídas por quatro anos letivos. Dentre as disciplinas, estavam disponíveis temas como a sociologia, psicologia, antropologia, economia, teorias da informação, além de disciplinas de metodologia e ordem prática. Apesar das críticas sobre a semelhança com a estrutura da Hfg-Ulm (e a perda de modelo após o seu fechamento, em 1968), da demora no reconhecimento oficial (estadual e federal), e do fato de a escola não ter sido voltada às questões da indústria brasileira, ainda assim a contribuição da ESDI ao desenvolvimento do design brasileiro é irrefutável.

Os cursos de desenho industrial passaram por dois currículos mínimos. O primeiro, aceito pelo CFE em 1968, determinava que as disciplinas, divididas entre básicas e profissionais, deveriam ser distribuídas em um período mínimo de três anos letivos, e um máximo de seis, com exigência do cumprimento de pelo menos 2.700 horas/aula e o estabelecimento de um sistema de créditos, de forma que o estudante pudesse construir seu currículo de maneira flexível ${ }^{74}$. Um aspecto desse primeiro currículo foi a liberdade dada aos cursos de cada instituição, em função da falta de especificações sobre as disciplinas. Esse fato também levou ao surgimento de disciplinas que pouco faziam sentido para a formação dos designers e/ou eram reaproveitadas de estruturas previamente estabelecidas nas IES (BOMFIM, 1977 apud COUTO, 2002, p.24). De acordo com Couto (2002, p.24), essa heterogeneidade levou o CFE à criação de uma comissão de especialistas com o objetivo de gerar um novo currículo mínimo, em 1978. O segundo currículo, definido pela Resolução $\mathrm{n}^{\circ}$ 02/87, foi aprovado em 16 de junho de 1987, e voltouse a uma direção oposta à liberdade disponível no primeiro. De acordo com o Parecer $n^{\circ} 62.187$ do CEF, dividiu-se o curso de desenho industrial em duas habilitações, projeto de produto e programação visual, com disciplinas distribuídas em um mínimo de quatro anos letivos e máximo de quatorze, com o cumprimento de pelo menos 2.700 horas/aula e, agora, com descrição de uma longa lista de

\footnotetext{
${ }^{74}$ Para Couto (2008, p.28), o sistema de créditos seria relevante para o design, em função de sua natureza interdisciplinar, no entanto, na prática, os currículos plenos demandam o cumprimento de tantas disciplinas obrigatórias que os alunos acabam impedidos de cursarem outras escolhas.
} 
tópicos a serem abordados (COUTO, 2002, p.26). Os módulos se dividiam em um bloco comum às duas habilitações e um bloco com matérias dedicadas à formação profissional específicas para cada uma, além de um possível complemento, por meio de disciplinas eletivas, sob responsabilidade das IES, cumprindo demandas regionais.

\subsubsection{A nova Lei de Diretrizes e Bases da Educação Nacional}

Em 1996, foi aprovada a nova Lei de Diretrizes e Bases da Educação Nacional (LDBN), Lei no 9.394/96, que permitia a avaliação dos cursos de graduação e das IES pelo MEC. O desempenho nas avaliações seria responsável pela possibilidade do credenciamento/recredenciamento ou descredenciamento junto ao MEC. Outra atribuição da lei foi a extinção do Currículo Mínimo, dando maior autonomia aos cursos. De acordo com Couto (2008, p.19), a nova LDBN parte de uma análise crítica do cenário vigente até então, e visa à busca por respostas efetivas de forma flexível, de acordo com a sociedade e novas tecnologias. Para a autora, a nova Lei:

...levou à geração das novas Diretrizes Curriculares Nacionais, que enfatizam a dimensão política das instituições de ensino superior, levando-as a assumir a responsabilidade de se constituírem respostas às efetivas demandas sociais e aos avanços tecnológicos e científicos do País (COUTO, 2008, p.19).

O ensino nas IES passa, então, a ter a possibilidade de se adaptar aos cenários sociais e políticos, além de ser capaz de reagir ao surgimento de novos paradigmas tecnológicos, não se restringindo a um modelo baseado em uma estrutura rígida que se torna rapidamente defasada em relação ao ritmo social e tecnológico atual. Segundo Moura (2002, p.62):

Até 1999, todos os cursos deveriam seguir o currículo mínimo, ao passo que, a partir de agora, todos os cursos podem, ou não, seguir as normas do passado. Pelas novas diretrizes curriculares, um determinado curso pode continuar adotando as matérias/disciplinas do currículo mínimo e, ao longo do tempo, fazer adaptações para garantir maior qualidade ao seu ensino, considerando as modificações tecnológicas, sociais e as especificidades das regiões. Isto porque a instituição tem liberdade para decidir sobre seus conteúdos.

Com os Pareceres CES/CNE nº 0146/2002, 77/2002, revisados pelo Parecer CES/CNE nº 0195/2003, a Camara de Educação Superior (CES) do Conselho Nacional de Educação (CNE) estabeleceu que as Diretrizes Curriculares Nacionais orientariam todas as IES, com princípios para a elaboração de seus currículos e 
ampla liberdade assegurada em diversos aspectos (carga horária para integralização, indicar unidades de estudo a serem ministradas e seleção de experiências de ensino-aprendizagem nos currículos, para citar alguns). Ou seja, a nova Lei tornou possível uma transformação gradual da estrutura de ensino no Brasil, com o Estado delegando mais responsabilidade às instituições de ensino, ao passo que deixam de existir os currículos mínimos. Com isso, estimula-se uma busca pelo aumento de qualidade do quadro docente e pela elaboração de projetos pedagógicos flexíveis, de acordo com o perfil desejado para o egresso de cada região. Os projetos pedagógicos devem, então, a partir de diretrizes orientadoras, considerar as competências e habilidades necessárias que o aluno deve desenvolver para se compatibilizar com o mercado, de acordo com a região e suas particularidades.

Para o caso do design, após a nova LDB, derivado de discussões realizadas no Fórum de Recife ${ }^{75}$, em 1997, houve um esforço conjunto ao longo do tempo para a elaboração de novas diretrizes curriculares para os cursos de design das IES. As questões abordadas no encontro geraram reflexões e influenciaram a redação das Novas Diretrizes Curriculares para Bacharelados em Design, iniciadas na Comissão de Especialistas de Ensino das Artes e do Design (CEEARTES) e prosseguidas, a partir de 1998, na Comissão de Especialistas no Ensino do Design (CEEDesign). Dentre os princípios básicos estabelecidos, destacam-se: a mudança da definição "Bacharelado em Desenho Industrial" para "Bacharelado em Design" (seguido da habilitação); a criação de um Núcleo Básico Comum de Conteúdos em quatro blocos $^{76}$ (Fundamentação, Planejamento e Configuração, Sistemas de Utilização e Sistemas de Produção) e a recomendação de carga horária mínima de 3.200 horas (na qual o Núcleo Básico Comum e a Habilitação não deveriam ocupar mais da metade do tempo). O documento foi apresentado à Secretaria de Educação Superior do Ministério da Educação (SESu/MEC), em novembro de 1999, e aprovado em 3 de abril de 2002 (COUTO, 2008, p.40).

75 Primeiro encontro realizado pela Comissão de Especialistas em Artes da Secretaria de Ensino Superior do Ministério da Educação - CEEArtes/SESu/MEC, para dirigentes de Cursos de Educação Superior em Design (COUTO, 2002, p.26)

${ }^{76}$ Couto (2008, p.39) ressalta que a composição dos currículos plenos, baseados no Núcleo Básico Comum de Conteúdos, diferentemente dos Currículos Mínimos, não deveria ser entendida como uma composição de blocos de conteúdos fechados e separados, trablhados de forma linear e compartimentada. 
Os Pareceres CES/CNE nº 0146/2002, 67/2003, 0195/2003 e a Resolução CNE/CES n ${ }^{\circ} 5 / 2004$, de 8 de março de 2004, apresentam diretrizes específicas para os cursos de bacharelado em Design. Com o perfil desejado do formando, estipulase, no Art. $3^{\circ}$, a:

[...] capacitação para a apropriação do pensamento reflexivo e da sensibilidade artística, para que o designer seja apto a produzir projetos que envolvam sistemas de informações visuais, artísticas, estéticas culturais e tecnológicas, observados o ajustamento histórico, os traços culturais e de desenvolvimento das comunidades, bem como as características dos usuários e de seu contexto sócio-econômico e cultural (BRASIL, 2004 MEC, p.2, grifo nosso).

As novas Diretrizes Curriculares, então, passam a ser o que norteia o presente e o futuro das IES. Para Couto (2002, p.70):

As Diretrizes Curriculares vieram para ficar. O abandono de antigos modelos no campo do ensino do Design constitui-se num exercício necessário. Pensar o papel do designer em formação, como fruto de uma relação global que inclui o meio, a subjetividade e a visão coletiva decorrente da cultura é o novo caminho a ser trilhado.

Já no âmbito do jornalismo, de forma análoga ao ocorrido no design, os debates no Seminário Nacional das Diretrizes Curriculares no Ensino de Jornalismo, nos dias 24 e 25 de abril de 1999, em Campinas, influenciaram a elaboração das propostas de novas Diretrizes Curriculares para o Curso de Comunicação Social. O documento, apresentado pela Comissão de Especialistas de Ensino de Comunicação Social (CEE/COM), visou à qualificação do ensino na área. De acordo com Moura (2002, p.63):

os novos projetos serão elaborados a partir de estruturas curriculares adequadas às necessidades e experiências dos estudantes de cada região. É provável que as instituições de ensino promovam debates sobre o assunto, nos quais docentes e discentes participarão das decisões. A construção do currículo será diferenciada nas escolas, porém os conteúdos inerentes às atividades profissionais deverão ser abordados.

O Parecer CNE/CES n ${ }^{\circ}$ 492/2001, de 3 de abril de 2001, veio aprovar as Diretrizes Curriculares para Comunicação Social e suas Habilitações, além de outros cursos. Ele teve colaboração de diversas entidades da área, como ABECOM, COMPÓS, ENECOS e INTERCOM, e ofereceu uma mudança em relação ao último currículo mínimo, propondo a flexibilização da estruturação dos cursos e o estabelecimento de orientações para a obtenção de padrão de qualidade na formação dos cursos existentes e futuros. As diretrizes visaram atender as "variedades de circunstâncias geográficas, político-sociais e acadêmicas, como para ajustar-se ao 
dinamismo da área, e para viabilizar o surgimento de propostas pedagógicas inovadoras e eficientes" (BRASIL, 2001a MEC, p. 16). Posteriormente, no mesmo ano, o Parecer CNE/CES n ${ }^{\circ}$ 1.363/2001, aprovado em 12 de dezembro de 2001, veio retificar o anterior, orientando as especificações que deveriam ser explicitadas nos projetos pedagógicos de formação profissional. O estabelecimento das Diretrizes Curriculares para a área de Comunicação Social e suas habilitações ocorreram por meio da Resolução CNE/CES n 16, de 13 de março de 2002 e vigoram até o momento.

Uma observação acerca das Diretrizes Curriculares para a área da Comunicação Social definidas na Resolução CNE/CES nº 16, é que apesar da oportunidade disponibilizada para se construirem currículos mais pertinentes às realidades regionais e seus mercados, há uma impressão de que parte dos cursos optou por permanecer como estavam. No caso da habilitação em Publicidade e Propaganda, por exemplo, de acordo com Neto (2015, p.15):

a grande maioria dos cursos permaneceu como estava, sem a promoção de mudanças significativas e mesmo, o que aconteceu a posteriori, muitos dos cursos criados já na vigência das diretrizes, seguiram o desenho definido pelo antigo currículo. A "fórmula" pareceu mais atraente que novas experiências formativas.

Portanto, apesar da potencialidade oferecida pelo estabelecimento de regras que norteiem os cursos visando à formatação de currículos adequados à realidade local e ao momento, isso não significa que as instituições realmente serão capazes de oferecer reformas que cumpram as expectativas. Há sempre o risco iminente de se preferir a segurança de um modelo já estabelecido.

Esse aspecto pode ser uma das razões pelas quais não se observa uma efetiva presença da infografia nos cursos brasileiros, tendo em vista que as novas diretrizes abriram espaço para uma disciplina que aborde a infografia como tema. Apesar do seu inerente viés multidisciplinar e do fato de ser um produto com intensa demanda de mercado, não se observa uma evidente adoção da infografia como opção aos alunos de jornalismo e design. Veremos, adiante, como ocorre a presença da infografia nas IES brasileiras, de forma a subsidiar as reflexões no próximo capítulo. 


\subsection{Dados sobre a presença da infografia no Jornalismo e Design}

Para refletir sobre a infografia nos cursos nacionais, é imprescindível coletar, organizar e analisar dados sobre a presença de disciplinas que abordem o tema nas IES, de forma ampla. Sem uma ideia das condições atuais de acesso a conteúdo relativo à infografia em nossos cursos superiores de jornalismo e design, dependeríamos de dados de países como EUA ou Espanha para compará-los a experiências pessoais ou dados com abrangência restrita (apenas algumas universidades ou com o recorte em uma região, por exemplo). Este trabalho visou disponibilizar dados do país como um todo, não se restringindo ao eixo Rio-São Paulo ou capitais, para que os gráficos resultantes sejam capazes de comparar as diferentes regiões e possibilitar uma visualização mais condizente com a realidade heterogênea do Brasil. Para tal, foi necessário considerar um percurso metodológico que contemplasse os dados provenientes de fontes que não são necessariamente organizadas, atualizadas ou concentradas em um banco de dados oficial. Pelo contrário, a fragmentação de informações nos pareceu ser a condição normal de acesso aos dados.

O primeiro passo para a obtenção dos dados foi acessar os últimos relatórios disponíveis com os resultados estatísticos do Censo da Educação Superior no Brasil (CENSUP), disponibilizado no portal do Instituto Nacional de Estudos e Pesquisas Educacionais Anísio Teixeira (INEP) do Ministério da Educação (MEC). Foram utilizadas as Sinopses Estatísticas da Educação Superior 2016, com data de última atualização em 20 de setembro de 2018, de acordo com a Coordenação-Geral de Controle de Qualidade e de Tratamento da Informação (CGCQTI) da Diretoria de Estatísticas Educacionais (Deed) do INEP. O documento, composto por 51 tabelas com dados consolidados da coleta feita pelo sistema CENSUP junto a instituições do Ensino Superior brasileiras, possui informações sobre modalidades de ensino (graduação e sequencial, presenciais ou de ensino a distância - EAD), docentes, vagas, cursos, localização, dentre outras.

A partir dos documentos, foram obtidos os dados consolidados sobre os cursos de design e comunicação social com habilitação em jornalismo. Os dados sobre a quantidade total de cursos presenciais constam da tabela 3.2 - Número de Cursos de Graduação Presenciais, por Organização Acadêmica e Categoria Administrativa das IES, segundo as Áreas Gerais, Áreas Detalhadas e Programas 
elou Cursos - Brasil 2016, no grupo de Ciência Sociais, Negócios e Direito, item Jornalismo e reportagem, linha Jornalismo e no grupo de Humanidades e Artes, item Design e estilismo, linha Design.

Foram identificados e incluídos nesta pesquisa os cursos de graduação em design, design gráfico, design de comunicação, design digital, design visual $^{77} \mathrm{e}$ cursos de comunicação social habilitação jornalismo de universidades, centros universitários, faculdades e IF/CEFETs. Foram filtrados e excluídos os cursos de design de ambientes, design de animação, design de carnaval, design de interiores, design de moda, design de produto, design educacional, design de games, design publicitário e design de calçados, de acordo com os nomes listados pelo MEC.

A partir das Sinopses Estatísticas da Educação Superior, com a identificação de 280 cursos de design e de 327 cursos de jornalismo, em uma segunda etapa, foi utilizado o Cadastro Nacional de Cursos e Instituições de Educação Superior, do portal do Cadastro e-MEC, para a obtenção de informações detalhadas de cada um dos cursos, tais como os nomes das instituições, localizações, endereços eletrônicos, dentre outras. O cruzamento dos dados do CENSUP com o Cadastro eMEC também serviu para identificar cursos adicionais em atividade, em processo de descredenciamento, desativação/extinção voluntária, com dados atualizados, tendo em vista que o portal é a base oficial dos cursos e Instituições de Educação Superior, com informações reguladas e supervisionadas pelo respectivo Conselho Estadual de Educação ou pelas IES do Sistema Federal. Pelo Cadastro e-MEC foi possível identificar um total de 299 cursos de design e de 398 cursos de jornalismo dentro das características buscadas para este trabalho.

A partir dos dados oficiais disponíveis no Cadastro e-MEC, uma vez listadas as quantidades de cursos, seus nomes e endereços, foi realizada uma filtragem dos cursos e portais sem informações suficientes ${ }^{78}$, desativados, indisponíveis ou offline (Quadro 11 e Quadro 12). Foram, então, coletados os dados sobre localização (cidade, estado, região, capital/interior), modalidade (presencial ou EAD), detalhes relativos aos nomes dos cursos, descrições, disponibilidade de grades curriculares,

77 Cursos com conteúdo gráfico-visual preponderante, onde, potencialmente, a infografia pode ser oferecida como parte da grade curricular.

${ }^{78}$ Para que os dados dos cursos fossem coletados e considerados válidos para esta pesquisa, seus respectivos portais deveriam estar online (em pelo menos um acesso durante o tempo de apuração de junho a dezembro de 2018) e oferecer informações sobre o nome e tipo de instituição, cidade, unidade federativa, nome do curso, descrição, estar presente no Cadastro e-MEC e estar ativo no ano de 2018 . 
ementas, se possuem disciplinas relacionadas à infografia, cargas horárias, características e links de referência.

\begin{tabular}{cccccc} 
Região & $\begin{array}{c}\text { Cursos } \\
\text { Identificados }\end{array}$ & Desativados & Fora do ar & Sem informações & Válidos \\
\hline SE & 118 & 1 & 0 & 18 & 99 \\
\hline$S$ & 68 & 3 & 0 & 6 & 59 \\
\hline CO & 29 & 1 & 0 & 7 & 21 \\
\hline N & 28 & 1 & 1 & 9 & 17 \\
\hline NE & 56 & 0 & 0 & 7 & 49 \\
\hline Total & 299 & 6 & 1 & 47 & 245 \\
\hline
\end{tabular}

Quadro 11 - Cursos de design identificados, desativados, fora do ar, sem informações e totais válidos, por Região. Fonte: do autor.

Em relação aos cursos de design, foi possível constatar um total de 292 graduações ativas disponíveis em território nacional, em 2018. Foram excluídas do total válido para a pesquisa seis unidades que indicam terem sido desativadas ou estão em processo de extinção e um portal que permaneceu fora do ar durante o período da pesquisa, de junho a dezembro de 2018. De acordo com o Cadastro eMEC, dos que indicam possuir cursos de design, 47 não disponibilizam informações suficientes em seus portais. Entre os 245 cursos válidos, separados por região, identificamos 99 na região Sudeste, 59 na região Sul, 21 na região CentroOeste, 17 na região Norte e 49 na região Nordeste.

Cursos

\begin{tabular}{cccccc} 
Região & Identificados & Desativados & Fora do ar & Sem informações & Válidos \\
\hline SE & 153 & 7 & 0 & 24 & 122 \\
\hline S & 77 & 0 & 0 & 7 & 70 \\
\hline CO & 39 & 1 & 1 & 3 & 34 \\
\hline N & 38 & 1 & 0 & 4 & 33 \\
\hline NE & 91 & 5 & 2 & 9 & 75 \\
\hline Total & 398 & 14 & 3 & 47 & 334 \\
\hline
\end{tabular}

Quadro 12 - Cursos de jornalismo identificados, desativados, fora do ar, sem informações e totais válidos, por Região. Fonte: do autor.

Dos cursos de jornalismo, foi possível identificar um total de 381 graduações ativas disponíveis em território nacional, em 2018. Foram excluídos 14 cursos que indicam terem sido desativados ou estão em processo de extinção. Três portais permaneceram off-line durante o período da pesquisa, de junho a dezembro de 2018. 
Segundo o Cadastro e-MEC, dos que indicam possuir cursos de jornalismo, 47 não disponibilizam informações suficientes em seus portais. Entre os 334 cursos válidos para esta pesquisa, separados por região, identificamos 122 na região Sudeste, 70 na região Sul, 34 na região Centro-Oeste, 33 na região Norte e 75 na região Nordeste.

Para que houvesse um mapeamento regional, foi realizada uma diferenciação entre os cursos presenciais e EAD oferecidos, tendo em vista que a modalidade influencia o tipo de instalações e infraestrutura necessária nos locais onde os cursos são disponibilizados. Foram identificados 212 cursos presenciais e 33 cursos de EAD de design (Quadro 13). Em jornalismo, foram assinalados 277 cursos presenciais e 57 cursos de EAD (Quadro 14 ).

\begin{tabular}{cccc} 
Região & Cursos presenciais & Cursos de EAD & TOTAL \\
\hline SE & 95 & 4 & 99 \\
\hline S & 55 & 4 & 59 \\
\hline CO & 16 & 5 & 21 \\
\hline$N$ & 11 & 6 & 17 \\
\hline NE & 35 & 14 & 49 \\
\hline Total & 212 & 33 & 245 \\
\hline
\end{tabular}

Quadro 13 - Total de cursos identificados de design por modalidade e Região. Fonte: do autor.

\begin{tabular}{cccc} 
Região & Cursos presenciais & Cursos de EAD & TOTAL \\
\hline SE & 114 & 8 & 122 \\
\hline S & 62 & 8 & 70 \\
\hline CO & 26 & 8 & 34 \\
\hline N & 19 & 14 & 33 \\
\hline NE & 56 & 19 & 75 \\
\hline Total & 277 & 57 & 334 \\
\hline
\end{tabular}

Quadro 14 - Total de cursos identificados de jornalismo por modalidade e Região. Fonte: do autor.

A partir dos dados obtidos, foi possível realizar um mapeamento das cidades brasileiras que oferecem cursos presenciais de design e jornalismo. Os dados coletados foram organizados e, então, processados e transformados em gráficos.

É importante frisar que há cidades com mais de um curso disponível e cidades com diversos cursos concentrados em uma mesma região metropolitana (Figura 64). Desconsiderando as instituições que não cumpriram os critérios de disponibilidade de informações em seus portais, destacamos, no caso de cidades 
com cinco ou mais cursos de design: Campinas (5), Belo Horizonte (7), Rio de Janeiro (14) e São Paulo (27), na região Sudeste; Florianópolis (5), Porto Alegre (7) e Curitiba (8), na região Sul; Goiânia (5) e Brasília (6), na região Centro-Oeste; e Salvador (5) e Recife (6), na região Nordeste.

\begin{tabular}{cccc} 
Região & Cursos presenciais & $\begin{array}{c}\text { Cidades com 5 } \\
\text { ou mais cursos }\end{array}$ & $\begin{array}{c}\text { Cidades com pelo } \\
\text { menos um curso }\end{array}$ \\
\hline SE & 95 & 4 & 36 \\
\hline S & 55 & 3 & 31 \\
\hline CO & 16 & 2 & 6 \\
\hline$N$ & 11 & 0 & 4 \\
\hline NE & 35 & 2 & 17 \\
\hline Total & 212 & 11 & 94 \\
\hline
\end{tabular}

Quadro 15 - Total de de cidades que oferecem pelo menos um curso presencial de design e total de cidades com cinco ou mais cursos, por Região. Fonte: do autor.

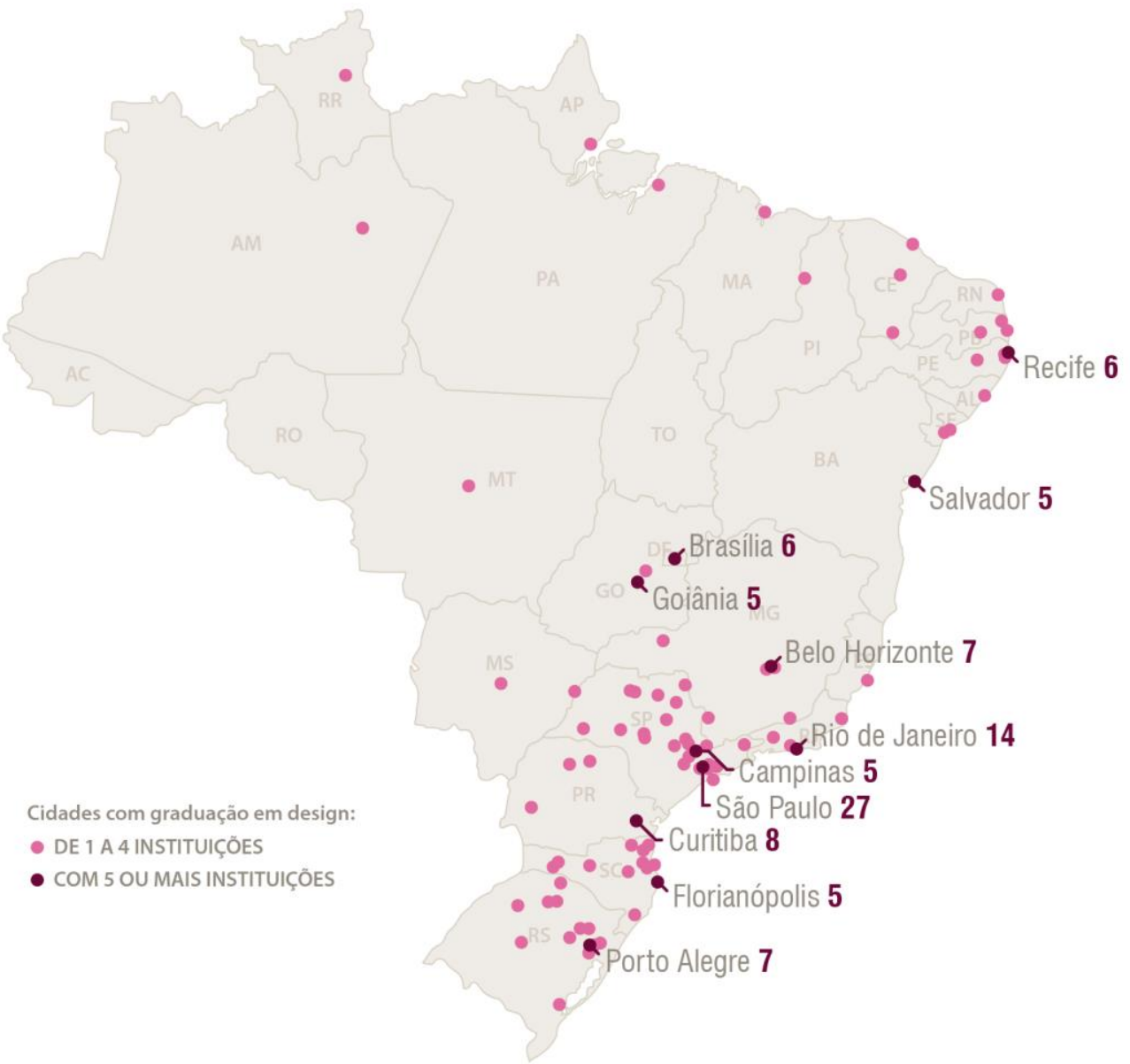

Figura 64 - Mapa com cidades que oferecem pelo menos um curso presencial de design, destacando nominalmente as cidades com cinco ou mais cursos. Fonte: do autor. 
No caso dos cursos de jornalismo, por quantidade de graduações na mesma cidade, destacam-se: Belo Horizonte (8), Rio de Janeiro (13) e São Paulo (22), na região Sudeste; Curitiba (10) e Porto Alegre (8), na região Sul; Brasília (9) e Goiânia (6), na região Centro-Oeste; Manaus (5) na região Norte; e Recife (6), Fortaleza (7) e Salvador (9), na região Nordeste (Figura 65).

\begin{tabular}{cccc} 
Região & Cursos presenciais & $\begin{array}{c}\text { Cidades com 5 } \\
\text { ou mais cursos }\end{array}$ & $\begin{array}{c}\text { Cidades com pelo } \\
\text { menos um curso }\end{array}$ \\
\hline SE & 122 & 4 & 85 \\
\hline$S$ & 67 & 3 & 34 \\
\hline CO & 34 & 2 & 9 \\
\hline$N$ & 33 & 1 & 11 \\
\hline NE & 75 & 3 & 27 \\
\hline Total & 331 & 13 & 166
\end{tabular}

Quadro 16 - Total de de cidades que oferecem pelo menos um curso presencial de jornalismo e total de cidades com cinco ou mais cursos, por Região. Fonte: do autor.

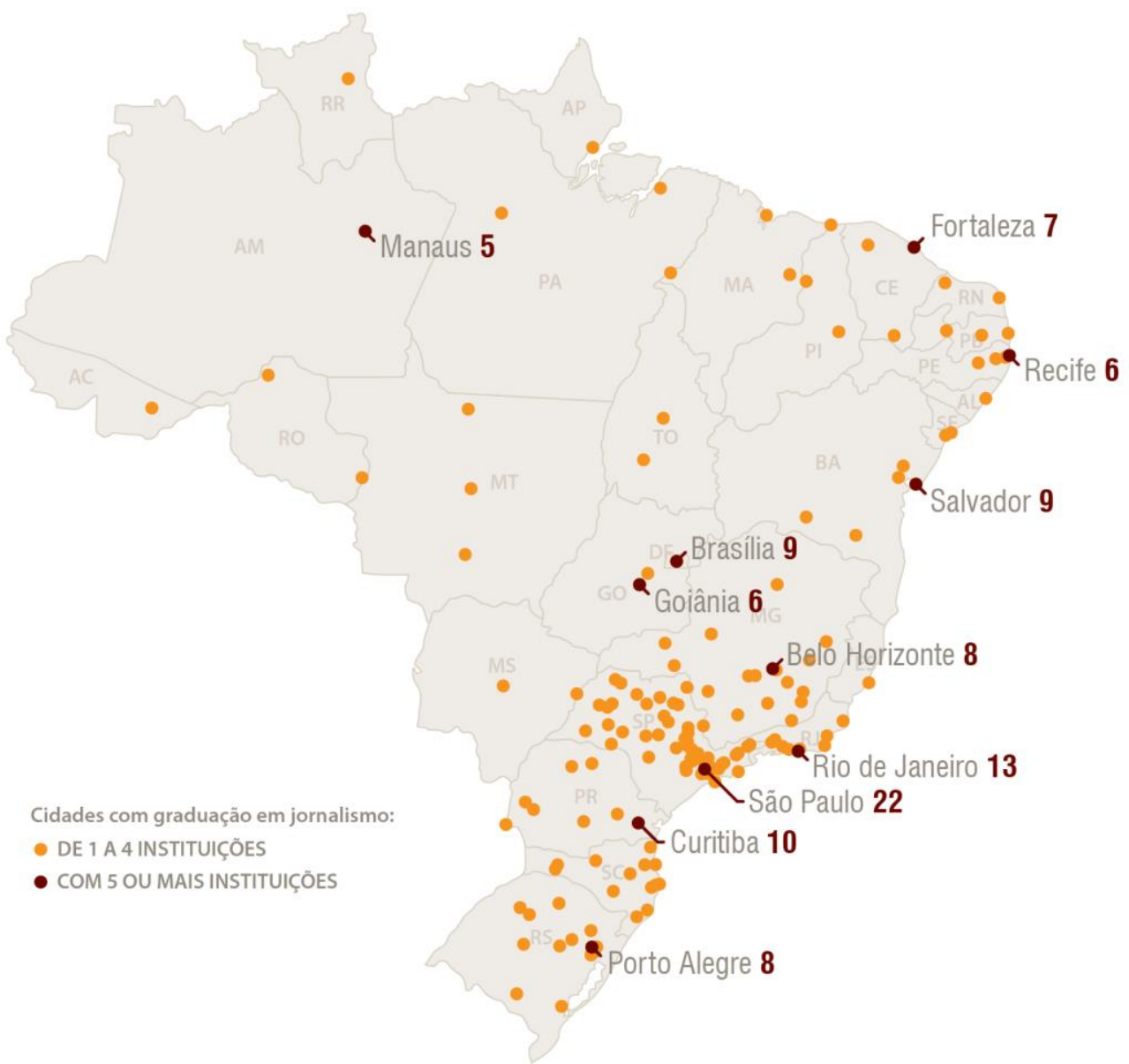

Figura 65 - Mapa com cidades que oferecem pelo menos um curso presencial de jornalismo, destacando nominalmente as cidades com cinco ou mais cursos. Fonte: do autor. 
Posteriormente, buscou-se detectar disciplinas nas quais o tema da infografia é abordado de forma direta, observando títulos e ementas que indicam a infografia como assunto principal. De forma complementar, foram identificadas disciplinas em que a infografia e as visualizações da informação sejam parte dos tópicos listados nas ementas, ou seja, que abordam indiretamente o tema. Cabe pontuar que, ao se observarem quais dados estavam disponíveis para consulta, descartou-se a viabilidade de construir um gráfico com uma série temporal acerca da presença das disciplinas ligadas ao tema da infografia nos cursos. $O$ fato de não haver possibilidade de consulta confiável das grades disciplinares dos anos anteriores foi decisivo nesse aspecto. No entanto, a partir dos resultados desta pesquisa, torna-se possível construir uma base de dados que permite a alimentação de uma série temporal, replicando os procedimentos da coleta aqui realizada em intervalos de tempo regulares no futuro.

Foram consultados todos os cursos de design e jornalismo nos portais das instituições identificadas e validadas, e, a partir de suas grades curriculares, observadas todas as disciplinas obrigatórias e eletivas, buscando-se as ligadas ao tema da infografia. As disciplinas incluídas possuem nomes variados, no entanto, na maior parte, o próprio título revela a relação com infografia, tais como: Design da informação, Design de informação: infografia e visualização de dados, Infografia (título com maior incidência), Infodesign, Infografia e videografia, Infografia e visualização de dados, Infografia jornalística, Infografia para jornalismo, Infográficos, Infográficos e vinhetas jornalísticas, Jornalismo de dados e infografia, Jornalismo gráfico, Jornalismo visual, Produção gráfica e infografia, Projeto visual e infográfico, Tópicos especiais em comunicação - jornalismo infográfico e Animação e infografia.

Dentre as disciplinas identificadas com abordagem indireta, observando-se suas ementas, com a infografia compondo parte do conteúdo, foram encontradas: Comunicação Visual, Design de notícia e planejamento visual, Design de notícias, Design em comunicação, Design em jornalismo, Design editorial, Design gráfico para jornalismo, Design visual em jornalismo, Edição em mídia impressa, Editoração eletrônica, Fundamentos de edição gráfica, Informática aplicada à comunicação visual, Inovação na narrativa jornalística, Jornalismo de dados, Jornalismo digital, Jornalismo impresso, Jornalismo gráfico, Jornalismo gráfico e editorial, Jornalismo visual, Laboratório de imagem e produção gráfica, 
Laboratório de narrativas digitais, Laboratório de Jornalismo I - Web, Linguagem jornalística dos meios gráficos, Planejamento gráfico e editoração, Planejamento gráfico em jornalismo, Planejamento visual e foto, Planejamneto visual em jornalismo, Processos gráficos em jornalismo, Produção e edição de textos jornalísticos, Produção gráfica e digital, Produção gráfica em jornalismo, Projeto gráfico em jornalismo, Projeto gráfico para jornalismo impresso, Redação para novos meios, Técnicas gráficas em jornalismo, Tópicos intercomunicacionais e Webdesign em jornalismo. Cabe frisar, no entanto, que não é possível afirmar que disciplinas com o mesmo título em instituições diferentes possuam conteúdo idêntico. Foram incluídos apenas os casos pontuais em que as ementas deixam claro que o tema da infografia é parte do conteúdo da disciplina, em cada curso das instituições analisadas nesta pesquisa.

Com os dados obtidos, foi possível elaborar mapas e gráficos que permitem observar a localização e comparar a quantidade de cursos presenciais de jornalismo e design no país. Além da questão geográfica, é possível identificar a relação entre a quantidade de cursos que disponibilizam disciplinas que incluem o tema da infografia de forma direta em suas ementas e/ou títulos e os cursos que não oferecem. 


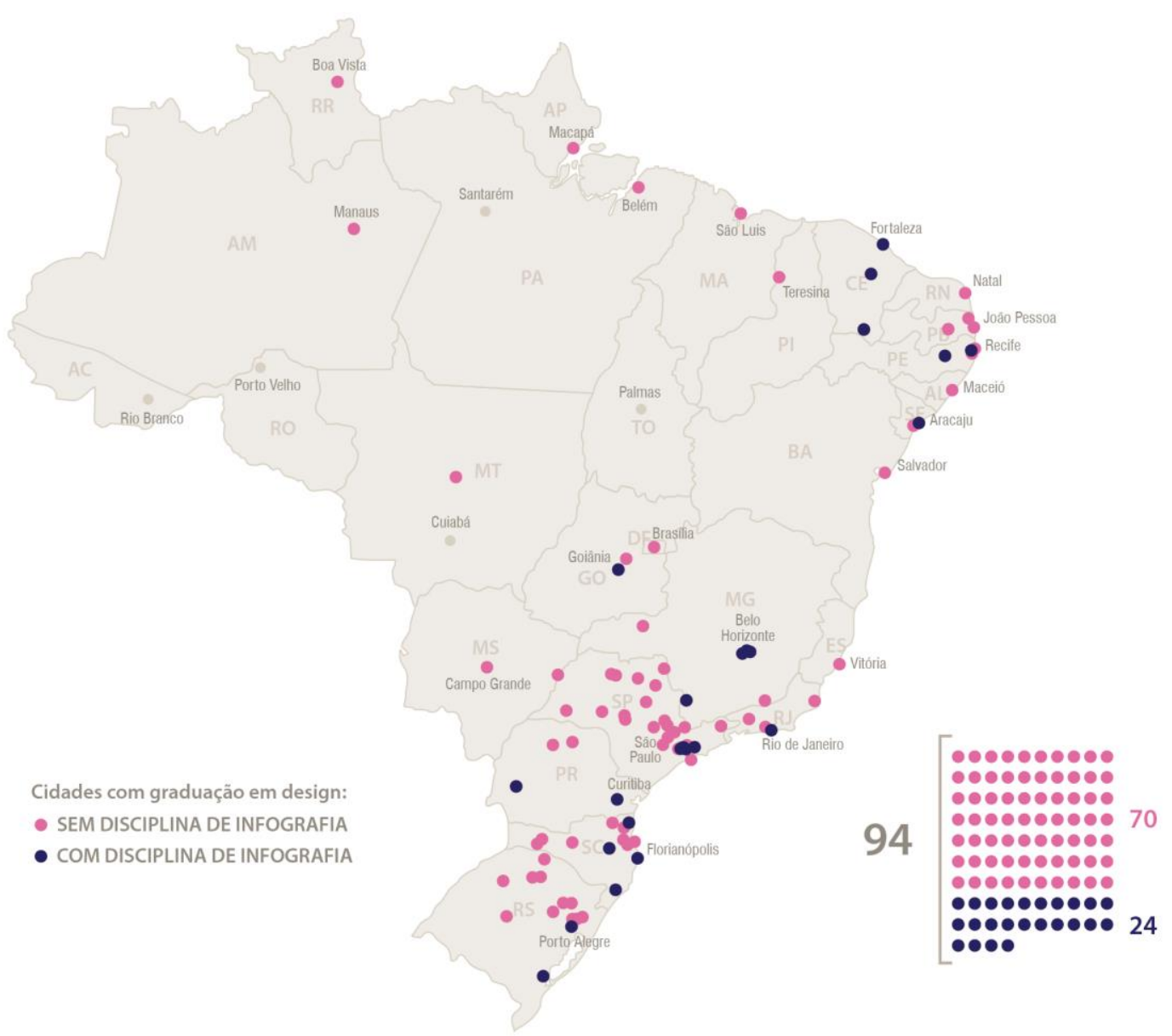

Figura 66 - Cidades com pelo menos um curso presencial de design, indicando a disponibilidade de pelo menos uma instituição com disciplina relacionada diretamente ao tema da infografia. Fonte: do autor.

Em relação aos cursos de design, das 94 cidades com pelo menos um curso identificado com informações disponíveis, há um total de 24 delas com disponibilidade de disciplina(s) relacionada(s) ao tema da infografia (Figura 66). Ou seja, em apenas $25 \%$ das localidades é possível encontrar subsídios sobre infografia em cursos superiores de design, em 2018. Há uma maior concentração na região Sudeste, com mais de um terço das cidades com cursos com disciplinas disponíveis.

Os dados coletados sobre os cursos de jornalismo também permitiram que uma representação gráfica fosse desenvolvida, de forma similar ao mapa anterior. 
Cidades com graduação em jornalismo: - SEM DISCIPLINA DE INFOGRAFIA - COM DISCIPLINA DE INFOGRAFIA

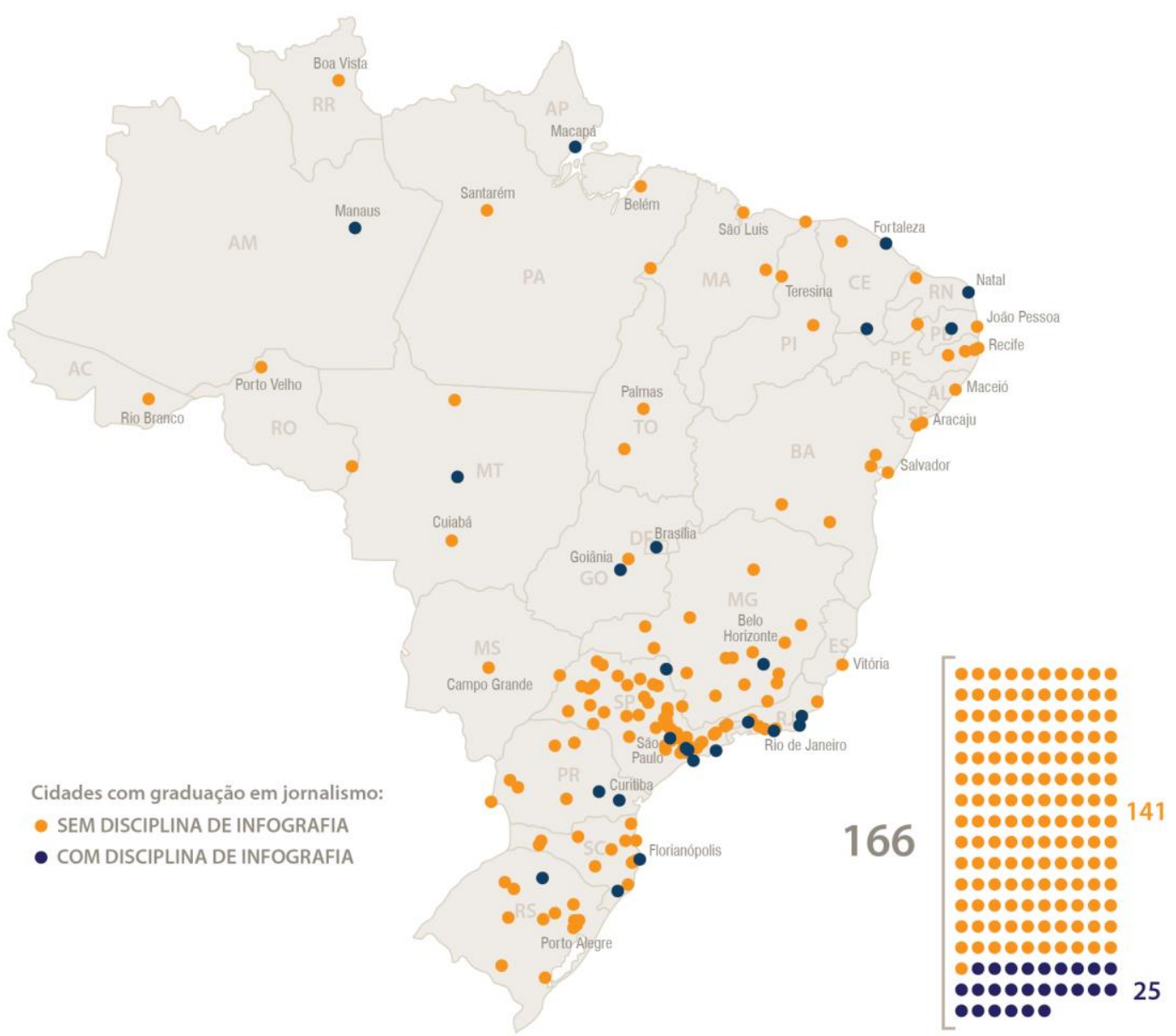

Figura 67 - Cidades com pelo menos um curso presencial de jornalismo, indicando a disponibilidade de pelo menos uma instituição com disciplina relacionada diretamente ao tema da infografia. Fonte: do autor.

Sobre os cursos de jornalismo, das 166 cidades com pelo menos um curso identificado com informações disponíveis, 141 não oferecem nenhuma disciplina com conteúdo direto relacionado ao tema da infografia, em 2018 (Figura 67). Um total de 25 cidades possuem cursos com disponibilidade, ou seja, em apenas $15 \%$ das localidades. Apesar do maior número de cursos de jornalismo em relação aos de design, e do maior número de cidades com pelo menos um curso, não há uma disponibilidade significativamente maior de cidades com disciplinas de infografia. Nota-se uma concentração ainda mais evidente na região Sudeste, com $44 \%$ das cidades com cursos com disciplinas de infografia.

Observando-se o total de instituições, sem levar em consideração a localização e com a computação apenas das disciplinas diretas, foram encontradas 38 instituições entre os cursos de design, de um total de 245 identificadas; e 58 entre os cursos de jornalismo, de um total de 334 instituições identificadas. Portanto, em 
2018, entre os cursos de design, apenas $15 \%$ oferecem disciplinas diretamente relacionadas ao tema da infografia e, entre os de jornalismo, o percentual é de $17 \%$. No caso dos cursos de jornalismo com disciplinas diretas, frisamos que 33 são presenciais e 25 são da modalidade de EAD. Esses percentuais revelam como o índice de presença de disciplinas diretamente relacionadas a infografia é baixo nas IES brasileiras, apesar da relevância do tema.

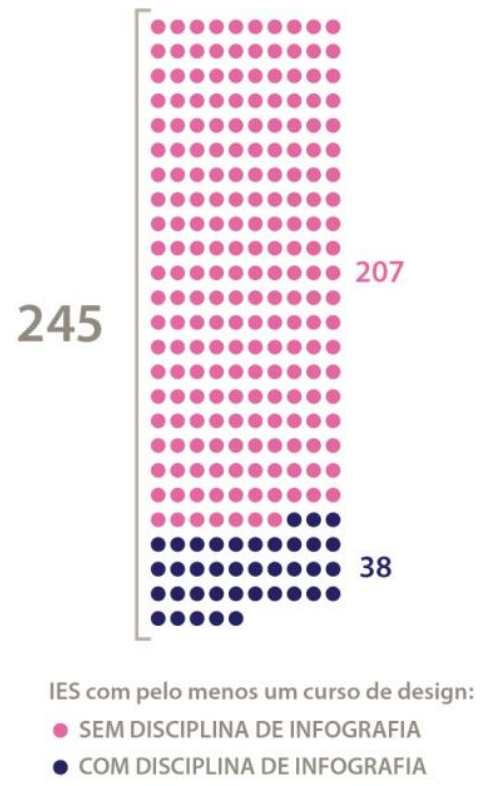

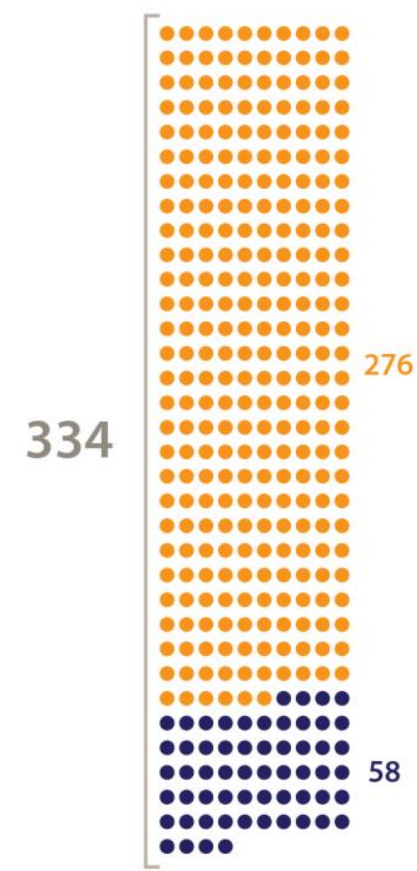

IES com pelo menos um curso de jornalismo: - SEM DISCIPLINA DE INFOGRAFIA - COM DISCIPLINA DE INFOGRAFIA

Figura 68 - Instituições com pelo menos um curso presencial de design (à esquerda) ou jornalismo (à direita), indicando a disponibilidade de disciplina relacionada ao tema da infografia. Fonte: do autor.

Já em números totais, levando-se em consideração a quantidade de disciplinas relacionadas ao tema da infografia de forma direta e/ou indireta, 118 cursos de design e 135 cursos de jornalismo oferecem algum conteúdo em suas disciplinas. Ou seja, $48 \%$ dos cursos de design disponibilizam algum conteúdo de infografia em disciplinas diretamente relacionadas ao tema ou apenas como parte menor do conteúdo. Já no caso dos cursos de jornalismo, $40 \%$ dos cursos oferecem algum conteúdo. É importante observar que "algum conteúdo" inclui disciplinas que podem abordar a infografia apenas como parte de uma aula, sem aprofundamento, o que, no entanto, não pode ser mensurado a partir das ementas. Portanto, a oferta 
de "algum conteúdo" de forma indireta não pode ser considerada um dado significativo para este trabalho, apesar de ser um indicador de que o tema é, pelo menos, mencionado em alguma disciplina ao longo do curso.

Abaixo, a proposta de infográfico realizada com os dados coletados sobre a presença da infografia nas IES brasileiras, em formato reduzido para visualização geral do layout.

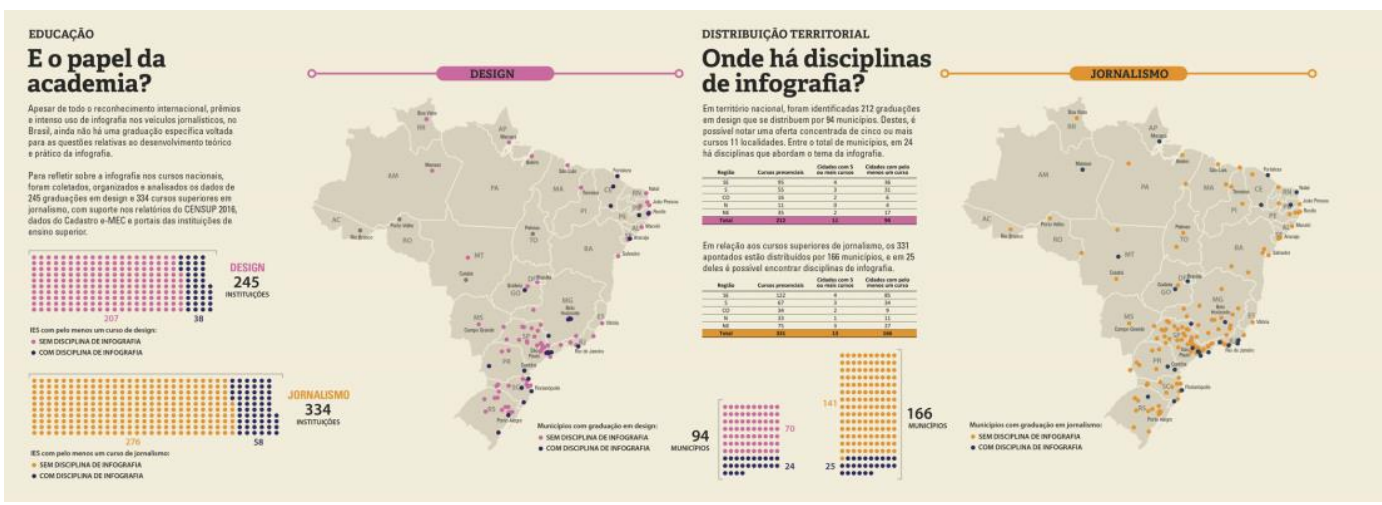

Figura 69 - Versão reduzida do infográfico sobre a disponibilidade de disciplinas relacionadas ao tema da infografia. Fonte: do autor.

A seguir, o infográfico sobre a presença da infografia na academia em uma versão adaptada para impressão em formato $\mathrm{A} 4$, de acordo com as diretrizes de diagramação deste trabalho. 


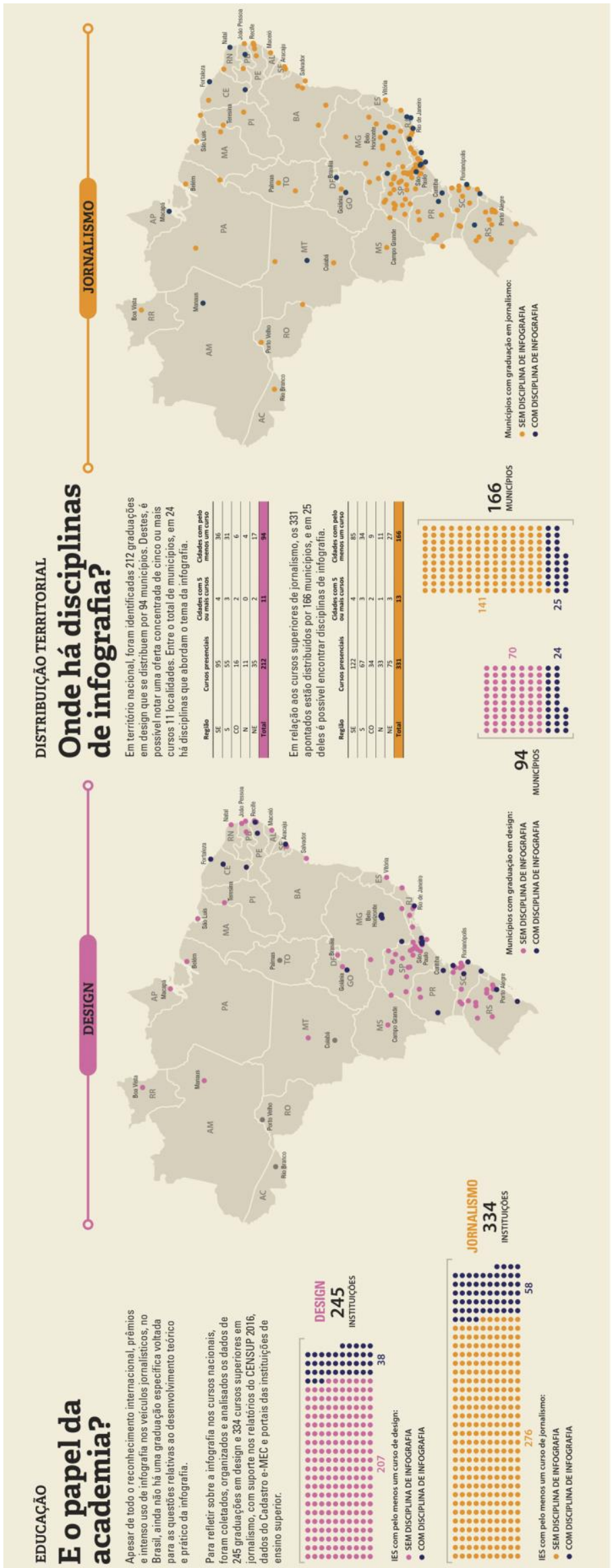

Figura 70 - Versão adaptada do infográfico sobre a infografia na academia. Fonte: do autor. 


\subsection{Considerações sobre o capítulo}

Como vimos, apesar dos inúmeros problemas estruturais no ensino superior no Brasil, o quadro atual não será resolvido apenas por meio de decretos ou com alguma "fórmula mágica" de fácil solução. É necessário, então, pensar e elaborar planos pedagógicos que tornem os alunos capazes de prevalecer e se adaptar às mudanças sociais, culturais, tecnológicas e econômicas ao longo do tempo, em suas profissões. A dicotomia presente na academia, entre uma formação humanista multicultural versus um pragmatismo técnico-profissional, pode ser ilustrada por Souza (1991, p.74), ao abordar o conflito entre os objetivos a serem alcançados na formação profissional:

Entre a criação de conhecimentos novos e a preparação da gande massa de estudantes para a vida profissional; entre as exigências da pesquisa científica e a busca de formação e expansão da personalidade; entre o imperativo da especialização inerente à civilização tecnológica e a necessidade de uma educação humanista existem tensões inevitáveis e difíceis de conciliar nos quadros tradicionais da instituição universitária.

Pode-se notar no perfil do egresso objetivado no Parecer CNE/ CES 492/2001, que inclui os cursos de Comunicação Social e suas habilitações, que há uma busca por atenuar a questão da formação profissional com um olhar horizontal e, ao mesmo tempo, especializado, considerando os processos sociais e a adequação ao ritmo e à complexidade do mundo atual. Os itens 2 e 3 , caracterizam o formando por "sua habilidade em refletir a variedade e mutabilidade de demandas sociais e profissionais na área, adequando-se à complexidade e velocidade do mundo contemporâneo" e, ainda, por "sua visão integradora e horizontalizada - genérica e ao mesmo tempo especializada de seu campo de trabalho possibilitando o entendimento da dinâmica das diversas modalidades comunicacionais e das suas relações com os processos sociais que as originam e que destas decorrem." (BRASIL, 2001(a), p.16). Ou seja, pelo menos “no papel” já há uma busca por um perfil do egresso crítico, atento às questões sociais, com capacidade de adaptação e com flexibilidade para inserção no mercado em sua profissão.

Portanto, após a nova LDBN, pavimentou-se a liberdade para a construção de grades currículares de acordo com as características regionais, tecnológicas, 
econômicas, sociais e de mercado. Há um reconhecimento dos problemas atuais dentro e fora do espectro das instituições de ensino superior. Há também uma busca por um egresso capaz de lidar com esses problemas e se adaptar ao "mundo real", não apenas como mera mão de obra. Cabe, então, às IES encontrar/implementar as soluções sem apenas se apegarem aos currículos previamente estabelecidos. No entanto, apesar de as ferramentas legais estarem postas à mesa e mesmo as diretrizes intelectuais apontarem um norte ideal, será que elas são suficientes para que as instituições realmente busquem novos projetos pedagógicos ou implementem disciplinas com conteúdo atual e relevante para os alunos?

Nesse caso, está o exemplo a infografia como disciplina, como os dados coletados e organizados nesta pesquisa demonstram. Um tema com intensa demanda, com características multidisciplinares, com capacidade de atuação em diversas modalidades de comunicação, uma ferramenta capaz de construir narrativas em canais tradicionais como o jornal impresso e inovadores como em realidade virtual que, no entanto, parece negligenciado pelos cursos superiores de design e jornalismo, no Brasil.

No próximo capítulo, discutem-se as perspectivas da linguagem infográfica em um jornalismo em constante mudança e os reflexos da presença (ou ausência) da academia no presente e futuro da infografia no país. 


\section{7 \\ Reflexões: perspectivas para a infografia em um jornalismo em mutação}

Ao discutirmos o papel da infografia e seus possíveis passos futuros, é necessário considerar sua atuação atrelada ao campo do jornalismo e à indústria da comunicação que, vinculados à sociedade, atravessam um período turbulento. $\mathrm{O}$ momento de transformação do jornalismo contemporâneo como prática social, como ferramenta de comunicação noticiosa, está subordinado ao cenário social atual e sob a influência das mudanças provenientes da participação de atores sociais como instituições, indivíduos, abstrações, convenções etc. O sujeito inserido na estrutura social a qual esses agentes pertencem compartilha uma visão, uma interpretação comum do mundo, sob uma ótica específica que influencia suas ações e costumes. A interação entre estes atores é constituída em diferentes níveis, de acordo com Pereira e Adghirni (2011, p.39), por meios que "vão de simples acordos entre um grupo de praticantes à codificação em um conjunto de normas ou mesmo à criação de um sistema teórico destinado a legitimar certos comportamentos." Para os autores, é importante situar o jornalismo como prática que passa por constante reinvenção e, dessa forma, evitar um reducionismo por meio de um discurso de "crise" ou pela expectativa de que o jornalismo possua uma forma estável "imune a inovações de ordem estrutural".

Os atuais problemas no campo do jornalismo também são questões de ordem estrutural e não se restringem apenas aos diversos entraves de aspecto conjuntural. Para que uma mudança seja considerada estrutural, segundo Pereira e Adghirni (2011, p.42), ela deve ser profunda a ponto de alterar radicalmente a prática de uma atividade e o seu reconhecimento simbólico por parte dos atores. Como exemplo, os autores mencionam que um novo software ou novo jornal poderiam alterar a prática do jornalismo, mas não o suficiente para serem considerados como fonte de mudanças estruturais. Já o surgimento da internet, de um meio diferente, ou de uma crise econômica generalizada nos veículos de comunicação são capazes de gerar alterações mais profundas. 
Em um período de convergência tecnológica, onde as diferentes mídias (jornais, revistas, rádio, televisão) são incorporadas em uma hipermídia (internet), e os indivíduos possuem a capacidade de acessar informações de diversas fontes "não tradicionais" (mídias sociais, aplicativos de mensagens, canais do YouTube, blogs, sites institucionais etc.), devemos nos perguntar se o produto do jornalismo ainda é reconhecido como principal ou "a legítima" fonte de informação ${ }^{79}$. Para o infografista Jaime Serra, a internet foi responsável pelo desmoronamento do modelo de negócios que era bem sucedido na mídia impressa do século XX. O autor cita que:

...não temos sido capazes de encontrar uma saída para um mundo novo. O resultado é uma nova situação econômica-já não é crise, visto estar efetivamente instaladoque, inevitavelmente, afeta a qualidade. Estamos vivendo, com toda probabilidade, a época onde a qualidade da informação nos meios é mais deficiente (SERRA, 2018, n.p.).

A convergência tecnológica alterou o jornalismo a ponto de seus valores não serem mais vistos como diferenciais ou necessários? Para Karam (2009, p.111), apesar de haver argumentos razoáveis para a falta de credibilidade atual, as práticas do jornalismo ganham importância na sociedade da informação justamente em função de sua teoria, ética, valores, métodos e técnicas da atividade profissional. Sendo assim, independentemente do nível de transformações na praxis provenientes dessa convergência, reformas estruturais ou em níveis mais superficiais, destacamos que valores e métodos não se dissipam de forma a se tornar o jornalismo irreconhecível como atividade. Existem alterações no paradigma, mas não a ponto do rompimento com o que se reconhece socialmente como prática jornalística e sua importância. De acordo com Karam (2009, p.118), "Sabe-se que a prática jornalística está relacionada ao continuum social e é resultado de valores profissionais afirmados ao longo da história". Portanto, mesmo mudanças estruturais, que podem caracterizar alterações significativas na prática e na sua identificação, ainda mantêm a atividade dentro do que é englobado como sendo "jornalismo" e sua ética. Para o autor, ao comentar a função do jornalismo e o que ele provê que outras atividades não o fazem:

Jornalismo tem um papel importante no sentido de ter responsabilidades que as conversas informais não têm. Tem que informar sobre fatos atuais com a

${ }^{79}$ Como mencionado anteriormente, de acordo com pesquisa realizada pelo Pew Research Center, entre julho e agosto de 2018, 43\% dos americanos adultos usam o Facebook como fonte de notícias, $21 \%$ utilizam o YouTube, $12 \%$ o Tweeter e $8 \%$ o Instagram. (PEW, 2019) 
responsabilidade de um profissional que, por causa de sua credibilidade, permite que outros façam escolhas sobre o presente e futuro com base nas informações que acabaram de receber. Esta informação deve ser produzida usando aspectos éticos e técnicos consolidados nos últimos 100 anos ou mais, e que infelizmente estão ameaçados em a era dos conglomerados de mídia (KARAM, 2009, p. 118).

É nesse cenário de produção de informações que auxiliam a tomada de decisões que se insere a infografia. As narrativas visuais resultantes da combinação de múltiplas modalidades comunicativas atuando de forma integrada são capazes de transitar variados suportes e tecnologias. Elas auxiliam o leitor a compreender e tomar decisões, adaptando os dados à sua cognição. A infografia faz uso de diversos modais de forma complementar para gerar um discurso eficiente, atraente e flexível, mas deve atuar sempre sob a égide dos aspectos técnicos e éticos que o jornalismo consolidou ao longo do tempo. Nota-se essa necessidade na resposta de John Grimwade, um dos mais importantes infografistas britânicos, quando questionado sobre a existência de uma crise e o estado da infografia, em 2002:

Há muitas pessoas fazendo gráficos e mais oportunidades de usá-las. Mas não me parece que a saúde da infografia hoje seja tão boa quanto alguns nos fazem pensar. Não desejo ser alarmista, mas é bom que nos questionemos continuamente. [...] Acredito sinceramente que nós, como infografistas, só podemos ganhar proeminência em nossas várias mídias se aderirmos aos mais altos padrões de jornalismo. Só assim podemos conquistar o respeito de nossos editores e leitores. Um gráfico super-ilustrado, inexato, com erros... pode desfazer tudo o que ganhamos com gráficos bem feitos ${ }^{80}$ (MALOFIEJ, 2002, p.17, tradução nossa).

Podemos complementar o argumento, ainda, com a afirmação de Cairo (2008, p.119, tradução nossa), ao abordar suas conclusões sobre as tendências em um futuro iminente na prática da infografia:

Sejam as características deste novo ecossistema de informação positivas ou negativas, a verdade é que sua expansão é imparável. O mundo do jornalismo e a visualização da informação estão evoluindo vertiginosamente ao nosso redor. Cabe aos profissionais aderirem a essa revolução e sobreviverem, permanecendo como servidores essenciais dos cidadãos, ou permanecerem ancorados nas práticas e atitudes de ontem. E extinguirem-se. ${ }^{81}$

${ }^{80}$ No original "There are a great many people doing graphics and more opportunities to use them. But it does not seem to me that the health of infography today is as good as some would have us think. I do not wish to be an alarmist, but it is good thath we question ourselves continuously... I sincerely believe that we as infographers can gain proeminence in our various media only if we adhere to the highest journalism standards. Only this way we can win the respect of our publishers and readers. An over-ilustrated graphic, inexact, with mistakes... can undo all we have earned with well-made graphics."

${ }^{81}$ No original "Sean las características de este nuevo ecosistema informativo positivas o negativas, lo cierto es que su expansión es imparable. El mundo del periodismo y la visualización de información está evolucionando de forma vertiginosa a nuestro alrededor. Depende de los profesionales el incorporarse a esta revolución y sobrevivir, manteniéndose como imprescindibles 
Abordaremos, então, neste capítulo, questões relativas ao papel da infografia em uma época de transformações na prática do jornalismo na sociedade pósindustrial. Caracterizamos a infografia como uma linguagem multimodal e, com base nos dados e resultados discutidos anteriormente, visamos pontuar a relevância dessa linguagem no cenário jornalístico atual, suas potencialidades, a capacidade de adaptação ao longo do tempo e a flexibilidade para sua inserção ou aproveitamento de seus princípios em novas tecnologias. Indo além, questionamos se, no país, em nossa academia, damos atenção suficiente a essa ferramenta comunicacional tão requisitada e com uma excelência internacionalmente reconhecida e premiada.

\subsection{Uma linguagem multimodal}

Ao longo deste trabalho, referimo-nos aos infográficos como uma linguagem. O termo linguagem, nesta pesquisa, não deve ser entendido apenas com uma alusão a uma estrutura reservada à linguística, como se emprega de forma recorrente. Há, em nossa cultura, uma valorização do contexto verbal, e uma constante tentativa de se organizar as mensagens não verbais em um sistema construído para análise da linguagem verbal. Dessa valorização deriva uma tendência a restringir a compreensão dos códigos não verbais ao campo da linguística. Para Braida (2012, p.45) “o uso da metáfora linguística mostra, também, como o termo 'linguagem' tem sido empregado, recorrentemente, em sua acepção mais restrita, circunscrita ao campo da linguística, como um sinônimo para 'língua'”. O autor lembra que o papel da língua é tão dominante que nos faz desconsiderar que há uma rede plural de linguagens que regem as relação humanas. Para Santaella (2001, p.10), ao abordar o tema:

[...] também nos comunicamos e nos orientamos através de imagens, gráficos, sinais, setas, números, luzes... Através de objetos, sons musicais, gestos, expressões, cheiro e tato, através do olhar, do sentir e do apalpar. Somos uma espécie animal tão complexa quanto são complexas e plurais as linguagens que nos constituem como seres simbólicos, isto é, seres de linguagem.

servidores de los ciudadanos, o quedarse anclados en las prácticas y actitudes del ayer. Y extinguirse." 
Para Braida, ao desenvolver sua argumentação sobre o design como um fenômeno de linguagem, afirma que o termo linguagem também é comumente usado por designers apenas em seu sentido mais restrito, sem o devido cuidado:

diversos autores têm afirmado que "design é linguagem". No entanto, as abordagens dentro do campo do design nem sempre têm tratado o termo "linguagem" com o cuidado e com a precisão requeridos, ou então, repetem-se os modelos que propõem adaptações simplistas e mecanicistas dos conceitos desenvolvidos dentro do campo da linguística (BRAIDA, 2012, p.45).

$\mathrm{O}$ autor afirma que, no caso dos teóricos que abordam o design como fenômeno de linguagem, seria impossível compreender o campo do design sem levar em consideração a sua função comunicativa. Assim, torna-se consequência lógica o fato de a infografia ser vetor de tal função, visto que o design da informação é uma área do design, e o infográfico é um de seus produtos. Moura (2003, p.105 apud BRAIDA, 2012, p.24) afirma que os autores que "refletem e discutem o design concordam que este campo se estabelece como linguagem, e seus objetivos/ projetos, sejam produtos informacionais ou de uso, são produções de linguagem." Sendo assim, o sentido amplo do termo linguagem pode ser compreendido como um fenômeno semiótico lato ${ }^{82}$, que engloba tanto as línguas quanto os signos não verbais (gestos, sons, símbolos, texturas, volumes, imagens etc.). Segundo Braida (2012, p.48) o conceito abrangente da linguagem, em um sentido de meio de troca de informações, engloba como verdadeiras linguagens "as expressões faciais, os gestos, a linguagem matemática, a linguagem dos computadores, do cinema, das artes, do design...". Inclui-se, portanto, neste sentido, a linguagem infográfica, sendo esta a amplitude que o termo adota nesta pesquisa.

As linguagens estão conectadas às condições culturais humanas. Sem a comunicação, sem os signos, sem os sistemas que tornam capazes a troca de informações e significados, a transmissão de uma cultura e sua perpetuação seriam impossíveis. Para Dondis (2003, p.18), as linguagens "são sistemas inventados pelo homem para codificar, armazenar e decodificar informações" e afirma que, no caso de um alfabetismo visual, apesar de haver um sistema visual básico comum a todos os seres humanos, o processo visual é influenciado por estados psicológicos,

${ }^{82}$ Considera-se aqui a Teoria Geral dos Signos, de Peirce, como base, tendo em vista apresentar-se como uma filosofia científica da linguagem, com o campo da lógica como terreno, como uma ciência que estuda todas as linguagens. É possível consultar sobre a comunicação infográfica e a semiótica de Peirce em Nogueira (2014, p.124). 
condicionamentos culturais e expectativas ambientais. As convenções, então, precisam ser aprendidas se um indivíduo condicionado a uma determinada cultura é inserido em outra. Braida (2012, p.49) afirma que "uma vez que não há cultura sem linguagem, a linguagem deve ser considerada como base de toda comunicação" e, complementado por Santaella (2003, p.127), "é através da linguagem que o ser humano se constitui como sujeito e adquire significância cultural". Portanto, as linguagens estão conectadas e regidas pelo contexto social/cultural, e estes, por sua vez, dependem das linguagens para existirem.

Sendo o design uma linguagem, ele manifesta-se como fenômeno de cultura e comunicação, tendo em vista que:

considerando-se que todo fenômeno de cultura só funciona culturalmente porque é também um fenômeno de comunicação, e considerando-se que esses fenômenos só comunicam, porque se estruturam como linguagem, pode-se concluir que todo e qualquer fato cultural, toda e qualquer atividade ou prática social constituem-se como práticas significantes, isto é, práticas de produção de linguagem e de sentido (SANTAELLA, p. 166 apud BRAIDA, 2012, p.52).

Para Braida (2012, p.55), ao se compreender o design como fenômeno de linguagem, deve-se "entendê-lo como fenômeno de comunicação, ou seja, que os produtos são mensagens e/ou produzem mensagens, são constituídos por meio de signos e sistemas de signos, os quais são capazes de gerar significados.” Dessa forma, o design estaria conectado a cultura e condicionamento humano, sendo manifestação destes, como ferramenta de compreensão do mundo. De acordo com o autor:

se design é linguagem, ele também carrega consigo essas propriedades e funciona como mediador para a apreensão do mundo. Os produtos do design, entendidos como signos, estabelecem relações entre o mundo e os homens e os ajudam a pensar sobre si e sobre o próprio mundo (BRAIDA, 2012, p.62).

Para Sudjic (2010, p.49 apud BRAIDA, 2012, p.60), o design revela a essência da sociedade atual (pós-industrial):

O design, em todas as suas manifestações, é o DNA de uma sociedade industrial ou pós-industrial, se é isso que temos hoje. É o código que precisamos explorar, se quisermos ter uma chance de entender a natureza do mundo moderno. É um reflexo de nossos sistemas econômicos. E revela a marca da tecnologia com que devemos trabalhar. É um tipo de linguagem, e é reflexo de valores emocionais e culturais. [...] O design é a linguagem que uma sociedade usa para criar objetos que reflitam seus objetivos e seus valores podem ser usados de formas manipuladoras e malintencionados, ou criativas e ponderadas. O design é a linguagem que ajuda a definir, ou talvez, a sinalizar valor. 
Sendo os infográficos produtos do design da informação, usados como ferramenta comunicacional na esfera do jornalismo, eles estariam imersos nessa lógica. O infografista, portanto, estaria inserido em um universo de construção de significados por meio de múltiplas linguagens, visto que ele lida com os sistemas de comunicação inerentes ao jornalismo, mediando mensagens pelo texto, pela retórica, pela argumentação, pela narrativa, e, ao mesmo tempo, por meio da construção de uma estrutura comunicacional visual (do design gráfico, do design da informação), além da língua, do verbal, com a manipulação dos atributos visuais dos infográficos de forma a impactar a carga persuasiva do discurso desejado. Dentro do contexto cultural, podemos observar o papel da infografia como ferramenta comunicacional no comentário de Lima (2018), em entrevista para esta pesquisa, sobre a relevância da infografia brasileira e sua contextualização:

...e outra questão que a gente esquece, que esse é o meu foco maior: qual o tipo de infografia que realmente atende a necessidade do público brasileiro? Porque se em New York as pessoas estão lendo de um jeito, não significa que em Oregon as pessoas vão querer ler aquelas coisas, e muito menos aqui no Brasil, no Rio de Janeiro, em São Paulo, em Recife ou em Curitiba. Essas são questões que me parece que as pessoas esquecem. A informação é contextual (LIMA, 2018).

Já Leite (2018) determina a infografia como linguagem, de forma ampla, inserindo o infográfico como parte de um processo de transmissão cultural, de "contar histórias", como fator determinante para a perpetuação do homem:

Hoje em dia, eu percebo que eu sou infografista, mas a minha profissão é contar histórias. Onde a infografia faz parte disso. Eu acho que a infografia é uma linguagem, a infografia é um recurso de algo maior, que é o "contar histórias". E o contar histórias foi o que trouxe o homem até aqui (LEITE, 2018).

O infografista atua, então, como articulador de linguagens em um contexto cultural, visto que a combinação de modais não ocorre de forma estanque, segregada. Ou seja, cada um dos sistemas de comunicação é usado de forma complementar, de modo que um não pode ser plenamente compreendido sem o outro. Assim, as linguagens combinadas, de forma intencional, com signos verbais e não verbais, fazem parte de um projeto, de uma construção de discurso planejada pelo designer ou jornalista visual - culturalmente dependente e, também, atuante.

Além de usarmos o termo linguagem, definimos os infográficos como uma linguagem multimodal. Por estar a infografia inserida no âmbito da comunicação e sua indústria, tendo como suporte principal o jornalismo e atuando como uma ferramenta comunicacional, o termo multimodal mostra-se um adjetivo apropriado 
para caracterizá-la, tendo em vista que um infográfico se utiliza de uma multiplicidade de modos comunicativos que passam a coexistir em uma mesma peça gráfica. Dentre as modalidades, podem se inserir texto, gráficos, imagens, animações, vídeos, áudios, narrações, músicas etc. dependendo do meio ou suporte onde o infográfico seja disponibilizado (impresso ${ }^{83}$ ou digital).

De acordo com Kress e Van Leeuwen (2006, p.177), em Gramática do design visual, ao abordarem os recursos disponíveis para o potencial de representação e comunicação do significado por meio de configurações dos elementos visuais no espaço, afirmam que "qualquer texto cujos significados são realizados através de mais de um código semiótico é multimodal". Os autores afirmam que há uma intensa presença na mídia impressa, eletrônica, em jornais, revistas, websites, anúncios etc. de textos com uma complexa interação entre a palavra escrita, imagens e outros elementos gráficos ou sonoros, de forma coerente no layout. Pontuam também que a habilidade de se produzir o que denominam de textos multimodais, mesmo tão centrais na sociedade contemporânea, não é ensinada em escolas (KRESS e VAN LEEUWEN, 2006, p.17).

Para os autores, no caso de textos multimodais, surgem questões sobre se cada um dos modais deve ser analisado de forma separada ou de forma integrada; se o sentido total da composição deve ser a soma dos sentidos das partes; ou se as as partes devem ser vistas como interativas, afetando umas as outras (KRESS e VAN LEEUWEN, 2006, p.177). Para este trabalho, consideramos a inter-relação entre os modais como parte essencial da construção de sentido da mensagem infográfica. Como afirmado anteriormente, não há um tratamento de superioridade do texto verbal em relação a imagem ou elementos gráficos. Também não há sentido em tratá-los como elementos distintos, pois devem ser encarados como parte de um sistema. Esta também é a visão de Kress e Van Leeuwen (2006, p.177, tradução nossa) em relação aos textos multimodais, ao afirmarem que "Nós buscamos ser capazes de olhar para a página toda como um texto integrado ${ }^{84}$ " e, ainda, que:

Procuramos romper as fronteiras disciplinares entre o estudo da linguagem e o estudo das imagens, e buscamos, tão quanto possível, usar linguagem e terminologia compatíveis para falar sobre ambos, pois na comunicação real os dois, e de fato

${ }^{83}$ Ressalta-se que, neste trabalho, as características de multimodalidade não se restringem às peças infográficas digitais, pois a combinação de texto, imagem e gráficos em um infográfico impresso já se estabelece por meio de diferentes modos comunicativos.

${ }^{84}$ No original "We seek to be able to look at the whole page as an integrated text." 
muitos outros, se juntam para formar textos integrados ${ }^{85}$ (KRESS e VAN LEEUWEN, 2006, p.177, tradução nossa).

Segundo os autores, a integração de diferentes modos semióticos é o trabalho de um código abrangente cujas regras e significados fornecem ao texto multimodal a lógica de sua integração. Nesse sentido, portanto, o termo multimodal mostra-se compatível com a visão pretendida neste trabalho: o destaque ao uso de diferentes modais pela infografia, sua inter-relação, sua essência complementar, de forma que a combinação entre elementos verbais e não verbais construam significado, indo além da soma de suas partes isoladas. No entanto, apesar da semelhança em função de o termo "multimodal" ser adotado nesta pesquisa, é importante ressaltarmos que, no caso do "texto multimodal" de Kress e Van Leeuwen, não há uma exigência de relação diagramática interatuante entre os elementos verbais e não verbais, como nos infográficos. Para os autores, uma peça de propaganda impressa, um website, uma embalagem ou uma matéria jornalística com uma ilustração podem ser caracterizados como textos multimodais. No nosso caso, não nos referimos a outras peças que não os infográficos, em que há um sistema onde os modais possuem papéis determinados e, sem um deles, a mensagem fica prejudicada ou incompleta.

A abordagem sobre a comunicação desenvolvida por Kress e Van Leeuwen (2006, p.20) parte de uma base social, na qual os significados expressos por escritores, oradores, fotógrafos, pintores, designers etc. são, antes de tudo, significados sociais, apesar de considerarem a importância das diferenças individuais existentes. Os estudos de ferramentas conceituais que investigam como indivíduos de uma comunidadade particular utilizam sistemas semióticos para a construção e compartilhamento de significados foram desenvolvidos pelos autores com base nos pressupostos de Halliday (1978). Para a semiótica social, a língua dispõe de um leque de escolhas em seu sistema, e elas não são aleatórias; são intencionais, de forma a expressar respostas às condições e às necessidades dos usuários da língua em contextos sociais determinados.

Por natureza, a infografia é uma linguagem que faz intenso uso de recursos imagéticos para comunicar. Segundo Kress e Van Leeuwen (2006, p.4), uma

${ }^{85}$ No original "We seek to break down the disciplinary boundaries between the study of language and the study of images, and we seek, as much as possible, to use compatible language, and compatible terminology to speak about both, for in actual communication the two, and indeed many others, come together to form integrated texts." 
"linguagem visual não é - apesar das hipóteses contrárias - transparente e universalmente entendida; é culturalmente específica ${ }^{86}$." Sendo fenômeno comunicacional e culturalmente específica, uma linguagem como a infografia fica, portanto, entrelaçada ao meio social onde atua. Se, ainda, ela é uma ferramenta usada em meio jornalístico, há uma relação entre a linguagem infográfica e o seu suporte essencial, o jornal, o qual está atravessando um persistente período de crises de diversas ordens (econômica, tecnológica, social, de credibilidade etc.). $\mathrm{O}$ fato de o jornalismo ter um papel atuante no meio social onde existe nos leva a considerar as perspectivas que a linguagem infográfica possui, dada a inobservância de uma "saída" ou uma solução para o modelo atuante do jornalismo contemporâneo, como veremos a seguir.

\subsection{A instabilidade pela falta de um modelo}

O jornalismo (e, consequentemente, a infografia) está vinculado ao continuum social e, assim, não escapa da influência de crises que vão além das já existentes na indústria da comunicação. No momento atual, para o sociólogo italiano Domenico de Masi (2013), há uma sensação de total desorientação em relação ao caminho para o qual a sociedade se dirige. $\mathrm{O}$ autor afirma que, ao longo do tempo, a humanidade atravessou mudanças relacionadas aos valores do trabalho, do poder, da riqueza e do saber. Além disso, a cada um desses períodos ocorreram rupturas históricas:

O início da agricultura, o nascimento da cidade, a invenção da escrita na Mesopotâmia, a organização da democracia e a elaboração do saber humanístico na Grécia, as grandes descobertas científicas realizadas entre os séculos XII e XVII, o advento da sociedade industrial no século XIX representam outros tantos saltos históricos que desorientaram gerações inteiras (MASI, 2013, p. 722).

Entretanto, nas sociedades antecessoras ao período pós-industrial era possível balizar-se em referências e modelos éticos, comportamentais, sociais, econômicos etc. A mitologia, a inteligência e o direito guiavam o homem no Ocidente clássico; a religião, na Idade Média; a estética e o príncipe, no Renascimento; as ideologias político-econômicas, nos séculos XVIII e XIX. Cada um desses momentos possuiu um período de transição da ordem de milênios (no caso rural) ou séculos, mas o

\footnotetext{
${ }^{86}$ No original "Visual language is not - despite assumptions to the contrary - transparent and universally understood; it is culturally specific."
} 
salto presente ocorre em termos de décadas ou anos. Para Masi (2013, p.723), em todos os aspectos “....as transformações foram mais rápidas e profundas do que a lei, que não teve tempo de regular-se, o mercado, que não conseguiu supri-la, e o nosso cérebro, que não conseguiu compreendê-las." Sobre a situação do sujeito atual:

Hoje, novos nômades transitam por percursos inéditos, sem um ponto de referência nem um itinerário preestabelecido, em uma condição transitória e perturbada, inserido em paisagens geográficas, científicas, tecnológicas, econômicas que mudam de hora em hora, sem deixar o tempo necessário para metabolizar seus efeitos (MASI, 2013, p.723).

Essa situação de desorientação, de uma manifestação de angústia em relação à falta de um modelo a ser seguido, de não se identificarem portos seguros e maneiras de conduzir as ações por falta de uma referência exemplifica a atual situação do jornalismo contemporâneo. Resumir a situação apenas como "crise" é negligenciar uma visão mais aprofundada, na qual se nota a característica de permanente mudança inerente à prática em "tensão entre ordem e dispersão, entre continuidade e descontinuidade que aparece como constitutiva da prática jornalística" (PEREIRA e ADGHIRNI, 2011, p.43). O vínculo com o tecido social, no entanto, revela que o jornalismo está em consonância com o atual estado da ausência do reconhecimento de um caminho que dê vazão ao que virá, uma vez rompidos os paradigmas atuais. Talvez, essa falta de referencial seja o que caracteriza a presente época. Sendo esse o caso, podemos afirmar que o jornalismo está em perfeita sintonia com o momento.

Visando propor novas perspectivas de solução para problemas relativos às práticas jornalísticas, os canadenses Jean Charron e Jean de Bonville (2004), na década de 1990, criaram o Groupe de Recherche sur les Mutations du Journalisme (GRMJ), na Universidade de Laval, Quebec. A partir do que definem como paradigma jornalístico, ou "uma maneira específica e singular de conceber e praticar o jornalismo ${ }^{87 "}$ (CHARRON e BONEVILLE, p.2, tradução nossa), segundo a noção de Khun (1987), postulam que é possível segmentar o jornalismo em quatro gerações, associadas a modelos de sociedade, suas circunstâncias e funcionalidades. Para os autores, a história do jornalismo consiste em episódios de relativa estabilidade pontuados por fases de profundas transformações.

\footnotetext{
${ }^{87}$ No original "une manière spécifique et singulière de concevoir et de pratiquer le journalisme"
} 
Observando-se as regras discursivas fundamentais e a emissão de discursos sociais, os autores apontam, em etapas historicamente subsequentes: o jornalismo de transmissão (le journalisme de transmission), em que se transmitem informações das fontes diretamente ao seu público, sem alterações de conteúdo, sem identidade discursiva real, atrelado à esfera pública burguesa, que surge no século XVII; o jornalismo de opinião (le journalisme d'opinion), financiado parte pelo patricínio político e, em parte, pela publicidade, predispõe-se às lutas políticas, em que o jornalista agora é um editor e prega aos convertidos recrutados das elites políticas, religiosas e mercantis, mas com alcance restrito em função do analfabetismo de grande parte da população do século XIX; o jornalismo de informação (le journalisme d'information), que emerge no fim do século XIX, com uma rede de coleta de notícias sobre a atualidade e com o desenvolvimento técnico e econômico que também possibilitou a distribuição em larga escala (ferrovias, telégrafos, telefone, rotativas, papel mais barato etc.) e o jornalismo de comunicação (le journalisme de communication), que se subordina às preferências do público-alvo ${ }^{88}$ e à diversificação, nascido nas décadas de 1970 e 1980. Este último seria o responsável pelos reflexos que notamos no momento atual, em que o (combalido) modelo de negócios sofre com a abundância de oferta, a intensa concorrência entre veículos, a perda de participação de mercado para novas mídias e até mesmo para áreas fora do jornalismo, tais como a publicidade, o entretenimento e a comunicação institucional corporativa, além da digitalização, da miniaturização dos equipamentos e da implantação da internet. De acordo com os autores "tecnologias cuja utilização tende a questionar normas e práticas costumeiras de produção, distribuição e consumo de informação e que colocam produtores e consumidores de informação em um ambiente de mídia em mudança ${ }^{89 "}$ (CHARRON E BONEVILLE, 2004, p.3, tradução nossa). Há, inclusive, o surgimento de um difusor do jornalismo corporativo, que Sant'anna define como mídia das fontes, em que mídias administradas por atores sociais passam a atuar como entidades representativas e grupos de interesse, tal como organizações políticas, de forma a

${ }^{88}$ Tema que Bourdieu (1997) aborda, afirmando que o campo do jornalismo está sob pressão do campo econômico em função da submissão aos índices de audiência, ou seja, fazendo com que a produção cultural esteja sujeita à lógica comercial. Apesar de a discussão girar em torno da televisão, que era o canal hegemônico na década de 1990, serve para outras mídias.

${ }^{89}$ No original "techniques dont l'usage tend à remettre en question les normes et les pratiques usuelles de production, de diffusion et de consommation de l'information et qui placent producteurs et consommateurs d'information dans un environnement médiatique en pleine mutation." 
influenciar a esfera pública. Desse modo, amplia-se a concorrência com mídia tradicional, agora com a participação de um ator que, antes, era apenas fonte (SANT'ANNA, 2005, p.3).

Além do aumento da concorrência, outra característica notável nas últimas décadas é a progressiva redução da janela de tempo entre a produção e a publicação das notícias. Essa aceleração no ciclo da notícia se intensifica não apenas com a própria concorrência por audiência, mas também com a informatização das editorias, com o surgimento da internet e, ainda, em função da mudança na percepção do tempo pela sociedade, com o seu acelerado ritmo social. Além disso, no país, um outro fator é preponderante: a "adoção do formato de agências de notícias pelos jornais brasileiros [...] a partir da influência de consultores contratados nos anos 1980 junto à Universidade de Navarra" (PEREIRA e ADGHIRNI, 2011, p.45). As consultorias espanholas, que também auxiliaram a difundir a linguagem infográfica (como vimos anteriormente), trouxeram o conceito de "turbina informativa", inicialmente por meio dos professores Carlos Soria e Juan Giner. O conceito, implementado de forma pioneira no país pelo jornal O Estado de S. Paulo, inaugurou uma era de demanda por fluxo contínuo de informações. A sociedade e as instituições se acostumaram com o ininterrupto fornecimento de notícias e as consomem em velocidades inimagináveis há duas décadas.

É curioso observar, no entanto, que, apesar do encolhimento no tempo de produção da notícia e do aumento da demanda por constante disponibilização de informações atualizadas, permanece a cobrança por boa apuração, diversidade de fontes, reflexão crítica e qualidade no produto. Ao abordar a pressão da urgência e o fast thinking no jornalismo televisivo, Bourdieu (1997, p.38) afirma que a concorrência entre os jornais, TV e veículos pelo furo $^{90}$ influenciam uma série de escolhas, ausências e presenças na construção de seus discursos. Para o autor, há um elo entre o pensamento e o tempo, relacionando problemas entre o pensamento e a velocidade:

Pode-se pensar com velocidade? Será que a televisão, ao dar palavra a pensadores que supostamente pensam em velocidade acelerada, não está condenada apenas a ter fast thinkers, pensadores que pensam mais rápido que a sua própria sombra...? (BOURDIEU, 1997, p.40).

\footnotetext{
${ }^{90}$ Jargão do meio jornalístico que se refere a uma informação publicada por um veículo antes dos demais.
} 
O pensamento que foge ao banal, portanto, que é elaborado, crítico, sem "receita pronta" e que não é consumido como fast food midiático ou como mera espetacularização, demanda tempo. O choque entre a "velocidade" e a "qualidade" é uma questão que se mantém em debate permanente no meio jornalístico, talvez de forma mais evidenciada hoje, em tempos de mídias sociais como fonte de informação ${ }^{91}$. Para quem produz notícia, resta se adaptar, resistir ou conviver com as pressões. No caso da infografia, para a qual o tempo é fundamental, fica a dúvida sobre a janela disponível para o seu aproveitamento, tendo em vista que suas peças costumam requerer um extenso trabalho em equipe, pesquisa, apuração, análise, construção de discurso visual, uso de diferentes tecnologias etc. Um exemplo seria a tarefa árdua de utilizar infografia em breaking news, pois é mais adequado elaborar peças que complementem as histórias depois da cobertura de urgência.

Outro fator de significativo ruído na difusão de notícias e que abala a credibilidade $^{92}$ dos veículos jornalísticos é a circulação intencional de fake news ${ }^{93}$, por mídias alternativas, ideologicamente direcionadas, ou por meio de mídias sociais e aplicativos de mensagens em grupo. Ao mesmo tempo, a mídia tradicional sofre intenso ataque institucional, enquanto atores políticos e sociais questionam a validade de suas apurações ou apenas direcionam acusações para gerar cortinas de fumaça ou desqualificar os veículos noticiosos. Se a angústia social pela falta de um modelo referente, por si só, já é uma questão crítica, a desconstrução dos modelos estabelecidos como tradicionalmente fornecedores de notícias amplia a sensação de desorientação. Há uma sensação de não se saber mais se um fato é "real" ou não. O relato de Lage (2018), acerca da influência da crise jornalística e

${ }^{91}$ Como vimos anteriormente, em 2018, quatro a cada dez americanos utilizam o Facebook como fonte de informação (PEW, 2019).

${ }^{92}$ A credibilidade é fundamental para o jornalista como mediador da realidade, visto que ela está ligada ao fazer noticioso e a uma estratégia objetiva de apuração dos fatos. Para Correia (2008, p.176), jornalistas, editores, proprietários e grupos que parcicipam da produção noticiosa podem ter sistemas de crenças e conhecimentos sociais variados e contraditórios entre si. As lógicas de interesse que atravessam a organização empresarial jornalística não são obrigatoriamente idênticas. Segundo o autor "à vontade de lucro soma-se a necessidade de eficácia, inteligibilidade, credibilidade e adequação aos valores sociais e éticos que legitimam socialmente a existência da instituição".

${ }^{93}$ Fake news, ou notícias falsas, são caracterizadas pela divulgação deliberada de notícias falsas, boatos e propagação de desinformação. Recurso usado pela imprensa marrom (o termo equivalente em inglês é yellow press - amarelo, não marrom), veículos sensacionalistas que buscam audiência a qualquer custo e transgridem a ética jornalística, e, também, em mídias sociais. 
a desvalorização do trabalho do jornalista corrobora com o problema das fake-news e as mídias sociais:

[...] acho que prejudica (a crise no jornalismo e as fake-news), na desvalorização do profissional "jornalista" mesmo, sabe? Até a própria notícia. Hoje em dia, você consome a notícia pelo facebook do seu amigo, você não entra naquele link para saber quem escreveu aquela matéria, para entender da apuração, você nem quer saber se tem um jornalista ali por trás. Acho um processo de desvalorização de uma história bem contada, acho que o fake-news está acabando com o jornalismo, você perde a credibilidade das notícias em geral. Agora, isso é um fenômeno de internet que está acabando mesmo com as notícias (LAGE, 2018).

O questionamento dos jornais da grande mídia como instituição social válida e as críticas diárias, que chegam ao absurdo de ofertarem "fatos alternativos" para contrapor fatos apurados e veiculados, minam as estruturas práticas e éticas construídas pelo jornalismo ao longo do tempo. Valoriza-se uma mídia corporativa que difunde a informação desejada, ainda que falsa, enquanto se desqualificam veículos e profissionais que realizam um trabalho investigativo dentro das premissas éticas jornalísticas.

Há um intenso debate sobre como reagir a esses ataques, mas, como afirmado por Serra (2018, n.p.) "no momento em que se enfrenta uma avalanche de desinformação gerada, especialmente, por e nas redes sociais, o trabalho jornalístico se faz mais necessário do que nunca". Assim, uma das opções exploradas por alguns veículos foi passar a dedicar atenção aos fact-checks ${ }^{94}$, que são as análises de discursos, informações divulgadas, notícias, dados etc. de forma a se observar se cada um dos fatos relatados é verdadeiro, falso ou induzem o leitor ao erro, ao tirar uma informação de contexto propositalmente. Mais evidente durante períodos de eleição, o espaço para análise da veracidade dos fatos mencionados em um discurso tem sido explorado por grandes publicações. Por exemplo, em função de o atual presidente americano ser um dos mais ostensivos críticos da mídia noticiosa e grande difusor de fake-news e "fatos alternativos", grandes veículos americanos como The Washington Post, CNN e NYT dedicam, em uma frequência significativa, análises dos seus discursos e declarações com textos, gráficos, infográficos, animações e vídeos (Figura 71).

${ }^{94}$ Fact-checking, ou checagem de informações, refere-se a uma checagem de fatos, conforntando histórias com dados, pesquisas e registros, como forma de qualificar o debate público, reportando o grau de verdade das informações transmitidas. 

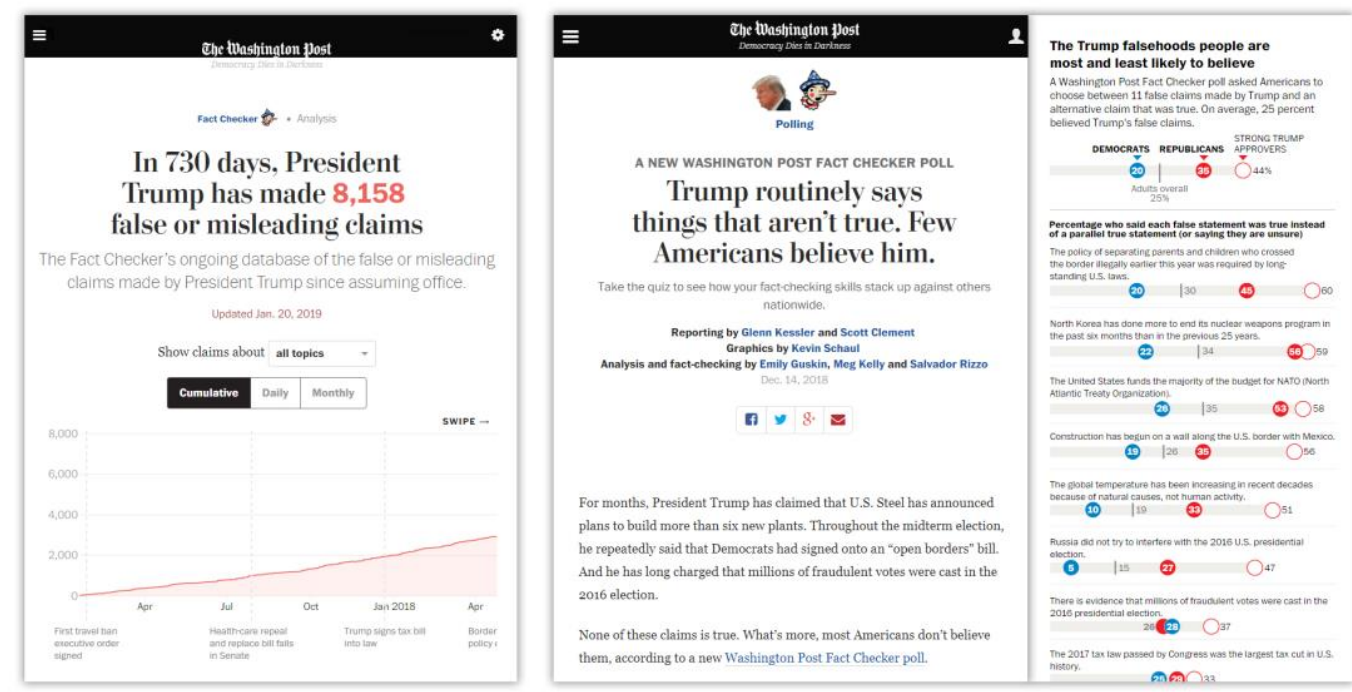

Figura 71 - Exemplo de reportagem da seção Fact Checker, do The Washington Post, com infográficos e interatividade, atualizada em 20 de janeiro de 2019. Disponível em: < https://www.washingtonpost.com/graphics/politics/trump-claims-database/?utm_term=.f0fb3ee7779 0\&noredirect=on> Acesso em: 20 jan. 2019.

Os fact-checkers, entretanto, não são exclusividade dos EUA. Já existe, inclusive, uma associação internacional de verificadores de fatos, a $\operatorname{IFCN}^{95}$, que estabelece uma série de códigos e princípios e possui mais de 61 entidades participantes. $\mathrm{O}$ aumento da presença da checagem de fatos em veículos de diversos países pode ser observado pela afirmação de Liz Spayd, no editorial do NYT:

As redações de todos os continentes vêm construindo equipes de relatórios de resposta rápida para avaliar as declarações de figuras políticas e afirmar se estão dizendo a verdade. A Turquia mal tem uma democracia, mas tem um site de checagem de fatos. A Argentina tem um que ajudou a semear outros na América Latina. Assim como partes da Europa Oriental e da África. Até mesmo alguns jornalistas na Síria devastada pela guerra começaram um. Nos Estados Unidos, eles estão em todos os lugares, a maioria deles ligada a grandes organizações de mídia (NYT, 2017, n.p.).

No Brasil, há serviços de checagem de conteúdos suspeitos realizados por grandes jornais e agências. Dentre os signatários do IFCN, estão: o Estadão Verifica, Agência Pública, Agência Lupa e Aos Fatos (IFCN, 2019). Já o portal G1, em 30 de julho de 2018, lançou a seção Fato ou Fake (Figura 72), que investiga

${ }^{95}$ IFCN (International Fact Checking Network), unidade do Poynter Institute, é uma entidade que estabelece princípios para a atuação na checagem de fatos. Seus signatários precisam mostrar comprometimento em cinco áreas: apartidarismo e imparcialidade, transparência das fontes, transparência do financiamento e organização, transparência da metodologia e política de correções aberta e honesta. Disponível em: < https://ifcncodeofprinciples.poynter.org/know-more> Acesso em: 3 jan. 2019. 
mensagens que causam desconfiança e realiza uma apuração em conjunto com jornalistas do O Globo, Extra, Época, Valor, CBN, GloboNews e TV Globo. Esse tipo de ferramenta, no entanto, demanda um investimento de recursos humanos e econômicos que nem todos os veículos possuem. Com isso, fica restrita aos grandes canais ou a agências dedicadas a esse tipo de atividade como produto principal.
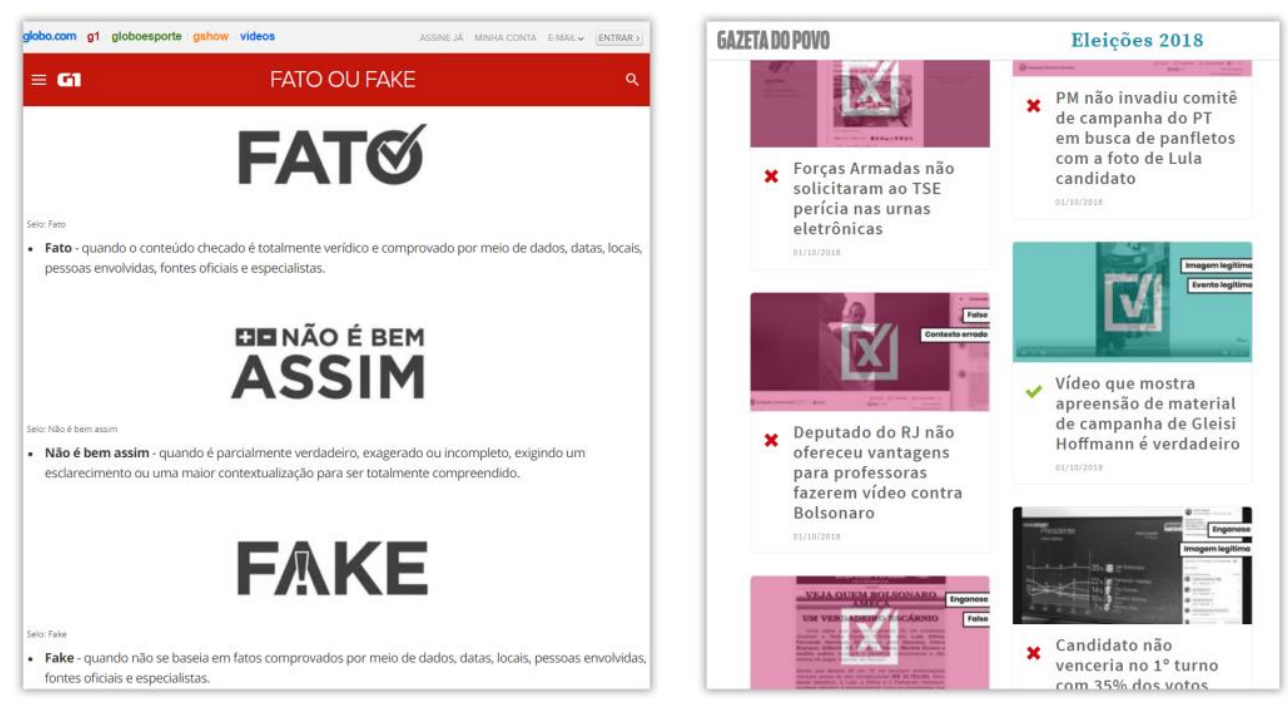

Figura 72 - O fact-check também está se consolidando no Brasil. Exemplos de selos de identificação e classificação entre verdadeiro, duvidoso e falso. Seção Fato ou Fake, do G1 (à esquerda). Disponível em: < https://g1.globo.com/fato-ou-fake/> Acesso em: 30 nov. 2018. Seção Verdade ou Mentira, da Gazeta do Povo (à esquerda), Disponível em: < https://especiais.gazetadopovo.com.br/ eleicoes/2018/fake-news/> Acesso em: 30 nov. 2019.

Um detalhe a se salientar acerca dos fact-checkers é que eles demandam um tempo de análise e apuração que não acompanha o impacto da notícia ou discurso circulante na maioria dos casos. Ou seja, de maneira geral, são apresentados posteriormente e não possuem o mesmo alcance do objeto analisado. Eles atenuam, de certa forma, o efeito de uma determinada notícia falsa, mas sem o mesmo impacto viral de fake news "bem utilizadas". Até que o fato seja conferido, uma notícia falsa viralizada age de forma similar a um boato popular. Pode ser desmentido, mas a impressão inicial não se anula por completo. Em determinados casos, o volume de declarações falsas ao longo do tempo é tão numeroso que o foco passa a ser a observação da quantidade e não do conteúdo (Figura 73). Buscando solucionar a vácuo temporal entre a afirmação e a apuração, o NYT, em 3 de outubro de 2012, declarou que havia preparado “...um pequeno exército de repórteres e 
editores - e com planilhas de 76 relatórios pré-escritos de checagem de fatos - para combater os esforços dos candidatos para embelezar ou desinformar.” (NYT, 2012). Foi uma grande mobilização para confrontar em tempo real as declarações no primeiro debate entre candidatos à presidência americana. Já em mídia televisiva, a CNN testou uma checagem de fatos em tempo real, inserindo gráficos e observações em cima das declarações da porta-voz do governo americano, em 27 de novembro de 2018 .
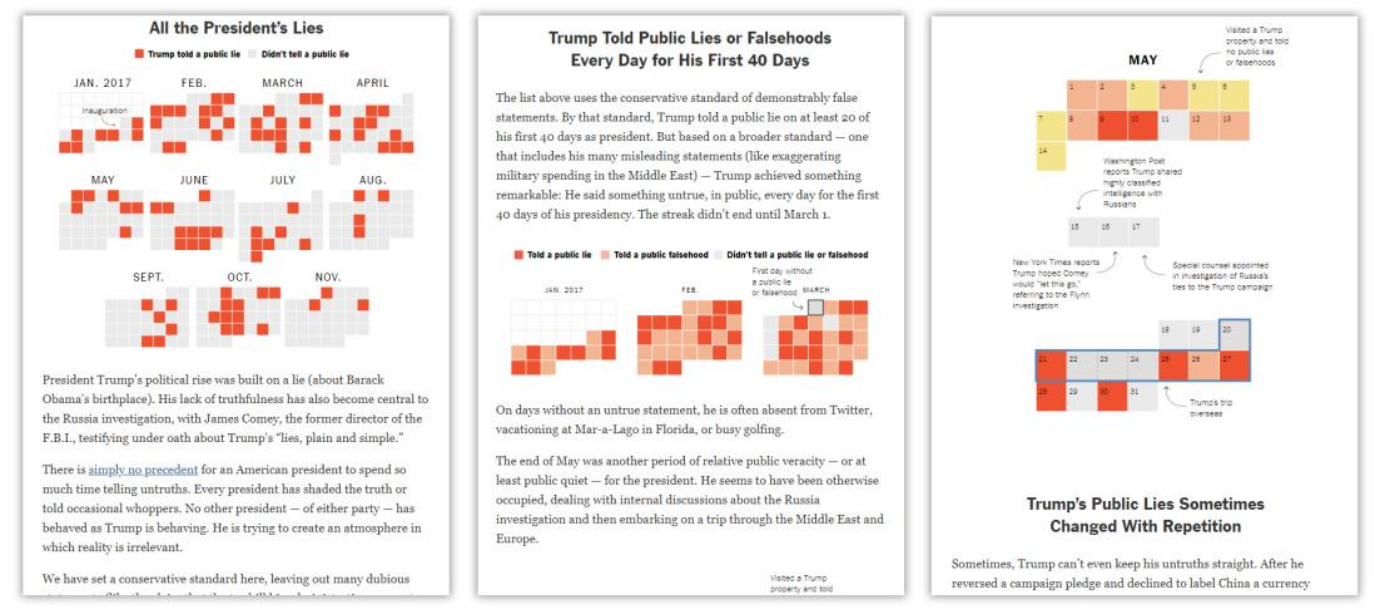

Figura 73 - Exemplo de reportagem com de checagem de fatos do $N Y T$, que usa infográficos e gráficos exploratórios para listar as declarações falsas do presidente americano ao longo do tempo. Disponível em: < https://www.nytimes.com/interactive/2017/06/23/opinion/trumps-lies.html> Acesso em: 30 dez. 2018.

Para este trabalho, é importante notarmos que o momento de questionamento dos meios tradicionais demanda uma reação. E esse momento pode caracterizar oportunidades para a exploração e uso da linguagem infográfica de novas maneiras, integrando-a na construção de discursos eficientes em novos produtos. Nos factchecks, por exemplo, o uso complementar de texto, imagens, diagramas, mapas, gráficos etc. é capaz de auxiliar de diversas formas a visualização dos problemas encontrados em discursos de forma clara e mensurável. O uso de recursos visuais também é útil quando há restrições de espaço disponível, aproveitando-se o pontencial de sintetizar informações e ordená-las de forma racional e lógica, em apelo ao logos do discurso. Os gráficos e imagens intensificam o impacto visual, o apelo a emoções e o pathos, por meio de imagens, de forma diferente do texto puro, o que reforça os resultados apresentados. Além disso, há um "argumento de 
autoridade" que acompanha os gráficos, enfatizando o ethos discursivo, com uma retórica de aparência "científica" ou "acadêmica" ao conteúdo apresentado. Ou seja, a infografia é capaz de se adaptar e está disponível como ferramenta, tanto na sua forma tradicional, como em novas tecnologias ou em demandas híbridas. Não sabemos como a prática jornalística atravessará o turbulento momento atual, mas a linguagem infográfica mostra-se uma ferramenta flexível para a construção de discursos eficientes em diversos suportes, o que pode ser um importante auxílio nessa travessia.

\subsection{Novas tecnologias: a linguagem infográfica perdura}

A versatilidade é uma das características que torna possível a longevidade da infografia. Nos capítulos anteriores, observamos um histórico da evolução dos gráficos informativos nos meios de comunicação, estabelecendo-se como uma importante ferramenta para esclarecer, evidenciar, descobrir novo conhecimento e contar histórias. Se suas origens remontam às estruturas comunicacionais em suportes físicos como paredes, tabuletas de argila, papiros e papel, agora, acompanhando a evolução dos meios de comunicação, transitam para a virtualidade em telas de desktops, smartphones, smart tvs, projetores e equipamentos para imersão em realidade virtual. Ao longo do tempo, a infografia acompanhou a evolução e as mudanças dos paradigmas do jornalismo, adaptando-se aos diferentes discursos sociais e suportes utilizados.

Entre os fundamentos necessários para a elaboração de um infográfico, estão a dimensão jornalística em si (a reportagem, a investigação, a apuração, a sua ética e a construção do discurso verbal da mensagem e o design gráfico, o resultado do conjunto de atributos visuais integrados ao texto, as imagens, linhas, cores etc.) ou seja, a exploração da percepção visual para a construção da peça gráfica, resultante de um discurso visual. Sobre esses dois aspectos paira a constante necessidade de adaptação do discurso (verbal e visual) ao repertório do leitor, para que a mensagem seja persuasiva e coerente. Em outras palavras, há uma retórica visual presente no discurso infográfico ${ }^{96}$, na narrativa inerente ao design da informação, de acordo com cada grupo potencial de leitores (o auditório) para o qual a mensagem é

\footnotetext{
${ }^{96} \mathrm{O}$ tema da retórica visual nos infográficos pode ser aprofundado em Visualização de dados: o discurso persuasivo dos atributos visuais nos infográficos (NOGUEIRA, 2014).
} 
direcionada, pois, como vimos anteriormente, a infografia, sendo uma linguagem, é culturalmente dependente. As variações culturais, decorrentes de questões geográficas, étnicas, sociais etc. terão suas próprias regras de uso dos atributos visuais reconhecíveis (linhas, cores, formas, texturas, proporções etc.) e serão passíveis de interpretação pelo aparato biológico visual e cognitivo humano.

Em relação a diferentes tecnologias para a elaboração de infográficos, podemos traçar um paralelo com a leitura de um caracter tipográfico. Há diferenças tecnológicas entre o uso de um cinzel para gravação em pedra, um bico de pena para cópia monástica em incunábulos, de tipos móveis metálicos para composição ou fontes digitais em formato OpenType. No entanto, independentemente da tecnologia, a exibição desse caracter sempre deverá ser orientada à cognição humana, observando-se a legibilidade, o contraste, as dimensões, a distância de observação, a luminosidade etc. A dimensão cultural se sobrepõe aos fatores tecnológicos, e o ser biológico determina limitações e fronteiras: o espectro visível do olho humano não é capaz de reconhecer o ultravioleta, por exemplo. Sem o apoio de recursos externos como câmeras especiais, o nosso olho não é sensibilizado por essa porção do espectro eletromagnético, enquanto uma abelha é capaz de identificá-lo naturalmente em flores. Portanto, os olhos de um alemão, de um japonês ou de um brasileiro, independentemente de classe social, religião ou região onde vivem, desde que considerados saudáveis, possuirão o mesmo espectro visível, entre o extremo vermelho (frequência $400 \mathrm{THz}$ e comprimento de onda $750 \mathrm{~nm}$ ) e o extremo violeta (frequência $750 \mathrm{THz}$ e comprimento de onda 400nm).

De forma análoga, então, um infográfico é capaz de se apresentar como ferramenta comunicacional em múltiplos meios, de possuir variadas formas de se elaborar e de permear diferentes tecnologias, ainda que os princípios essenciais de projeto não sejam consideravelmente distintos. Como dito por Serra, "não há tecnologia que venha a superar o infografista com um lápis na mão" e, complementando, ressalta que "para fazer uma boa infografia, o único fator indispensável é um bom profissional" (SERRA, 2018, n.p.). Seja em um impresso, uma tela de computador ou em realidade virtual, independentemente da tecnologia usada, o infográfico deverá: (1) ser estruturado por quem o elabora (o orador) de modo a informar leitores que possuem repertórios específicos (o auditório), construindo uma retórica (a argumentação e suas escolhas) de acordo com o público-alvo do veículo onde será exibido; (2) considerar a legibilidade, a distância 
de leitura, as proporções, os grids, e as características inerentes ao suporte físico; (3) explorar os atributos visuais de acordo com o potencial cognitivo de seu público e (4) observar o espaço (físico e/ou virtual) disponível e as limitações técnicas (se é estático, animado, se usa bancos de dados, se demanda intenso processamento, resolução etc.).

Atualmente, há uma busca por inovações na forma de usar texto e imagens diagramáticas de forma a criar narrativas que causem impacto no público em novos produtos nos meios de comunicação. Em alguns casos, podem ser consideradas versões multimidiáticas derivadas de infografias tradicionais impressas/online. Um exemplo dos novos formatos é uma apresentação em mixed reality (MR) realizada pelo canal The Weather Channel, sobre a aproximação do furacão Florence na costa leste dos Estados Unidos (Figura 74). Veiculada no dia 12 de setembro de 2018, a exibição virou notícia nos meios jornalísticos internacionais ao simular como poderiam ser os efeitos das inundações em um cenário virtual "dentro do estúdio". O formato tornou possível demonstrar o impacto do aumento do nível da água em até quase três metros, integrando animações 3D, sons, dados e gráficos sobrepostos a uma locação similar a uma rua com casas típicas de zona residencial, unidos à imersão do apresentador Greg Postel "ao vivo" no ambiente virtual. O efeito dramático do nível da água subindo, suspendendo carros, carregando detritos e a comparação com o apresentador e sua narração, causou reverberação mundial.

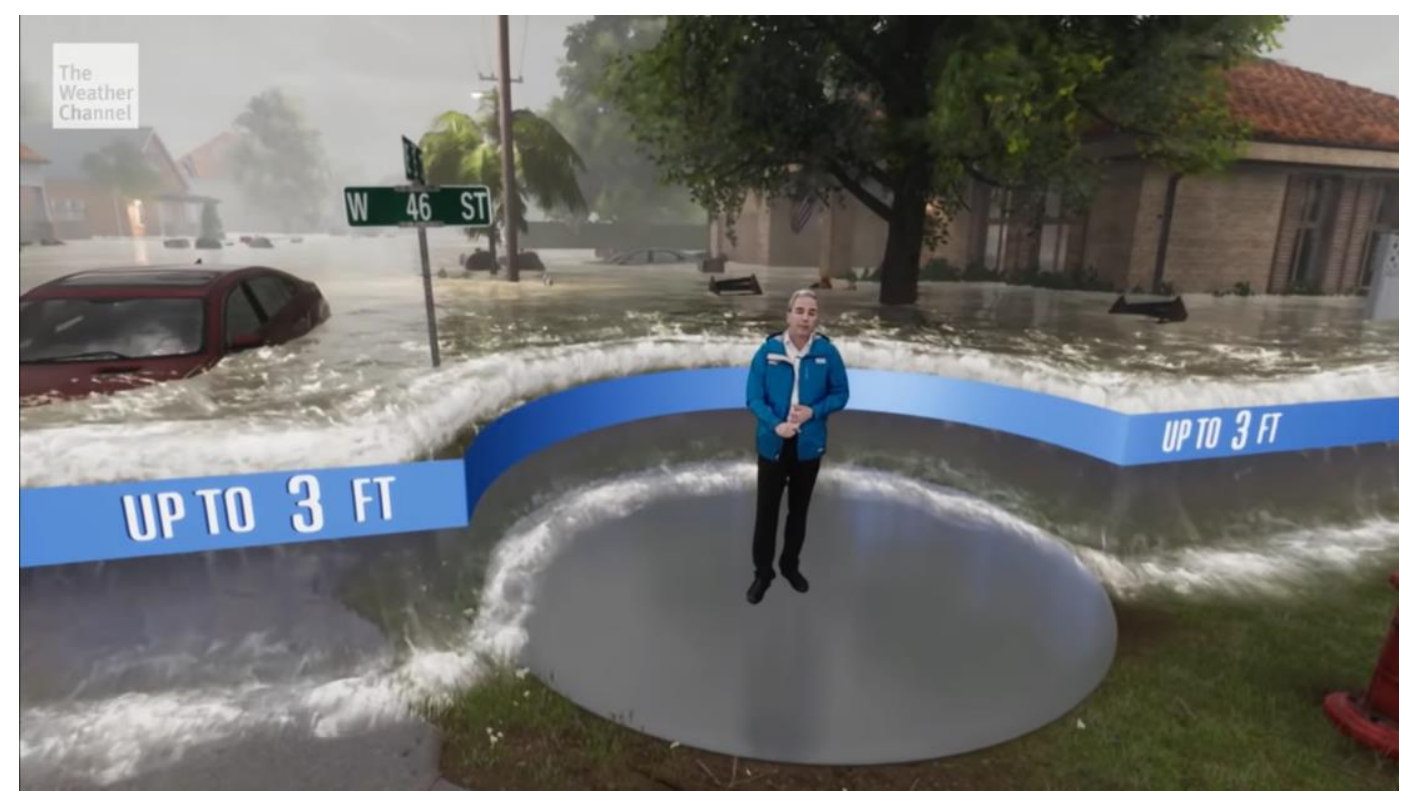

Figura 74 - Imagem da apresentação videográfica The Dangers of Storm Surge, em mixed reality, do canal The Weather Channel, demonstrando os efeitos das inundações do furacão Florence, na 
costa da Carolina, nos Estados Unidos, exibida em 12 de setembro de 2018. Disponível em: < https://www.youtube.com/watch?v=x7mt2gJx5b0> Acesso em: 28 dez. 2018.

Em mídia nacional, um exemplo inovador é o cenário composto por sobreposição de apresentadores, realidade aumentada, animações em $3 \mathrm{~d}$, vinhetas, vídeos, dados, gráficos, textos e imagens, em tempo real, no estúdio do Jornal Nacional, da Rede Globo. O ambiente em si não se caracteriza como uma narrativa de um infográfico, por apresentar um teor de ilustração temática de reforço ao texto verbal. No entanto, em determinados momentos, ao longo do jornal, nota-se a integração entre texto, imagem, diagramas, informações que usam a lógica hierárquica e gráfico-visual que remetem ao projeto de um "ambiente" informativo. O uso complementar de texto, dados, gráficos e mapas em composição com o cenário e apresentadores fica mais evidente durante a abordagem de temas como previsão do tempo, dados econômicos, explicação de um evento ou funcionamento de um sistema. Ou seja, tal qual um infográfico em um jornal impresso, suas características são exploradas em momentos oportunos. O importante é que existe a consolidação de um produto novo, nacional, que usa componentes de variadas tecnologias em sobreposição a uma proposta diferenciada e que possui premissas informativas gráfico-visuais em diferentes camadas.
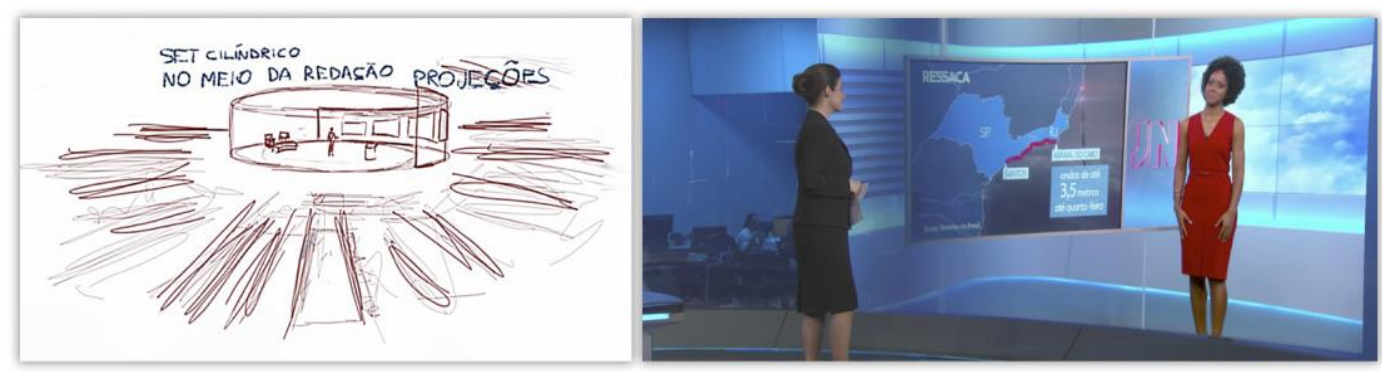

Figura 75 - Ambiente com sobreposição de tecnologias e realidade aumentada, do Jornal Nacional, da Globo. Imagem de um dos rascunhos iniciais do projeto (à esquerda) e exemplo de interação da apresentadora, ao vivo, com a projeção da meteorologista em outro estúdio, com mapas e informações em outro suporte e a redação como parte do cenário, em outro plano ao fundo (à direita). Disponível em: <https://www.newscaststudio.com/2017/08/07/globo-augmented-reality/> Acesso em: 28 dez. 2018.

O uso dessas tecnologias envolvem equipes multidisciplinares com jornalistas, desenvolvedores, animadores 3D, especialistas em robótica, designers, entre outros, porém os princípios básicos de uma visualização de informações estão 
presentes: hiearquia dos elementos, composição, proporções, contrastes, formas, cores, narrativa, dados consolidados, integração entre o texto (verbal, escrito ou por voz) e os elementos gráficos e pictóricos etc. Ou seja, mesmo em peças visuais que testam os limites das capacidades tecnológicas atuais e buscam inovação, evidencia-se o uso de fundamentos teóricos e práticos advindos do design da informação e de elementos básicos do design gráfico aliados aos princípios de comunicação social do jornalismo. O impacto trazido pelo mixed reality do furacão Florence, do The Weather Channel, pode ser comparado ao realizado pelo USA Today, com os mapas climáticos de Rorick. Mudam-se a tecnologia, a época, a abrangência, a cultura, mas o papel de traduzir a informação integrando texto, imagens e gráficos perdura, guiado pelos fundamentos que regem uma boa peça gráfica. Portanto, mesmo não caracterizando um infográfico "clássico", se é que pode haver tal definição, a identificação do uso dos preceitos fundamentais em novas abordagens demonstra a longevidade, a contemporaneidade e a importância da linguagem multimodal infográfica como ferramenta comunicacional.

\subsection{O papel da academia no país}

Se considerarmos que fatores de ordem tecnológica estão em constante mudança, de forma que o tempo de duração média de um curso superior de design ou jornalismo possa ser maior que o tempo de vida de determinadas tecnologias, é imprescindível que esse impacto seja previsto na formação dos alunos. As transições tecnológicas no jornalismo tornaram necessárias constantes adaptações por parte dos diversos profissionais atuantes no setor. Esse associado a outros ${ }^{97}$ que levaram à precarização das relações de trabalho ao longo do tempo ${ }^{98}$, resultou em baixas nos quadros de editorias jornalísticas, tal como no período de informatização, na década de 1990, ou na implementação do digital/online, na

\footnotetext{
${ }^{97}$ Apesar de não ser o foco da discussão, cabe mencionar aqui a Lei de Imprensa, de 1967, que instituiu a segregação oficial dos profissionais de imagem. Essa lei foi derrubada pelo Supremo Tribunal Federal (STF) apenas décadas depois, no dia 30 de abril de 2009.

${ }^{98}$ Segundo Sant'anna (2005, p.23) a organização jornalística brasileira se vale intensamente de produtos de fora da redação, reduzindo a necessidade de jornalistas dentro das empresas. Há um cenário de aumento da difusão de matérias prontas provenientes de jornalistas atuantes junto às fontes, como assessorias de imprensa, por exemplo. Para o autor "A história aponta que os veículos reduziram suas equipes, eliminaram coberturas jornalísticas setorizadas, dispensaram os profissionais especializados em temas considerados de segunda importância editorial pelo novo paradigma mercantil e passaram a atuar nestas áreas quase que apenas com os informes institucionais" (SANT'ANNA, 2005, p.16).
} 
década de 2000. Mesmo já no período digital, um exemplo de mudança repentina na atuação de jornalistas visuais, designers e desenvolvedores foi o impedimento do uso do Flash ${ }^{99}$ como plataforma de desenvolvimento de peças interativas online, por iniciativa da Apple - posteriormente adotada pelas demais gigantes do mercado. Profissionais especializados em ActionScript e Flash precisaram se adaptar a novas linguagens e tecnologias emergentes à época, como HTML5 e CSS3, para se manterem no mercado. Portanto, se por um lado deve-se demonstrar a importância de constante atualização e desenvolver a capacidade de aprendizado autônomo dos alunos (aprender a aprender), por outro, deve-se focar nos princípios de projeto que podem ser usados/adaptados às tecnologias existentes e vindouras.

Levando-se em conta, então, que a linguagem infográfica (1) está presente em diversos meios informativos, (2) é uma relevante e versátil ferramenta comunicacional capaz de abordar temas variados, (3) apresenta-se em diferentes suportes, (4) resistiu ao teste do tempo, sendo usada, inclusive, em formatos que vão além dos agora ubíquos smartphones, e (5) que permanece evoluindo, inovando, buscando novas formas de contar histórias, por que não há uma oferta significativa de disciplinas que abordem a infografia em cursos superiores de jornalismo e design ${ }^{100}$ no Brasil?

Segundo Leite (2018), seria importante haver uma formação específica para infografistas no país. Comenta que nenhuma das origens dos infografistas atuais fornece as ferramentas necessárias para atuação na profissão e que todos precisam passar por um processo de "educação" para se adaptarem, dentre outros fatores, ao que é da esfera do visual e o que é da esfera do textual. Ao falar sobre a formação, no Brasil, o infografista afirma:

Eu acho que, infelizmente, não existe um curso de formação de infografistas no Brasil. Eu adoraria que houvesse esse curso. [...] Tenho muita fé de que isso, um dia, venha a se concretizar. E acho que é um profisisonal que faz muita falta que seja formado no Brasil, porque eu creio plenamente que o futuro do jornalismo está na

99 Em abril de 2010, em carta aberta, Steve Jobs informa as razões pelas quais torna os Iphones e Ipads incompatíveis com o Flash, decretando o início do fim da plataforma da Adobe. Dentre as principais razões listadas, estavam a necessidade de uma plataforma de desenvolvimento aberta com open web standarts, não proprietária de uma empresa (Adobe); problemas de segurança; baixa performance; consumo de energia; e compatibilidade com dispositivos mobile e interfaces touch (JOBS, 2010, n.p.).

100 Como visto no capítulo anterior, destacamos a relevância dos cursos de design e jornalismo em função de formarem comunicadores (visuais e sociais). Como construtores de discursos, em suas devidas esferas, diferenciam-se dos cursos e segmentos de onde outros infografistas podem se originar, como estatística, matemática, programação, belas artes, geografia, cartografia etc. 
categoria dos infografistas. [...] Como não há essa formação tradicional, acadêmica, de infografistas, as entradas para a infografia acontecem de maneiras muito diversas. Às vezes você tem um cara que é um bom ilustrador, e isso, em teoria, capacita ele para que ele possa ilustrar para o jornal. Você tem, entrando para a infografia, caras formados em design de produto, você tem gente formada em gravura, você tem gente formada em design, acredito eu que na maioria. E eu posso te falar com toda a tranquilidade que nenhuma dessas formações encaixam como uma luva, perfeitamente, para a profissão que a gente executa. Então, acho muito carente e muito necessário que houvesse esse tipo de formação (LEITE, 2018).

Nos meios de comunicação, a infografia ganhou espaço e reconhecimento nas últimas décadas. Como citado anteriormente, para Noblat (2002, p.152), “Tudo que puder ser correta e convenientemente informado por meio de recursos visuais assim deverá ser", ou seja, a prioridade extrema ao texto, e apenas o texto, é característica do "velho jornal", enquanto no "novo jornal" o que importa é comunicar bem ao leitor. Para o autor, se um infográfico contar melhor uma história, que ele então seja priorizado em detrimento ao texto.

Ao longo deste trabalho, evidenciou-se um reconhecimento da relevância da linguagem infográfica, sua atuação abrangente, com uso que vai do meio impresso aos meios digitais e uma intensa presença nos veículos nacionais, internacionalmente premiados. Por que, então, dependemos de "sorte" para encontrar profissionais?

Podemos notar esse fator "sorte" pelo relato do ilustrador e infografista Gabriel Silveira $^{101}$ (2016), ganhador de prêmio Malofiej, pelo IG. Silveira afirma que foi para São Paulo, após se formar em 2006, para trabalhar como designer, mas, ao ser contratado como assistente de ilustrador, acabou tendo contato com projetos editoriais e, consequentemente, com infografia. Seu aprendizado foi empírico, acumulando experiência aos poucos, sem ter tido contato com infográficos durante sua formação acadêmica em design. Sobre o tema da infografia em sua graduação, declara "Não era uma coisa muito conversada, não. Acho que nunca tive, durante a faculdade, um trabalho, um projeto acadêmico que fosse criar um infográfico ou que tivesse uma infografia como uma linguagem a ser discutida" (SILVEIRA, 2016). Sobre como efetivamente se desenvolveu na infografia, comenta que:

Foi bem orgânico. Não foi assim "fiz um curso e aprendi”, uma experiência profissional que foi definitiva. Foi, realmente, ao longo dos anos, um crescimento natural, de experiência, de adquirir novas soluções e pensar em "se eu já fiz tantas

${ }^{101}$ Entrevista concedida por SILVEIRA, Gabriel. [dez. 2016]. Entrevistador: Daniel Moura Nogueira. São Paulo, 2016. 
vezes isso aqui, vou tentar fazer diferente". Dá certo, dá errado, mas eventualmente a gente vai chegando em um caminho que é legal (SILVEIRA, 2016).

Sobre a seleção de profissionais, a Editora Assistente do jornal $O$ Globo, Carolina Cavaleiro, em resposta à indagação feita pelo presente pesquisador, afirma que os próprios portfólios dos candidatos já demonstram um certo desentendimento sobre o que é infografia e que o foco de quem julga o processo seletivo dos candidatos acaba sendo o "interesse", já que o tema é algo específico que a formação acadêmica não fornece, como podemos ver no relato:

Eu cansei de entrevistar pessoas com um portfólio cheio de mangá. E, assim, o jornal não precisa publicar mangá. $\mathrm{O}$ jornal não precisa publicar mais uma charge, ele já tem o Chico Caruso e a vaga dele é dele. A gente não precisa renovar os chargistas do $O$ Globo. E isso é muito difícil, quando a gente fala de um infografista, a gente não quer um infografista que desenhe bem, isso não é o pré-requisito. Eu acho que, mais do que tudo, a gente quer alguém que tenha interesse em entender o jornal, em fazer parte do jornal, em modernizar o jornal e aprender muitas e muitas e muitas coisas que a faculdade realmente não vai ensinar porque é uma coisa muito específica. E o enxugamento das redações tem gerado um problema ainda maior, porque você não encontra esses profissionais por aí. Não é fácil contratar um infografista. A gente ficou com uma vaga aberta de um infografista sênior. Aonde ele está? ... É difícil, né? É muito específico. (CAVALEIRO, 2017)

Mesmo depois da nova LDBN, com a maior liberdade e possibilidade de inclusão de disciplinas de acordo com as necessidades e as características regionais, culturais, de mercado ou do momento, de acordo com as iniciativas das IES, não é possível notar uma larga oferta de discipinas com o tema da infografia no país, como vimos no capítulo anterior. Ao não haver subsidios suficientes durante a formação, cabe aos contratantes identificarem indivíduos que se interessem pelo assunto, que possuam características adequadas e que tenham se desenvolvido de forma praticamente autodidata, caso busquem um jovem profissional para seus quadros. Para os que desejam se tornar infografistas, não havendo disponibilidade suficiente de disciplinas focadas no tema, eles dependerão de estar "na hora certa, no lugar certo" para ingressarem em uma vaga em um ambiente que proporcione o seu devido aprendizado, com a cultura local daquele veículo?

É lógico que uma graduação não se resume a formar profissionais técnicos. Um infografista não precisa possuir uma formação acadêmica para exercer a função e uma ou duas disciplinas não são suficientes para exaurir os conhecimentos teóricos e práticos necessários para que um determinado indivíduo se torne um infografista profissional. Seriam levianas tais afirmações. No entanto, tendo em 
vista o extenso uso de infográficos e visualizações de dados nos veículos de comunicação, bem como o surgimento de novas tecnologias que também fazem uso de princípios da linguagem infográfica, fica evidente a demanda por indivíduos que atuem no setor. A questão da formação dos infografistas não é novidade, no entanto, pouco se percebe de mudança efetiva nos últimos anos. Em 2009, Teixeira (2009, p.12) comentou sobre o tema:

Enquanto teóricos e profissionais experientes apostam no futuro da infografia jornalística, sobretudo em um tempo de contínua transformação no jornalismo em pleno século XXI, a formação profissional de infografistas ainda não está estabelecida de forma consolidada e nem se tem uma definição clara sobre quem pode ser um infografista - no UOL, por exemplo, esta função cabe a um profissional graduado em Arquitetura. Isto talvez ajude a explicar porque há uma queixa generalizada nas redações.

A disponibilidade de bases teóricas fundamentais em disciplinas nos cursos de jornalismo e design seria um fator preponderante para apoiar a formação dos futuros infografistas, ou seja lá qual a denominação dada no futuro a quem exerça as funções em novas tecnologias que da infografia derivem ou se aproveitem. A dependência do acaso e da sorte não trará benefícios. Não se sugere aqui a imposição de transitar por tais disciplinas, mas presume-se que os efeitos benéficos se manifestariam ao longo do tempo, no caso de haver uma carga formal de apoio na academia. Como vimos no capítulo anterior, apenas $15 \%$ dos cursos de design e $17 \%$ dos cursos de jornalismo, no Brasil, oferecem disciplinas diretamente relacionadas ao tema da infografia em suas grades curriculares. Isso é muito pouco para uma ferramenta amplamente usada em diversos meios de comunicação.

Os fatos de a infografia ser multidisciplinar e de ainda ter como principais formações originais o jornalismo e o design são um entrave, pois a fundamentação é diferente - para um "o texto", para o outro "a imagem”, o que amplia a dificuldade entre a identificação de um problema (não há disciplina de infografia) e a implementação de possível solução (que questões essa disciplina deve abordar?). No entanto, uma saída pode ser justamente a busca por disciplinas híbridas, que tragam mais do jornalismo para os designers e mais do design aos jornalistas. Enquanto designers necessitam ter contato com o texto, a narrativa, a investigação, a pesquisa, a apuração de dados e os preceitos éticos inerentes ao jornalismo; a apresentação de princípios da psicologia da gestalt, a percepção visual, a diagramação, os grids, o desenvolvimento de gráficos e o uso de imagens para a 
construção de uma narrativa visual seria útil aos jornalistas, caso haja interesse do aluno em atuar com infografia. Cabe frisar que, em ambos os casos, devem ser consideradas atribuições e talentos inerentes aos cursos - a princípio, alunos de jornalismo não possuem facilidade similar aos de design ao se lidar com imagem, e o mesmo se dá em relação ao texto, habitat natural do jornalismo, para os designers.

Ao comentar sobre a possibilidade de os jornalistas estarem preparados para fazer infografias, Cairo afirma que:

Qualquer jornalista que saia de uma carreira de jornalismo, em princípio, estará capacitado para entender a infografia como uma linguagem jornalística. Isso não quer dizer que qualquer jornalista esteja capacitado para fazer infografia. Para a fazer são precisos conhecimentos técnicos, assim como para escrever, para fazer televisão, etc. (CAIRO, 2006, n.p.).

Acerca da abrangência da formação do jornalista e de sua possibilidade de atuação na infografia, complementa:

[o estudante de jornalismo] deve receber um formação geral sobre todos os gêneros jornalísticos que existem. Tem de aprender a analisar não só a notícia escrita, mas também a reportagem, a crónica, a entrevista, tem de aprender algo de fotojornalismo e tem de aprender também as bases da infografia. Tem também de haver um curso básico de aprendizagem de infografia" (CAIRO, 2006, n.p., grifos nossos).

Já sobre o designer gráfico que visa atuar com jornalismo, Cairo afirma que deve "Aprender a contar histórias e aprender as regras pelas quais se rege qualquer repórter. Deve, também, aprender a escrever notícias, reportagens, crónicas, entrevistas, e saber consultar e confrontar fontes" (CAIRO, 2006, n.p.).

Sobre a necessidade de o infografista ter as atribuições de um jornalista em sua formação, para poder se desenvolver como "contador de histórias", Leite (2018), afirma que a falta de uma formação de infografistas faz com que eles tenham que ser educados, no dia a dia, sobre as diferenças de conteúdo do que é visual e o que é do textual:

Eu tenho um jornalista na minha equipe que faz o texto, mas ele está com a gente já há seis anos, então, ele também já se moldou a "o que é infografável ou não". O que é matéria prima do que é visual ou do que é textual. Ele já está bem mais "educado". E essa "educação" do jornalista também é um processo, não é algo imediato, como os jornalistas, na maioria das vezes, pensam que é. Por isso eu acho que é uma pena a gente não ter uma formação de infografistas. [...] Não se pode falar de futuro da infografia, no Brasil, sem entender que o infografista tem que ser jornalista. Ele tem que ser responsável pela sua apuração. Eu não estou falando de pessoas solitárias, trancadas nos seus guetos, não. O trabalho é participativo, é comunitário, mas ele tem que saber fazer a apuração, ele tem que saber escrever o texto, ele tem que saber 
contar a história. O futuro da infografia está na transformação do infografista, que, por si só, é uma palavra que carrega um peso tecnocrático terrível para o contador de histórias, mas essa é a transformação necessária. Porque, a partir do momento que o infografista também é jornalista, ele tem o aval da redação, ele tem a confiança da redação (LEITE, 2018).

Em entrevista para este trabalho, o infografista e professor Ricardo Oliveira da Cunha Lima (2018), diretor do IED, comenta que há determinadas atribuições necessárias aos que desejam atuar com infografia:

Para ter uma inserção no mercado, me parece interessante você procurar uma formação em infografia. A infografia, das coisas que eu aprendi em design, foi a que demorou mais tempo. Porque ela exige muitos conhecimentos diferentes. Ela exige um conhecimento de uso de gráficos estatísticos, ela exige um domínio da linguagem pictórica, o que a gente chama de ilustração, ela exige um conhecimento de conteúdo escrito, de pesquisa, levantamento de dados e também de diagramação e uso de tipografia. Eu já falei de áreas que são gigantescas. Se você não tiver um domínio mínimo dessas cinco áreas, fica difícil fazer um infográfico. E, é claro, juntar todo esse conhecimento para o infográfico, que é uma mídia específica. Então, não é fácil. Fazer infografia não é fácil (LIMA, 2018).

Lima (2018) afirma, também, que já surgem cursos com matérias em infografia e até mesmo cursos híbridos em jornalismo e design, como na $N Y U$, que imagina terem disciplinas de infografia. Cita, inclusive, que uma de suas alunas fez o curso no IED exatamente porque descobriu que havia disciplina de infografia disponível. Isso indica uma possível demanda reprimida ainda não avaliada.

Em relação à distância entre o meio acadêmico e o mercado, pode-se perceber uma busca por uma conexão entre ambos, que parte de iniciativas dos profissionais. Existem alguns eventos e palestras sobre infografia, organizados por alguns dos principais profissionais do campo. Um dos exemplos é o evento In.Rio, que teve a sua segunda edição em 2017. O encontro reúne profissionais, professores, pesquisadores e interessados sobre o tema da infografia em uma série de palestras, disponibiliza um documento digital com uma mostra sobre infografia a cada edição e promove cursos introdutórios online gratuitos. Um de seus organizadores, Rubens Paiva, Editor de Arte do jornal $O G L O B O$, afirma que toda uma geração pioneira de infografistas saiu do mercado quase simultaneamente e que se preocupa com a renovação, com a formação das pessoas que vão entrar no mercado, pois há um "salto enorme entre o que a gente está aprendendo na universidade e o que tem que se fazer nas redações. E o pior que, sem a capacidade de reciclagem, de ter esses profissionais passando esses conhecimentos que eles tinham, vai ficar bem difícil" 
(PAIVA, 2017). O editor afirma que foi crucial para a sua carreira um treinamento recebido no Correio Braziliense, que convidou um dos infografistas proeminentes na época, Jeff Goertzen, para ministrar um workshop. Menciona que a frase de Goertzen "o infografista é jornalista também” causou uma mudança em sua visão e que aprendeu que o infografista poderia até mesmo ir a campo com o repórter apurar, mas realizar uma apuração da visualidade, do seu lado. Por conta da preocupação com a formação e de conseguir observar a distância entre o que se aprende na academia e o que é realizado na prática, Paiva busca promover mais pontes entre as universidades e os veículos de comunicação, como podemos ver pelo relato:

É preciso a universidade se "achegar mais" a gente. Eu fico muito apreensivo que sempre que eu faço um evento, tento conversar mais com os professores, conversar com os chefes de departamento, eu fiz isso [com várias instituições] e, assim, a gente tem uma dificuldade de convencer os professores, as universidades de que isso aqui [o encontro e a mesa redonda de infografistas] é muito raro. Vocês não fazem ideia do quão difícil é juntar esse pessoal que está aqui, vocês não fazem ideia. [...] Esses profissionais que estão aqui são extremamente raros, é uma pena que sejam tão raros assim hoje em dia. É uma pena que nós, infografistas, sejamos tão poucos que a gente se conhece. [...] A gente precisa criar pontes mais sólidas entre os veículos, os sites, e tudo mais, entre nós profissionais, mas a gente precisa criar pontes mais sólidas com o meio acadêmico. Eu sempre faço questão de convidar pesquisadores [para o evento], para vocês entenderem que nós falamos sobre as mesmas coisas, só que as vezes nos usamos de maneira diferente. (PAIVA, 2017)

Do lado da academia, também é possível pontuar iniciativas que visam encurtar a distância entre a prática e a sala de aula. Um exemplo é o evento InfoView, realizado por este pesquisador, quando criou e lecionou a disciplina de Projeto de Infografia, na UFRJ, em 2016. O projeto reuniu infografistas, professores do campo e alunos, a fim de promover uma série de palestras e uma mostra competitiva, com a participação de mais de 100 trabalhos selecionados, que se tornaram uma exposição na UFRJ. A disciplina foi implementada no curso de Comunicação Visual - Design, da Escola de Belas Artes da UFRJ, em 2014, e foi lecionada por quatro semestres, até 2016. Como resultado, além do aumento do interesse por parte dos alunos em relação ao tema, houve uma maior exposição deles ao mercado, onde, dois anos depois, foi possível notar que pelo menos cinco deles atuam com infografia em meios de comunicação.

Nota-se que o mercado se preocupa com a formação e a renovação de seus quadros. Percebe-se que as leis já deram a flexibilidade necessária para a atualização das disciplinas por parte das IES. Ao se aceitar que o infografista é um 
profissional híbrido, que deve dominar diferentes linguagens, vemos que há uma necessidade de cruzamento de expertises inerentes ao jornalismo e ao design na formação dos que desejam atuar no campo. O Brasil foi capaz de se destacar no cenário internacional, em função do uso da linguagem infográfica de forma criativa e eficiente, com peças criadas por jornalistas visuais que praticamente se inventaram, desenvolveram técnicas de modo empírico e expandiram o uso de uma linguagem que era usada em meios internacionais, mas com adaptações culturais próprias. Nossos futuros infografistas merecem que mais atenção seja dedicada à sua formação. A academia deve reconhecer a importância da infografia no jornalismo atual, que é amplamente explorada nos veículos tradicionais e é testada em meios híbridos e inovadores. Além disso, deveria dar o devido destaque ao papel dos nossos infografistas do passado e do presente, de forma que a história desses profissionais sirva de exemplo e que os estudantes não sintam que precisam "reinventar a roda" a cada turma formada. Ao melhor preparar os futuros infografistas em formação, seremos capazes de aproveitar o potencial criativo e multicultural tão característico de nosso país, não se contentando em replicar fórmulas prontas de veículos do exterior, obter diretrizes ouvidas em palestras de eventos fora do país ou copiar os últimos vencedores de prêmios internacionais. Nosso material humano não deve nada em relação aos demais países, no entanto é necessário considerar as condições precárias na formação de grande parcela dos estudantes de jornalismo e design no Brasil e investir em soluções para o problema. O primeiro passo pode ser reconhecer a ausência de disciplinas suficientes sobre o tema em nossos cursos.

\subsection{A infografia não é a "salvadora da pátria"}

Muito embora este trabalho ressalte a importância da linguagem infográfica como ferramenta nos veículos jornalísticos e afirme que ela venha a se estabelecer como meio eficiente, flexível e adaptável aos novos produtos que estão surgindo para contar histórias com tecnologias híbridas e de afirmar que devemos concentrar esforços em oferecer subsídios à formação de futuros infografistas nos cursos superiores de design e jornalismo, é necessário pontuar que a infografia não é uma "bala de prata" capaz de resolver os problemas atrelados ao mercado jornalístico. Como visto, o jornalismo está passando por mudanças que acompanham o tecido 
social e busca saídas para seus problemas atuais em um modelo de negócios de futuro questionavelmente sustentável. Para tal, seria ingênuo pensar que tudo se tornará jornalismo visual, que a infografia salvará as publicações impressas do fechamento ou que um infográfico serve para toda e qualquer situação. Não. Os infográficos são parte do sistema.

Nos anos 2000, com a disseminação de projetos de infográficos interativos e visualizações de dados online, evidenciaram-se as vantagens em relação à infografia impressa, com suas restrições características de um suporte estático bidimensional. O impacto da "participação do leitor" em uma peça digital, que podia clicar, filtrar, explorar, ter os dados atualizados em tempo real, acessar bancos de dados, ver animações, vídeos, mapas de terrenos em 3D, construções, sistemas etc. de formas criativas, gerou uma expectativa de um produto que poderia arregimentar inúmeros leitores. Atualmente, nem duas décadas depois, retorna-se a uma certa simplicidade na maior parte dos projetos. De acordo com Gregor Aisch (2016, n.p.), editor de gráficos do NYT, hoje, os desafios no campo são: (1) os displays que estão ficando cada vez menores, obrigando a simplificar o conteúdo, imagens e gráficos; (2) o acúmulo de meios em que o conteúdo deve funcionar (impresso, online, mobile), além da necessidade de geração de conteúdo para mídias sociais (Facebook, Instagram etc.) e adaptações para plataformas diferentes (Windows, IOS, Android) e (3) a pouca interação efetiva por parte dos usuários.

Sobre a diminuição dos displays, Lage (2018) afirma que essa é uma das grandes dificuldades para a prática da infografia, atualmente e para o futuro. $\mathrm{O}$ infografista afirma que mais da metade do público do GE (67\%) acessa o conteúdo via mobile, e que desenvolver conteúdo para telas tão pequenas é um desafio:

Vou te dar uma dificuldade muito prática, muito óbvia: o celular. Você tem uma tela muito pequena para contar uma história. Isso, para mim, está sendo um grande desafio. Porque pegar um gráfico que você faz em uma tela enorme... antigamente você tinha um monitor de 15", era pequenininho, vai crescendo, crescendo e, daqui a pouco, aquilo ali virou um celular. Então, tem pouca área para passar a informação visual. Isso é um grande desafio para mim. Está sendo. E como é que vai ser isso no futuro? Hoje em dia, o nosso número (de acessos ao conteúdo) chegou a $67 \%$ de mobile, de celular. Então, o desktop está morrendo. Vai morrer. Vai chegar o momento que as pessoas não vão mais consumir (o conteúdo) em uma tela grande. Então, eu tenho que contar aquela história visual, tenho que mostrar um estádio do Zenith em um celular. Como é que eu vou fazer isso, sabe? E depois do celular, vai ser o que, aquele telefone (de pulso), o Apple Watch? Esse é o grande desafio, é a tela, o monitor (LAGE, 2018). 
Aisch (2016, n.p.), acerca da participação do público, comenta ter observado que, nas visualizações interativas do NYT, mais de $80 \%$ dos usuários via mobile não clicam nos botões ou executam interações além do nível básico do movimento de scroll até o fim da matéria. Em um dos exemplos citados, os editores, ao observarem que apenas $10 \%$ dos leitores havia clicado no botão para ver a outra metade de um gráfico sobre migração, resolveram destacar que era necessário "clicar no botão" para visualizar o resto com um aviso proeminente e o fizeram, adicionando um balão amarelo. Após o aviso, o número de leitores que clicaram no botão aumentou para $14 \%$ dos que acessaram a matéria, um acréscimo de apenas $4 \%$. Notaram também que resultados similares se replicaram em outras peças produzidas.

Portanto, as inovações em visualizações exploratórias complexas, animadas, com intensa participação do usuário e com boa oferta de informações, parecem surgir apenas em casos pontuais. No momento, a simplificação de conteúdo predomina na infografia para o mobile, com imagens mais estáticas e quase sem interação além do scroll, ou seja, de forma similar à estática característica do impresso, mas com a rolagem de tela no lugar da interação de "virar a página" do jornal ou da revista. Essas diretrizes podem ser resumidas pelas "três regras para o Visual Storytelling ${ }^{102 "}$ sugeridas por Archie Tse (2016, p.11, tradução nossa), diretor de gráficos do NYT, em palestra realizada no Malofiej, em 2016:

1 - Se você fizer o leitor clicar ou fizer algo diferente de scroll, algo espetacular tem que acontecer;

2 - Se você fizer um tooltip rollover ${ }^{103}$, suponha que ninguém jamais o verá. Se o conteúdo for importante para os leitores verem, não o oculte;

3 - Ao decidir se deve tornar algo interativo, lembre-se de que fazê-lo funcionar em todas as plataformas é caro.

O exemplo do mobile serve para notarmos que houve momentos em que se esperou muito dos infográficos e das visualizações de dados. Entretanto, a realidade nos trouxe de volta ao que é realmente fundamental: contar histórias bem e

\footnotetext{
${ }^{102}$ No original "3 rules of Visual Storytelling: (1) If you make the reader click or do anything other than scroll, something spectacular has to happen. (2) If you make a tooltip rollover assume that no one will ever see it. If content is important for readers to see, don't hide it. (3) When deciding whether to make something interactive, remember that getting it to work on all plataforms is expensive."

${ }^{103}$ Fazer surgir um pequeno box ou menu com informações adicionais ao se posicionar o mouse em cima de algum objeto na tela.
} 
gerenciar o investimento de recursos para o desenvolvimento de uma determinada peça. A infografia, para Cairo (2006, n.p.), "é apenas mais uma linguagem, outra forma de contar histórias. Nem todas as histórias podem contar-se de maneira infográfica, da mesma forma que nem todas as histórias se podem contar bem em texto." Ou seja, dentro do contexto do jornalismo atual, há projetos nos quais os infográficos serão úteis, e matérias nas quais são desnecessários ou mesmo inapropriados. Não é apenas o caso de falta de tempo ou investimento; é por não obter o mesmo sucesso que apenas o texto poderia ser capaz de ter, por exemplo. De acordo com Serra (2018, n.p.), "Não se pode imaginar um meio sem palavra, dificilmente sem fotografia, mas existem muitos meios sem infografias ${ }^{104}$. E não necessariamente piores do que os que as incluem. A infografia segue sendo um plus." Portanto, apesar de ser uma ferramenta útil e reconhecida pelos leitores, é, ao mesmo tempo, a mais dispensável. Ao abordar o futuro da infografia, Serra ressalta a sua relação com o jornalismo:

Depende do futuro do jornalismo. O que está em crise não é a ferramenta infográfica. Pelo contrário, o que está em crise é o próprio jornalismo. O jornalismo desaparecendo ou jornalismo desaparecido, ao menos tal e como o conhecemos. Se o jornalismo encontrar o modo de se recuperar, ou achar um novo espaço interessante, haverá espaço para a infografia. Se o jornalismo desaparecer, a infografia jornalística, obviamente, também desaparecerá. (SERRA, 2018, n.p.)

Em 2008, o jornalista, presidente da SND-E e coordenador do Malofiej, Javier Errea, publicou um texto que gerou debate entre os infografistas, com o título Por que a infografia salvará o jornalismo ${ }^{105}$. A então editora de arte da revista Mundo Estranho, Alessandra Kalko (2008, n.p.), expôs algumas observações pertinentes:

Não sei se a infografia é a grande salvação do jornalismo impresso. Não vejo a infografia como a grande cura milagrosa para a queda das vendas, mas mais como um dos remédios que pode prolongar sua vida com melhor qualidade. O bom uso deste instrumento pode ajudar a manter os leitores fiéis de mais idade e atrair os leitores jovens que estão cada vez mais imersos num mundo eletrônico, de informações simultâneas e se afastando da leitura.

Com ressalvas, a editora demonstra que a infografia pode auxiliar a longevidade do meio, mas não a vê como uma salvação. Informa, ainda, que a publicação, a qual tinha como carro chefe a infografia, com mais de um terço das

${ }^{104}$ Um outro fator que deve ser considerado é o econômico, pois nem todos os veículos possuem recursos para investir em um departamento de infografia.

105 No original: Por qué la infografía salvará al periodismo. Disponível em: < http://visualmente.blogspot.com/2008/02/exclusivo-por-qu-la-infografa-salvar-al.html> Acesso em: 05 jan. 2019. 
páginas com infográficos, apresentava um crescimento nas vendas, enquanto outras revistas conviviam com declínio no número de exemplares vendidos. Na época da publicação do texto, em fevereiro de 2008 , comentou que "Se um dia a revista irá acabar para dar lugar ao nosso site, não sei. Em 2007, o número de leitores do nosso site foi duas vezes maior do que o da revista impressa" (KALKO, 2008, n.p.). Ou seja, apesar das dificuldades, ainda não havia uma certeza sobre o futuro do impresso, mesmo com aumento nas vendas. De fato, dez anos depois, em 6 de agosto de 2018, o Grupo Abril anunciou o encerramento de diversas marcas ${ }^{106} \mathrm{em}$ função de seu processo de reestruturação - dentre elas a Mundo Estranho, umas das revistas nacionais com o maior número de prêmios no Malofiej.

Portanto, é razoável frisarmos que a infografia jornalística não salvará o jornalismo de seus percalços, pois depende dele para sobreviver. É uma parte do sistema, uma ferramenta, um recurso que pode ser útil, pode elucidar questões e atrair atenção do leitor, pode auxiliar a construir formas de comunicar adequadas ao novo ritmo social e participar de novas tecnologias. Contudo não se deve pensar que a infografia é capaz de reestruturar um sistema econômico, social ou político, apesar de ser qualificada a auxiliar a compreendê-los e, assim, contribuir para a tomada de decisões que ajudem a encontrar soluções.

\subsection{Conclusões sobre o capítulo}

Não é objetivo deste trabalho apresentar ou formatar as diretrizes de tal ou tais disciplinas sobre infografia, mas afirmar o papel da linguagem infográfica nos meios de comunicação, com a observância de sua evolução ao longo do tempo, verificar a presença da infografia brasileira em premiações de âmbito internacional e apresentar dados sobre as disciplinas ligadas ao tema nos cursos de jornalismo e design no Brasil. A partir dos dados coletados, notou-se uma discrepância entre a relevância da infografia nos veículos de comunicação nacionais, representados pelos prêmios recebidos por diversos veículos, e a presença de disciplinas que

$106 \mathrm{Na}$ nota oficial, o Grupo Abril comunica que “...como parte do seu processo de reestruturação, está reformulando o portfólio de marcas da editora com o objetivo de garantir sua saúde operacional em um ambiente de profundas transformações tecnológicas, cujo impacto vem sendo sentido por todo o setor de mídia. O processo tornou-se obrigatório dentro das circunstâncias impostas por uma economia e um mercado substancialmente menores do que os que trouxeram a Abril até aqui." Disponível em: <https://www1.folha.uol.com.br/mercado/2018/08/abril-iniciacortes-de-revistas-e-pessoal.shtml> Acesso em: 4 jan. 2019. 
ofertam fundamentação aos alunos no meio acadêmico. Viu-se que a infografia é uma ferramenta explorada por diversos meios, estando presente em suportes tradicionais (como o jornal impresso), móveis (smartphones e tablets) e inovadores (como realidade virtual e mixed reality), mas, ao mesmo tempo, é prescindível não é indispensável para que um veículo jornalístico exerça sua função. Apesar disso, é uma ferramenta reconhecida e valorizada pelos leitores.

Disponibilizar fundamentação teórica e prática projetual na academia, de forma ampla, aumentando sua presença em uma parcela significativa de cursos, é uma estratégia que proporcionaria a possibilidade de um desenvolvimento constante, de geração de tecnologia nacional, do refinamento de processos e de um incremento na formação de profissionais. Indo além de questões relativas ao mercado, cria-se um ecossistema propício ao pensamento crítico, de modo a auxiliar o surgimento de novos métodos, teorias e pesquisas. 


\section{8 Conclusão e desdobramentos futuros}

A presente pesquisa apresentou uma busca por um percurso lógico que visa construir um panorama da infografia no Brasil, fornecendo dados tanto sobre a esfera acadêmica, quanto relativas ao mercado e sua prática. Dessa forma, geramse pontos de partida para uma conscientização da importância da presença de disciplinas sobre a linguagem infográfica em meio acadêmico. Além disso, buscouse discutir alguns dos principais pontos de discordância no campo, como nomenclatura, tipologias, abordagens, categorizações, linhas cronológicas, dentre outros, reunindo dados variados sobre o tema em um mesmo documento.

Iniciamos observando que, apesar do desenvolvimento da infografia como linguagem e do amplo uso de infográficos como ferramenta comunicacional, ainda persiste o debate sobre o que é efetivamente um infográfico. Esse fato acarreta em problemas no meio acadêmico e no mercado, pois provoca ruídos em relação aos produtos do design da informação atrelados ao campo da infografia. Para oferecer uma solução, na tentativa de auxiliar o estabelecimento de uma nomenclatura, buscou-se investigar os termos usados pelos principais autores e pesquisadores sobre o tema, tais como Horn (1999), De Pablos (1999), Cairo (2008), Sancho (2000), Moraes (1998) e Kanno (1998). Por fim, foram propostas, com intento didático para este trabalho, definições próprias acerca dos termos gráfico, visualização de dados, infográfico, infográfico digital e pseudo infográficos.

Estabelecidos os termos, como forma de contextualizar a infografia contemporânea, foram revisitadas as origens da linguagem infográfica, sua evolução diversificada e seus suportes. Foram analisadas diferentes propostas de marcos em linhas cronológicas, como as de Tufte (1983), Few (2009), Cairo (2008), Kanno (2013) e Holmes (2011). A partir do cruzamento de seus dados e a adição de elementos que consideramos relevantes, elaboramos uma linha do tempo com os principais marcos da comunicação por meio de artefatos gráficos ou diagramas informativos, desde os primeiros registros arqueológicos até o presente momento. 
Uma vez consolidadas as bases teminológicas e uma contextualização em uma linha do tempo, observando sua participação como ferramenta de apoio cognitivo ao desenvolvimento das ciências e difusão de informações em meios de comunicação, foram investigadas as funções e abordagens conceituais ou ideológicas que podem ser aplicadas aos diferentes tipos de peças que usem a linguagem infográfica. Dessa forma, visamos compreender o processo de como os dados brutos podem se tornar conhecimento ou sabedoria por meio de diferentes abordagens, com maior teor estético ou analítico, entre o adorno e a objetividade. Além disso, foram pesquisadas e apresentadas diferentes propostas de classificação de gráficos e catalogações, notando-se a utilidade para consulta, principalmente em relação ao campo da visualização de dados.

Posteriormente, investigamos a trajetória da infografia no Brasil, pontuando marcos relevantes, desde suas origens até o momento atual, com base nas obras de Cairo (2008, 2013), Kanno (1998, 2013), Moraes (1998, 2013, 2015) e Teixeira (2010). Situamos o surgimento das premiações internacionais, fenômeno que auxiliou a reflexão acerca do design de informação nas páginas jornalísticas, destacando o Malofiej como o mais importante mundialmente. Na sequência, verificou-se a participação dos infográficos brasileiros na premiação, por meio dos dados coletados de registros de 26 anos de história do evento e de entrevistas com profissionais e pesquisadores. Assim, foi possível traçar um panorama do desempenho da infografia brasileira no cenário internacional ao longo do tempo, com a identificação dos principais veículos brasileiros laureados com medalhas e da importância dos prêmios internamente, o que influencia o desenvolvimento do campo nas editorias nacionais.

Apesar do reconhecimento internacional, dos prêmios e do intenso uso de infografia nos veículos noticiosos brasileiros, notamos que a inexistência de uma formação superior específica voltada para as questões relativas ao desenvolvimento teórico e prático da infografia é um empecilho para o desenvolvimento da área. Os infografistas possuem diversas origens, tais como estatísticos, cartógrafos, programadores, artistas gráficos, ilustradores, jornalistas, designers gráficos, e alguns, inclusive, não possuem graduação acadêmica. Esse fato leva à necessidade de se "educar" o profissional sobre questões relativas aos conteúdos verbais e não verbais envolvidos na elaboração de infográficos. Essa questão seria mitigada, caso 
houvesse maior disponibilidade de disciplinas de infografia nos principais cursos de origem dos infografistas, design e jornalismo.

A partir de Couto (2008) e Moura (2002), verificamos um histórico dos currículos mínimos e as possibilidades proporcionadas após a nova LDBN, que deram mais liberdade e flexibilidade para a construção de projetos pedagógicos por parte das IES. No entanto, ao concluirmos a investigação dos dados coletados sobre as instituições em território brasileiro, confirmamos que apenas $15 \%$ dos 245 cursos de design identificados e $17 \%$ dos 334 cursos de jornalismo validados para a pesquisa possuem conteúdo diretamente relacionado ao tema da infografia. A constatação teve, ainda, o apoio de gráficos que foram desenvolvidos para mostrar a distribuição geográfica dos cursos e a proporção de instituições com ou sem disciplinas de infografia. Portanto, apesar da possibilidade (leis), da demanda (mercado) e da necessidade (por uma formação), não se observou uma presença significativa de conteúdo sobre a linguagem infográfica em nossas graduações de design e jornalismo.

As reflexões, desenvolvidas a partir do cruzamento dos conteúdos e dados investigados, trataram das perspectivas para a infografia em um jornalismo em mutação, observando os seus possíveis passos futuros. Pontuamos que não se devem resumir como mera "crise", de forma simplista, os problemas estruturais e conjunturais enfrentados pelo jornalismo, pois a mudança é inerente à prática jornalística, com base em Charron e Bonville (2004) e Pereira e Adghirni (2011). Caracterizamos a infografia como uma linguagem multimodal, a partir de paralelos com investigações de Braida (2012), Santaella (2001) e Kress e Van Leeuwen (2006). Verificamos que o momento de transformação do jornalismo contemporâneo como ferramenta de comunicação noticiosa está vinculado ao continuum social e suas angústias pela a falta de um modelo a ser seguido, de acordo com Masi (2013). Pontuamos também o questionamento da legitimidade do jornalismo como a principal fonte de notícias, bem como a sua crise de credibilidade por meio de ataques institucionais e disseminação de fake news e com a expansão de mídias sociais e meios não tradicionais de comunicação. Como reação da indústria da comunicação, vimos a expansão dos fact-checks e a oportunidade de uso da linguagem infográfica como ferramenta de análise neste setor, reforçando o pathos, o ethos e o logos dos discursos. Destacou-se, ainda, a capacidade de 
adaptação da infografia aos diversos suportes disponíveis, dos impressos aos digitais, chegando ao mixed reality.

Em relação ao papel da academia no país, a pesquisa verificou que a linguagem infográfica, utilizada por diversos veículos, é uma ferramenta comunicacional versátil que se apresenta em diferentes suportes, resiste ao teste do tempo e permanece inovando, buscando novas formas de contar histórias. No entanto, não há uma oferta significativa de disciplinas que abordem a infografia em cursos de jornalismo e design no Brasil. A formação dos profissionais é deficitária, dependendo de oportunidades em empresas que foquem em aprimorar e educar os infografistas de seus quadros que desejam atuar no campo. Como busca por uma solução, notamos a necessidade de se implementarem disciplinas de infografia híbridas, que visem oferecer maior contato com o texto, a apuração e o levantamento de dados, ou seja, da prática jornalística para os designers e, também, que objetivem um contato com o desenvolvimento de construção de discursos não verbais, do trato com o conteúdo visual, da manipulação de atributos visuais, da compreensão da psicologia da gestalt e demais princípios do design para os jornalistas. Essa mistura ocorreu a partir da observação de que o infografista necessita desenvolver expertises inerentes a ambos os cursos: ele deve ser um jornalista, saber contar a história e deve saber lidar com múltiplas linguagens além do texto, de forma visual.

Relatamos que o Brasil, com o uso da linguagem infográfica de forma criativa em seus veículos, por meio de uma geração de profissionais talentosos que praticamente se desenvolveu de forma autodidata, foi capaz de se destacar internacionalmente. No entanto, afirmamos que é preciso que os futuros infografistas possuam mais atenção dedicada à sua formação, não dependendo apenas do autotreinamento oferecido pelas empresas. $O$ reconhecimento da importância da infografia, por parte da academia, é fundamental para o desenvolvimento do campo, para o registro da história de uma linguagem multimodal amplamente explorada por nossos veículos nas últimas décadas e para que se gere um ecossistema propício para o pensamento crítico-reflexivo em nossas universidades. Por fim, como um lembrete, observamos que a infografia não é capaz de salvar o jornalismo de seu insustentável modelo de negócios atual, como proposto por alguns profissionais. 
Concluímos as reflexões com o destaque para a discrepância entre o relevante papel da infografia nos veículos de comunicação nacionais e a pouca presença de disciplinas sobre o tema nas IES brasileiras. Viu-se que a infografia é uma ferramenta explorada por diversos meios, que ela é uma linguagem multimodal reconhecida e valorizada pelos leitores, que há demanda por profissionais e por formações que contemplem o tema em suas grades curriculares. No entanto, não se observam maiores movimentações por parte das instituições acadêmicas em relação ao tema.

Aos olhos de um incauto, os itens abordados em cada capítulo desenvolvido neste trabalho podem parecer fora de um percurso lógico previsível, tendo em vista a abordagens de pontos em campos que, normalmente, são investigados isoladamente, com recortes fechados. No entanto, ao delinear esta pesquisa, ao traçar os objetivos primordiais que ela deveria cumprir, há mais ou menos quatro anos, foram elencadas as lacunas encontradas ao longo do projeto desenvolvido anteriormente, a dissertação do mestrado, bem como as frequentes observações ouvidas no cotidiano do trabalho junto ao mercado e, ainda, no ambiente acadêmico. A questão básica, presente em conversas com profissionais, professores e alunos é: por que não há uma formação em infografia ou boa oferta de disciplinas sobre o tema? Se ela é tão usada, aceita, útil, flexível, permeia várias tecnologias e comunica de forma diferenciada, o fato de não haver ampla abordagem ao tema em meio acadêmico intriga os envolvidos no campo. Seria a crise no jornalismo? Seriam as leis brasileiras engessando as grades curriculares, impedindo a implementação de disciplinas atualizadas? Haveria um declínio da importância da linguagem infográfica não mapeado por nós, profissionais e professores?

Com essas perguntas tocando em questões aparentemente heterogêneas, portanto, foi necessário buscar uma fundamentação que permitisse uma "visão ampla" do cenário no qual a infografia está inserida. O desafio de se buscar respostas em um vasto território era claro: havia o risco de se desenvolver um documento raso, com poucos dados ou sem o devido tratamento, visto que a diversidade, o volume e a fragmentação das informações que seriam investigadas eram, para dizer o mínimo, assustadores. Apesar dessa constatação, com o objetivo de subsidiar futuros pesquisadores, profissionais e interessados no campo da infografia, o desafio foi enfrentado e espera-se que seus resultados impulsionem a discussão e uma reflexão crítica da presença (ou ausência) da infografia em nossas 
graduações, bem como estimulem uma maior aproximação entre o meio acadêmico e o mercado, a fim de encontrarmos perspectivas viáveis em relação ao futuro da formação dos infografistas.

Para que os frutos deste trabalho não ficassem restritos ao meio acadêmico, os dados foram transformados em um cartaz infográfico (Figura 76), que estará disponível ao público de forma online e, com menor abrangência, também de forma impressa, em tiragens limitadas. A transformação de 242 páginas de uma tese, reunindo dados de 245 cursos de graduação em design, 334 cursos de graduação em jornalismo, a participação brasileira em 26 anos de premiação do Malofiej e uma linha do tempo de 16.000 a.C. aos dias de hoje, com marcos importantes para a linguagem infográfica, em uma peça gráfica integrada, só foi possível, justamente, usando o que este trabalho tanto visa valorizar, a linguagem multimodal infográfica.

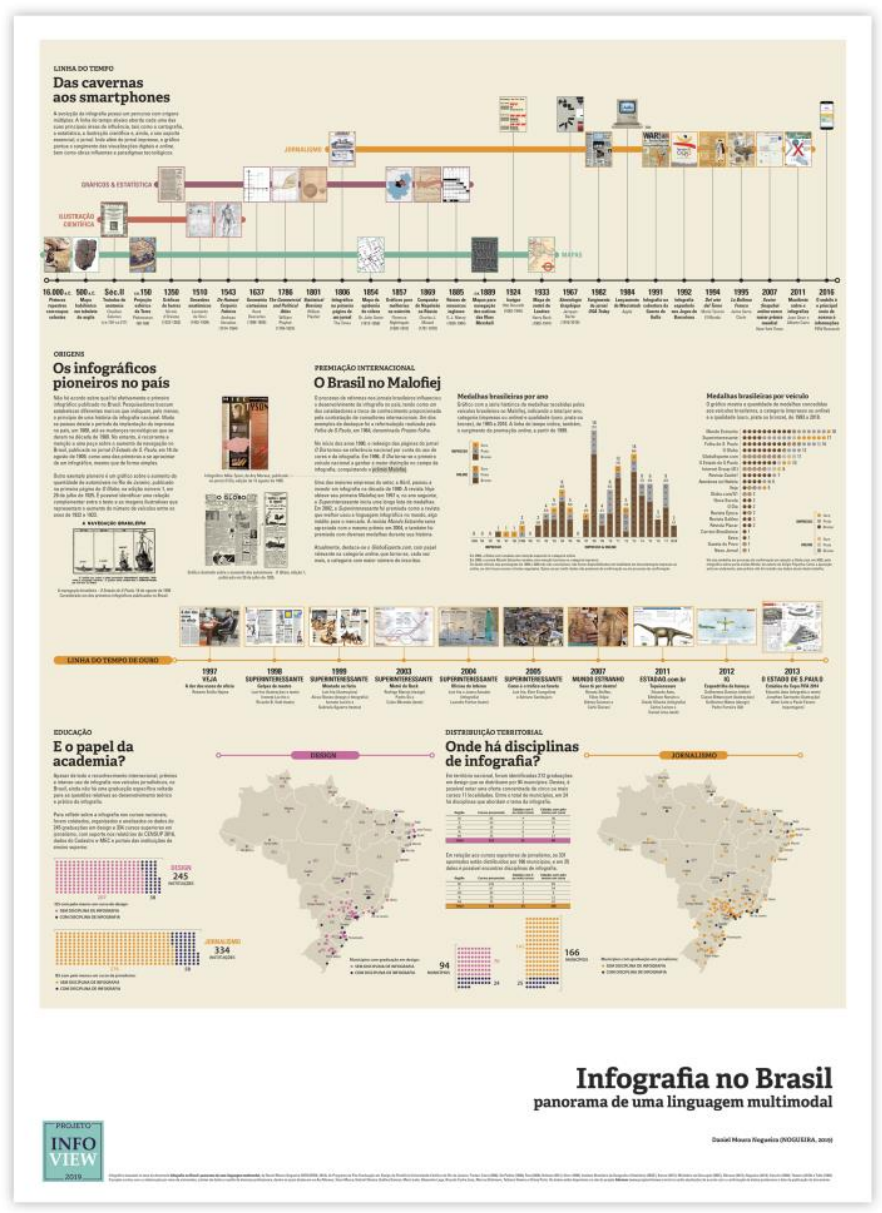

Figura 76 - Proposta de cartaz Infografia no Brasil: panorama de uma linguagem multimodal, reunindo o conteúdo da tese em um infográfico. Uma versão para A4 do cartaz pode ser observada no Apêndice IV deste documento. Fonte: do autor. 
Como desdobramentos futuros, visamos dar continuidade ou estimular que futuros pesquisadores continuem o processo de coleta de dados em intervalos de tempo regulares, pois o desenvolvimento de uma série temporal dos dados presentes nesta pesquisa pode trazer à luz do pensamento científico as tendências e transformações das IES brasileiras ao longo do tempo, pelo menos no que diz respeito aos cursos de comunicação social com habilitação em jornalismo e aos cursos de design.

Outro ponto a ser levado adiante são as entrevistas realizadas junto a profissionais, professores e pesquisadores. Neste documento, elas foram usadas como apoio ao discurso, reforçando a argumentação em momentos pertinentes, demonstrando a opinião de quem está envolvido com a prática e o cotidiano da infografia. No entanto, por questões de espaço e continuidade do texto, não houve um capítulo dedicado exclusivamente à análise do discurso, nem a um aprofundamento em relação a cada entrevistado. Ou seja, há mais de 15 horas de gravações realizadas que são uma fonte rica de material que ainda pode, e deve ser explorado. Outra razão para a continuidade das entrevistas é que a dificuldade logística no deslocamento envolvido do equipamento de gravação e o desencontro de agendas fizeram com que algumas entrevistas agendadas não pudessem ser incluídas no documento final ou, em alguns casos, que ainda não tenham sido realizadas. Portanto, existe, ainda, uma adição programada ao material já existente, que pode ser estruturado e analisado futuramente.

Constato, por fim, que este documento, apesar do esforço, é apenas um passo inicial para encontrar caminhos que auxiliem a tornar clara a situação da infografia no Brasil, tanto nos veículos de comunicação quanto na academia. Ao sermos capazes de obsevar um retrato, um panorama da infografia brasileira, de forma ampla, teremos a capacidade de identificar os problemas e, dessa forma, encontrar justificativas plausíveis para investir na ampliação da presença da infografia nas instituições de ensino superior brasileiras. Talvez, assim, mesmo em meio a um turbulento período do jornalismo, sejamos capazes de pavimentar um futuro melhor para uma profissão que tem um único objetivo: contar histórias da melhor maneira possível. Em tempo, é bom lembrar que foi por meio da cultura, contanto histórias, que o homem prevaleceu. 


\section{Referências bibliográficas}

AISCH, G. Data visualization and the news. In: Interdisciplinary Conference Information +, 17 de junho de 2016. Vancouver: ECUAD, 2016.

ARISTÓTELES, Arte retórica e arte política. Intr. e notas de J. Voilquin e J. Capelle. Trad.de A. P. de Carvalho. São Paulo: Difel, 1964.

Retórica. Trad. e notas de Manual A. Júnior, Paulo F. Alberto e Abel do N. Pena. Lisboa: Imprensa Nacional-Casa da Moeda, 2005.

BERTIN, J. Semiology of graphics, Wisconsin: University of Wisconsin Press, 1983.

BONSIEPE, G. Visuell-verbale Rhetorik: Über einige Techniken der persuasiven Kommunikation. In: Interface - Design neu begreifen. Mannheim: Bollmann, 1996.

Design, cultura e sociedade. São Paulo: Blucher, 2011.

Design como prática projetual. São Paulo: Blucher, 2012.

BOURDIEU, P. Sobre a televisão. Rio de Janeiro: Zahar, 1997.

BRAIDA, F. A linguagem híbrida do design um estudo sobre as manifestações contemporâneas. Tese (Doutorado em Design). Departamento de Artes. Pontifícia Universidade Católica. Rio de Janeiro, 2012.

BRASIL, 2001(a) MEC. Parecer CNE/CES n 492/2001: Disponível em: < http://portal.mec.gov.br/cne/arquivos/pdf/CES0492.pdf> Acesso em: 8 jan. 2019.

. 2001(b) MEC. Parecer CNE/CES no 1.363/2001: Disponível em: < http://portal.mec.gov.br/cne/arquivos/pdf/2001/pces1363_01.pdf> Acesso em: 10 jan. 2019.

. 2002(a) MEC. Parecer CNE/CES n ${ }^{\circ}$ 146/2002: Disponível em: < http://portal.mec.gov.br/cne/arquivos/pdf/CES0146.pdf> Acesso em: 13 jan. 2019. - 2002(b) MEC. Resolução CNE/CES no 16: Disponível em: < http://portal.mec.gov.br/cne/arquivos/pdf/CES162002.pdf> Acesso em: 10 jan. 2019. 
2003 MEC. Parecer CNE/CES n ${ }^{\circ}$ 195/2003: Disponível em: < http://portal.mec.gov.br/cne/arquivos/pdf/2003/pces195_03.pdf> Acesso em: 13 jan. 2019.

. 2004 MEC. Resolução CNE/CES no 5: Disponível em: < http://portal.mec.gov.br/cne/arquivos/pdf/rces05_04.pdf> Acesso em: 13 jan. 2019. 2016 MEC. INEP Sinopses Estatísticas da Educação Superior - Graduação: Disponível em: < http://portal.inep.gov.br/web/guest/sinopses-estatisticas-daeducacao-superior> Acesso em: 01 out. 2018

CAIRO, A. Infografía 2.0 visualización interactiva de información en prensa. Madrid: Alamut, 2008.

The functional art: an introduction to information graphics and visualization. Berkeley: New Riders, 2013.

. Infografia não é uma linguagem do futuro, é do presente. Entrevista concedida a Carina Branco. JPN, edição de 11 de julho de 2006. Porto: Universidade do Porto, 2006. Disponível em: <https://jpn.up.pt/2006/07/11/ infografia-nao-e-uma-linguagem-do-futuro-e-do-presente/> Acesso em: 27 nov. 2018.

CARD, S. K.; MACKINLAY, J. D.; SHNEIDERMAN, B. Readings in Information Visualization: Using Vision to Think. São Francisco: Morgan Kaufmann Series in Interactive Technologies, Academic Press, 1999.

CAVALEIRO, C. Arte que transforma: como a infografia mudou a cara e a cultura do globo. Palestra ministrada no In.Rio, em 18 ago. 2017. Rio de Janeiro: ESPM, 2017.

CHARRON, J.; BONVILLE, J. Typologie historique des pratiques journalistiques. In: Nature et transformation du journalisme: théories et recherches empiriques, Cap. 5, p.141-217. Québec: Les Presses de L’Université Laval, 2004.

CITRARO, D. When an Infographic Isn't: the Rise of Digital Posters. Portland: Periscopic, 2013. Disponível em: <http://www.periscopic.com/news/when-aninfographic-isnt-the-rise-of-digital-posters> Acesso em: 20 mar. 2018.

COATES, K.; ELLISON, A. An introduction to information design. Londres: Laurence King Publishing, 2014.

COPER, E. P. Bienvenidos los megagráficos. Revista Latina de Comunicación Social. La Laguna (Tenerife), n. 17, maio de 1999. Disponível em: 
<http://www.revistalatinacs.org/a1999hmy/97info/coper.htm> Acesso em: $18 \mathrm{dez}$. 2018.

CORREIA, J. C. Teoria e Crítica do Discurso Noticioso: Notas sobre Jornalismo e representações sociais. Série Estudos em Comunicação. UBI: Covilhã, 2008.

CORREIA, M. B. F. A comunicação de dados estatísticos por intermédio de infográficos: uma abordagem ergonômica. Dissertação (Mestrado em Design). Departamento de Artes. Pontifícia Universidade Católica. Rio de Janeiro, 2009. COUTO, R.M.S. Escritos sobre ensino de design no Brasil. Rio de Janeiro: Rio Books, 2008.

DAMIAN, G.P. Guilhermes Prates Damian. INFOVIEW 2016. Entrevista concedida a Daniel Moura Nogueira. São Paulo, 11 dez. 2016. Disponível em: <http://www.projetoinfoview.com.br> Acesso em: 28 mar. 2017.

DASTANI, M. The role of visual perception in data visualization, Utrecht: Journal of Visual Languages and Computing. v. 13, n. 6, pp. 601-622, 2002.

DE PABLOS, J. M. Infoperiodismo - el periodista como creador de infografía. Madrid: Editorial Síntesis, 1999.

Siempre ha habido infografia. Revista Latina de Comunicación Social 5, 1998. Disponível em <http://www.ull.es/publicaciones/latina/a/88depablos.htm> Acesso em: 20 mar. 2018.

Infografia o infoperiodismo, el nuevo género periodístico: cómo y cuándo? XVIII Conference of the International Association for Mass Communications Research. São Paulo: IAMCR, 1992.

DÍAZ NOCI, J. Multimedia y modalidades de lectura: una aproximación al estado de la cuestión. Comunicar, $\mathrm{n}^{\mathbf{0}}$ 33, v. XVII, 2009, Revista Científica de Educomunicación. Barcelona, 2009. Disponível em: <https://www.revista comunicar.com/index.php? contenido=detalles\&numero=33\&articulo=33-200925> Acesso em: 20 mar. 2018.

DONDIS, D.A. Sintaxe da linguagem visual. $4^{a}$ ed. São Paulo: Martins Fontes, 2003.

DURAND, J. Une méthode de choix des supports de publicité: la méthode séquentielle. Paris: Communications volume 15, 1970.

ELAM, K. Geometria do design: estudos sobre proporção e composição. São Paulo: Cosac Naify, 2014. 
ERREA, J. Por qué la infografía salvará al periodismo. Visualmente, 4 de fevereiro de 2008. Disponível em: < http://visualmente.blogspot.com/2008/02/exclusivopor-qu-la-infografa-salvar-al.html>. Acesso em: 5 jan. 2019.

FEW, S. Show me the numbers. Oakland: Analytics Press, 2004.

Information Dashboard Design. Sebastopol: O’Reilly Media, 2006.

Now you see it. Oakland: Analytics Press, 2009.

Periodic table of visualization methods exhibits poor visual design.

Perceptual Edge, 2007. Disponível em: <http://www.perceptualedge.com/blog/ ?p=81> Acesso em: 27 abr. 2018.

FOLHA DE S. PAULO. Manual da redação da Folha de S. Paulo. São Paulo: Folha de S. Paulo, 2001.

Veja o que mudou na reforma gráfica da Folha impressa. São Paulo. Edição do dia 23 de abril de 2018. Disponível em: <https://www1.folha.uol.com.br/ poder/2018/04/veja-o-que-mudou-na-reforma-grafica-da-folha-impressa.shtml> Acesso em: 29 abr. 2018.

FRIENDLY, M.; DENIS, D. J. Milestones in the history of thematic cartography, statistical graphics, and data visualization. 2001. Disponível em: <http://www.datavis.ca/milestones/> Acesso em: 24 abr. 2018.

GIL, A. C. Como elaborar projetos de pesquisa. $3^{\circ}$ ed. São Paulo: Atlas, 1996. GINER, J. A.; CAIRO, A. Editors, artists chafe at the errors and hype in bin Laden death story graphics. Nieman Fundation for Journalism at Harvard University. Cambridge: Harvard, 2011. Disponível em: <http://www.niemanwatch dog.org/index.cfm?fuseaction=Showcase.view\&showcaseid=00152> Acesso em: 20 abr. 2018.

GLOBONEWS. Estúdio I. Edição do dia 03 de outubro de 2016. Disponível em: <https://www.youtube.com/watch?v=Feysg5u_51w>Acesso em: 16 jan. 2018.

HARLEY, J. B.; WOODWARD, D. The History of Cartography Volume 1: Cartography in Prehistoric, Ancient, and Medieval Europe and the Mediterranean. Chicago: University of Chicago Press, 1987.

HARRIS, R. L. Information Graphics A Comprehensive Illustrated Reference. New York: Oxford University Press, 1999.

HELLER, S. Nigel Holmes: On Information Design. New York: Jorge Pinto Books, 2006. 
HIME, G. V. V. C. Na Fundação da Primeira Escola de Jornalismo do Brasil, Cásper Líbero Gera o Conceito de Jornalismo Moderno. Revista PJ BR Jornalismo Brasileiro. v. 03, 2004. São Paulo, 2004.

HOLMES, N. Wordless Diagrams. New York: Bloomsbury, 2005.

HORN, R. E. 1999. Information Design: Emergence of a New Profession. In: Jacobson, R. Information Design. Massachusetts: The MIT Press, 1999.

HOUAISS, A.; VILLAR, M.; FRANCO, F. M. M.; INSTITUTO ANTÔNIO HOUAISS. Dicionário da língua portuguesa. Rio de Janeiro: Objetiva, 2001. 2922p.

IDC. The Digital Universe in 2020: Big Data, Bigger Digital Shadows, and Biggest Growth in the Far East. IDC iVIew, 2012. Disponível em: < https://www.emc.com/collateral/analyst-reports/idc-the-digital-universe-in2020.pdf> Acesso em: 12 fev. 2018.

INFOLIDE, $\mathbf{6}^{\text {a }}$ Mostra de Infografia. São Paulo: Infolide, 2012.

IVC. Circulação de alguns jornais diários no Brasil. São Paulo: IVC Brasil, 2017.

JOBS, S. Thoughts on Flash. Apple, carta aberta. Abril de 2010. Disponível em < https://www.apple.com/hotnews/thoughts-on-flash/> Acesso em: 22 dez. 2018.

JOLY, M. Introdução a Análise da Imagem. São Paulo: Papirus, 2007.

KALKO, A. Especial: A infografia vai salvar o jornalismo? Visualmente, 2008. Disponível em: < http://visualmente.blogspot.com/2008/02/especial-infografiavai-salvar-o.html> Acesso em: 10 mar. 2018.

KANNO, M. Infografe. São Paulo: Ed. Eletrônica, 2013.

BRANDÃO, R. Manual de infografia. São Paulo: Folha de S. Paulo, 1998.

Marcos na História da Visualização de Dados. Infografe, 2008.

Disponível em: <http://euclid.psych.yorku.ca/SCS/Gallery/milestone/historia_ infografia.pdf> Acesso em: 10 mar. 2018.

KARAM, F. J. C. Journalism in the age of the information society, technological convergence, and editorial segmentation. Journalism, vol 10. Los Angeles: Sage, 2009.

KEELE, K. D. Leonardo Da Vinci's Elements of the Science of Man. New York: Academic Press, 2014.

KRESS, G.; VAN LEEUWEN, T. Reading images: the grammar of visual design Londres: Routledge, 1996. 
KIRSCHNER, S. Nicholas Oresme: French bishop, scholar and economist. Britannica, 1998. Disponível em: <https://www.britannica.com/biography/ Nicholas-Oresme\#accordion-article-history> Acesso em: 12 mar. 2018

KOFFKA, K. Perception: an introduction to the Gestalt-Theorie. Psychological Bulletin, 19. Berkeley: University of California, 1922.

KOHLER, W. Gestalt psychology. Londres: Bell \& Sons, 1930.

KOSARA, R. Visualization Criticism: The Missing Link Between Information Visualization and Art. Charlotte: University of North Carolina, 2007.

LAGE, A.G.L. Alexandre Lage. INFOVIEW 2018. Entrevista concedida a Daniel Moura Nogueira. Rio de Janeiro, 10 mar. 2018. Disponível em: <http://www.projetoinfoview.com.br> Acesso em: 28 abr. 2018.

LEITE, M.G.V. Mário Guilherme de Vasconcelos Leite. INFOVIEW 2018. Entrevista concedida a Daniel Moura Nogueira. Rio de Janeiro, 10 mar. 2018. Disponível em: <http://www.projetoinfoview.com.br> Acesso em: 29 abr. 2018. LENGLER, R.; EPPLER, M. J. Towards a Periodic Table of Visualization Methods for Management. IASTED Proceedings of the Conference on Graphics and Visualization in Engineering (GVE 2007). Clearwater, 2007.

LIMA, M. El estallido de la visualización. Etápes, vol. 10. Barcelona: Pyramyd, 2008 .

LIMA, R.O.C. Análise da Infografia Jornalística. Dissertação (Mestrado em Design). ESDI/UERJ. Rio de Janeiro, 2009.

Ricardo Oliveira da Cunha Lima. INFOVIEW 2018. Entrevista concedida a Daniel Moura Nogueira. Rio de Janeiro, 29 mar. 2018. Disponível em: <http://www.projetoinfoview.com.br> Acesso em: 29 abr. 2018.

LUPTON, E.; MILLER, A. Critical Wayfinding, em The Edge of the Millennium, ed. Susan Yelavich, p 220-232. New York: Whitney Library of Design, 1993.

LYONS, H. The Sailing charts of the Marshall Islanders: a paper read at the afternoon meeting of the Society, 14 maio de 1928, Londres: F.R.S., 1928.

MACEACHREN, A. M. How Maps Work, New York: Guilford Press, 1995.

MACKINLAY, J. Automating the design of graphical presentations of relational information. ACM Transactions on Graphics, v. 5, n.2, pp.110-141. Abril, 1986.

ROBERTSON, G. G.; CARD, C. The perspective wall: detail and context smoothly integrated. In: Proceedings of ACM CHI'91 Conference on Human 
Factors in Computing Systems and Graphics Interface, ACM SIGCHI. ACM-Press, 1991.

MALOFIEJ. Infographic Awards Malofiej 1997. Pamplona: SND-E, 1997.

10 Premios internacionales de infografía. Pamplona: SND-E, 2002.

MASI, D. O futuro chegou. Rio de Janeiro: Casa da Palavra, 2013

MAREY, E. J. Le Méthode Graphique, Paris: Masson, 1885.

MORAES, A. Infografia o design da notícia. Dissertação (Mestrado em Design).

Departamento de Artes. Pontifícia Universidade Católica. Rio de Janeiro, 1998.

Infografia: História e projeto. Rio de Janeiro: Blucher, 2013.

Design de Notícias: a acessibilidade do cotidiano. Rio de Janeiro: Blucher, 2015.

MOURA, C. P. O curso de comunicação social no Brasil: do currículo mínimo às novas diretrizes curriculares. Porto Alegre: EDIPUCRS, 2002.

MUMFORD, D. Math for non-math majors Applied Mathematics 18. Part I: Discovering the tools for measuring and modeling the world. Brown University, 2006. Disponível em: <http://www.dam.brown.edu/people/mumford/beyond/ history.html> Acesso em: 05 mar. 2018.

NASA. Apollo Operations Handbook, Lunar Module, LM 10 and Subsequent. Section 2.1, Guidance, Navigation, and Control Subsystem, Volume I, Subsystems Data, Grumman Document LMA790-3-LM10-and-Subsequent. Apollo Lunar Module Documentation, NASA, 1971. Disponível em: <https://www.hq.nasa.gov/ alsj/alsj-LMdocs.html> Acesso em: 26 fev. 2018.

NETO, A. O. F. Novas Diretrizes Curriculares para o Curso de Publicidade e Propaganda - Reflexões e Inflexões. Intercom - Sociedade Brasileira de Estudos Interdisciplinares da Comunicação XXXVIII Congresso Brasileiro de Ciências da Comunicação. Rio de Janeiro, 2015.

NEURATH, O. International Picture Language. The Department of Typography \& Graphic Communication. Reading: University of Reading Press, 1936. English edition 1980.

NICHANI, M.; RAJAMANICKAN, V. Interactive visual explainers: a simple classification. Elearningpost.com. Disponível em <http://www.elearningpost.com/ articles/archives/interactive_visual_explainers_a_simple_classification> Acesso em: 12 mar. 2018.

NOBLAT, R. A arte de fazer um jornal diário. São Paulo: Contexto, 2002. 
NYT, In Real Time, and Beforehand, Checking Facts on the Presidential Debate. New York. Edição do dia 3 de outubro de 2012. Disponível em:< https://publiceditor.blogs.nytimes.com/2012/10/03/in-real-time-and-beforehandchecking-facts-on-the-presidential-debate/> Acesso em: 10 jan. 2019.

A late entry by The Times into the Fact-Check Biz. New York. Edição do dia 6 de maio de de 2017. Disponível em: < https://www.nytimes.com/ 2017/05/06/public-editor/a-late-entry-by-the-times-into-the-fact-check-biz.html> Acesso em: 9 jan. 2019.

O GLOBO, Globo completa 93 anos de cara nova. Rio de Janeiro. Edição do dia 29 de julho de 2018a. Disponível em: <https://oglobo.globo.com/brasil/globocompleta-93-anos-de-cara-nova-22927481> Acesso em: 30 jul. 2018.

Dados que viram arte: Jaime Serra cria soluções visuais para temas cotidianos. Rio de Janeiro. Edição do dia 27 de abril de 2018b. Disponível em: $<$ https://oglobo.globo.com/cultura/dados-que-viram-arte-jaime-serra-criasolucoes-visuais-para-temas-cotidianos-22632232> Acesso em: 20 dez. 2018.

PAIVA, R. In.Rio. Palestra, em 18 ago. 2017. Rio de Janeiro: ESPM, 2017.

PEIRCE, C. S. Semiótica, São Paulo: Perspectiva, 2010.

Collected papers. Edited by Charles Hartshorne and Paul Weiss. Vols. 1-6 edited by A.W. Burks. Cambridge: Belknap Press of Harvard University Press, 1958-1966.

PELTZER, G. Periodismo iconográfico. Madrid: Ediciones Rialp, 1991.

Jornalismo Iconográfico. Lisboa: Planeta, 1992.

PEREIRA, F.H.; ADGHIRNI, Z.L. O jornalismo em tempo de mudanças estruturais. Intexto, v. 1, n. 24, p. 38-57. Porto Alegre: UFRGS, 2011.

PEW. State of the News Media: Data and trends about key sectors in the U.S. news media industry. Washington: Pew Research Center, 2017. Disponível em: < http://www.pewresearch.org/topics/state-of-the-news-media/> Acesso em: 10 out. 2017.

Americans' online news use is closing in on TV news use. Washington: Pew Research Center, 7 set. 2017. Disponível em: < http://www.pewresearch.org/ fact-tank/2017/09/07/americans-online-news-use-vs-tv-news-use/> Acesso em: 10 out. 2017.

Use of mobile devices for news continues to grow, outpacing desktops and laptops. Washington: Pew Research Center, 17 jul. 2018. Disponível em: < 
http://www.pewresearch.org/fact-tank/2018/07/17/use-of-mobile-devices-fornews-continues-to-grow-outpacing-desktops-and-laptops/> Acesso em: 10 out. 2018.

10 facts about Americans and Facebook. Washington: Pew Research Center, 1 fev. 2019. Disponível em: <http://www.pewresearch.org/facttank/2019/02/01/facts-about-americans-and-facebook/> Acesso em: 19 fev. 2019. PORTILHO, G. Como se tornar um infografista. Mundo Estranho, Edição 76, p. 20. São Paulo: Abril, 2008.

RAPPENGLÜCK, M. A. A palaeolithic planetarium underground the cave of Lascaux. Migration e Diffusion, Vol. 5, n.19. Viena: Odyssey, 2004.

RENDGEN, S. Information Graphics. Köln: Taschen, 2012.

RIBAS, B. Ser infográfico - apropriações e limites do conceito de infografia no campo do jornalismo. In: ENCONTRO NACIONAL DE PESQUISADORES EM JORNALISMO - SBPJor 3, Florianópolis - SC. Anais. Florianópolis, 2005.

Infografia Multimídia: um modelo narrativo para o webjornalismo. V Congreso Iberoamericano de Periodismo en Internet. Faculdade de Comunicação da Universidade Federal da Bahia, 2004.

RINALDI, M. O uso da infografia no jornalismo científico brasileiro - estudo da revista Superinteressante. Artigo publicado no VIII Congresso Brasileiro de Ciências da Comunicação da Região Sul, 2007.

ROAM, D. The back of the napkin: solving problems and selling ideas with pictures. New York: Penguim Group, 2008.

RUYS, F. Infographic Taxonomy. Visualism. 2013. Disponível em: < https://www.vizualism .nl /infographic -taxonomy/> Acesso em: 11 mar. 2018.

SANCHO, J. L. V. La infografía técnicas, análisis y usos periodísticos. Barcelona: Aldea Global, 2001.

La infografía de prensa. Ámbitos, vol. 4. Sevilla: Universidade de Sevilla, 2000 .

SANTAELLA, L. A teoria geral dos signos: como as linguagens significam as coisas. $2^{\text {a }}$ Ed. São Paulo: Pioneira, 2000.

Matrizes da linguagem e do pensamento: sonora, visual, verbal. São Paulo: Iluminuras, 2001.

NÖTH, W. Comunicação e semiótica. São Paulo: Hacker Editores, 2004. 
NÖTH, W. Imagem: cognição, semiótica, mídia. 4 ed. São Paulo: Iluminuras, 2005.

SANT'ANNA, F. C. C. M. Mídia das Fontes: o difusor do jornalismo corporativo. Brasília: Casa das Musas, 2005.

SERRA, J. Entrevista concedida a William Robson Cordeiro. Barcelona: Universitat Autònoma de Barcelona (UAB), 23 ago. 2018. Disponível em: < https://medium.com/nephi-jor/serra-a-infografia-no-jornalismo-segue-sendo-umplus-d1793583c6d4> Acesso em: 11 jan. 2019.

SHERDOFF, N. Information Interaction Design: A Unified Field Theory of Design. São Francisco: Vivid Publishing, 1994.

SILVA, T.M.L. Tarso Moura Lourenço da Silva. INFOVIEW 2018. Entrevista concedida a Daniel Moura Nogueira. Rio de Janeiro, 16 fev. 2018. Disponível em: <http://www.projetoinfoview.com.br> Acesso em: 04 mar. 2018

Tarso Moura Lourenço da Silva. INFOVIEW 2016. Entrevista teste/piloto concedida a Daniel Moura Nogueira. Rio de Janeiro, 04 dez. 2016. Disponível em: <http://www.projetoinfoview.com.br> Acesso em: 02 mar. 2018 SILVEIRA, G.A. Gabriel Afonso da Silveira. INFOVIEW 2016. Entrevista concedida a Daniel Moura Nogueira. São Paulo, 11 dez. 2016. Disponível em: <http://www.projetoinfoview.com.br> Acesso em: 26 mar. 2017.

SNDE, Malofiej Awards Society for News Design Capítulo Español. Arquivo de premiações. Disponível em: 〈http://www.snd-e.com/en/malofiej/premios〉. Acesso em: 20 mar. 2018.

SOCIEDADE BRASILEIRA DE DESIGN DA INFORMAÇÃO. SBDI: Entidade de caráter científico que congrega pesquisadores, docentes e profissionais da área de design gráfico, e que atuam em sistemas de informação e comunicação analógicos e digitais na gestão e produção da informação. Disponível em: <http://www.sbdi.org.br>. Acesso em: 14 nov. 2013.

SILVA, M. R. Visualização de informação e retórica visual no jornalismo digital. Dissertação (Mestrado em Design). Departamento de Artes. Pontifícia Universidade Católica. Rio de Janeiro, 2012.

SKIRBEKK, M. V. The Current State of Graphics in British Newspapers and News Magazines, Reino Unido. Berkshire: University of Reading, 2011. SOUZA, P.L.P. Notas para uma história do design. Rio de Janeiro: 2AB, 2008. 
SOUZA, P.N.P. Estrutura e funcionamento do ensino superior brasileiro. São Paulo: Pioneira, 1991.

SPENCE, I.; WAINER, H. William Playfair and His Graphical Inventions: An Excerpt from the Introduction to the Republication of His Atlas and Statistical Breviary. The American Statistician, Vol. 59, Número 3, Agosto de 2005. Oxfordshire: Taylor \& Francis, 2005.

SUDJIC, D. A linguagem das coisas. Rio de Janeiro: Intrínseca, 2010.

TASCHOW, U. Nicole Oresme and the Spring of Modern Age: The Origins of our modern quantitative-metric Strategies of World-Conquest and modern Culture of Consciousness and Science. Leipzig: Editora Avox, 2003.

Oresme-Biography: Mathematics. 2003. Disponível em <http://nicoleoresme.com/seiten/oresme-biography.html> Acesso em 12 mar. 2018.

TEIXEIRA, T. Infografia e Jornalismo: conceitos, análises e perspectivas. Salvador: EDUFBA, 2010.

A presença da infografia no jornalismo brasileiro proposta de tipologia e classificação como gênero jornalístico a partir de um estudo de caso. Revista Fronteiras - estudos midiáticos 09, n. 2. São Leopoldo: Unisinos, 2007.

Inovações e desafios da linguagem jornalística: o uso dos infográficos na cobertura de Ciência, Tecnologia e Inovação. Trabalho apresentado no IV Encontro Nacional de Pesquisadores em Jornalismo (SBPJOR), 2006.

. O futuro do presente: os desafios da Infografia jornalística. Revista Ícone, v.11, n.2, dezembro de 2009. Recife: UFPE, 2009.

PASQUAL, L. A história da infografia no Brasil - uma análise de edições d'O Estado de S. Paulo publicadas entre 1986 e 1994. In: $9^{\circ}$ Encontro Nacional de Pesquisadores em Jornalismo. Rio de Janeiro, 2011.

TSE, A. Why we are doing fewer interactives. Pamplona: Malofiej, 2016.

TUFTE, E. R. The Visual Display of Quantitative Information. Cheshire: Graphics Press, 2011.

Beautiful Evidence. Cheshire: Graphic Press, 2006.

WARE, C. Information Visualization - Perception for Design. São Francisco: MK, 2004.

Information Visualization - Perception for Design. 3 ed. São Francisco: MK, 2013.

Visual Thinking for Design. São Francisco: MK, 2008. 
WILDBUR, P.; BURKE, M. Information Graphics: Innovative Solutions in Contemporary Design. Londres: Thames \& Hudson, 1998.

WONG, D. M. The Wall Street Journal. Guide to Information Graphics the do's and don'ts of presenting data facts, and figures. New York: Norton, 2010.

WURMAN, R. S. Information Anxiety 2. Indianapolis: Que, 2001. 


\section{Apêndice I}

\section{INFOVIEW - ENTREVISTA SEMI ESTRUTURADA}

Nome: data: Empresa/IES: Local:

\section{Bloco 1 - Informações sobre o autor}

Qual seu nome, idade, profissao?

$\square$ Onde trabalha atualmente, em qual cargo e função?

Há quanto tempo atua no campo da infografia? (Atuou em outros lugares? Quais os principais clientes - caso freelancer?)

\section{Bloco 2 - Informações sobre aprendizagem / formação}

$\square$ Qual a sua formação? (Fez algum curso específico de infografia?)

$\square$ O que lhe motivou ou levou a trabalhar com infografia?

$\square$ Teve contato com projeto de infografia durante a formação ou aprendeu no mercado de trabalho?

- Caso tenha tipo contato na formação (TCC, projeto relevante etc.), aprofundar.

$\square$ (No local onde trabalha) Há algum tipo de treinamento ou curso para a equipe?

- Caso haja, aprofundar (Saber como funciona, qual a carga horária, conteúdo ministrado, quais os objetivos e o que mais for relevante).

$\square$ O que aprendeu no dia-a-dia que não viu na graduação (ou durante a formação)?

\section{Bloco 3 - Infografia e a práxis}

$\square$ Na sua opinião, o que é um infografico?

$\square$ Infográficos se restringem ao jornalismo?

Quando deve-se usar um infográfico (e quando não usar)?

$\square$ Quais pessoas estão envolvidas na elaboração de um infográfico?

- É possível um profissional exercer mais de uma função ou realizar um infográfico sozinho? 
Quais as principais diferenças entre os suportes (impresso, digital, mobile)?

$\square$ Como é a sua metodologia de projeto (quais etapas do processo do início até a publicação)?

(No local onde trabalha) Como são feitas as avaliações de erros, melhorias e padrões?

Como são escolhidas as pautas e os destaques?

O que define como será a interação (ou não) e a presença elementos diferenciados em um determinado infográfico?

Como foi a evolução do papel da infografia na empresa onde atua (qual a relevância dentro do contexto geral do negócio ou produto)?

De que forma se diferenciam dos demais concorrentes?

\section{Bloco 4 - Infografia contemporânea - Problemas e vantagens}

Quais principais dificuldades observa na prática da infografia hoje?

$\square$ É possível apontar dificuldades do passado que hoje estão superadas?

$\square$ Como foi a evolução da prática da infografia desde quando começou até os dias de hoje (quais os principais marcos)?

Como avaliam a visibilidade, sucesso ou fracasso de um projeto?

$\square$ Como identificam o público-alvo? Onde ele "consome” a infografia realizada por vocês?

Como se dá a integração com as propagandas e a monetização nas matérias?

$\square$ A crise no jornalismo impresso influencia o online? (Há um modelo de negócios online estabelecido ou a ser seguido?)

\section{Bloco 5 - Malofiej}

Como é a sua percepção sobre a infografia brasileira contemporânea em relação aos demais países que se destacam no campo?

Qual a importância do Malofiej? Ele é considerado no seu trabalho?

Prêmios como o malofiej influenciam a pratica da infografia? Eles geram tendências a serem seguidas, por exemplo?

Como são selecionados os infográficos para premiações?

$\square$ Dentre os principais projetos premiados que realizou, destacaria qual (ou quais)?

$\square$ Como foi realizar projeto(s) agraciado(s) com um malofiej, o que ele(s) tinha(m) de diferente dos demais (havia essa intenção no início do projeto)? 
-Solicitar aprofundamento sobre o projeto mencionado e investigar por quê se diferenciou a ponto de receber uma premiação.

\section{Bloco 6 - Questões sobre iniciantes e o futuro}

$\square$ Quais as maiores deficiências dos iniciantes ou recém formados na àrea?

$\square$ Quais principais dificuldades vê para o futuro da prática da infografia?

$\square$ A quantidade de texto e conteúdos densos sofrem uma aparente "redução" nos textos online (pela falta de atenção ou tempo de leitura dispendido pelos usuários)?

$\square$ A linguagem de video está ganhando espaço na infografia?

- Ela faz parte da expertise da equipe ou há interesse em se desenvolver infografia em video?

$\checkmark$ Durante alguns anos, a infografia ganhou grande destaque na imprensa - o que levou a uma saturação. Hoje há um uso moderado/equilibrado de infográficos nos grandes veículos de informação. A infografia está perdendo espaço?

- Desenvolver de acordo com a resposta (Por quê? O que influencia? Como acha que vai ser mais adiante?)

\section{Considerações finais}

Possui alguma dica para os iniciantes ou quem deseja atuar no campo?

Observações ou perguntas extras: 


\title{
Apêndice II
}

\begin{abstract}
INFOVIEW - TERMO DE CONSENTIMENTO LIVRE E ESCLARECIDO $\mathrm{Eu}$, idade profissão

$\mathrm{RG}$ - Órgão Expedidor , $\mathrm{CPF}$

endereço cidade

Estado CEP celular

estou sendo convidado a participar de um estudo denominado INFOVIEW Infografia no Brasil: panorama de uma linguagem multimodal, cujo objetivo é buscar relações entre o passado e o presente da infografia no país. Compreendo que justificam-se as entrevistas junto a profissionais de relevância reconhecida, bem como professores e pesquisadores relacionados ao tema, de forma a auxiliar a coleta de informações acerca de dados relativos à metodologias, projetos realizados, experiências, nomenclaturas, tecnologias, mudanças de paradigma, identificação de problemas e potenciais soluções.
\end{abstract}

A minha participação no referido estudo será no sentido de fornecer depoimento audiovisual, documental e fotográfico.

Fui alertado de que, da pesquisa a se realizar, não há benefícios comerciais ou materiais de quaisquer natureza.

Recebi, por outro lado, esclarecimentos necessários sobre a possibilidade de meus depoimentos, imagens e gravações de voz se tornarem disponíveis para consultas públicas, em sua totalidade ou em parte, em documentos impressos, digitais ou arquivos de natureza audiovisual.

Estou ciente de que minha privacidade será respeitada, ou seja, dados de documentos, números telefônicos, emails e endereço serão mantidos em sigilo. Dados como nome, profissão, cidade ou demais declarados em gravações poderão ser disponibilizados. 
Também fui informado de que posso me recusar a participar do estudo, ou retirar meu consentimento a qualquer momento antes de sua publicação, sem precisar justificar, e, por desejar sair da pesquisa, não sofrerei qualquer prejuízo.

O pesquisador envolvido com o referido projeto é Daniel Moura Nogueira, Mestre em Design, aluno de doutorado do Programa de Pós Graduação da PUC-Rio e com ele poderei manter contato pelo telefone (XX) XXXX-XXXX ou pelo email XXX@XXX.com. A orientação do projeto é realizada por Vera Nojima, Doutora em Arquitetura e Urbanismo (PUC-Rio), email: XXX@XXX.com e Frederico Braida, Doutor em Design (UFJF), email: XXX@XXX.br.

Enfim, tendo sido orientado quanto ao teor de todo o aqui mencionado e compreendido a natureza e o objetivo do já referido estudo, manifesto meu livre consentimento em participar, estando totalmente ciente de que não há nenhum valor econômico, a receber ou a pagar, por minha participação.

de de 20

Nome e assinatura do sujeito da pesquisa

Daniel Moura Nogueira (pesquisador responsável) 


\section{Apêndice III}

\section{INFOVIEW - TERMO DE AUTORIZAÇÃO DE USO DE IMAGEM E DEPOIMENTOS}

Declaro para os devidos fins que eu , RG Órgão Emissor

$\mathrm{CPF}$ Endereço

CEP celular e-mail

depois de conhecer e entender os objetivos, procedimentos metodológicos, riscos e benefícios da pesquisa, bem como de estar ciente da necessidade do uso de minha imagem e/ou depoimentos, especificados no Termo de Consentimento Livre e Esclarecido (TCLE), AUTORIZO, através do presente termo, Daniel Moura Nogueira, CPF: XXX, RG: XXX DICRJ, designer, professor e pesquisador, doutorando do Programa de Pós Graduação em Design da PUC-Rio, registro XXX, a realizar as fotos, imagens em vídeo e gravações de áudio que se façam necessárias e/ou a colher meu depoimento sem quaisquer ônus financeiros a nenhuma das partes.

AUTORIZO, ainda, a utilização destas fotos e/ou depoimentos para fins científicos, de estudos (livros, artigos, apresentações, slides e transparências); publicações impressas, digitais ou audiovisuais comerciais ou não (livros, artigos, capítulos de livro, entrevistas, sites, documentários) em favor do pesquisador acima especificado, por prazo indeterminado, obedecendo ao que está previsto nas Leis que resguardam os direitos das crianças e adolescentes (Estatuto da Criança e do Adolescente - ECA, Lei N. ${ }^{\circ} 8.069 / 1990$ ), dos idosos (Estatuto do Idoso, Lei N. ${ }^{\circ}$ 10.741/2003) e das pessoas com deficiência (Decreto No 3.298/1999, alterado pelo Decreto $\left.N^{\circ} 5.296 / 2004\right)$.

de de 20

Entrevistado(a):

Daniel Moura Nogueira CPF: XXX 


\section{Apêndice IV}

usmescion

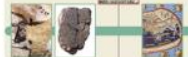

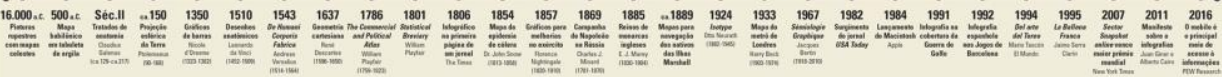

Oresens infográficos

pioneiros no país

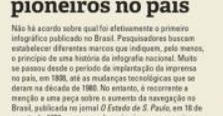

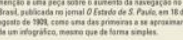

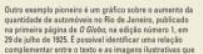

-

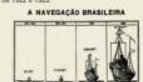

$\therefore a$

$k x-2$

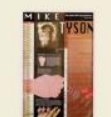

10 -2

O Brasil no Malofiej

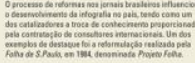

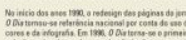

was

-

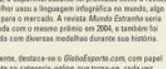

s=

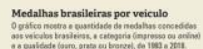

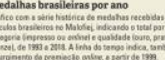

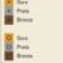

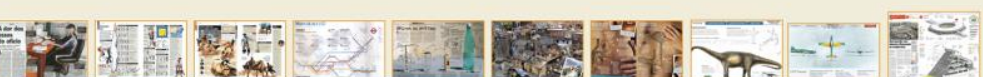

UNHA DO TEMPODEOURO

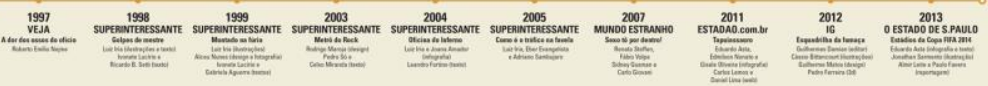

E o papel da

and

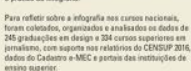

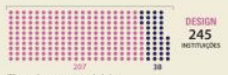

:

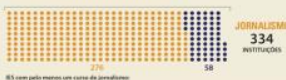

俄:

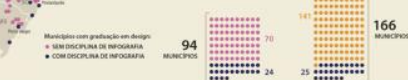

166

Onde há disciplinas

de infografia?

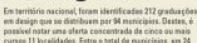

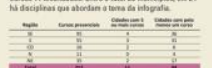

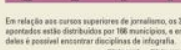

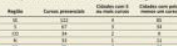

Infografia no Brasil

panorama de uma linguagem multimodal 